\title{
Interorgan protein and glutamine metabolism in the tumor bearing rat
}

Citation for published version (APA):

de Blaauw, I. (1996). Interorgan protein and glutamine metabolism in the tumor bearing rat. [Doctoral Thesis, Maastricht University]. Universiteit Maastricht. https://doi.org/10.26481/dis.19961220ib

Document status and date:

Published: 01/01/1996

DOI:

10.26481/dis.19961220ib

Document Version:

Publisher's PDF, also known as Version of record

\section{Please check the document version of this publication:}

- A submitted manuscript is the version of the article upon submission and before peer-review. There can be important differences between the submitted version and the official published version of record.

People interested in the research are advised to contact the author for the final version of the publication, or visit the DOI to the publisher's website.

- The final author version and the galley proof are versions of the publication after peer review.

- The final published version features the final layout of the paper including the volume, issue and page numbers.

Link to publication

\footnotetext{
General rights rights.

- You may freely distribute the URL identifying the publication in the public portal. please follow below link for the End User Agreement:

www.umlib.nl/taverne-license

Take down policy

If you believe that this document breaches copyright please contact us at:

repository@maastrichtuniversity.nl

providing details and we will investigate your claim.
}

Copyright and moral rights for the publications made accessible in the public portal are retained by the authors and/or other copyright owners and it is a condition of accessing publications that users recognise and abide by the legal requirements associated with these

- Users may download and print one copy of any publication from the public portal for the purpose of private study or research.

- You may not further distribute the material or use it for any profit-making activity or commercial gain

If the publication is distributed under the terms of Article $25 \mathrm{fa}$ of the Dutch Copyright Act, indicated by the "Taverne" license above, 


\title{
INTERORGAN
}

\section{PROTEIN AND GLUTAMINE METABOLISM}

\author{
IN THE TUMOR BEARING RAT
}




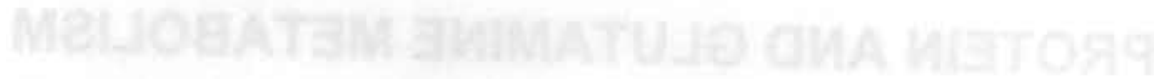




\section{INTERORGAN PROTEIN AND GLUTAMINE METABOLISM IN THE TUMOR BEARING RAT}

\section{PROEFSCHRIFT}

ter verkrijging van de graad van doctor aan de Universiteit Maastricht

op gezag van de Rector Magnificus, Prof. mr. M.J. Cohen, volgens besluit van het College van Decanen in het openbaar te verdedigen op vrijdag 20 december 1996 om 12.00 uur

door

Ivo de Blaauw

geboren te Amsterdam op 28 november 1959 
Promotor:

Prof. dr. M.F. von Meyenfeldt

Co-promotor

Dr. N.E.P. Deutz

Beoordelingscommissie

Prof. dr. R.F.A. Zwaal (voorzitter)

Prof. dr. F.C. Fearon (University of Edinburgh)

Prof. dr. D. Halliday

Prof. dr. H.F.P. Hillen

Dr. A.J. Meijer (Universiteit van Amsterdam)

Prof. dr. P.B. Soeters

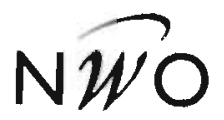

CIP-DATA KONINKLIJKE BIBLIOTHEEK, DENHAAG

de Blaauw, Ivo

Interorgan protein and glutamine metabolism in the tumor bearing rat/lvo de Blaauw

Ponsen \& Looijer E.V. (drukwerk)

Thesis Maasiricht. - With ref. - With summary in dutch.

ISBN 90-9010122-5

Subject headings: cancer cachexiajamino acid metabolism/protein metabolism.

The studies presented in this thesis were financially supported by grant 900-562-125 from the Netherlands Organization for Scientific Research (N.W.O.). Publication of the thesis was financially supported by Dr. Ir. J.H.J. van de Laar foundation, Nutricia Nederland B.V. Pharmacia \& Upjohn B.V. and N.W.O. 
Aan mijn ouders 



\section{Chapter 1}

Chapter 2

Chapter 3

Chapter 4

Chapter 5

Chapter 6

Chapter 7

Chapter 8

\section{General introduction}

1.1 Cancer cachexia

1.2 Tumor models to study cancer cachexia

1.3 Outline of the thesis

Methods to measure in vivo amino acid and protein turnover

Muscle protein and amino acid turnover in rats in vivo: effects of short-term and prolonged starvation

Clnical Science (1996) 90, 457-466.

In vivo amino acid metabolism of gut and liver during short and prolonged starvation

American Joumal of Physiology; gastrointestinal and Liver Physiology. (1996) 220 (35):G295-G306.

Increased whole body glutamine turnover in advanced cancer is not matched by an increased muscle protein and glutamine turnover

Submitted

Glutamine depletion and increased gut permeability in non-anorectic, non-weight losing tumor bearing rats Gastroenterology, in press

Hepatic amino acid metabolism in moderate cancer cachexia.

Journal of Hepatology, in press.

Hepatic glutamine metabolism in moderate cancer cachexia.

Submitted. 
Chapter 9

Chapter 10

Chapter 11

Samenvatting

Nawoord

Curriculum vitae
Cancer reduces the metabolic response of muscle to surgical stress in the rat

Submitted.

Intestinal responses to surgery in tumor bearing rats

Submitted

203

223

Summary and perspectives for the future 


\section{GENERAL INTRODUCTION}

\subsection{CANCER CACHEXIA}

Weight loss and malnutrition have long been associated with a poor clinical outcome after surgery (1). Anorexia, muscle wasting and progressive depletion of adipose tissue have often been described in cancer patients and the clinical syndrome associated with these symptoms is referred to as cancer cachexia $(2,3)$. Cachexia is derived from the Greek word kakos meaning ugly or bad and hexis meaning circumstances or condition. Cachexia is associated with several diseases e.g. tuberculosis, malaria, AIDS and cancer. A broad spectrum of symptoms, physical findings and laboratory findings have been attributed to the syndrome (Table 1) (4). The condition of the cachectic cancer patient differs from simple malnutrition due to fasting or starvation because host intermediary metabolism (carbohydrate, lipid and protein metabolism) is abnormal making nutritional therapy less successful $(3,5)$.

Reports on the incidence of cancer cachexia at the time of presentation in a clinical setting vary between $3 \%$ and more than $80 \%(4,6-10)$. The variation is first of all caused by the fact that different cancer populations from and in different socioeconomical settings are studied. Moreover, there appears to be a lack of convenient indicators to asses nutritional depletion. Most surveys have concentrated on weight loss, lean body mass, depletion of fat mass or serum protein levels $(1,8,11)$. These parameters, however, are not only a reflection of the nutritional status but are also influenced by the disease state of the patient $(12,13)$. To improve the nutritional assessment of patients, several nutritional indices were introduced to better identify patients at risk for nutritional related complications and to assess the efficiency of nutritional interventions $(8,11,12,14,15)$. Most of these indices, however, remain more dependent on the disease status than on nutritional status. 
In our hospital approximately $60 \%$ of the patients admitted to the surgical ward for gastrointestinal cancer are nutritionally depleted. In a multivariate analysis blood loss and age but not nutritional depletion, were associated with the development of postoperative complications (12). Nutritional depletion was only associated with the severity of a complication once a complication was present. This emphasizes that impact of the nutritional status only mildly affects the risk of complications compared to other factors and that a nutritional intervention will have limited impact.

Although the prevalence of cancer cachexia decreased over the years $(8,16)$, nutritional intervention did not improve the nutritional status as much as first expected (17). Nutritional support to cancer patients was greatly improved in the seventies with the introduction of Total Parenteral Nutrition (TPN). Although it was first thought that TPN could completely reverse protein catabolism and improve clinical outcome of cachectic cancer patients (18), this was not reaffirmed in later studies $(17,19)$. This was mostly attributed to the abnormal metabolic response to nutrients by cancer patients and the inability to reverse metabolic defects by artificial nutrition. In an elegant study Wolfe et al showed with ${ }^{14} \mathrm{C}$ [urea] that whole body protein anabolism, which can be achieved when giving parenteral nutrition to unstressed depleted patients with benign disease, cannot be achieved in cancer patients, whether depleted or not $(13,20)$. The ongoing catabolism could only be blunted with parenteral nutrition and, for that matter, more in depleted than in nondepleted cancer patients. In general, TPN may only be effective in a subgroup of patients who are at risk $(13,15,16)$. Thus, advantages of TPN must be weighed against the risk of complications of parenteral nutrition.

A point of controversy remains whether nutritional support influences tumor growth in cancer patients. Most evidence for nutritional support associated stimulation of tumor growth has arisen from early animal studies $(21,22)$, although a recent human study also suggests that tumor protein synthesis and tumor growth increase with nutritional interventions $(23,24)$. Most clinical studies and other animal studies, however, show that tumor growth is relatively independent of the nutritional status of the host and nutritional interventions are only of benefit for the host (25-27). Norton et al suggest that nutritional stimulation of cancer is only present when the tumor burden exceeds $10 \%$ of the body weight $(4,7)$. In man, the tumor burden rarely exceeds $1 \%$ of the body mass and therefore may be uninfluenced by these mechanisms. Furthermore, Bozetti recently showed that good nutritional status of the host was associated with a lowered tumor cell proliferation in patients with nonHodgkin's lymphoma (28).

In conclusion, perioperative parenteral nutrition only improved clinical outcome of a limited subgroup of patients with severe malnutrition at high risk for the development of postoperative complications $(8,15,16)$. Protein anabolism cannot be 
Weakness

Fatigue

Malaise

Anorexia
Weight loss

Skeletal muscle atrophy

Adipose tissue loss

Myopathy
Anemia

Hypoproteinemia

Hyperglycemia

Deficiency states

Electrolytes

Vitamins

Minerals

Anergy

achieved in cancer patients with TPN or enteral nutrition, in contrast to patients with benign disease $(3,13,28,29)$. To further improve the efficacy of nutritional support in cancer patients it became clear in the early nineteen-eighties that fundamental research investigating the underlying changes in intermediary metabolism due to the presence of cancer was needed to appropriately counter these changes and improve clinical outcome $(17,19)$.

\section{Metabolic features}

Persistent weight loss despite nutritional support which is observed in cachectic cancer patients has been attributed to abnormalities in carbohydrate, lipid, protein and amino acid metabolism. Most of these findings have been demonstrated to occur before any signs of weight loss and anorexia are present, suggesting that these metabolic changes are a cause rather than an consequence of cancer cachexia (30-36).

\section{Increased energy expenditure}

It has repeatedly been demonstrated that both resting and non-resting energy expenditure is elevated in cancer patients and it has been suggested that this contributes to weight loss in patients with solid tumors $(20,37)$, lung cancer patients $(32,38)$ and patients with pancreatic cancer (39). However, unchanged and hypometabolic responses have also been described in gastrointestinal and hepatobiliary cancer patients when compared with patients with weight loss of a 
similar magnitude due to benign disease or with weight stable cancer patients $(20,32,40,41)$. It is, however, clear that resting energy expenditure reduces in normal patients during fasting or starvation and that this normal response appears to be blunted in malnourished cancer patient (42-44).

\section{Carbohydrate metabolism}

Both in man and in animal tumor models severe abnormalities in carbohydrate metabolism are observed. As early as 1925 , Cori and Cori demonstrated decreased glucose levels and increased lactate levels across sarcoma bearing chicken wings when compared with the opposite wing suggesting high glycolytic activity in solid tumors (45). The early observation that malignant cells had high anaerobic glycolysis and increased lactate production also suggested that tumor cells could influence carbohydrate metabolism in cancer patients (46). Increased uptake of glucose with concomitant increased lactate release has been demonstrated in a variety of tumors transplanted on a vascular pedicle (47). Finally, Norton et al showed that human sarcoma bearing limbs also had increased glucose consumption and lactate release compared to the non-tumor bearing limb (48). This first suggested that the tumor interfered with glucose metabolism by acting as a "glucose trap" (31). However, in a study with esophageal cancer patients Burt et al observed increased glucose uptake and lactate release from forearm muscle suggesting that humoral factors induced by the presence of cancer also increase glycolysis of non-tumor tissue of the host (49).

Lactate produced by glycolysis can either be oxidized or be regenerated to glucose via gluconeogenesis in the kidney or liver (50). Increased gluconeogenesis has been observed in vitro and in vivo in both cancer patients and in tumor bearing animals (31,51-55). Peripheral glycolysis with a concomitant visceral gluconeogenesis has been referred to as Cori cycling and is considered to be an energy wasting process. In animal studies glucose recycling via the Cori cycle increased to approximately $52 \%$ in large tumor bearing animals (54). Increased Cori cycling has been postulated to be at the basis of cachectic energy depletion of cancer patients $(52,56,57)$. However, energy wasting by gluconeogenic loss accounts for only $20-40 \%$ of the increased energy expenditure $(9 \mathrm{kcal} / \mathrm{kg} / \mathrm{day})(7,58)$. Furthermore, Young et al estimated that if $85 \%$ of lactate production would be used to produce glucose and only $15 \%$ would be completely oxidized, there would be no energy loss (59). It is therefore generally not accepted that the increased Cori cycle is fully responsible for the energy depletion in cancer cachexia but rather plays a minor role. It has, however, been proven that gluconeogenesis increases during cancer and that, certainly in advanced cancer, it apparently does not respond to usual homeostatic mechanisms. Shaw et al showed with isotopically labeled glucose 
that glucose infusions do not suppress endogenous glucose production in advanced cancer patients as observed in healthy controls (51).

Increased gluconeogenesis has also been observed from glycerol (58) and alanine $(30,31,54,60,61)$. The contribution, however, of these substrates to gluconeogenesis is of relatively minor importance compared to the contribution of lactate $(20,30,54,58)$.

Blocking gluconeogenesis in cancer patients has been successfully tried with hydrazine sulfate which inhibits the enzyme phosphoenol pyruvate carboxykinase. Chlebowski et al showed that hydrazine sulfate improves glucose tolerance and reduces fasting glucose production in cancer patients (62). The same group further showed in a double blind trial with lung cancer patients that one month of hydrazine sulfate treatment reduced whole body protein breakdown by approximately $27 \%$ which was accompanied with a maintenance of serum albumin concentrations. latrogenic ketosis has also proposed to reduce glucose supply to the tumor with a simultaneous preservation of host energy reserves (63). Although a 7 days ketogenic diet decreased arterial glucose concentrations of cachectic cancer patients, it had no effect on nitrogen balance or whole body protein turnover (63).

Another important phenomenon in carbohydrate metabolism of the cancer bearing state is decreased glucose tolerance $(64,65)$. Reduced peripheral sensitivity to insulin has been observed in cancer patients and several rodent cancer models (6467), although in a few cases also increased glucose sensitivity has been observed in cancer patients and tumor bearing animals $(49,64,67)$. Reduced hepatic insulin sensitivity (64) and reduced pancreatic release in response to feeding has been observed and may be responsible for the decreased glucose tolerance $(2,54,66)$. Interestingly, protein metabolism of incubated muscle cells of both cancer patients and tumor bearing mice has a normal (anabolic) response to insulin $(64,66)$ and two recent studies by Brennan in cancer patients showed that insulin supplementation increases whole body and regional muscle protein synthesis of cancer patients to a similar extent as in control patients $(68,69)$.

In conclusion, carbohydrate metabolism in cancer is characterized by increased glucose turnover, increased gluconeogenesis and insulin resistance for glucose.

\section{Lipid metabolism}

A great proportion of the weight loss in cancer patients is fat loss $(32,37,70)$ which in animals can reach $80 \%$ of the fat stores $(71,72)$. Although depletion of fat reserves in cancer patients is partly due to the reduced caloric intake, several specific changes in fat metabolism are attributed to the presence of cancer. Depletion of fat stores in the progress of cancer is associated with hypertriglyceridemia $(20,72)$. The latter may be of particular importance for the immune response of the host to cancer 
as increased lipid concentrations have long been recognized as being immunosuppressive $(2,73,74)$.

Depletion and hyperlipidemia in cancer have first of all been attributed to increased lipolysis $(20,72)$. Using stable isotopes, Shaw and Wolfe demonstrated that weight losing cancer patients had increased glycerol and free fatty acid turnover and release into plasma $(20,75)$. However, not in all studies increased glycerol and fatty acid turnover rates were observed $(58,76)$. Furthermore, decreased plasma clearance of free fatty acids and VLDL-tryglycerides has also been described $(33,77)$. Lipoprotein lipase is the protein responsible for triglyceride clearance and decreased mRNA and activity of the enzyme have been observed in both cancer patients (78) and animals (33,79). In addition, decreased tolerance to enteral and parenteral lipid infusions has been observed with disproportionately increased free fatty acid concentrations indicating impaired lipogenesis in cancer (80). In summary, depletion of fat stores, hyperlipidemia and increased turnover of glycerol and fatty acids are common findings in both cancer patients and tumor bearing animals.

\section{Whole body protein metabolism}

Whole body protein turnover measurements reflect protein synthesis and breakdown of several organs. Increased turnover rates of one organ may be accompanied by decreased turnover rates of other organs and thus not influence whole body turnover rates. However, protein turnover is an energy expensive process which accounts for approximately $10-20 \%$ of the basal metabolic expenditure (81). Therefore, whole body protein turnover measurements in cancer patients inform us of the energy expenses involved in changes in protein metabolism but do not effectively inform us on protein metabolism of specific organs (81).

Most studies on whole body protein kinetics suggest an increased protein turnover in cancer patients and tumor bearing animals $(40,51,69,82-89)$. In a few studies whole body protein turnover remained unchanged $(90,91)$ and it was suggested that this was observed because it was performed in the fed state (91). Norton et al similarly showed in an animal study that a period of fasting-refeeding increased whole body protein turnover in normal rats but had no effect on whole body protein turnover of tumor bearing rats ( $\left.877^{\prime}\right)$. However, in a study by Melville and Garlick, lung cancer patients had increased whole body protein turnover rates in the fasted state which remained so during feeding (85). Therefore, the differences in whole body protein turnover are generally explained by the fact that small patient groups are studied, different control groups are used, different methods are used to measure whole body protein turnover and, most important, the fact that whole body protein turnover is a compilation of severall turnoiver rates of individual organs as stated above (see also chapter 2). 


\section{Regional protein tumover}

Muscle tissue is the largest protein pool in the body and has been suggested to account for approximately $50 \%$ of the whole body protein turnover under normal circumstances (4). Despite the observed increased whole body protein turnover in tumor bearing rats, muscle protein synthesis decreased in the same animals (87). Decreased protein synthesis, rates have also been observed in Yoshida and Novikoff tumor bearing rats, $(35,92)$. However, increased protein degradation rates are held equally or more responsible for the loss of muscle proteins in cancer $(34,92-94)$. The protein loss in muscle of tumor bearing rats appears to be limited to myofibrillar proteins (95). In this study sarcoplasmatic and extracellular proteins increased by approxirnately $25-30 \%$ compared to the myofibrillar proteins. Despite these changes, the performance of muscle over a wide range of stimulation frequencies was not affected by the presence of cancer (96).

Lundholm showed that in vitro muscle protein synthesis rates were decreased in cancer patients $(97,98)$. However in another study Lundholm et al showed that, after an overnight fast, cancer patients had no significant increase in amino acid efflux from the leg compared to malnourished non-cancer patients (99) suggesting that peripheral nitrogen conservation after fasting remains unchanged. In response to enteral nutrition, however, the non-cancer patients decreased their amino acid efflux whereas cancer patients had an unchanged amino acid efflux (99).

Increased protein fractional synthetic rates in cancer patients have also been observed (100). As nitrogen loss occurred in muscle, this would implicate that protein degradation increased even further. Heber et al showed that urinary 3methylhistidine/creatinine excretion rates were elevated in lung cancer patients (101). This was not confirmed in another study (102) and, thus, data on protein breakdown in human cancer cachexia remain conflicting when using 3methylhistidine effluxes from muscle and urinary excretion ratios. Previous studies by Lundholm showed increased lysosomal protease activity in cancer patients and mice (97). Increased tissue protease's have also been found by others and increased protein breakdown thus appears to be a major determinant of muscle wasting during cancer cachexia $(103,104)$. It is noteworthy, however, that another proteolytic pathway has recently been discovered which possibly has a much greater impact on muscle wasting during catabolic diseases $(105,106)$. Muscle contains three major proteolytic pathways: the classical lysosomal pathway (cathepsins $B, H, L$ and $D$ ), the cytosolic $\mathrm{Ca}^{2+}$-dependent pathway ( $\mu$ - and m-calpains) (107) and the cytosolic ATP-ubiquitin-dependent proteolytic pathway $(108,109)$. The latter was first believed to degrade abnormal and short-lived proteins but is now also recognized to be responsible for the degradation of long-lived proteins during sepsis (110), acidosis 
(111), glucocorticoid induced protein breakdown $(105,112,113)$ and in cancer $(114,115)$. A coordinated activation of all three proteolytic pathways seems to prevail in different wasting conditions to eliminate different classes of proteins $(105,112)$.

In vivo protein breakdown rates have always been difficult to measure. Most data on protein breakdown are indirectly measured or studied ex vivo. In 1987 Barret and Gelfand developed an in vivo two compartment model to calculate protein breakdown rates across an organ (116). This model was also shown to be valid in humans (117). The model has recently been extended to three compartments by Biolo and Wolfe which not only made it possible to simultaneously calculate in vivo membrane transport rates but also appeared to improve the accuracy of intracellular protein turnover data $(118,119)$. Methods and models to calculate protein turnover are more extensively discussed in chapter 2

Studies on regional protein turnover of other organs are generally limited to visceral organs. In early research tumor growth was associated with an increased liver mass (120). Both in vitro and in vivo studies showed that hepatic protein synthesis increases $(35,87,121)$. Warren et al showed that in MCA tumor bearing rats, liver protein synthesis increases proportionally to the tumor load and that this applies equally for secretory and structural proteins of the liver (122). This was, however, not confirmed in a human study which showed that the synthesis rates of fixed hepatic proteins decreased whereas the synthesis of acute phase export proteins increased (89). Emery et al also showed in a very aggressive tumor model that synthesis of export proteins is more affected by the presence of cancer than synthesis of fixed proteins (94). Acute phase protein production has a central role in the development of cancer cachexia (vide infra).

Spleens of tumor bearing animals also have increased protein contents, whereas visceral organs like the kidney and heart remain unaffected by the presence of a tumor (120). This was also reflected by unchanged protein synthesis rates in tumor bearing animals of most visceral organs, e.g. lung, heart and kidney $(22,97)$. Tumor bearing rats also had intestines which weighed approximately $10 \%$ less than those of pairfed controls (123). This was accompanied by a $26 \%$ decrease in villus height in the same tumor bearing animals (123). However, the fractional synthetic rate of jejunal protein in tumor bearing rats reaches approximately $260-330 \%(124)$ which is almost twice as high as the normal jejunal protein synthetic rate $(125,126)$. This suggests that protein breakdown must increase more than twofold in tumor bearing animals but this has not been measured yet.

The contribution of the individual tissues to whole body protein kinetics was estimated by Kawamura ef al (88). In this study the major contribution to the increased whole body protein turnover came from the tumor. The relative 
contribution of liver and muscle tissue decreased whereas that of other organs remained relatively unchanged.

\section{Glutamine metabolism}

Glutamine is the most abundant free amino acid in the body (127). It is biochemically a non-essential amino acid of five carbons and two nitrogen side chains (an $\alpha$-amino group and a $\delta$-amide group). It can be synthesized from glutamate and ammonia by an ATP dependent reaction catalyzed by glutamine synthetase (EC 6.3.1.2) which activity is present in brain, liver, kidney, muscle, spleen and lungs (128-130). Muscle contributes to approximately $40-50 \%$ of the body mass and it has been estimated that as much as $70-80 \%$ of the total body free amino acid pool is within skeletal muscle $(131,132)$. Excluding taurine, glutamine contributes to approximately $61 \%$ (human) $(131,132)$ or $20-30 \%$ (rat) $(133-135)$ of the free amino acid pool in muscle and several studies have shown that the majority of the total body glutamine is synthesized in and released from skeletal muscle $(136,137)$.

Glutamine has several important biological functions. It first of all serves as a nontoxic nitrogen shuttle to transport ammonia from peripheral tissues, to visceral organs (liver and kidney) where ammonia can be transformed to urea or directly excreted. Glutamine is also a major gluconeogenic amino acid. Although alanine is thought to be the major gluconeogenic amino acid, a recent study in human volunteers showed that glutamine is the gluconeogenic amino acid by which quantitatively the majority of carbon skeletons, derived from proteins, are transferred to the glucose pool (138). Glutamine metabolism of the liver and kidney is also closely linked to acid-base homeostasis (139-141). Furthermore, glutamine is avidly consumed by dividing cells, such as fibroblasts (142-145), lymphocytes (146-149), tumor cells (150-153) and enterocytes $(154,155)$. These cells consume glutamine at a high rate for nucleotide production and as energy source $(146,155)$. Finally, it has been shown that in cases of oxidant stress, glutamine supports the production of the intracellular radical scavenger glutathione (156-159).

Tumor cells are rapidly dividing celis and interfere with host glutamine metabolism. It has been suggested that intracellular glutamine concentrations of the tumor negatively correlates with fumor growth rate $(153,160,161)$. This is attributed to the increased purine and pyrimidine biosynthesis pathways which utilize glutamine. However, glutaminase is the main glutamine utilizing enzyme in cancer cells. On further processing of glutamate controversy still exists. Further oxidation of the carbon skeleton could occur completely in the mitochondria via glutamate dehydrogenase activity but it has also been suggested that glutamine is oxidized exclusively via a pathway involving glutamate-oxaloacetate transaminase (153). 
Whatever the case, tumor cells are major glutamine consumers and compete with the host for circulating glutamine (162). In several animal models the tumor appears to act as a "glutamine trap" $(152,161-164)$. This observation was not confirmed in human tumor tissue $(165,166)$. The presence of a tumor does, however, induce remarkable changes in host glutamine metabolism (162).

Changes in host glutamine metabolism induced by the presence of cancer result in depletion of the arterial and intracellular muscle glutamine pool $(123,159,162,167,168)$. It has been postulated that depletion of these pools occur because during progression of cancer, the tumor and an activated immune system become major glutamine consumers whereas muscle tissue becomes exhausted over time and, in a pre-cachectic phase, loses it's capacity to produce sufficient glutamine (162). This finally results in decreased functioning of several other glutamine consuming organs of the host (169-171). Within this concept, glutamine thus becomes a "conditionally" essential amino acid because the capacity of endogenous biosynthesis is exceeded by tissue utilization (159,172-176). A similar concept has been postulated to occur in cases of severe stress, infections or trauma $(173,177,178)$.

\section{Postulated mechanisms for the mediation of cancer cachexia}

The mediation of cancer cachexia is incompletely understood. It is generally assumed that cachexia is humorally mediated by mediators of an inflammatory response (cytokines), classical hormones and other regulatory peptides. Tumor induced anorexia and weight loss was shown to be transmittable in tumor bearing rats through plasma factors $(2,179)$. By using parabiotic cross circulation of normal and tumor bearing rats, Norton et al showed that cancer cachexia was humorally mediated (180). Humoral mediation of cancer cachexia was also confirmed in studies in which metabolic alterations of cachexia like muscle wasting could be induced with plasma of tumor bearing rats given to control rats (72) and prevention of cancer cachexia by, e.g. a splenectomy (181).

\section{Mediators of the inflammatory response and cachexia}

Cytokines such as Tumor Necrosis Factor $\alpha$ (TNF $\alpha$ ) and Interleukin-1 (IL-1) have been proposed to be the main mediators of cancer cachexial (182-186). TNF $\alpha$ was first isolated as mediator of cachexia by decreasing plasma lipoprotein lipase activity (187). In vitro studies also showed that TNF $\alpha$ suppresses tipoprotein lipase activity in adipocytes (188-190). In vivo studies with TNF $\alpha$ showed that it can give similar metabolic changes as observed in wasting and cachectic disease states: arterial 
hypertriglyceremia, increased muscle protein breakdown, increased glycogenolysis and increased peripheral lactate production (182,191-194). Increased serum TNF $\alpha$ levels have been observed in several cachectic diseases, e.g. AIDS, chronic parasitic infections $(195,196)$. Elevated TNF $\alpha$ levels have also been observed in cachectic tumor bearing rats and correlated well with the tumor burden (197). Elevated TNF $\alpha$ levels were confirmed in other tumor bearing animals but correlated not always with tumor burden (198). In several other studies serum TNF $\alpha$ was not elevated at all (199-202). Similarly, in cancer patients elevated TNF $\alpha$ levels have been observed in some studies $(203,204)$ but not in other studies $(39,205-207)$. Anticachectin antibodies attenuated cachexia induced by the implantation of a tumor in several studies $(208,209)$. It is therefore generally assumed that TNF $\alpha$ has a regulatory role in tumor associated metabolic changes, even though no measurable plasma concentrations were observed. It must therefore act as local mediator $(210,211)$.

The biological function of IL1 greatly overlaps that of TNF $\alpha$ (212) and infusions: with IL1 also induced anorexia, weight loss and loss of body proteins in rats (186). Elevated IL1 plasma concentrations are seldom found in cancer patients $(89,204)$ or tumor bearing animals $(185,198)$ but antibodies against an IL1 receptor do attenuate cachectic symptoms in tumor bearing mice to a similar extent as anti-TNF $\alpha$ antibodies (185). As with $\mathrm{TNF} \alpha, \mathrm{IL} 1$ is thought to act locally as an autocrine mediator. Local involvement of IL1 has been confirmed in a study by Strassmann (213). In this study it was shown that by systematically blocking the IL1 receptor no change in cancer cachexia was observed whereas local injection in the tumor of anti IL1 receptor antibodies cachexia could be prevented (without influencing tumor growth). Local involvement was also confirmed by increased IL1 production by the spleen of tumor bearing mice without any effect on plasma levels (211).

$\gamma$-Interferon (IFN $\gamma$ ) is also suggested to be a central mediator of cancer cachexia (201). Although elevated plasma levels were not detectable, repetitive intraperitoneal administration of recombinant murine INFy induced anorexia and weight loss. Furthermore, polyclonal antibodies against rat IFNy partly attenuated cancer induced anorexia and weight loss (201). The multiple synergistic interactions of IFNy with TNF $\alpha$ and IL1 suggest that that these mediators are all part of a final common pathway.

Another important and multifunctional cytokine involved in cancer cachexia is IL6 (214). In contrast to TNF $\alpha$ and IL1, IL6 is generally detectable in serum or plasma of cancer patients and tumor bearing animals $(39,42,89,199,200,204,213)$. Again, IL6. blockades attenuated the anorexia and weight loss associated with tumor growth in animal models (200). This was also confirmed with the experimental drug, suramin 
which inhibits the binding of IL6 with its receptor (215). Because IL6 has been reported to be increasingly produced by many tissues of the cancer bearing host, e.g. liver tissue, kidney, small intestine and tumor tissue, Lundholm postulated that IL6, unlike TNF $\alpha$ an IL-1, acts more in a paracrine fashion than in an autocrine fashion which is induced by other host-derived factors (210). Strassman postulated that in his tumor model the direct cellular source of IL6 are the tumor cells responding to IL1 produced by tumor infiltrating phagocytes (215).

Other studies have also confirmed that endogenous IL6 production is a more distal and direct mediator of cachexia (than e.g. IL1, TNF $\alpha$ ) and the acute phase response during inflammation $(216,217)$. IL6 is known to be the principal factor to elicit an acute phase protein response both in vitro (218) and in vivo (219). Furthermore, circulating IL6 levels of tumor bearing rats correlated well with tumor load and plasma acute phase proteins (220-222). Although this was not confirmed in a human study (39), an increased spontaneous IL6 release of peripheral blood monocytes was associated with a positive acute phase response.

The acute phase response refers to a series of physiologic and metabolic changes in response to tissue damage induced by injury, infection or inflammation (223). In the liver protein synthesis shifts from albumin synthesis to the production of acute phase proteins such as $\mathrm{C}$-reactive protein, serum amyloid $\mathrm{A}$ protein, $\alpha_{2}$ macroglobulin and $\alpha$-1-antitrypsin (224). The role of the acute phase proteins in cancer is still subject of debate but several ideas have been postulated. It has been hypothesized that acute phase proteins inhibit tumor growth $(225,226)$, increase tumor growth and spreading (227), bind to damaged tissue, membrane phospholipids and DNA (224) or create an inflammatory barrier around the tumor similar as during bacterial infections (223). The acute phase response is, however, mostly recognized as a relatively unspecific response to microbes and subsequent tissue destruction $(220,223)$. Moreover, increasing evidence exists that the acute phase response has a relation with, and an etiologic role in, metabolic disturbances observed in cancer cachexia (216).

The acute phase response is not only activated but also modulated by cytokine production. Examples of cytokines with inhibitory function are IL4 and IL10 (223). IL4 is primarily released by T-helper 2 (Th2) cells and appear to modulate the acute phase response by downregulating TNF $\alpha$, IL 1 and IL 8 release of monocytes and macrophages $(223,228)$. It furthermore enhances apoptosis of monocytes hereby decreasing the amount of inflammatory cells. IL10, produced by macrophages and Th2 lymphocytes, also inhibits IL1, TNF $\alpha$ and IL6 production.

These changes in the cytokine network should be seen in the light of the extensive studies on protein energy malnutrition reporting decreased lymphocyte proliferation response to mitogens, decreased $\mathrm{CD}_{4}{ }^{*} \mathrm{~T}$ helper cells, decreased complement 
activity and decreased secondary antibody response to certain antigens or vaccines $(229,230)$. Interestingly, it was recently observed that monocytes of malnourished children produced less TNF $\alpha$ (and IL6) after stimulation with lipopolysacharide (LPS) at the time of admission than after nutritional rehabilitation (231). Another study also reported a reduced capability of IL1 produced by monocytes of malnourished patients to produce fever in a rabbit (232). It appears that protein energy malnutrition attenuates the immune response in the non-cancer bearing state, whereas protein energy malnutrition during the cancer bearing state activates the immune system. It goes beyond the scope of this overview to unravel the entire network of cytokines related to cancer cachexia, in particular related to the relative importance of each individual cytokine but it has become increasingly evident that they have a central role in the development of cancer cachexia.

The cytokines and acute phase proteins also have a close relationship with, and partly depend on, concomitant hormonal changes. TNF $\alpha$ or IL6 infusions in human volunteers increase the stress hormone response $(194,233)$. Anti-TNF $\alpha$ antibodies reverse the early changes in insulin and corticosteroid levels of tumor bearing animals (208). On the other hand, insulin reduces the IL1 and IL6 type cytokine effects on whereas glucocorticoids enhance most cytokine effects on the acute phase response (223). The close relationship between the acute phase response and the classical hormones was also elegantly shown by Lundholm in a study where the in vivo cytokine induced acute phase protein synthesis depended on intact adrenal function and plasma glucocorticoid concentrations (234).

\section{Hormones and cachexia}

Many of the metabolic changes observed in cancer have long been conceived to be mediated by the classical hormones. Hormone profiles alter rapidly after tumor transplantation in animals (235) and in malnourished cancer patients $(198,236)$. It appears that the presence of a tumor rapidly elicits a complex endocrine response of the host (235).

Increased cortisol secretion was one of the earliest hormonal changes observed in cancer cachexia $(6,104,237)$. In tumor bearing animals marked adrenal hypertrophy was observed $(6,238)$ and hypophysectomy could not prevent this hypertrophy (239) Early studies also suggested that the adrenals are hyporesponsive to ACTH in the early stage of tumor growth, become hyperresponsive when the tumor grows, and become hyporesponsive again at the end stage (6,240). Increased cortisol or corticosterone has been observed in several other tumor animal models $(104,198,208,241)$ although not in all (121). Whether increased plasma corticosterone levels are specific for cancer was doubted by Inculet and colleagues who showed that in MCA tumor bearing rats no relationship existed between plasma 
corticosterone levels and tumor burden (30). Moreover, Tessitore showed that in spite of sustained elevation of plasma corticosterone concentrations, adrenalectomy did not substantially alter the general course of cachexia in tumor bearing animals (104).

In mainourished cancer patients an increased 24 hours urinary cortisol excretion compared with matnourished control patients was also observed (236). Similarly, the same study showed increased urinary excretion of adrenaline and noradrenaline in malnourished cancer patients although this elevation was still within the reference value for well-nourished individuals (236). In tumor bearing animals the increasec urinary catecholamine excretion appeared to be linear and proportionally to tumo load (198). However, in another animal study increased catecholamire concentrations were only temporarily observed (235). It therefore remains uncertain what exact role corticoids and catecholamines have in the development of cancer cachexia Despite this uncertainty, several studies have already been performed to counter these effects with $\beta 2$-agonists such as cimaterol and clenbutero!

Cimaterol both decreased protein breakdown and increased protein synthesis of muscle of tumor bearing animals $(242,243)$. Cimaterol also increased muscle protein content of MCA tumor bearing rats when given in conjunction with TPN. Similar effects have been observed with the $\beta 2$-agonist clenbuterol $(244,245)$. In a recent study it was further shown that the anabolic effects of $\beta 2$-agonists are realized by decreasing the ATP-ubiquitin dependent proteolysis which, as discussed earlier, is upregulated in cancer (114).

Many of the aberrations in host glucose metabolism have also been attributed to decreased host insulin/glucagon ratios (55). This can in part be explained by increased glucagon levels which have been observed in most studies concerning tumor bearing animals and cancer patients $(49,55,198,246-248)$. Furthermore, the rat tumor burden appears to correlate well with plasma glucagon levels (30). Hyperglucagonemia causes anorexia, insulin resistance, increased gluconeogenesis and increases nitrogen loss (249). Wolfe further showed with insulin clamping that glucose substrate cycling is dependent on plasma glucagon concentrations (250). As mentioned previously, these metabolic alterations have all been observed in cancer cachexia.

Cancer induced decreased insulin/glucagon ratio's can also be explained by decreased insulin concentrations. Although both in cancer patients and in turnor bearing animals decreased insulin levels are observed $(30,49,104,198,208,246,247)$. it is at present not clear whether this is a primary or secondary response to cancer. Several animals studies show that the decreased insulin concentrations and concomitant insulin resistance are secondary to the decreased food intake and not the presence of a tumor per se $(66,247)$. In one other study, even a $63 \%$ increase of 
the insulin concentration was observed in tumor bearing animals secondary to increased gluconeogenesis and elevated giucose concentrations (121). Although unknown whether decreased insulin concentrations are primary or secondary, insulin supplementation is one of the most widely used therapies against cancer cachexia.

The possibility to use insulin suppletion against cancer cachexia was particularly lucrative because of the early documentation that the insulin resistance to carbohydrate metabolism did not affect protein metabolism (4). In animal studies supplementation with insulin reversed cancer induced anorexia $(202,247,251,252)$, decreased the weight loss $(55,202,246)$, reduced tumor glycolysis and host gluconeogenesis (246), improved nitrogen accretion of host tissue $(66,202,252)$, and even reduced mortality rates (253). Insulin has also been given to cancer patients and this resulted in a decreased whole body protein breakdown rate in both weight stable and weight losing cancer patients (69). The anabolic effects of insulin was also confirmed in another study by measuring protein synthesis rates in forearm muscle (68). Both weight losing and non-weight losing cancer patients showed appropriate stimulation of muscle protein synthesis rates in response to insulin (68).

In a recent study, cancer cachexia was prevented with octreotride, which prevents glucagon secretion, combined with exogenously given insulin (55). Increased carcass weight, muscle and liver protein content and retardation of tumor growth compared with untreated tumor bearing controls was observed. Strangely, liver gluconeogenic enzymes were increased in the glucagon deprived rats which may be an effect of increased levels of other counter regulatory hormones. Of further interest is the fact that several studies have shown that the toxic and metabolic changes in glucose and protein metabolism induced by TNF $\alpha$ can be reversed or at least ameliorated by insulin supplementation $(254,255)$.

Changes in several other plasma hormone concentrations have also been observed (235). Recently, much interest in literature is given to the interaction of cancer and growth hormone. Growth hormone has been given to patients with several cachectic or acute catabolic disease states (46). Growth hormone has anabolic effects in healthy volunteers $(256,257)$, is effective against postoperative muscle protein breakdown (258) and also appears to be of benefit against the wasting during diabetes (259), AIDS (260) and sepsis (261). In MCA tumor bearing rats, human growth hormone failed to attenuate host body wasting and muscle protein loss (262). In a study with metastatic mammary adenocarcinoma, growth hormone did improve muscle weight and protein content (263). Combined with protein deprivation, growth hormone even reduced tumor growth possibly due to the rate limiting availability of amino acids (263). Furthermore, rat growth hormone appears to improve host body composition of tumor bearing rats with approximately a thousand fold less doses $(264,265)$. In a clinical study with cancer patients human 
growth hormone increased whole body protein synthesis simultaneously with whole body protein breakdown but the effects on protein synthesis were larger (266). In the same study, however, no changes in muscle protein turnover was observed.

Tumor growth stimulation with growth hormone still remains a point of concern (4) although most in vivo studies showed no increase in tumor progression by growth hormone $(262,263)$. Malignancy is, however, still regarded as a contraindication to growth hormone treatment until the differential regulation of metabolic and mitogenic actions of growth hormone are better understood (46).

\subsection{TUMOR MODELS TO STUDY CANCER CACHEXIA}

Although metabolic changes of cancer cachexia and the possible mechanisms involved in the mediation of the syndrome have been studied widely in the past three decades, this has not yet resulted in an adequate understanding of the disturbances or in adequate nutritional therapy. Several tumor models have been utilized to study cancer induced anorexia and cachexia in animals. The clinical relevance of several of these animal models has been questioned because the tumor generally grows to a size not observed in clinical practice (20). Nonetheless, important information regarding host-tumor interactions have been acquired over the last years. In this respect, the methylcholantrene-incluced sarcoma (MCA tumor) has been used by several investigators, including from our laboratory, to study host-tumor interactions related to, e.g. protein metabolism, arnmonia metabolism, interorgan glutamine metabolism and several neuro-humoral changes $(123,163,167,247,270-272)$. The use of MCA tumors has several advantages over murine models. First, the larger size of the animals makes it possible to study regional metabolism of several organs (gut, liver and hindquarter muscle). Second, the large organs and plasma pool of the rat do not require pooling of tissue or plasma from several animals. However, the major disadvantage of using rats instead of mice is that most immunological laboratory tests are suitable for mice and not in all cases for rats. Most studies on MCA tumor bearing rats report that the tumor becomes palpable at day 7-11 after tumor implantation and grows more or less exponentially $(21,31,163,267)$. From day 14-20 food intake starts to decline until death which occurs approximately five weeks after inoculation $(21,27,31,120,121,163,199,252)$. The tumor is malignant and locally very aggressive but does not metastasize. Metabolic changes observed in the MCA tumor bearing rat are related to alterations in carbohydrate, nitrogen and lipid metabolism summarized in Table 2. 
Carbohydrate metabolism

Arterial glucose

Glucose pool size

Glucose turnover

Gluconeogenesis

Glucose tolerance

Cori cycle activity

\section{Protein metabolism}

Nitrogen balance

Protein turnover

Muscle.

Protein synthesis

Protein breakdown

Liver

Protein synthesis

Protein breakdown

Alanine turnover

Ammonia concentrations

Glutamine concentrations

Lipid metabolism

Triglyceride concentrations

Lipoprotein lipase activity

decreased, unchanged
decreased
increased
increased
decreased
increased

$(31,66,72),(246,247,251)$

(31)

$(31,60)$

$(252,267)$

decreased, unchanged

increased

(87), (242)

(87)

$(87,121,122)$

$(72,122)$

(31)

$(247,268)$

$(123,167,246,269)$

decreased

Most disturbances in glucose metabolism which are described in the first part of this chapter, were also found in MCA tumor bearing rats. These include an increased glucose turnover, increased gluconeogenesis, decreased glucose tolerance and increased insulin resistance. Nitrogen metabolism of MCA tumor bearing rats is characterized by increased nitrogen loss, increased whole body protein turnover rates and wasting of peripheral muscle tissue with a relatively sparing of visceral organ nitrogen. Changes in amino acid metabolism have also been reported for alanine and glutamine, the major nitrogen carriers of the body. The MCA tumor model is therefore appropriate for the study of interorgan amino acid metabolism, particularly of these two amino acids. Furthermore, studies on fat metabolism displaying increased arterial triglyderide concentrations and decreased triglycerides clearance by lipoprotein lipase 
Several studies showed that MCA tumors induce an inflarnmatory response. These include, sometimes but not always, increased TNF $\alpha$ concentrations $(197,199,201)$, increased systemic (199) and local IL6 (210) concentrations and an increased acute phase protein response $(220,274)$. It is generally believed that the induction of these inflammatory mediators in MCA tumor bearing rats is essential for the altered carbohydrate and nitrogen metabolism but the exact role of each mediator and the interactions between these mediators and the neuro-hormonal response remains to be elucidated.

\section{Control}

$<50$

$\alpha_{2}$ Macroglobulin

TNF $\alpha$

IL6
Small tumor burden

$$
200 \pm 22
$$

not detectable

not detectable not detectable
Large tumor burden

$$
6000 \pm 300
$$

not detectable

$257 \pm 50$

Table 3. Systemic inflammatory response of MCA tumor bearing Lewis rats. $\alpha_{2}$ Macroglobulin (IU/ml) was tested by single immuno diffusion (275). TNF $\alpha$ was tested by both ELISA using anti-murine TNF $\alpha$ monoclonal TN3 and by the WEHI 164 bio-assay (276). IL6 (pg/ml) was tested by the B9 hybridoma bioassay using the MTT detection method (277).

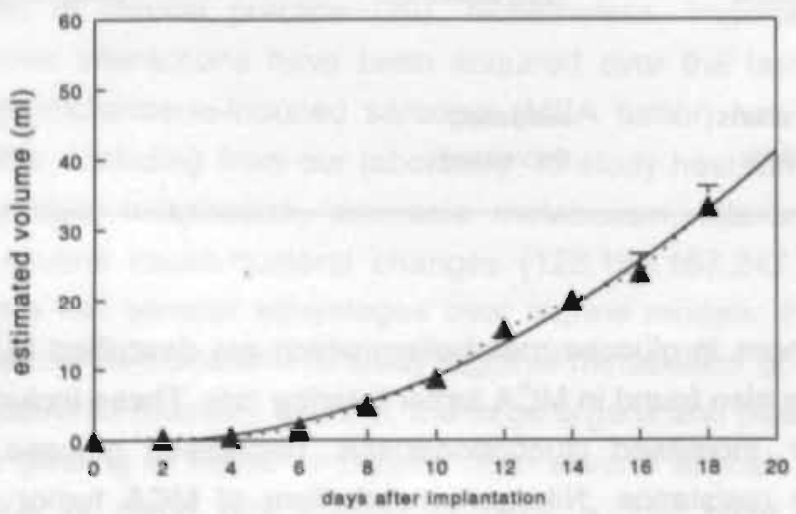

Figure 1. Growth curve of MCA tumors in Lewis rats $(n=5)$. Curve fitting reveals that the fumor grows polynomal (see also chapter 5 ).

Figure 2 (page 27). 1A: Paraffine section of MCA tumor tissue subjected to hematoxylin and eosin staining (100x). 1B: same paraffine section as $1 \mathrm{~A}$ at $400 \mathrm{x}$. 2A: Lymphocyte staining of tumor tissue ( $\mathrm{CD}^{\circ}$ cells, 100x). 2B: same section as $2 \mathrm{~A}$ at $400 \mathrm{x}$. The tumor appears as a fibrosarcoma. Local aggressiveness is shown by the many dividing cells and aneuploid cell fractions ( $1 \mathrm{~A}$ and $1 \mathrm{~B}$ ). Lymphocyte infiltration is observed at the peripheral sides of the tumor and at several spots within the tumor (2A and $2 B$ ). 
Studies of the MCA tumor model are mostly derived from the MCA tumor originally induced by Grant and Wells in 1974 into Fisher 344 rats and subsequently passaged on in this strain $(120,162,278)$. At the starting point of the work on this thesis no tumor was present in our laboratory. We therefore chemically induced a MCA tumor in rats (279). Lewis rats were used for practical reasons because they are homebred at the University (Centralized Animal Facilities, University of Limburg). MCA (10 mg, Sigma W6501, St Louis, USA) was dissolved in alcohol (1 ml, 75\%), paraffine (1 ml, Merck 7174) or DMSO (1 ml, Merck 2931) and injected subcutaneously in the rats. When the tumor was approximately $5-10 \%$ of the body weight it was serially transplanted to other rats to maintain the tumor in vivo. Tumor tissue was further made to a cell suspension to grow in vitro and to maintain a stock in liquid nitrogen. The in vitro stock has also been tested and proven to be malignant in vivo again. At present approximately 15 MCA cell-lines are stored in liquid nitrogen.
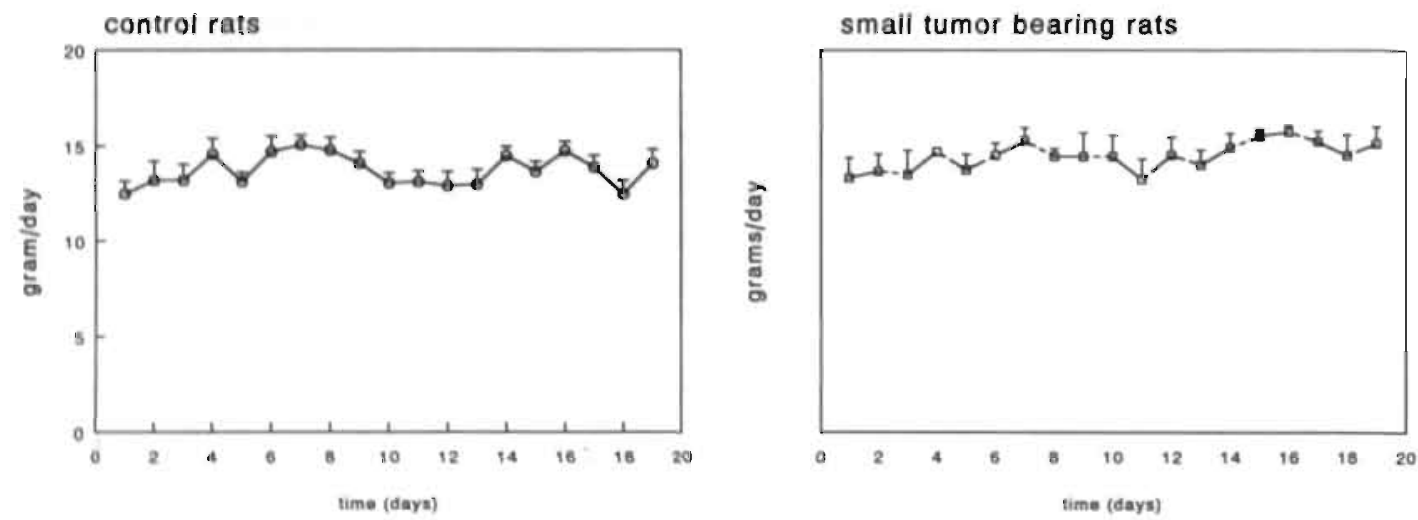

large tumor bearing rats

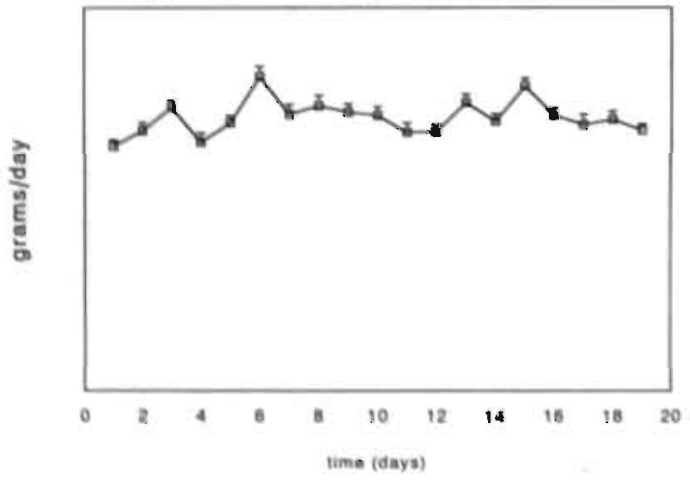

Figure 3. Food intake by control and MCA. tumor bearing rats. Small tumor bearing rats had a tumor burden of $5-10 \%$ of the body weight, large tumor bearing rats a tumor burden of $15-30 \%$ of the body weight. No changes in food intake were observed in any of the experiments over the last three years. 
The MCA tumor induced in Lewis rats grows rapidly, is locally very aggressive and does not metastatize. The tumor appears to grow exponentially (Fig. 1) but the curve fitting of the growth curve reveals that it grows according to a polynomal curve. This indicates that the growth of larger tumors is inhibited with increasing tumor load. Hematoxylin and eosin staining of the tumor (Fig. 2A) shows the malignant and locally very aggressive character of the tumor similar to the description in literature (280). Lymphocyte staining (anti-CD3, DAKO A452, Glostrup, Danmark) further shows that the tumor induces an immune response in the rats (Fig. 2B). The immune response was also confirmed by the systemic presence of high levels of the acute phase proteins and IL6 (Table 3). We also tested whether TNF $\alpha$ was present in serum but we could not find detectable levels using either an ELISA or bio-assay.

MCA tumors were transplanted for more than 3 years without any signs of anorexia (Fig. 3). The reason for this contrast with most studies reported in literature are unknown but the food intake of tumor bearing rats being normal made it possible to observe changes in host metabolism which were only induced specifically by tumorhost interactions. The lack of decreased food intake also induced a moderate cancer cachexia as can be seen in figure 4 .
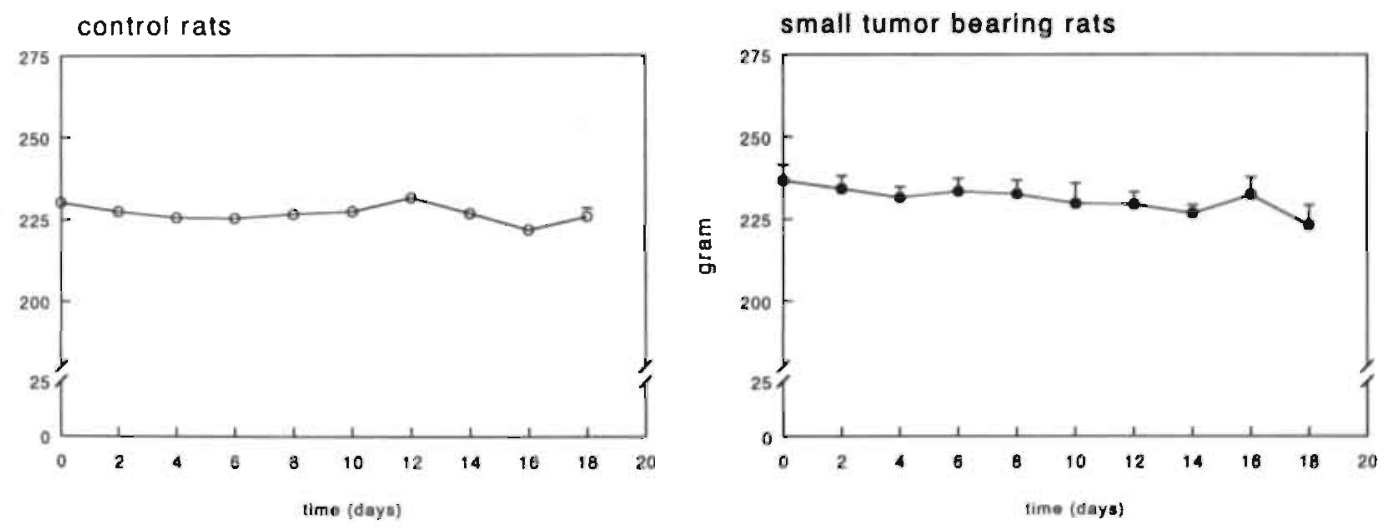

large tumor bearing rats

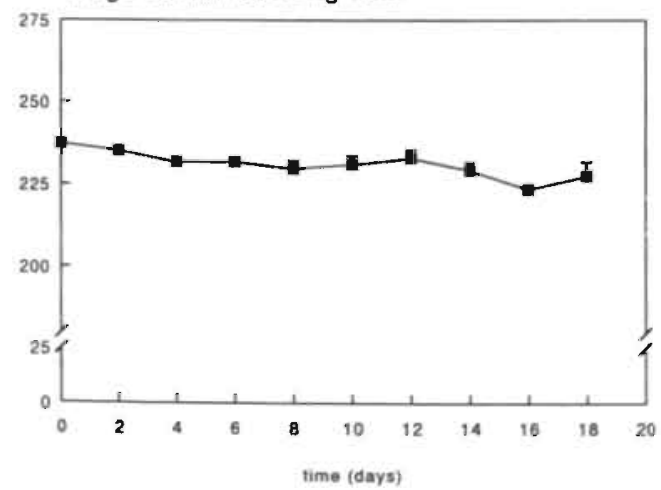

Figure 4. Carcass weight of control, small tumor bearing and large tumor bearing rats. 
In contrast to several reports in literature, carcass weight of the host (total body weight minus the tumor) remained fairly constant. However, wasting of muscle tissue and redistribution of nutrients to visceral organs were observed (Fig. 5) making the model suitable to study moderate cancer cachexia as is more often seen in the clinical practice of oncology.

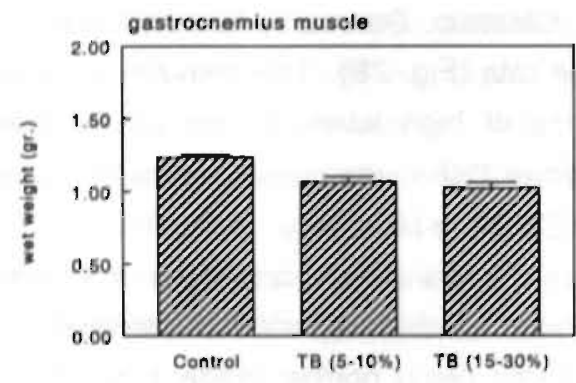

Figure 5. Dry weight of several organs (gastrocnemius muscle, small intestine, liver and spleen) in control, small tumor bearing and large tumor bearing rats.
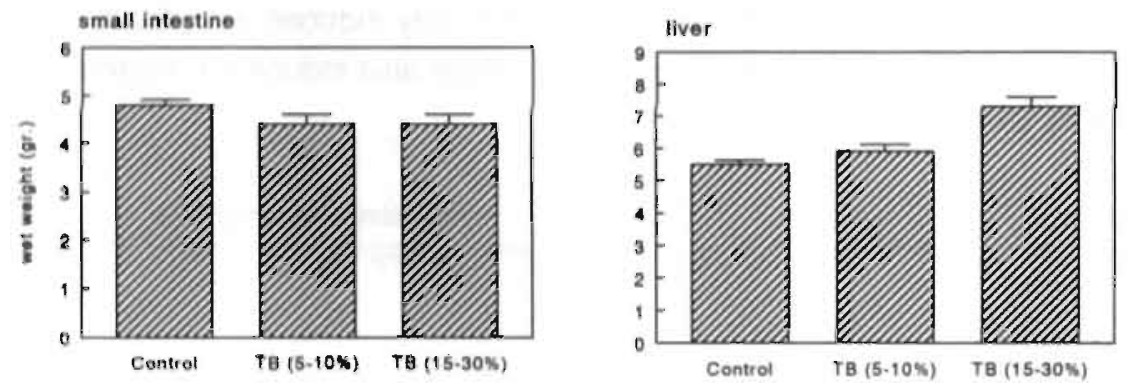

\subsection{OUTLINE OF THE THESIS}

The thesis is based on three principal questions which arose at the starting point. The first one was whether we were able to measure in vivo protein synthesis and breakdown rates of muscle tissue and splanchnic organs in small laboratory animals. The second question was how the presence of a tumor affected protein and glutamine metabolism of these organs and, lastly, we wanted to know whether these organ specific changes influenced the normal metabolic response after a surgical challenge.

The first aim of this thesis was to evaluate in vivo intracellular protein and amino acid measurements in muscle, gut and liver tissue of the rat (chapter 2, 3 and 4). Selective catheterization of arterial and venous vessels across several organs and 
constant infusions of radioactive labeled amino acids has made it possible to simultaneously measure in vivo protein synthesis, protein breakdown, intracellular amino acid disposal and production and amino acid membrane transport rates of several organs. Assumptions underlying the different methods are briefly outlined in chapter 2. Because these methods were previously used in large animals and humans, we tested the possibility to use the methods in small laboratory animals (chapter 3,4 ). The effects of starvation on protein and amino acid kinetics were also tested in these models because decreased food intake often accompanies cancer cachexia.

As no tumor model was present in our laboratory, methylcholantrene (MCA) was used to chemically induce a subcutaneous sarcoma in rats. These tumors have previously been used by others to study metabolic changes of cancer cachexia. After induction of the tumor we first studied the effects of these tumors on food intake, weight changes, whole body and regional muscle protein and amino acid kinetics (chapter 5). Amino acid turnover was focused to glutamine as this amino acid is a specific nutrient for rapidly dividing cells, e.g. tumor cells, enterocytes and immune cells.

The effects of increasing tumor loads on gut protein and amino acid turnover are studied in chapter 6 and these changes are related to morphological and functional changes. The liver has a central role in amino acid homeostasis. Liver protein metabolism was studied in chapter 7 and related to urea production and the acute phase response. Liver glutamine kinetics during growth of cancer are discussed in chapter 8 .

After a surgical trauma amino acid and protein kinetics change dramatically to supply host defense organs with nutrients. To test whether postoperative amino acid and protein metabolism were disturbed in the cancer bearing host, we also studied muscle and gut protein and amino acid turnover on the second postoperative day after a hysterectomy. These results are described and discussed in chapter 9 and 10.

\section{References}

1. Studley HO. Percentage of weight loss. A basic indicator of surgical risk in patients with chronic peptic ulcer. JAMA 1936;106:458-60.

2. Kem KA, Norton JA. Cancer cachexia. J Parenter Enteral Nutr 1988:12:286-98.

3. Nixon DW, Lawson DH, Kutner M, Ansley J, Schwarz M. Heymsfield S, Chawa R, Cartwright TH, Rudman D. Hyperalimentation of the cancer patient with protein-calorie undernutrition. Cancer Res 1981;41:2038-45.

4. Pisters PWrT, Pearlstone DB. Protein and amino acid metabolism in cancer cachexia: investigative techniques and therapeutic interventions. Crit Rev Clin Lab Sci 1993;30:223-72. 
5. Hill JM. Impact of nutritional support on the clinical outcome of the surgical patient. Clin Nutrition 1994;13:331-40.

6. Lawson DH, Richmond A, Nixon DW, Rudman D. Metabolic approaches to cancer cachexia. Annu Rev Nutr 1982;2:277-301.

7. Norton JA, Peacock JL, Morrison SD. Cancer cachexia. CRC Crit Rev Oncol Hematol 1987;7:289-327.

8. Detsky AS, Baker JP, O'Rourke K, Goel V. Perioperative parenteral nutrition: a meta-analysis. Ann Intern Med 1987;107:195-203.

9. Dewys WD, Begg C, Lavin PT, Band PR, Bennett JM, Bertino JR, Cohen MH, Douglass HO, Jr., Engstrom PF, Ezdinli EZ, et al. Prognostic effect of weight loss prior to chemotherapy in cancer patients. Eastern Cooperative Oncology Group. Am J Med 1980;69:491-7.

10. Nixon DW, Heymsfield SB, Cohen AE, Kutner MH, Ansley J, Lawson DH, Rudman D. Proteincalorie undernutrition in hospitalized cancer patients. Am J Med 1980;68:683-90.

11. Dempsey DT, Mullen JL, Buzby GP. The link between nutritional status and clinical outcome: can nutritional intervention modify it? Am J Clin Nutr 1988;47:352-6.

12. Meijerink, W.J.H.J. Perioperative nutrition in GI cancer patients 1992; Thesis, University of Limburg, The Netherlands.

13. Shaw JH. Influence of stress, depletion, and/or malignant disease on the responsiveness of surgical patients to total parenteral nutrition. Am J Clin Nutr 1988;48:144-7.

14. Muller JM, Brenner U. Dienst $C$. Pichlmaier $H$. Preoperative parenteral feeding in patients with gastrointestinal carcinoma. Lancet 1982;1:68-71

15. Meyenfeldt MF, Meijerink WJHJ, Rouflart MM, Builmaassen MTHJ, Soeters PB. Perioperative nutritional support: a randomised clinical trial. Clin Nutrition 1992;11:180-6.

16. Perioperative total parenteral nutrition in surgical patients. The Veterans Affairs Total Parenteral Nutrition Cooperative Study Group. N Engl J Med 1991;325:525-32.

17. Brennan MF. Total parenteral nutrition in the cancer patient. N Engl J Med 1981;305(7):375-82.

18. Copeland EM, Macfayden BV, Jr., Dudrick SJ. Intravenous hyperalimentation in cancer patients. J Surg Res 1974;16:241-7.

19. Brennan MF, Ekman L. Metabolic consequences of nutritional support of the cancer patient. Cancer 1984;54:2627-34.

20. Douglas RG, Shaw JH. Metabolic effects of cancer. Br J Surg 1990;77:246-54.

21. Popp MB. Morrison SD, Brennan MF. Total parenteral nutrition in a methylcholanthrene-induced rat sarcoma model. Cancer Treat Rep 1981;65(Suppl 5):137-43.

22. Stein TP, Oram Smith JC, Leskiw MJ, Wallace HW, Miller EE. Tumor-caused changes in host protein synthesis under different dietary situations. Cancer Res 1976;36:3936-40.

23. Garlick PJ, McNurlan MA. Protein metabolism in the cancer patients. Biochimie 1994;76:713-7.

24. Heys SD, Park KG. McNurlan MA, Milne E, Eremin O. Wernerman J, Keenan RA, Garlick PJ. Stimulation of protein synthesis in human tumours by parenteral nutrition: evidence for modulation of tumour growth. Br J Surg 1991;78:483-7.

25. Mullen JL, Buzby GP, Gertner MH, Stein TP, Hargrove WC. Oram Smith J, Rosato EF. Protein synthesis dynamics in human gastrointestinal malignancies. Surgery 1980;87:331-8.

26. Daly JM, Copeland EM, Dudrick SJ. Effects of intravenous nutrition on tumor growh and host immunocompetence in malnourished animals. Surgery 1978;84:655-8.

27. Stallion A, Foley Nelson $\mathrm{T}$, Chance WT, Zhang FS, Fischer JE. Parenteral vs enternal nutrition in tumor-bearing rats. JPEN J Parenter Enteral Nutr 1994;18:148-53.

28. Bozzetti F. Nutritional support in the adult cancer patient. Clin Nutrition 1992;11:167-9.

29. Koretz RL. Parenteral nutrition: Is it oncologically logical? J Clin Oncol 1984:2:534-8. 
30. Inculet RI, Peacock JL, Gorschboth CM, Norton JA. Gluconeogenesis in the tumor-influenced rat hepatocyte: importance of tumor burden, lactate, insulin, and glucagon. I Nati Cancer Inst 1987:79:1039-46.

31. Burt ME, Lowry SF, Gorschboth C, Brennan MF. Metabolic alterations in a noncachectic animal tumor system. Cancer 1981;47:2138-46.

32. Fredrix EW, Soeters PB, Wouters EF, Deerenberg IM, von Meyenfeldt MF, Saris WH. Effect of different tumor types on resting energy expenditure. Cancer Res 1991;51:6138-41.

33. Younes RN, Vydelingum NA, Noguchi Y, Brennan MF. Lipid kinetic alterations in tumor-bearing rats: reversal by tumor excision. J Surg Res 1990;48:324-8.

34. Tessitore L, Bonelli G, Baccino M. Early development of protein metabolic pertubations in the liver and skeletal muscle of tumour-bearing rats. Biochem J 1987;241:153-9.

35. Tayek JA, Blackburn GL, Bistrian BR. Alterations in whole body, muscle, liver and tumor tissue protein synthesis and degradation in Novikoff hepatoma and Yoshida sarcoma tumor growth studied in vivo. Cancer Res 1988;48:1554-8.

36. Hyltander A, Drott C, Korner U, Sandstrom R, Lundholm K. Elevated energy expenditure in cancer patients with solid tumours. Eur J Cancer 1991;27:9-15.

37. Warnold I, Lundholm K, Schersten $\mathrm{T}$. Energy balance and body composition in cancer patients. Cancer Res 1978;38:1801-7.

38. Fredrix EW, Wouters EF, Soeters PB, van der Aalst AC, Kester AD, von Meyenfeldt MF, Saris. WH. Resting energy expenditure in patients with non-small cell lung cancer. Cancer 1991;68:1616-21.

39. Falconer JS, Fearon KCH, Plester CE, Ross JA, Carter DC. Cytokines, the acute-phase response, and resting energy expenditure in cachectic patients with pancreatic cancer. Ann Surg 1994;219:325-31.

40. Fearon KCH, Hansell DT, Preston T, Plumb JA, Davies J, Shapiro D, Shenkin A, Calman KC, Burns HJG. Influence of whole body protein tumover rate on resting energy expenditure in patients with cancer. Cancer Res 1988;48:2590-5.

41. Dempsey DT, Feurer ID, Knox LS, Crosby LO, Buzby GP, Mullen JL. Energy expenditure in malnourished gastrointestinal cancer patients. Cancer 1984;53:1265-73

42. Grande $F$, Anderson JT, Keys A. Changes of basal metabilic rate in man in semistarvation and refeeding. J Appl Physiol 1958;12(2):230-8.

43. Soares MJ, Piers LS, Shetty PS, Jackson AA, Waterlow JC. Whole body protein turnover in chronically undernourished individuals. Clin Sci Colch 1994;86:441-6.

44. Even PC, Nicolaidis S. Adaptive changes in energy expenditure during mild and severe feed restriction in the rat. Br J Nutr 1993;70:421-31.

45. Cori CF. Cori GT. The carbohydrate metabolism of tumors. II. Changes in sugar, lactic acid, and CO2-combining power of blood passing through a tumor. J Biol Chem 1925;66:397-405.

46. Crown AL, Holly JMP. The insulin-like growth factor system in critical illness: pathophysiology and therapeutic potential. Clin Nutrition 1995;14:321-8.

47. Gullino PM, Grantham FH, Courtney AH. Glucose consumption by transplanted tumors in vivo. Cancer Res 1967;27:1031-40.

48. Norton JA, Burt ME. Brennan MF. In vivo urilization of substrate by human sarcoma-bearing limbs. Cancer 1980;45:2934-9.

49. Burt ME, Norton JA, Brennan MF. The human tumor-bearing limb: an ex vivo model. Surgery 1980;87:128-32.

50. Stryer L. Biochemistry. 3rd ed. New York: Freeman and Company; 1988;p. 495-515. 
51. Shaw $\mathrm{JH}_{1}$ Wolfe RR. Glucose and urea kinetics in patients with early and advanced gastrointestinal cancer: the response to glucose infusion, parenteral feeding, and surgical resection. Surgery 1987;101:181-187.

52. Holroyde CP, Gabuzda TG, Putnam RC, Paul P, Reichard GA. Altered glucose metabolism in metastatic carcinoma. Cancer Res 1975;35:3710-4.

53. Bartlett DL, Scott L, Charland PD, Torosian MH. Glucose metabolism and hormone treatment in cancer cachexia. Surg Forum 1995;42:14-6.

54. Singh J, Grigor MR, Thompson MP. Glucose homeostasis in rats bearing a transplantable sarcoma. Cancer Res 1980;40:1699-706.

55. Bartlett DL, Charland SL, Torosian MH. Reversal of tumor-associated hyperglucagonemia as treatment for cancer cachexia. Surgery 1995;118:87-97.

56. Gold J. Proposed treatment of cancer by inhibition of gluconeogenesis. Oncology 1968;22:185207.

57. Tayek JA, Heber D, Chlebowski RT. Effect of hydrazine sulphate on whole-body protein breakdown measured by $14 \mathrm{C}$-lysine metabolism in lung cancer patients. Lancet 1987;2:241-4.

58. L.undholm K, Edstrom S, Karlberg I, Ekman L, Schersten T. Glucose turnover, gluconeogenesis from glycerol, and estimation of net glucose cycling in cancer patients. Cancer 1982;50:1142-50.

59. Young VR. Energy metabolism and requirements in the cancer patient. Cancer Res 1977;37:2336-47.

60. Lowry SF, Foster DM, Norton JA, Berman M, Brennan MF. Glucose disposal and glucoñeogenesis from alanine in tumor-bearing fischer 344 rats. J Natl Cancer Inst 1981;66:6538.

81. Waterhouse C, Jeanpretre N, Keilson J. Gluconeogenesis from alanine in patients with progressive malignant disease. Cancer Res 1979;39:1968-72.

62. Chlebowski RT, Heber D, Richardson B, Block. JB. Influence of hydrazine sulfate on abnormal carbohydrate metabolism in cancer patients with weight loss. Cancer Res 1984;44:857-61.

63. Fearon KC, Borland W, Preston T, Tisdale MJ, Shenkin A, Calman KC. Cancer cachexia: influence of systemic ketosis on substrate levels and nitrogen metabolism. Am J Clin Nutr 1988:47:42-8.

64. Lundholm K, Holm G, Schersten T. Insulin resistance in patients with cancer. Cancer Res 1978;38:4665-70.

65. McCall JL. Tuckey JA. Parry BR. Serum Tumour Necrosis Factor alpha and insulin resistance in gastrointestinal cancer. Br J Surg 1992;79:1361-3.

66. Svaninger $G$, Drott $C$. Lundholm $K$. Role of insulin in development of cancer cachexia in nongrowing sarcoma-bearing mice: special reference to muscle wasting. J Natll Cancer Inst 1987;78:943-50.

67. Lowry SF, Foster DM. Norton JA, Berman M, Brennan MF: Glucose disposal and gluconeogenesis from alanine in tumor-bearing Fischer 344 rats. J Natl Cancer Inst 1981;66:6538.

68. Newman E, Heslin MJ, Wolf RF, Pisters PW. Brennan MF. The effect of insulin or glucose and protein metabolism in the forearm of cancer patients. Surg Oncol 1992;1:257-67.

69. Heslin MJ, Newman E, Wolf RF, Pisters PW, Brennan MF. Effect of systemic hyperinsulinemia in cancer patients. Cancer Res 1992;52:3845-50.

70. Lundholm KG. Body compositional changes in cancer patients. Surg Clin North Am 1986;66:101323.

71. Garattini S, Bizzi A, Donelli GM, Guaitani A, Samanin R, Spreafico F. Anorexia and cancer in animals and man. Cancer Treat Rev 1980;7:115-40. 
72. Devereux DF, Redgrave TG, Loda MF, Clowes GH, Jr., Deckers PJ. Tumor-associated metabolism in the rat is a unique physiologic entity. J Surg Res 1985;38:149-53.

73. Chapman HA, Jr., Hibbs JB. Modulation of macrophage tumoricidal capability by components of normal serum: a central role for lipid. Science 1977; 197:282-5.

74. Yumura W, Hattori S, Morrow WJ, Mayes DC, Levy JA, Shirai T. Dietary fat and immune function. II. Effects on immune complex nephritis in (NZB $\times$ NZW)F1 mice. J Immunol 1985;135:3864-8.

75. Shaw JH, Wolfe RR. Fatty acid and glycerol kinetics in septic patients and in patients with gastrointestinal cancer. The response to glucose infusion and parenteral feeding. Ann Surg 1987;205:368-76.

76. Torosian MH, Bartlett DL, Chatzidakis C, Stein TP. Effect of tumor burden on futile glucose and lipid cycling in tumor bearing animals. J Surg Res 1993;55:68-73.

77. Redgrave TG, Devereux DF, Deckers PJI. Hyperlipidemia in tumor-bearing rats. Biochim Biophys Acta 1984; 795:286-92.

78. Vlassara H, Spiegel RJ, San Doval D, Cerami A. Reduced plasma lipoprotein lipase activity in patients with malignancy-associated weight loss. Horm Metab Res 1986;18:698-703.

79. Noguchi Y: Vydelingum NA, Younes RN, Fried SK, Brennan MF. Tumor-induced alterations in tissue lipoprotein lipase activity and mRNA levels. Cancer Res 1991;51:863-9.

80. Devereux DF, Redgrave TG, Tilton M, Hollander D, Deckers PJ. Intolerance to administered lipids in tumor-bearing animals. Surgery 1984;96:414-9.

81. Wolfe RR. Wolfe RR, editors. Tracers in Metabolic Research. New York: Alan R. Liss Inc; 1992;

82. Waterhouse $\mathrm{C}$, Mason J. Leucine metabolism in patients with malignant disease. Cancer 1981;48:939-44

83. Norton JA, Stein TP, Brennan MF. Whole body protein synthesis and turnover in normal man and malnourished patients with and without known cancer. Ann Surg 1981;194:123-8.

84. Jeevanandam M. Horowitz GD, Lowry SF, Brennan MF. Cancer cachexia and protein metabolism. Lancet 1984;(i):1423-7.

85. Melville S, MCNurlan MA, Calder AG, Garlick PJ. Increased protein tumover despite normal energy metabolism and responses to feeding in patients with lung cancer. Cancer Res 1990;50:1125-31.

86. Richards EW, Long CL, Nelson KM, Tohver OK, Pinkston JA, Navari RM, Blakemore WS. Protein tumover in advanced lung cancer patients. Metabolism 1993;42:291-6.

87. Norton JA, Shamberger R, Stein TP, Milne GW, Brennan MF. The influence of tumor-bearing on protein metabolism in the rat. J Surg Res 1981;30:456-32.

88. Kawamura I, Moldawer LL, Keenan RA, Batist G, Botha, Jr A, Bistrian BR, Blackburn GL. Altered amino acid kinetics in rats with progressive tumor growth. Cancer Res 1982;42:824-9.

89. Fearon $\mathrm{KCH}$, MCMillan DC, Preston T, Winstanley P, Cruickshank AM, Shenkin A. Elevated circulating interleukin- 6 is associated with an acute-phase response but reduced fixed hepatic protein synthesis in patients with cancer. Ann Surg 1991;213:26-31.

90. Dresler $\mathrm{CM}$, Jeevanandam M, Brennan MF. Metabolic efficacy of enteral feeding in malnourished cancer and noncancer patients. Metabolism 1987;36:82-8.

91. Emery PW. Edwards RHT, Rennie MJ, Souhami RL, Halliday D. Protein synthesis in muscle measured in vivo in cachectic patients with cancer. Brit Med J 1984;289:584-6.

92. Garcia Martinez C, Lopez Soriano FJ, Argiles JM. Alanine metabolism in rats bearing the Yoshida AH-130 ascites hepatoma. Cancer Lett 1994;87:123-30.

93. Norton JA, Shamberger R, Stein TP, Milne GW, Brennan MF. The influence of tumor-bearing on protein metabolism in the rat. J Surg Res 1981;30:456-62.

94. Emery PW, Lovell L, Rennie MJ. Protein synthesis measured in vivo in muscle and liver of cachectic tumor bearing mice. Cancer Res 1984;44:2779-84. 
95. Clark CM, Goodlad GA. Depletion of proteins of phasic and tonic muscles in tumour-bearing rats. Eur J Cancer 1971;7:3-9.

96. Muscaritoli M, Whitlock D, Meguid MM. Muscle performance and adenine-nucleotides status in MCA-Sarcoma tumor-bearing rats. Physiol Behav 1992;52:803-7.

97. Lundholm K, Edstrom S. Ekman L, Karlberg I, Bylund AC, Schersten T. A comparative study of the influence of malignant tumor on host metabolism in mice and man: evaluation of an experimental model. Cancer 1978;42:453-61.

98. Lundholm K, Edstrom S, Ekman L, Karlberg I, Schersten T. Metabolism in peripheral tissues in cancer patients. Cancer Treat Rep 1981;65 Suppl 5:79-83.

99. Bennegard K, Lindmark L, Eden E, Svaninger G, Lundholm K. Flux of amino acids across the leg in weight losing cancer patients. Cancer Res 1984;44:386-93.

100. Shaw JH, Humberstone DA, Douglas RG, Koea J. Leucine kinetics in patients with benign disease, non-weight-losing cancer, and cancer cachexia: studies at the whole-body and tissue level and the response to nutritional support. Surgery 1991;109:37-50.

101. Heber D, Chlebowski RT, Ishibashi DE, Herrold JN. Block JB. Abnormalities in glucose and protein metabolism in noncachectic lung cancer patients. Cancer Res 1982;42:4815-9.

102. Lundholm K, Bennegard K, Eden E, Svaninger G, Emery PW, Rennie MJ. Efflux of 3methylhistidine from the leg in cancer patients who experience weight loss. Cancer Res 1982; $42: 4807-4811$

103. Tessitore L, Costelli P. Bonetti G, Baccino FM. Cancer cachexia, malnutrition, and tissue protein turnover in experimental animals. Arch Biochem Biophys 1993;306:52-8.

104. Tessitore L, Costelli P. Baccino FM. Pharmacological interference with tissue hypercatabolism in tumour- bearing rats. Biochem J 1994;299:71-8.

105. Dardevet D, Sornet C, Taillandier D, Savary I, Attaix D, Grizard J. Sensitivity and protein turnover response to glucocorticoids are different in skeletal muscle from adult and old rats. Lack of regulation of the ubiquitin-proteasome proteolytic pathway in aging. $\mathrm{J}$ Clin Invest 1995;96:2:113-9.

106. Garcia Martinez C, Agell N, Llovera M, Lopez Soriano FJ, Argiles JM. Tumour necrosis factoralpha increases the ubiquitinization of rat skeletal muscle proteins. FEBS Lett 1993;323:211-4.

107. Johnson P. Calpains (intracellular calcium-activated cysteine proteinases): structure-activity relationships and involvement in normal and abnormal cellular metabolism. Int $\mathrm{J}$ Biochem 1990;22:811-22.

108. Hershko A, Ciechanover A. The ubiquitin system for protein degradation. Amnu Rev Biochem 1992:61:761-807.

109. Hershko A. The ubiquitin pathway for protein degradation. Trends Biochern Sci 1991;16:265-8.

110. Tiao G, Fagan JM, Samuels N, James JH, Hudson K, Lieberman M, Fischer JE, Hasselgren PO. Sepsis stimulates nonlysosomal, energy-dependerit proteolysis and increases ubiquitin mRNA levels in rat skeletal muscle. J Clin Invest 1994:94:22:55-64.

111. Price SR, England BK. Bailey JL. Van Vreede K. Mitch WE. Acidosis and glucocorticoids concomitantly increase ubiquitin and proteasome subunit mRNAs in rat muscle. Am J Physiol 1994:267:C955-60.

112. Wing SS, Goldberg AL. Glucocorticoids, activate the ATP-ubiquitin-dependent proteolytic system in skeletal muscle during fasting. Am J Physiol 1993;264:E668-76.

113. Tiao G, Fagan J, Roegner V, Lieberman M, Wang JJ, Fischer JE, Hasselgren PO. Energyubiquitin-dependent muscle proteolysis during sepsis in rats is regulated by glucocorticoids. Journal of Clinical Investigation 1996;97(2):339-48.

114. Costelli P. Garcia Martinez C. Llovera M. Carbo N. Lopez Soriano FJ, Agell N. Tessitore L. Baccino FM, Argiles JM. Muscle protein waste in tumor-bearing rats is effectively antagonized by 
a beta 2-adrenergic agonist (clenbuterol). Role of the ATP-ubiquitin-dependent proteolytic pathway. J Clin Invest 1995;95:2367-72.

115. Garcia Martinez C, Llovera M, Agell N, Lopez Soriano FJ, Argiles JM. Ubiquitin gene expression in skeletal muscle is increased by tumour necrosis factor-alpha. Biochem Biophys Res Commun 1994;201:682-6.

116. Barrett EJ, Revkin JH, Young LH, Zaret BL, Jacob R, Gelfand RA. An isotopic method for measurement of muscle protein synthesis and degradation in vivo. Biochem J 1987;245:223-8.

117. Thompson GN, Pacy PJ, Merritt H, Ford GC, Read MA, Cheng KN, Halliday D. Rapid measurement of whole body and forearm protein turnover using a [2 $\mathrm{H} 5]$ phenylalanine model. Am J Physiol 1989;256:E631-639.

118. Biolo G, Chinkes D. Zhang XJ, Wolfe RR. A new model to determine in vivo the relationship between amino acid transmembrane transport and protein kinetics in muscle. JPEN J Parenter Enteral Nutr 1992;16:305-15.

119. Biolo G, Fleming RY, Maggi SP. Wolfe RR. Transmembrane transport and intracellular kinetics of amino acids in human skeletal muscle. Am J Physiol 1995;268:E75-84.

120. Radcliffe JD, Fontanez IN, Morrow S. The effect of a methylcholanthrene-induced sarcoma on the protein status of fischer rats. Nutr Res 1986,6:539-47.

121. Warren RS, Jeevanandam M, Brennan MF. Comparison of hepatic protein synthesis in vivo versus in vitro in the tumor-bearing rat. J Surg Res 1987;42:43-50.

122. Warren RS, Jeevanandam M, Brennan MF. Protein synthesis in the tumor-influenced hepatocyte. Surgery 1985;98:275-82.

123. Souba $\mathrm{WW}$, Strebel FR, Bull JM, Copeland EM, Teagtmeyer $H_{1}$ Cleary $\mathrm{K}$. Interorgan glutamine metabolism in the tumor-bearing rat. J Surg Res 1988;44:720-6.

124. Kaibara A, Yoshida S, Yamasaki K, Ishibashi N, Kakegawa T. Effect of glutamine and chemotherapy on protein metabolism in tumor- bearing rats. J Surg Res 1994;57:143-9.

125. McNulan MA, Tomkins AM, Garlick PJ. The effect of starvation on the rate of protein synthesis in rat liver and small intestine. Biochem J 1979;178:373-9.

126. Preedy VR, Paska L, Sudgen PH, Schofiled PS, Sugden MC. The effects of surgical stress and short-term fasting on protein synthesis in vivo in diverse tissues of the mature rat. Biochem $J$ 1988;250:179-88.

127. Bergstrom J, Furst $P$, Noree LO, Vinnars E. Intracellular free amino acid concentration in human muscle tissue. J Appl Physiol 1974;36:693-7.

128. Lund $P$. A radiochemical assay for glutamine synthetase, and activity of the enzyme in rat tissues. Biochem J 1970;118:35-9.

129. Arola Lt, Palou A, Remesar X. Alemany M. Glutamine synthetase activity in the organs of fed and 24-h fasted rats. Horm Metab Res 1981;13:199-202.

130. Sarantos $P$. Howard D, Souba WW. Dexamethasone regulates giutamine synthetase expression in rat lung. Metabolism 1993;42:795-800

131. Moskovitz B, Katz $Y$, Singer $P$, Nativ $O$, Rosenberg $B$. Glutamine metabolism and utilization: relevance to major problems in health care. Pharmacol Res 1994;30:61-71.

132. Souba WW, Smith RJ, Wilmore DW. Glutamine metabolism by the intestinal tract. JPEN J Parenter Enteral Nutr 1985;9:608-17.

133. Dejong CHC, Kampman MT, Deutz NEP, Soeters PB. Altered glutamine metabolism in rat portal drained viscera and hindquarter during hyperammonemia. Gastroenterology 1992;102:936-48.

134. Heeneman S, Deutz NEP. The effect of 4 days methionine sulfoximine administration on net muscle protein breakdown in rats. Clin Nutrition 1993;12:182-90.

135. Millward DJ, Jepson MM, Omer A. Muscle glutamine concentration and protein turnover in vivo in malnutrition and in endotoxemia. Metabolism 1989;38:6-13. 
136. Chang TW, Galdberg AL. The metabolic fates of amino acids and the formation of glutamine in skeletal muscle. J Biol Chern 1978;253:3685-95.

137. Ruderman NB, Berger $M$. The formation of glutamine and alanine in skeletal muscle. J Biol Chem 1974;249:5500-6.

138. Nurjhan N, Bucci A, Perriello G, Stumvoll M, Dailey G, Bier DM, Toft I, Jenssen TG, Gerich JE. Glutamine: a major gluconeogenic precursor and vehicle for interorgan carbon transport in man. J Clin Invest 1995:95:272-7.

139. Haussinger D. Glutamine metabolism in the liver: overview and current concepts. Metabolism 1989;38:14-7.

140. Haussinger D. Liver glutamine metabolism. JPEN J Parenter Enteral Nutr 1990;14:56S-62S.

141. Meijer AJ, Verhoeven AJ. Regulation of hepatic glutamine metabolism. Biochem Soc Trans 1986;14:1001-4.

142. Darmaun D, Matthews DE, Desjeux JF, Bier DM. Glutamine and glutamate nitrogen exchangeable pools in cultured fibroblasts:a stable isotope study. J Cell Physiol 1988;134:143-8.

143. Zielke HR, Zielke CL, Ozand PT. Glutamine: a major energy source for cultured mammalian cells. Federation Proc 1984;43:121-5.

144. Sumbilla $\mathrm{CM}$, Zielke CL, Reed WD, Ozand PT, Zielke HR. Comparison of the oxidation of glutamine, glucose, ketone bodies and fatty acids by human diploid fibroblasts. Biochem Biophys Acta 1981;675:301-4.

145. Zielke HR, Ozand PT, Tildon JT, Sevdalian DA, Cornblath $M$. Reciprocal regulation of glucose and glutamine utilization by cultured human diploid fibroblasts. J Cell Physiol 1978:95:41-8.

146. Ardawi MS, Newsholme EA. Glutamine metabolism in lymphocytes of the rat. Biochem J 1983:212:835-42.

147. Ardawi MS, Newsholme EA. Intracellular localization and properties of phosphate-dependent glutarninase in rat mesenteric lymph nodes. Biochem J 1984;217:289-96.

148. Ardawi MS. Glutamine and glucose metabolism in human peripheral lymphocytes. Metabolism 1988;37:99-103.

149. Wu G. Greene LW. Glutamine and glucose metabolism in bovine blood lymphocytes. Comp Biochem Physiol [B] 1992;103:821-5.

150. Pasieka $A E$, Morton $H J$, Morgan JF. The metabolism of animal tissues cultivated in vitro. $N$. Comparative studies on human malignant cells. Cancer Res 1960:20:362-7.

151. Moreadith RW. Lehninger AL. The pathways of glutamate and glutamine oxidation by tumor cell mitochondria. J Biol Chem 1984;259:6215-2.1.

152. Sauer LA, Webster, Stayman, III J, Dauchy RT. Amino acid, glucose, and lactic acid utilization in vivo by rat tumors. Cancer Res 1982;42:4090-7.

153. Angel, Medina M, Sanchez-Jimenez F, Marques J, Rodriquez, Quesada A, Nunez de Castro I. Relevance of glutamine metabolism to turnor cell growth. Mol Cell Biochem 1992;113:1-15.

154. Windmueller HG. Spaeth AE. Intestinal metabolism of glutamine and glutamate from the lumen as compared to glutamine from blood. Arch Biochem Biophys 1975; 171:662-72.

155. Windmueller HG. Spaeth AE. Respiratory fuels and nitrogen metabolism in vivo in smali intes;ine of fed rats. J Biol Chem 1980:255:107-12.

156. Abdalla EK. Caty MG, Guice KS, Hinshaw DB, Oldham KT. Arterial levels of oxidized glutathione (GSSG) reflect oxidant! stress in vivo. J Surg Res 1990;48:291-6.

157. Welboume TC, King AB, Horton K. Enteral glutamine supports hepatic glutathione efflux during inflammation. J Nutr Biochem 1993;4:236-42.

158. Rouse K, Nwokedi E. Woodliff JE, Epstein J, Klimberg VS. Glutamine enhances selectivity of chemotherapy through changes in glutathione metabolism. Ann Surg 1995;221:420-6. 
159. Fahr MJ, Kornbluth J, Blossom S, Schaeffer R, Klimberg VS. Harry M. Vars Research Award. Glutamine enhances immunoregulation of tumor growth. JPEN J Parenter Enteral Nutr 1994; 18:471-6.

160. Okada K. Takehara H, Okada A. Tumor glutamine level is negatively correlated with tumor weight in tumor- bearing rats administered a glutamine antagonist and a new imbalanced amino acid solution. J Clin Biochem Nutr 1992;12:183-91.

161. Chance WT, Cao L, Kim MW, Nelson JL, Fischer JE. Reduction of tumor growth following treatment with a glutamine antimetabolite. Life Sci 1988;42:87-94.

162. Souba WW. Glutamine and Cancer. Ann Surg 1993:218:715-28.

163. Fischer JE, Chance WT. Total parenteral nutrition, glutamine, and tumor growth. JPEN J Parenter Enteral Nutr 1990;14:86S-9S.

164. Chen MK, Austgen TR, Klimberg VS, Copeland, III EM, Souba WW. Tumor glutamine use exceeds intestinal glutamine use in cachectic tumor- bearing rats. Surg Forum 1990;41:12-14

165. Holm E, Hagmuller E, Staedt U, Schlickeiser G, Gunther HJ, Leweling H, Tokus M, Kollmar HB. Substrate balances across colonic carcinomas in humans. Cancer Res 1995;55:1373-8.

166. Deutz NEP, Heeneman S, van Eijk HIMH, Dejong CHC, Meyerink WJHJ, Van der Hulst RRWJ, Soeters PB, Von, Meyenfeldt MF. Selective uptake of glutamine in the gastrointestinal tract. $\mathrm{Br} J$ Surg 1992;79(3):280

167. Chen MK, Espat NJ, Bland KI, Copeland EM, Souba WW. Influence of progressive tumor growth on glutamine metabolism in skeletal muscle and kidney. Ann Surg 1993;217:655-67.

168. Parry Billings $M$, Leighton $B$, Dimitriadis GD, Curi R, Bond J, Bevan S, Colquhoun A, Newsholme EA. The effect of tumour bearing on skeletal muscle glutamine metabolism. Int $\mathrm{J}$ Blochem 1991;23:933-7.

169. Van der Hulst RRWJ, Kreel BK, Meyenfeldt MF, Brummer RJM, Arends JW. Deutz NEP, Soeters PB. Glutamine and the preservation of gut integrity. Lancet 1993;341:1363-5.

170. Souba WW. Glutamine: a key substrate for the splanchnic bed. Annu Rev Nutr 1991:11:285308

171. Dudrick PS, Souba WW. The role of glutamine in nutrition. Curt Opin Gastroenterol 1991;7:299305.

172. Mobrahan S. Glutamine: A conditionally essential nutrient or another nutritional puzzle. Nutr Rev 1992;50:331-3.

173. Lacey JM, Wilmore DW. Is glutamine a conditionally essential amino acid? Nutr Rev 1990;48:297-309.

174. Newsholme EA, Parry Billings M. Properties of glutamine release from muscle and its importance for the immune system. JPEN J Parenter Enteral Nutr 1990;14:63S-7S.

175. Ogle CK, Ogle JD, Mao JX, Simon J, Noel JG, Li BG, Alexander JW. Effect of glutamine on phagocytosis and bacterial killing by normal and pediatric burn patient neutrophils. JPEN J Parenter Enteral Nutr 1994;18:128-33.

176. Tremel H, Kienle B, Weileman LS, Stehle P. Furst P. Glutamine dipeptide-supplemented parenteral nutrition maintains intestinal function in critically ill. Gastroenterology 1994;107:1595601.

177. Parry Billings $M$, Evans J, Calder PC, Newsholme EA. Does glutamine contribute to immunosuppression after major burns? Lancet 1990;336:523-5.

178. Wilmore DW, Smith RJ, O'Dwyer ST, Jacobs DO, Ziegler TR, Wang XD. The gut: a central organ after surgical stress. Surgery 1988;104:917-23.

179. Illig KA, Maronian N, Peacock JL. Cancer Cachexia is transmissible in plasma. J Surg Res $1984 ; 52: 353-358$ 
180. Norton JA, Moley JF, Green MV, Carson RE, Morrison SD. Parabiotic transfer of cancer anorexia/cachexia in male rats. Cancer Res 1985;45:5547-52.

181. Yoneda T, Alsina MA, Chavez JB, Bonewald L, Nishimura R, Mundy GR. Evidence that tumor necrosis factor plays a pathogenetic role in the paraneoplastic syndromes of cachexia, hypercalcemia, and leukocytosis in a human tumor in nude mice. J Clin Invest 1991;87:977-85.

182. Flores E, Bistrian B, Pomposelli J, Dinarello C, Blackbum G, Istfan N. Infusion of tumor necrosis factor/cachectin promotes muscle catabolism in the rat. J Clin Invest 1989;83:1614-22.

183. Tracey KJ, Wei H, Manogue KR, Fong Y, Hesse DG, Nguyen HT, Kuo GC, Beutler B, Cotran RS. Cerami A, et al. Cachectin/Tumor necrosis factor induces cachexia, anemia, and inflammation. J Exp Med 1988;167:1211-1227

184. Tracey KJ, Lowry SF, Fahey, III TJ, Albert JD, Fong Y, Hesse D, Beutler B, Manogue KR, Calvano $\mathrm{S}$, et al. Cachectin/tumor necrosis factor induces lethal shock and stress hormone responses in the dog. Surg Gynecol Obstret 1987;164:415-22.

185. Gelin J, Moldawer LL, Lonnroth C, Sherry B, Chizzonite R, Lundholm K. Role of endogenous tumor necrosis factor alpha and interleukin 1 for experimental tumor growth and the development of cancer cachexia. Cancer Res 1991:51:415-21.

186. Fong $\mathrm{Y}$, Moldawer LL, Marano $M$, Wei $H$, Barber A, Manogue $K$, Tracey KJ, Kuo G, Fischman DA, Cerami A, ef al. Cachectin/TNF or IL-1alpha induces cachexia with redistribution of body proteins. Am J Physiol 1989;256:R659-665.

187. Kawakami M, Cerami A. Studies of endotoxin-induced decrease in lipoprotein lipase activity. $J$ Exp Med 1981;154:631-9.

188. Greenberg AS, Nordan RP, Mcintosh J, Calvo JC, Scow RO, Jablons D. Interleukin 6 reduces lipoprotein lipase activity in adipose tissue of mice in vivo and in 3T3-L1 adipocytes: a possible role for interleukin 6 in cancer cachexia. Cancer Res 1992;52:4113-6.

189. Fried SK, Zechner R. Cachectin/lumor necrosis factor decreases human adipose tissue lipoprotein lipase mRNA levels, synthesis, and activity. J Lipid Res 1989;30:1917-23.

190. Zechner R, Newman TC, Sherry B, Cerami A, Breslow JL. Recombinant human cachectin/tumor necrosis factor but not interleukin-1 alpha downregulates, lipoprotein lipase gene expression at the transcriptional level in mouse 3T3-L1 adipocytes. Mol Cell Biol 1988;8:239-4-401.

191. Evans DA, Jacobs DO. Wilmore DW. Effects of tumour necrosis factor on protein metabolism. Br J Surg 1993;80:1019-23.

192. Sakurai Y, Zhang XJ, Wolfe RR. Short-term effects of Tumor Necrosis Factor on energy and substrate metabolism in dogs. $\mathrm{J}$ Clin invest 1993;:91:2437-45.

193. Starnes HF, Warren RS, Jeevanandam M, Gabrilove JL, Larchian W, Oettgen HF, Brennan MF. Tumor Necrosis Factor and the acule metabolic response to tissue injury in man. J Clin Invest 1988;82:1321-5.

194. Van der Poli T, Romijn JA, Endert E, Borm JJ, Buller HR, Sauerwein HP. Tumor necrosis factor mimics the metabolic response to acute infection in healthy humans. Am J Physiol 1991;261:E457-65.

195. Lahdevirta J, Maury CP. Teppo AM, Repo H. Elevated levels of circulating cachectin/tumor necrosis factor in patients with acquired immunodeficiency syndrome. Am J Med 1988;85:289. 91.

196. Grau GE, Taylor TE, Molyneux ME, Wirima JJ, Vassalli P, Hommel M, Lambert PH. Tumor necrosis factor and disease severity in children with falciparum malaria. N Engl J Med 1989;320:1586-91.

197. Stovroff MC, Fraker DL. Norton JA. Cachectin activity in the serum of cachectic, tumour-bearing rats. Arch Surg 1989;124:94-9. 
198. Tessitore L, Costelli P, Baccino FM. Humoral mediation for cachexia in tumour-bearing rats. Br J Cancer 1993;67:15-23.

199. Smith BK, Conn CA, Kluger MJ. Experimental cachexia: effects of MCA sarcoma in the Fischer rat. Am J Physiol 1993;265:E376-384.

200. Strassmann G, Fong M, Kenney JS, Jacob CO. Evidence for the involvement of interleukin 6 in experimental cancer cachexia. J Clin Invest 1992;89:1681-4.

201. Langstein HN, Doherty GM, Fraker DL, Buresh CMI, Norton JA. The roles of gamma-interferon and tumor necrosis factor alpha in an experimental rat model of cancer cachexia. Cancer Res 1991:51:2302-6.

202. Tomas FM, Chandler CS, Coyle P. Bourgeois CS, Burgoyne JL, Rofe AM. Effects of insulin and insulin-like growth factors on protein and energy metabolism in tumour-bearing rats. Biochem $\mathrm{J}$ 1994:301:769-75.

203. Balkwill F, Osborne R, Burke F, Naylor S, Talbot D, Durbin H, Tavernier J, Fiers W. Evidence for tumour necrosis factor/cachectin production in cancer. Lancet 1987;(ii):1229-32.

204. Nakazaki H. Preoperative and postoperative cytokines in patients with cancer. Cancer 1992;70:709-13

205. Elsasser-Beile U, Von, Kleist S, Stahle W, Schurhammer-Fuhrmann C, Schulte, Monting J, Gallati H. Cytokine levels in whole blood cell cultures as parameters of the cellular immunologic activity in patients with malignant melanoma and basal cell carcinoma. Cancer 1993;71:231-6.

206. Selby PJ, Hobbs S, Viner C, Jackson E, Smith IE, McElwain TJ. Endogenous tumour necrosis factor in cancer patients. Lancet 1988;(i):483

207. Socher SH, Martinez D, Craig JB, Kuhn JG, Oliff A. Tumor necrosis factor not defectable in patients with clinical cancer cachexia. J Natl Cancer Inst 1988;80:595-8.

208. Costelli P, Carbo N, Tessitore L, Bagby GJ, Lopez-Soriano FJ, Argiles JM, Baccino FM. Tumor Necrosis Factor-alpha mediates changes in tissue protein turnover in a rat cancer cachexia model. J Clin Invest 1993;92:2783-9.

209. Sherry BA, Gelin J, Fong $Y$, Marano $M$, Wei $H$, Cerami A, Lowry SF, Lundholm KG, Moldawer LL. Anticachectin/tumor necrosis factor-a antibodies attenuate development of cachexia in tumor models. FASEB J 1989;3:1956-62.

210. Lonnroth C. Gelin J, Lundholm K. Expression of interteukin-6 in tumor bearing mice with cytokine dependent cachexia. Int J Oncol 1994;5:329-36.

211. Lonnroth C, Moldawer LL, Gelin J, Kindblom L, Sherry B, Lundholm K. Tumor necrosis factoralpha and interleukin-1 alpha production in cachectic, tumor-bearing mice. Int $\mathrm{J}$ Cancer 1990:46:889-96.

212. Tracey KJ, Vassara $H$, Cerami A. Cachectin/tumour necrosis factor. Lancet 1989;1:1122-6.

213. Strassmann G, Masui $Y$, Chizzonite R, Fong M. Mechanism of experimental cancer cachexia. Local involvement of IL-1 in colon-26 tumor. J Immunol 1993;150:2341-5.

214. Strassmann $G$, Kambayashi $T$. Inhibition of experimental cancer cachexia by anti-cytokine and anti-cytokine-receptor therapy. Cytokines \& Molecular Therapy 1995:1(2):107-13.

215. Strassmann G, Fong M, Freter CE, Windor S. D'Alessandro F, Nordan RP. Suramin interferes with interleukin-6 receptor binding in vitro and inhibits colon-26-mediated experimental cancer cachexia in vivo. J Clin Invest 1993;92:2152-9.

216. Oldenburg HS, Rogy MA, Lazarus DD, Van Zee KJ, Keeler BP, Chizzonite RA, Lowry SF, Moldawer LL. Cachexia and the acute-phase protein response in inflammation are regulated by interleukin-6. Eur J Immunol 1993;23:1889-94.

217. Jablons DM, Mule JJ, Mcintosh JK, Sehgal PB, May LT, Huang CM, Rosenberg SA, Lotze MT. IL-6/IFN-beta-2 as a circulating hormone. Induction by cytokine administration in humans. J Innmunol 1989; $142: 1542-7$. 
218. Bereta J, Kurdowska A, Koj A, Hirano T, Kishimoto T, Content J, Fiers W. Van Damme J. Gauldie J. Different preparations of natural and recombinant human interleukin-6 (IFN-beta 2, BSF-2) similarly stimulate acute phase protein synthesis and uptake of alpha-aminoisobutyric acid by cultured rat hepatocytes. Int J Biochem 1989;21:361-6.

219. Geiger T, Andus T, Klapproth J, Hirano T, Kishimoto T, Heinrich PC. Induction of rat acutephase proteins by interleukin 6 in vivo. Eur $\mathrm{J}$ Immunol 1988;18:717-21.

220. Andersson C, Gelin J, Iresjo BM, Lundholm K. Acute-phase proteins in response to tumor growth. J Surg Res 1993;55:607-14.

221. Mclntosh JK, Jablons DM, Mule JJ, Nordan RP, Rudikoff S, Lotze MT, Rosenberg SA. In vivo induction of $\mathrm{IL}-6$ by administration of exogenous cytokines and detection of de novo serum levels of IL-6 in tumor-bearing mice. J Immunol 1989;143:162-7.

222. Jablons DM, McIntosh JK, Mule JJ, Nordan RP, Rudikoff S, Lotze MT. Induction of interferonbeta 2 /interleukin-6 (IL-6) by cytokine administration and detection of circulating interleukin-6 in the tumor-bearing state. Ann N Y Acad Sci 1989:557:157-60.

223. Baumann $H_{1}$ Gauldie J. The acute phase response. Immunol Today 1994;15:74-80.

224. Yamada Y, Kimball K, Okusawa S, Vachino G, Margolis N, Sohn JW, Li JJ, Wakabayashi G. MCAdam K, Burke JF, et al. Cytokines, acute phase proteins, and tissue injury. C-reactive protein opsonizes dead cells for debridement and stimulates cytokine production. Ann N Y Acad Sci 1990:587:351-61.

225. Bama BP, James K, Deodhar SD. Activation of human monocyte tumoricidal activity by C. reactive protein. Cancer Res 1987; 47:3959-63.

226. Dowton SB, Colten HR. Acute phase reactants in inflammation and infection. Semin Hematol 1988;25:84-90.

227. Liotta LA, Abe S, Robey PG, Martin GR. Preferential digestion of basement membrane collagen by an enzyme derived from a metastatic murine tumor. Proc Natl Acad Sci USA 1979;76:226872.

228. Kushner I, Ganapathi $M$, Schultz $D$. The acute phase response is mediated by heterogeneous mochanisms. Ann N Y Acad Sci 1989:557:19-29.

229. Chandra RK. 1990 McCollum Award lecture. Nutrition and immunity: lessons from the past and new insights into the future. Am J Clin Nutr 1991;53:1087-101.

230. Castaneda C, Chamley JM, Evans WJ. Crim MC. Elderly women accommodate to a low-protein diet with losses of body cell mass, muscle function, and immune response. Am J Clin Nutr 1995;62:30-9.

231. Doherty JF, Golden MH, Remick DG, Griffin GE. Production of interleukin-6 and tumour necrosis factor-alpha in vitro is reduced in whole blood of seyerely malnourished children. Clin Sci Colch 1994,86:347-51.

232. Kauffman CA, Jones PG. Kluger MJ. Fever and malnutrition: endogenous pyrogen/interleukin-1 in malnourished patients. Am J Clin Nutr 1986;44:449-52.

233. Stouthard JM, Romijn JA, Van der Poll T, Endert E, Kiein S. Bakker PJ, Veenhof CH. Sauerwein HP. Endocrinologic and metabolic effects of interleukin-6 in humans. Am J Physiol 1995;268:E813-9.

234. Gelin JL., Moldawer LL. Iresjo BM, Lundholm KG. The role of the adrenals in the acute phase response to interleukin-1 and tumor necrosis factor-alpha. J Surg Res 1993;54:70-8.

235. Besedovsky HO, del Rey A, Schardt M, Sorkin E, Normann S, Baumann J, Girard J. Changes in plasma hormone profiles after tumor transplantation into syngeneic and allogeneic rats. Int J Cancer 1985:36:209-16.

236. Drott C, Svaninger G, Lundholm K. Increased urinary excretion of cortisol and catecholami-NES in malnourished cancer patients. Ann Surg 1988;208:645-50. 
239. Ball HA, Samuels LT. Adrenal weights in tumor bearing rats. Proc Soc Exp Biol Med 1938;38:441-3.

240. Kavetsky RE, Samundgean EM, Butenko ZA. Changes in the functional state of the adrenal cortex during development of tumours. Acta Unio Int Contra Cancrum 1962;18:115-7.

241. Svaninger G, Gelin J, Lundholm K. Tumor-host wasting not explained by adrenal hyperfunction in tumor-bearing animals. J Natl Cancer Inst 1987;79:1135-41.

242. Stallion A, Foley Nelson T, Chance WT, James JH, Fischer JE. Anticatabolic effect of the beta 2-agonist cimaterol in vivo in tumor-bearing animals. J Surg Res 1995;59:387-92.

243. Stallion A, Foley Nelson T, Chance WT. Fischer JE. Effects of increased beta 2-agonist dose in tumor-bearing animals. Nutr Cancer 1993,20:251-60.

244. Benson DW, Foley Nelson T, Chance WT, Zhang FS, James JH, Fischer JE. Decreased myofibrillar protein breakdown following treatment with clenbuterol. J Surg Res 1991;50:1-5.

245. Chance WT, Cao LQ, Zhang FS, Foley Nelson T. Fischer JE. Clenbuterol treatment increases muscle mass and protein content of tumor-bearing rats maintained on total parenteral nutrition. JPEN J Parenter Enteral Nutr 1991;15:530-5.

246. Chance WT. Muggia Sullam M, Chen MH, Murphy RF, Fischer JE. Reversal of tumor-induced biochemical abnormalities by insulin treatment in rats. J Natl Cancer Inst 1986;77:497-503.

247. Chance WT, Thomas I, Fischer JE. Insulin reverses ammonia-induced anorexia and experimental cancer anorexia. Nutr Cancer 1994;21:213-22.

248. Burt ME, Aoki TT, Gorschboth CM, Brennan MF. Peripheral tissue metabolism in cancer-bearing man. Ann Surg 1983;198:685-91.

249. Bloom SR, Polak JM. Glucagonoma syndrome. Am J Med 1987;82:25-36.

250. Miyoshi H, Shulman GI, Peters EJ, Wolfe MH, Elahi D, Wolfe RR. Hormonal control of substrate cycling in humans. J Clin Invest 1988;81:1545-55.

251. Moley JF. Morrison SD, Norton JA. Insulin reversal of cancer cachexia in rats. Cancer Res 1985;45:4925-31.

252. Moley JF, Morrison SD, Gorschboth CM, Norton JA. Body composition changes in rats with experimental cancer cachexia: improvement with exogenous insulin.CancerRes 1988;48:2784-7.

253. Moley JF, Morrison SD, Norton JA. Preoperative insulin reverses cachexia and decreases mortality in tumor-bearing rats. J Surg Res 1987;43:21-8.

254. Fraker DL, Merino MJ, Norton JA. Reversal of the toxic effects of cachectin by concurrent insulin administration. Am J Physiol 1989;256:E725-731.

255. Sakurai $Y$, Zhang $X J$, Wolfe RR. Insulin-like growth factor-I and insulin reduce leucine flux and oxidation in conscious tumor necrosis factor-infused dogs. Surgery 1995:117:305-13.

256. Fryburg DA, Barrett EJ. Growth hormone acutely stimulates skeletal muscle but not whole-body protein synthesis in humans. Metabolism 1993;42:1223-7.

257. Lundeberg S, Belfrage $M$, Wernerman J, von der Decken A, Thunell S, Vinnars $E$. Growth hormone improves muscle protein metabolism and whole body nitrogen economy in man during a hyponitrogenous diet. Metabolism 1991;40:315-22.

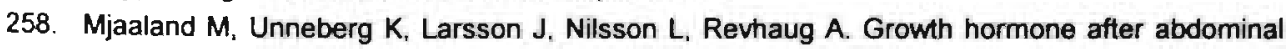
surgery attenuated forearm glutamine, alanine, 3-methylhistidine, and total amino acid efflux in patients receiving total parenteral nutrition. Ann Surg 1993;217:413-22.

259. Tomas FM, Knowles SE, Owens PC, Read LC, Chandler CS, Gargosky SE, Ballard FJ. Increased weight gain, nitrogen retention and muscle protein synthesis following treatment of diabetic rats with insulin-like growth factor (IGF)-I and des(1-3)IGF-I. Biochem J 1991:276:54754. 
260. Murphy WJ, Rui H, Longo DL. Effects of growth hormone and prolactin immune development and function. Life Sci 1995:57:1-14.

261. Okamura $K$, Okuma $T$, Tabira $Y$, Miyauchi $Y$. Effect of administered human growth hormone on protein metabolism in septic rats. JPEN J Parenter Enteral Nutr 1989;13:450-4.

262. $\mathrm{Ng}$ EH, Rock CS, Lazarus D, Staiano Coico L, Fischer E, Moldawer LL, Lowry SF. Impact of exogenous growh hormone on host preservation and tumor cell-cycle distribution in a rat sarcoma model. J Surg Res 1991;51:99-105.

263. Bartlett DL, Stein TP. Torosian MH. Effect of growth hormone and protein intake on tumor growth and host cachexia. Surgery 1995:117:260-7.

264. Wolf RF, Ng B, Weksler B, Burt M, Brennan MF. Effect of growth hormone on tumor and host in an animal model. Ann Surg Oncol 1994;1:314-20.

265. Ng B, Wolf RF, Weksler B, Brennan MF, Burt M. Growth hormone administration preserves lean body mass in sarcoma-bearing rats treated with doxorubicin. Cancer Res 1993:53:5483-6.

266. Wolf RF, Peartstone DB, Newman E, Heslin MJ, Gonenne A, Burt ME, Brennan MF. Growth hormone and insulin reverse net whole body and skeletal muscle protein catabolism in cancer. patients. Ann Surg 1992;216:280-8.

267. Karlberg HI, Kem KA, Fischer JE. Albumin tumover in sarcoma-bearing rats in relation to cancer anorexia. Am J Surg 1983;145:95-101.

268. Klimberg VS, Souba WW, Salloum RM, Plumley DA, Cohen FS, Dolson DJ, Bland KI, Copeland EM. Glutamine-enriched diets support muscle glutamine metabolism without stimulating tumor growth. J Surg Res 1990;48:319-23.

269. Chen MK. Salloum RM, Austgen TR, Bland JB, Bland KI, Copeland EM, Souba WW. Tumor regulation of hepatic glutamine metabolism. JPEN J Parenter Enteral Nutr 19911:15:159-64.

270. von Meyenfeldt $M$, Chance WT, Fischer JE. Correlation of changes in brain indoleamine metabolism with onset of anorexia in rats. Am J Surg 1982;143:133-8.

271. Chance WT, von Meyenfeldt MF. Fischer JE Changes in brain arnines associated with cancerr anorexia. Neurosci Biobehav Rev 1983;7:471.9.

272. Chance WT, Balasubramaniam A, Fischer JE. Neuropeptide $Y$ and the development of canceir anorexia. Ann Surg 1995;221:579-87.

274. Sandstrom R, Gelin J, Lundholm K. The effect of indomethacin on food and water intake, motor activity and survival in tumour-bearing rats. Eur $J$ Cancer 1990:26:811-4

275. van Gool J, van Vugt $H_{s}$, Helle $M$, Aarden LA. The relation among stress, adrenalin, interleukin 6 and acute phase proteins in the rat. Clin Immunol Immunopathol 1990;57:200-10.

276. Engelberts I, von Asmuth EJU, van der Linden CJ, Buurman WA. The interrelation between TNF, IL-6 and PAF secretion induced by L.PS in an in vivo and in vitro murine model. Lyrnphokine Cytokine Research 1991:10:127'-31.

277. Aarden LA, De Groot ER, Schaap OL, Lansdorp P. Production of hybridoma growth factor by human monocytes. Eur J immunol 1987;17:1411-6.

278. Grant JP. Wells SA. Tumor resistance in rats immunized to fetal tissues. J Surg Res; $1974 ; 16: 533-40$

279. Boyland $\mathrm{E}_{\mathrm{a}}$ Warren FL. The induction of tumours by methylcholanthrene in two strains of mice. J Path Bact 1937:45:171-7.

280. Stovroff MC. Fraker DL, Tracis. WD, Norton JA. Altered macrophage activity and tumor necrosiss factor: fumor necrosis and host cachexia. J Surg Rles 1989;46:462-9. 
CHAPTER 2

\section{METHODS TO MEASURE IN VIVO AMINO ACID AND PROTEIN TURNOVER}

Introduction

The fact that proteins are constantly synthesized and broken down has been described in the early works of Schoenheimer (1) and Cuthbertson (2). Since then several techniques have been developed to study protein and amino acid metabolism. Early techniques were mostly clinical descriptive assessments which provide qualitative information whereas the more recently used techniques involve isotopically labeled amino acids which provide more quantitative information on amino acid and protein turnover. This chapter of the thesis will concentrate on reviewing the latter techniques. Because we used radioactive amino acids as tracers to study amino acid and protein turnover rates, all formulas described in this chapter use the specific activity (SA, dpm/nmol) of these amino acids in different plasma and tissue pools. Although the nature of stable isotopes is different, the underlying principles and assumptions are similar to calculate amino acid and protein turnover. Isotope enrichment of amino acids is analogue to SA in the formulas (3).

\section{Nitrogen-balance studies}

Nitrogen balance studies have often been used to study whole body nitrogen metabolism (4). It is a relatively simple clinical tool to grossly evaluate nitrogen metabolism. Nitrogen loss (fecal and urinary) is subtracted from nitrogen intake and as approximately $16 \%$ of protein consist of nitrogen, net protein loss or gain can be calculated by multiplying nitrogen loss or gain with 6.25 . Several limitations of nitrogen balance studies have been outlined previously (5). In general, the technique is rather gross and imprecise. Nitrogen losses are often underestimated because of incomplete collection of feces and urine. It is further underestimated by an undefined 
amount of nitrogen lost through insensible skin loss. Also, nitrogen intake is often overestimated because of unconsummated nutrients (5). Therefore, this technique has been criticized by studies which compared nitrogen balance techniques with protein turnover measurements using labeled amino acids. Golden et al studied patients recovering from protein energy malnutrition with both techniques (6) and showed that nitrogen balances correlated very poorly with the actual protein synthesis and breakdown rates. Nitrogen balance studies should therefore only be seen as gross estimates to evaluate protein metabolism.

Whole body protein turnover and amino acid flux

Proteins are built of a repertoire of 20 amino acids (7). Metabolism and turnover of amino acids has been used to estimate protein turnover. The majority of the amino acids present in the body are bound to proteins and only approximately $0.5 \%$ is present in the intracellular and extracellular free amino acid pool. Fluxes and turnover rates in this pool have been used to describe protein metabolism.

Both stable $\left({ }^{2} \mathrm{H},{ }^{13} \mathrm{C}\right.$ or $\left.{ }^{15} \mathrm{~N}\right)$ and unstable $\left({ }^{3} \mathrm{H}\right.$ or $\left.{ }^{14} \mathrm{C}\right)$ isotopes of amino acids have been used to quantitatively evaluate whole body protein turnover. Whole body protein turnover can be calculated in an one compartment model (Fig. 1). The model evaluates the exchange of amino acids from and into the extracellular free amino acid pool. It is assumed that the infusion of a labeled amino acid and the rate of appearance ( $\mathrm{Ra}$ ) of the same (unlabeled) amino acid occur in this single pool. Thus, a primed constant infusion of a labeled amino acid is given and at steady state conditions samples are drawn from the plasma pool. At steady state (Fig. 1) the amount of tracer amino acid lost will be equal to the tracer amino acid infused and plasma Ra can be calculated as follows (3):

$\begin{array}{lll}\text { Tracer in } & = & \text { Tracer out or } \\ \text { Ra } & = & \text { Rd } \\ \text { I } & = & \text { Ra } \times S A \\ \text { Ra } & = & I / S A .\end{array}$

Where $\mathrm{Ra}$ is the rate of appearance in $\mathrm{nmol} / \mathrm{min}, \mathrm{Rd}$ the rate of disappearance ( $\mathrm{nmol} / \mathrm{min}), 1$ is the infusion rate of the labeled amino acid $(\mathrm{dpm} / \mathrm{min}$ ) and SA the specific activity ( $\mathrm{dpm} / \mathrm{nmol}$ ) of the infused amino acid measured in plasma at steady state. Infusion and sampling of labeled amino acids can in fact be performed in two ways: a venous infusion with arterial sampling ( $V-A$ mode) and an arterial infusion with central venous sampling (A-V mode). In a study by Katz et al. considerable 


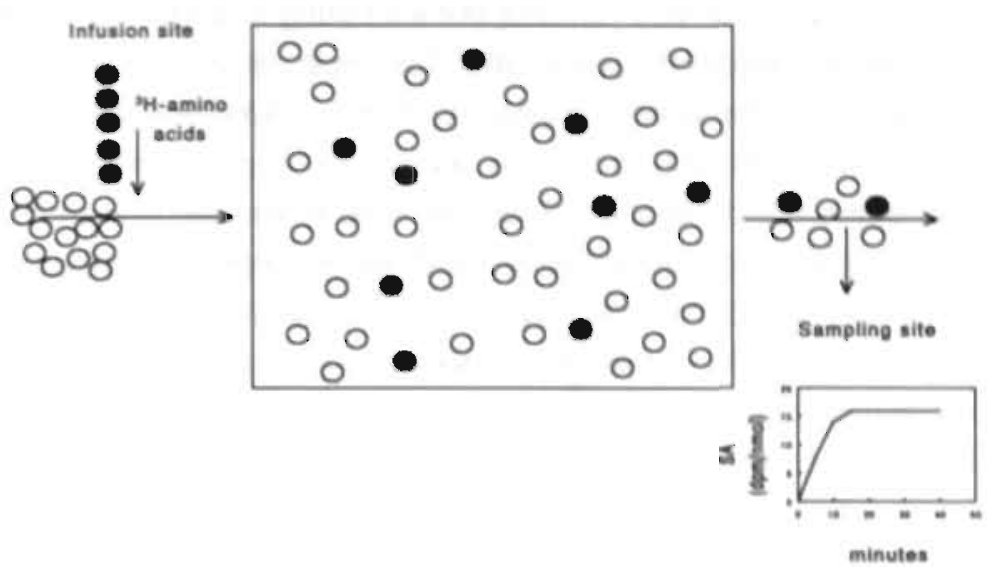

Figure 1. One compartment model to measure whole body protein turnover. After a primed constant infusion of labeled amino acid (see inlet), steady state conditions are reached (tracer infused equals tracer lost from the whole body) and samples are drawn downstream of the infusion site after complete mixing of the tracer with the amino acid pool. The inlet shows the theoretical arterial specific activity reached after adequate priming and constant infusion of the tracer.

These differences can be attributed to differences in cardiac output, the fractional turnover of the unlabeled amino acid pool (tracēe) and to the sites of utilization or production of the traceee $(3,11,12)$. It is generally agreed upon that if the tracer which is infused in blood, fully mixes with all the tracēe being produced by the body before uptake in tissue occurs, the whole body Ra, which is calculated with V-A mode, is valid because arterial $S A$ is the $S A$ at the site where the tracer/tracee disappears. This is true for glucose, glycerol and fatty acids. However, amino acids are both released and metabolized intraceliularly throughout the body. Turnover or uptake thus takes place with a SA more closely to the capillary or venous SA $(11,12)$. The A$V$ mode would thus be more appropriate to calculate whole body turnover and the $V$ A mode underestimates the actual turnover rates. The major draw-back of the A-V mode to calculate whole body protein and amino acid tumover is, however, the fact that it is impractical to obtain the central venous samples (right atrium). Furthermore, the contribution of the lungs to whole body protein turnover is ignored. The V-A mode is therefore generally used to calculate whole body protein and amino acid turnover.

When using ${ }^{15} \mathrm{~N}$ amino acid labeling, whole body protein turnover can also be assessed by determining urinary metabolite (urea or ammonia) enrichment (13). The 
latter method has repeatedly been used in early studies but has several practical and methodological problems. Long infusion times (up to 30 hours) are needed to acquire isotopic steady state conditions for urea in plasma and urine. This not only induces practical problems to perform such studies but also bring in doubt the metabolic and isotopic steady state conditions which are assumptions which must be met to perform these studies. The ammonia pool is much smaller but ammonia nitrogen enrichment is derived primarily from the amide $N$ of glutamine and thus only represents part of the total $\mathrm{N}$ pool (3). Thus, turnover rates calculated with ammonia instead of urea are consistently lower and have been suggested to reflect predominantely muscle protein turnover. The controversy which endproduct, ammonia or urea, appropriately reflects whole body protein turnover has not yet been resolved and the method has generally been abandoned $(3,4)$.

Whole body amino acid turnover rates measured by the V-A mode can be determined by the dilution of labeled carbon, hydrogen and nitrogen. Dilution of ${ }^{15} \mathrm{~N}$ labeled amino acids also include the movement of nitrogen between the different amino acids through the ample transamination and transamidation reactions. However, discrepancies have also been observed in some studies using different carbon and hydrogen labeled $\left({ }^{14} \mathrm{C},{ }^{13} \mathrm{C},{ }^{3} \mathrm{H}\right.$ or $\left.{ }^{2} \mathrm{H}\right)$ amino acids $(3,9,10,14)$ [pp392]. It has been suggested that these differences occur because the turnover of ${ }^{3} \mathrm{H}$ or ${ }^{2} \mathrm{H}$ labeled amino acids measure replacement of the complete mass whereas ${ }^{14} \mathrm{C}$ or ${ }^{13} \mathrm{C}$ labeled amino acids also include recycling of carbons (10). For carbon and hydrogen labeled phenylalanine and leucine no differences in whole body protein turnover rates were observed using either isotopic label (15-17).

Labeled leucine and phenylalanine are currently the most commonly used amino acids to measure protein turnover. Both amino acids have the advantage that they rapidly equilibrate with the intracellullar free amino acid and amino-acyl-tRNA pool (18). Leucine has the additional advantage that it is intracellularly in rapid equilibration with it intracellular transamination product, $\alpha$-ketoisocaproate (KIC), which rapidly equilibrates with plasma $\mathrm{KIC}$. Gut, muscle kidney and adipose tissue all have active transaminase activity and plasma $\mathrm{KIC}$ is thus a pooled value reflecting intracellular enrichment or specific activity of leucine in these tissues $(3,19)$. However, KIC specific activity is not at equilibrium with the entire intracellular leucine pool and plasma KIC specific activity is generally higher than intracellular leucine specific activity (3). Muscle intracellular leucine specific activity is thus approximately $30 \%$ lower than plasma KIC specific activity (20). However, for other essential amino acids (phenylalanine, lysine) no interaction and equilibrium as for leucine-KiC is present and tumover rates calculated with these amino acids in the V-A mode also result in an underestimation of the true whole body protein turnover depending on the tracer amino acid used. Obled and collegues $(21)$ constantly infused several ${ }^{14} \mathrm{C}$ 
labeled amino acids for six hours in rats. They showed that the whole body intracellular specific activity was $67 \%, 71 \%, 56 \%$ and $35 \%$ of the arterial specific activity for ${ }^{14} \mathrm{C}$ labeled threonine, lysine, tyrosine and leucine, respectively. The study shows that arterial leucine specific activity is not a good value to calculate whole body turnover. However, $\mathrm{KIC}$ specific activity underestimates the actual turnover rate to a similar extent $(30-40 \%)$ as the arterial specific activity in studies with other tracer amino acids.

To determine whole body protein synthesis with leucine-KIC labeling the leucine fraction which is oxidized has to be determined from $\mathrm{CO}_{2}$ specific activity or enrichment in breath samples. This also requires adequate priming of the bicarbonate pool which is approximately 85 times the labeled $\mathrm{CO}_{2}$ production rate under normal conditions (3). To appropriately collect $\mathrm{CO}_{2}$ samples metabolic chambers with isolated ventilation systems are neccesary to prevent contamination of breath samples by unlabeld $\mathrm{CO}_{2}$ from normal air (3).

Using phenylalanine as tracer amino acid has the advantage that it enables the simultaneous estimation of whole body amino acid oxidation by calculating whole body hydroxylation of phenylalanine to tyrosine (22). Hydroxylation of phenylalanine can be calculated by the relative arterial SA of phenylalanine and tyrosine at steady state, their relative concentrations in the arterial plasma pool multiplied by their relative content in protein (22). In formula:

$$
\text { Hydroxylation }=\text { WBRaphe } \times[\text { Prot }]_{\text {phod }} /[\text { Prot }]_{\text {ty }} \times 1 /\left[\left(\mathrm{SA}_{p h e} / \mathrm{SA}_{\mathrm{ty}}\right)-1\right]
$$

where $\mathrm{WHRa}_{\text {phe }}$ is the whole body rate of appearance of phenylalanine, $S A_{\text {phenylalanine }}$ and $\mathrm{SA}_{\mathrm{tyrosine}}$ are the arterial specific activity of phenylalanine and tyrosine and [Prot] $]_{\text {pho. }}$ [Prot $]_{\mathrm{tyr}}$ the relative content of both amino acids in body protein. Unless accumulation of tyrosine occurs, hydroxylation of phenylalanine also reflects oxidation rate of amino acids at steady state (22). At steady state whole body Ra is equal to whole body disappearance rate (Rd). Subtracting hydroxylation from whole body $R d$ results in a Rd which is used for protein synthesis because activity of other metabolic routes of phenylalanine (e.g. transamination) are considered to be low. Thus using phenylalanine as tracer gives a fairly easy and good estimation of changes in whole body protein turnover, whole body hydroxylation, whole body protein synthesis and is at present the tracer amino acid of preference in several laboratories.

Whole body protein turnover was first seen as a reflection of muscle protein turnover. Muscle accounts for approximately $50-70 \%$ of the bodies proteins and whole body protein turnover has been estimated to be determined for $50 \%$ by muscle in healthy volunteers (23). It becomes, however, more and more clear that changes in whole body protein turnover rates can be determined by changes in the smaller 
but more rapidly turning-over, protein pools of other organs like the liver and gut. Fryburg et al (14) for example observed that administration of growth hormone increased muscle protein synthesis by approximately $70 \%$ whereas no effects on whole body protein turnover were observed. Similarly. Wolfe et al (24) observed that insulin did not affect whole body protein turnover in cancer patients whereas muscle protein synthesis rates increased by approximately $65 \%$. It can be postulated that the whole body turnover measurements were not sensitive enough to detect these differences but assuming muscle to contribute to approximately $50 \%$ of the whole body turnover, an expected increase in whole body protein turnover of $30-35 \%$ should have been observed. This is more than the detection limit and it must therefore be assumed that the increase in muscle protein turnover is accompanied by decreased protein turnover rates of other organs. These data emphasize the difficulties in interpreting whole body protein turnover data and question the value of these turnover rates.

\section{$50 \%$ reduction}

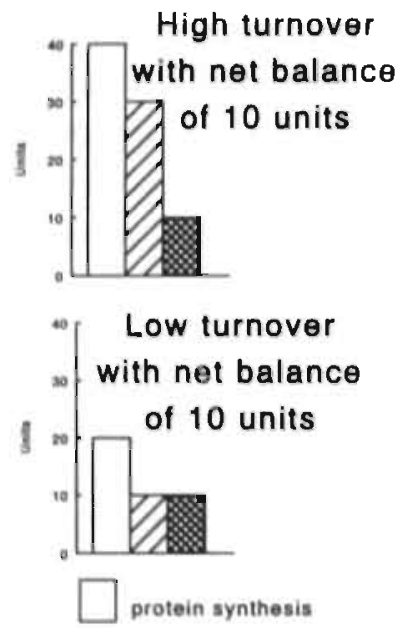

\section{in breakdown}
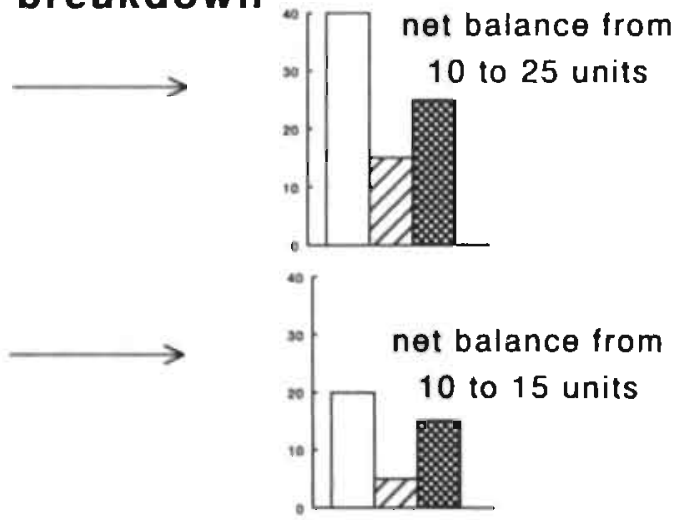

P protein breakdown

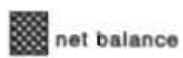

Figure 2. Schematic view of how higher protein tumover rates amplify a percentual effect of changes in protein synthesis, or breakdown. If low turnover rates are present a percentual change in either protein synthesis or breakdown has a smaller effect than if higher turnover rates are present. It is generally assumed that this is of benefit to adapt more rapidly to a changing environment. However, a similar kind of metabolic process can also be described as futile resulting in energy loss.

Two other considerations concerning whole body protein tumover rates have, however, not yei been mentioned. First of all, it has been estimated that approximately $20 \%$ of the resting energy expenditure is the result of protein turnover (4). Changes in whole body protein tumover are therefore also a reflection of 
changes in energy expenditure or whole body energy status. Secondly, knowledge of the level whole body protein turnover may also be of value to estimate the possibility of the whole body protein pool to adapt to environmental changes. It has been estimated that approximately $80 \%$ of the amino acids released by protein breakdown are reutilized for protein synthesis (4). Protein synthesis and breakdown are present at the same time within an organ, tissue or cell because this may improve the regulation of protein metabolism. Two opposite metabolic processes simultaneously present will give a biochemical substrate cycle which can amplify metabolic signals $(7,25,26)$. For instance, a substrate cycle has been described for the simultaneous presence of phosphorylation and hydrolysis of fructose 6-phosphate and fructose 1,6-biphosphate. Newsholme et al (27) also postulated that the same mechanism may be the driving force of protein turnover. Increased protein turnover rates facilitate the possibility to adapt rapidly to changing conditions because the net effects of a certain change is amplified by the magnitude of the turnover rates. The concept is further explained in figure 2. The level of whole body protein turnover rates is thus an indication of its possibility to adapt to its changing surroundings. It must, however, also be kept in mind that these biological roles of substrate cycles are purely hypothetical and the presence of substrate cycles may be futile and indicate imperfectness of the regulation of metabolic routes.

\section{Protein synthesis in tissue}

Protein synthesis has also been measured at regional tissue levels. These methods can be divided into two types of assessments: the direct incorporation technique and the $\mathrm{A}-\mathrm{V}$ dilution technique.

\section{Incorporation technique}

The incorporation technique was first introduced in studies Loftfield and Harris (28) and later by Waterlow $(29,30$ ) and by Haliday (23) (Fig. 3). It requires a (primed) constant infusion of a labeled amino acid and the measurement of enrichment or specific activity during a specific period in the precursor pool of protein synthesis and in the protein pool. The method thus requires biopsies of tissue and fairly straightforward measures the incorporation of a certain amino acid into proteins over a certain time period. In formula: 
FSR $=\frac{S A_{\text {prot }}(t)-S A_{\text {prot }}(0)}{\int_{0}^{1} S A_{\text {prearior }}(t) d t}$

where $t$ is the time of infusion (minutes or hours), FSR is the fractional synthetic rate $\left(\% /\right.$ minute or hour), $S A_{\text {prot }}(t)-S A_{\text {prot }}(0)$ the difference between the protein bound specific activity of tracer amino acid at time point $t$ (end of experiment) and zero in $\mathrm{dpm} / \mathrm{nmol}$ and $\iint_{1} \mathrm{SA}_{\text {precursor }}(\mathrm{t}) \mathrm{dt}$ the area under the curve of the precursor pool for protein synthesis (arterial or intracellular $\mathrm{SA}$ ).

Controversy, however, still exists whether the enrichment or specific activity of the true precursor pool is measurable or whether a good estimate of the enrichment or specific activity of the precursor pool can be made. The true precursor pool enrichment or specific activity for protein synthesis is the amino-acyl-tRNA of the amino acid studied $(3,19,31,32)$. This pool, however, is limited in size and aminoacylation of tRNA has a half-life of approximately 1 second $(3,33)$. This obviously limits direct measurements of tRNA enrichment or specific activity and estimations of the precursor pool labeling have been derived from the arterial, venous and intracellular free amino acid pool. It has been observed that muscle tissue tRNA labeling during a constant infusion of labeled amino acids lies between the labeling of the arterial pool and the intracellular free amino acid pool $(3,19,33)$. It has thus been proposed by Wolfe (34) to calculate upper bounds and lower bounds of protein synthesis rates. The specific activity in the arterial pool exceeds that of the tRNA pool and calculations with the arterial enrichment or specific activity will thus underestimate protein synthesis rates and can be seen as the lower bounds. The intracellular and venous specific activity is generally lower than the IRNA pool and calculations with these two pools as precursor pool labeling will overestimate the true protein synthesis rates and thus may be seen as upper bounds.

In light of this controversy, Garlick et al developed the so-called "flooding dose" technique in small animals $(35,36)$. The underlying principle is that the differences in enrichment and specific activity of the different amino acid pools (arterial, intracellular, (RNA, venous) are all minimized by giving a very large amount of amino acid with a certain, measurable, specific activity. Thus all free amino acid pools are flooded with the amino acid with a constant specific activity during a short period of time. Although the method has given valid and reproducible results by the group of Garlick in mostly small animals $(35,37-42)$, it remains controversial as to whether flooding the free pool of a single amino acid influences measurements of protein synthesis $(19,43)$. The major criticism therefore is that giving such an excess of amino acids above the total body free amino acid pool, influences amino acid 
metabolism and protein synthesis rates $(3,19)$. Several studies using both techniques indicate that the flooding dose technique artificially increases protein synthesis rates whereas other studies could not confirm this (44). To make data from the flooding dose technique comparable to data using a constant infusion, Chinkes, Rosenblatt and Wolfe suggested to reanalyze the data derived from flooding dose experiments with the assumption that protein synthesis rates are stimulated proportional to the change in intracellular concentration. In this manner a lower bound of protein synthesis rates can be calculated whereas protein synthesis rates calculated by the standard flooding dose technique account for a upper bound of protein synthesis rates (43).

Protein synthesis in vitro is also measured by the incorporation of isotopicallylabeled amino acids. Phenylalanine and tyrosine are for muscle the amiño acid of choice since neither is appreciably metabolized by muscle tissue (45-47). In vitro protein synthesis rates of hepatocytes are generally determined by the incorporation of valine into protein as the metabolic fate of branched chain amino acids in hepatocytes is in majority into proteins (48-51). By adding an $5 \mathrm{mM}$ solution of labeled valine to hepatocytes a similar situation as the flooding dose is achieved to attain a constant specific activity of the precursor pool $(49,50)$.

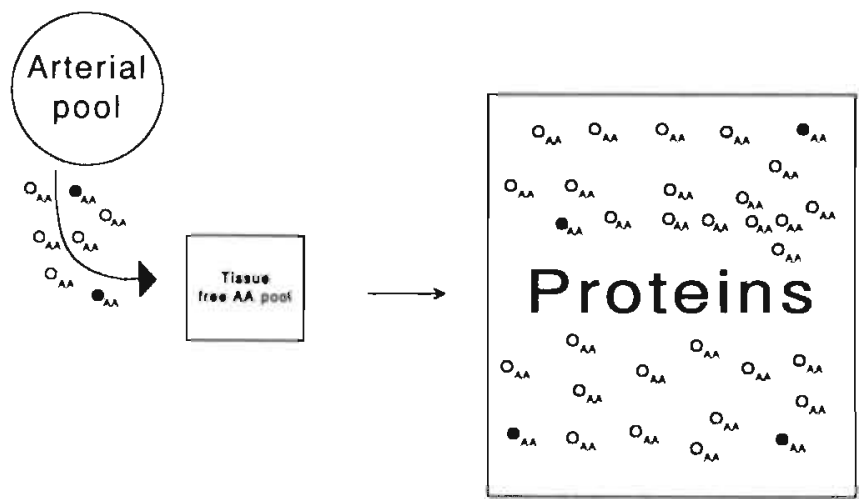

Figure 3. Model to measure protein synthesis by the incorporation technique. Constant labeling of the precursor pool during a specific time results in labeling of protein and by using formula 3 protein synthesis rate can be calculated as fraction per time unit.

\section{A- $V$ dilution technique}

In 1987, Barret and Gelfand (52) described a two compartment model to measure in vivo protein turnover of an extremity based on calculations performed in earlier work of Rannels and colleagues (53) (Fig 4). After a primed constant infusion of labeled phenylalanine plasma flow is measured and samples are drawn from the arterial and venous blood across an extremity. Calculations in a two compartment 
model enable the simultaneous measurements of protein synthesis and breakdown rates. The technique is relatively noninvasive as no tissue biopsies are required. The model has been used to describe protein turnover of muscle and splanchnic tissue of both man and large animals $(14,16,54-57)$.

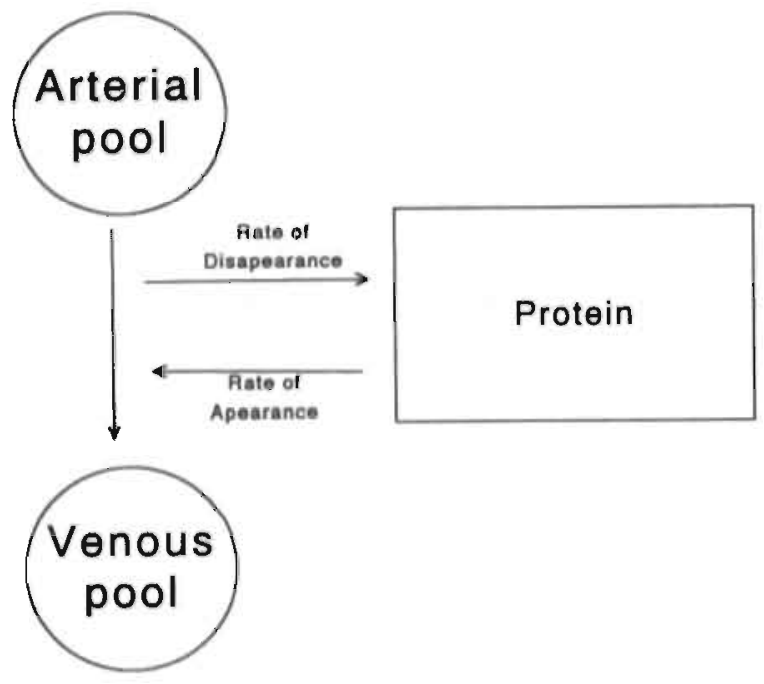

Figure 4. Model described by Barret and Gelfand to calculate protein synthesis and breakdown in a two compartment model $(52,58)$. The two compartments where samples are drawn are the arterial pool and the venous pool. Protein tumover is calculated by the venous dilution of labeled amino acid arriving through the arterial pool under steady state conditions. The first mathematical model (52) assumes the venous pool specific activity to be: a reflection of the specific activity of the precursor pool for protein synthesis whereas the second model (58) assumes the arterial pool to give a better estimate.

In the A-V dilution model protein degradation is estimated from the venous dilution of phenylalanine specific activity and the extraction rate (ER) of both tracer and tracee; e.g. the ER of labeled phenylalanine is equal to:

$E R=\left([D P M]_{x}-[D P M]_{\text {ven }}\right) /[D P M]_{\text {art }}$

where [DPM] art, ven is the amount of dpm derived from radioactive phenylalanine in the arterial and venous pool, respectively. Phenylalanine entry in the venous compartment is equal to the sum of: 1) the arterial inflow which is not extracted and, 2) phenylalanine derived from protein breakdown which is not reutilized for protein synthesis. In formula:

$$
\begin{aligned}
\text { Total entry in the vein } & =\left[\mathrm{PF} \times[\mathrm{Phe}]_{n+1} \times(1-E R)\right]+\quad[\mathrm{Ra} \times(1-E R)] \text { or } \\
& =\left(\mathrm{PF} \times[\mathrm{Phe}]_{a+1}+\mathrm{Ra}\right) \times(1-E R)
\end{aligned}
$$

where [Phe] art is the arterial phenylalanine concentration $(\mu \mathrm{mol} / \mathrm{f})$, PF the organ plasma flow ( $\mathrm{ml} \times 100 \mathrm{gr}$. body weight $\left.\mathrm{t}^{-1} \times \mathrm{min}^{-1}\right)$ and Ra the rate of appearance of 
phenylalanine by protein breakdown ( $\mathrm{nmol} \times 100 \mathrm{gr}$. body weight $\left.\mathrm{f}^{-1} \times \mathrm{min}^{-1}\right)$. The net uptake of tracer activity can also be calculated (assuming no net production of radioactive amino acids by tissue during the study period) with the following formula:

Uptake tracer $\quad=\mathrm{PF} \times[\mathrm{DPM}]_{\mathrm{N}} \times(1-\mathrm{ER})$

where Uptake is the net uptake of phenylalanine in dpm and [DPM] the amount of arterial dpm derived from radioactive phenylalanine. Dividing equation (6) by (5) results in:

$\mathrm{SA}_{\min }=\frac{\mathrm{PF} \times[\mathrm{DPM}]_{\operatorname{mon}}}{\left.\mathrm{PF} \times(\text { PPhe }]_{\text {ant }}+\mathrm{Ra}\right)}$

which can be rearranged to:

Ra

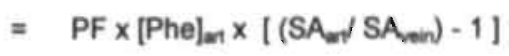

Phenylalanine rate of disappearance (Rd, protein synthesis rates) can further be calculated by the difference between net balance of unlabeled phenylalanine and protein breakdown rates:

net balance

$\mathrm{Rd}$

$$
=\operatorname{PF} \times\left([\mathrm{Phe}]_{\mathrm{m}}-[\mathrm{Phe}]_{\text {ven }}\right)
$$$$
=\text { net balance }+\mathrm{Ra}
$$

It was explicitly noted that protein synthesis rates $(R d)$ calculated in this manner use the venous specific activity as precursor pool for protein synthesis. $R a$ and $R d$ are expressed as nmol phenylalanine $\times 100 \mathrm{gr}$. body weight $\times \mathrm{min}^{-1}$

In 1987 Gelfand and Barret almost simultaneously published the same two compartment model, only now calculating $\mathrm{Ra}$ and $\mathrm{Rd}$ using the arterial specific activity instead of the venous specific activity as reference pool for estimating phenylalanine kinetics (58). Calculations are based on the disappearance of labeled phenylalanine. Formulas derived thus become:

Ra

$$
=P F \times[P h e]_{\operatorname{ven}} \times\left(1-\mathrm{SA}_{\text {ven }} / \mathrm{SA}_{\mathrm{wr}}\right)
$$

Rd

$$
=\text { net balance }+\mathrm{Ra}
$$

In several studies using two compartment modeling, protein synthesis rates were simultaneously measured with the incorporation technique and A-V compartment 
modeling and similar synthesis rates were observed which suggest the model to be valid $(56,57,59,60)$.

In the early nineties, the two compartment model was extended to a three compartment model $(34,60,61)$ (Fig. 5). The three compartment model enabled the simultaneous measurements of intracellular protein turnover with transmembrane transport of amino acids. Biolo and Wolfe further suggest this model to be a better reflection of protein turnover because it also includes the intracellular use of amino acids derived from intracellular protein breakdown. Membrane transport rates are calculated for the in vivo phenylalanine flux from the arterial pool to the intracellular muscle pool, the intracellular pool to the venous pool and for direct shunting from the arterial pool to the venous pool. Disposal and production of intracellular free phenylalanine are calculated and from these protein synthesis rates and protein breakdown rates are deduced.

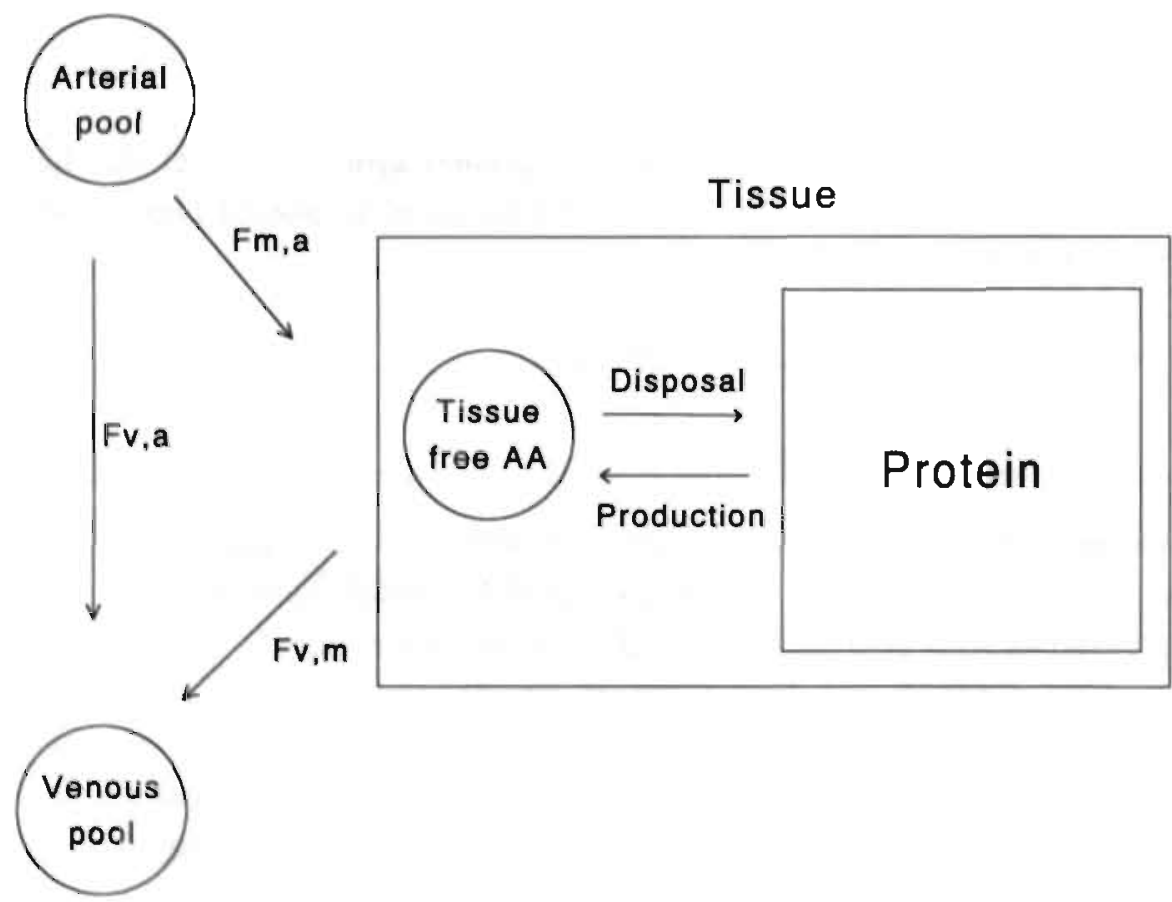

Figure 5. Three compartment model to describe protein turnover and amino acid membrane transport introduced by Biolo and Wolfe (34). Amino acids enter the hindquarter via the arterial pool $\left(F_{i n}\right)$ and leave via the venous pool $\left(\mathrm{F}_{\text {out }}\right)$. Membrane transport rates from the arterial pool to the intracellular free amino acid pool $\left(F_{m, a}\right)$, from the intracellular pool to the venous pool $\left(F_{v, m}\right)$ and direct $A-V$ shunting $\left(F_{v, a}\right)$, are calculated as described in methods. Intracellular disposal (D) and production (P) of free amino acids are calculated simultaneously with membrane transport rates and is for phenylalanine directly related to respectively protein synthesis and breakdown. 
Net balance of both phenylalanine and ${ }^{3} \mathrm{H}$-phenylalanine across the organ is equal to:

NB

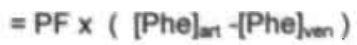

and,

nb

$$
=P F \times\left(S A_{m} \times[P h e]_{m}\right)-\left(S_{\operatorname{men}} \times[\text { Phe }]_{\text {men }}\right)
$$

where NB and $\mathrm{nb}$ are the net balances of phenylalanine ( $\mathrm{nmol} \times 100 \mathrm{gr}$. body weight $\left.{ }^{1} \mathrm{x} \mathrm{min}{ }^{-1}\right)$ and ${ }^{3} \mathrm{H}$-phenylanine ( $\mathrm{dpm} \times 100 \mathrm{gr}$. body weight ${ }^{-1} \times$ min $^{-1}$ ) across the organ, [Phe] ar or ven are arterial or venous plasma concentrations ( $\mu \mathrm{mol} / \mathrm{l})$, and $\mathrm{PF}$ is plasma flow $\left(\mathrm{ml} \times 100 \mathrm{gr}\right.$. body weight $\left.\mathrm{f}^{-1} \times \mathrm{min}^{-1}\right)$. The two net balances are equal to differences between the transport rate of amino acid entering and leaving the tissue:

$$
\begin{aligned}
& \text { NB } \quad=F_{m, a}-F_{v, m} \\
& \text { nb. } \quad=\left(S A_{m,} \times F_{m, a}\right)-\left(S A_{m m} \times F_{v, m}\right)
\end{aligned}
$$

$F_{m, a}$ and $F_{v, m}$ are plasma membrane transport rates from the arterial plasma pool to the free intracellular amino acid tissue pool and from intracellular pool to the venous plasma pool ( $\mathrm{nmol} \times 100 \mathrm{gr}$. body weight ${ }^{-1} \times \mathrm{min}^{-1}$ ). By substituting equations (12) and (13) in (14) and (15), transport rates are calculated:

$$
\begin{aligned}
& \mathrm{SA}_{\text {ersue }}-\mathrm{SA}_{\text {ven }} \\
& F_{\text {m.a }}
\end{aligned}
$$

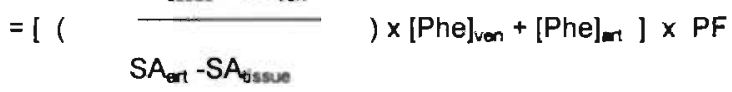

$$
\begin{aligned}
& =\left[\left(\frac{S A_{\text {ossue }}-S A_{\text {ven }}}{S A_{\text {ver }}-S A_{\text {osue }}}\right) \times[\text { Phe }]_{\text {ven }}+[\text { Phe }]_{\text {ven }}\right] \times P F \\
& =F_{\text {in }}-F_{m, a}
\end{aligned}
$$

$F_{v, a}$ is equal to the direct arterial venous shunting and $F_{\text {in }}$ the rate to which phenylalanine enters the arterial pool (= PF $\left.\times[P h e]_{a r t}\right)$. Assuming no de novo intracellular production of ${ }^{3} \mathrm{H}$-phenylalanine during the infusion period reaching isotopic steady state, the $\mathrm{nb}$ of ${ }^{3} \mathrm{H}$-phenylalanine equals the disposal of ${ }^{3} \mathrm{H}$ phenylalanine from the intracellular pool. The NB of phenylalanine equals the difference between disposal and production of phenylalanine and therefore we can derive the following formula's: 
where $D$ is equal to the disposal of the intracellular phenylalanine and $P$ is the production of phenylalanine into this pool ( $\mathrm{nmol} \times 100 \mathrm{gr}$. body weight ${ }^{-1} \times \mathrm{min}^{-1}$ ). Rd calculated in the two compartment model (equations (9) and (11) ) has great similarities with intracellular disposal calculated in a three compartment model. Rd in equation (9) is equivalent to:

Rd

$$
=\mathrm{nb} / \mathrm{SA} \text { wen }
$$

$\mathrm{Rd}$ in equation (10) is equivalent to:

$\mathrm{Rd}$

$$
=n b / S A_{\text {nn }}
$$

Looking more closely, protein synthesis in the three proposed models are thus calculated assuming that $\mathrm{SA}_{\text {tisssus. }} \mathrm{SA}_{\text {ven }}$ or $\mathrm{SA}_{\text {ar }}$ to reflect precursor pool labeling.

Similar as in the incorporation technique the true precursor pool labeling for protein synthesis rates is not measured in any of the A-V dilution models. Two compartment modeling therefore: already resulted in two models to calculate protein synthesis rates. The first model uses the arterial pool to determine the disappearance rate of an amino acid (from the relative change in specific activity or enrichment in the incomming arterial plasma). The other model takes calculates the venous dilution of the specific activity or enrichment of amino acids. The first is thus like the mentioned lower bound whereas the second is thus like the upper bound. The three compartment model uses the intracellular dilution of the specific activity or enrichment and can be considered as an upper bound most close to the true value of protein synthesis.

The A-V dilution models have only been applied in large animal and human studies $(14,16,54-57)$. Small animal studies have been used to study metabolism under a variety of circumstances but not for protein turnover studies in this manner. Potential technica! problems concerning selective arterial and venous catheterization and flow measurements have been suggested to be responsible for this (18). However, a similar technical procedure has been used in several laboratories to measure interorgan glucose, lactate and amino acid metabolism (62-66). We therefore decided to study the possibility to use the A-V dilution model to measure in viva protein kinetics in small laboratory animals (chapter 3 and 4). 
In vitro and ex vivo techniques

Protein breakdown rates have mostly been measured in vitro (18). Phenylalanine or tyrosine release of incubated muscle in the presence of cycloheximide (to block protein synthesis and thus prevent re-incorporation of amino acids in protein) is generally used to measure total protein breakdown. The release of 3-methylhistidine $(3 \mathrm{MH})$ is also used to specifically calculate the proportion of myofibrillar protein breakdown (actin and myosin). The major problem with in vitro measurements is the fact that the in vivo humoral and physical conditions are not preservecl. This obviously influences the observed protein breakdown rates and impede an understanding of its regulation (18). This shortcoming of in vitro breakdown measurements becomes evident by the fact that in most studies proteolysis of control muscles is quite high $(46,67,68)$. Effects of disease or interventions are thus always tested under standard catabolic conditions.

\section{3-Methylhistidine flux and excretions}

$3 \mathrm{MH}$ urinary excretion and extremity flux have been used to calculate in vivo protein breakdown (69-73). $3 \mathrm{MH}$ is an amino acid residue in actin and myosin and found at a 1:1 concentration ratio in these proteins ( $1 \mathrm{~mol}$ protein consists of $1 \mathrm{~mol}$ $3 \mathrm{MH})(3)$. It is formed by posttranslational methylation of histidine present in proteins and, when released by protein breakdown, cannot be used for protein synthesis because no specific t-RNA exists for $3 \mathrm{MH}$ (74). 3MH is also not metabolized to any significant extent and its major metabolic fate therefore is urinary excretion. Urinary excretion of $3 \mathrm{MH}$ has thus been employed to evaluate skeletal protein breakdown during starvation $(72)$, infections $(73,75)$, trauma $(70,76,77)$ and cancer cachexia $(69,78,79)$. However, several studies demonstrated that urinary excretion of $3 \mathrm{MH}$ is not only specific for protein breakdown of skeletal muscle but may be determined for $20-50 \%$ by splanchnic protein turnover $(80,81)$. The problem can be circumvented by the measurement of arterial-venous concentration differences across an extremity $(62,70,73,82)$. This, however, requires an invasive procedure whereas the urinary collection provides a relatively simple, noninvasive clinical procedure to evaluate protein breakdown.

Recently, deuterium labeled $3 \mathrm{MH}$ has been given as a bolus to healthy volunteers to determine whole body protein breakdown rates (83). Using a three compartment model, Rathmacher et al were able to calculate intracellular $3 \mathrm{MH}$ turnover which correlated well with urinary $3 \mathrm{MH}$ excretion. Although the method has the advantage that it excludes the errors induced by quantitative urine collection, further validation in 
catabolic diseases is needed, in particular related to the proportional changes in protein turnover of different tissues which determine $3 \mathrm{MH}$ release into plasma.

\section{A-V dilution technique}

At present, the A-V dilution model appears to be the best method to determine in vivo protein breakdown rates. As discussed above the technique involves selective catheterization and infusion of isotopically labeled amino acids which has been proven to be valid in humans and large animals. In vivo measurements of protein breakdown rates have the great advantage that measurements are made under normal physical and humoral conditions. It has thus been suggested that caution should be obtained in interpreting results obtained from in vitro data $(3,18)$ and warranted a further exploration of possibilities to measure in vivo protein breakdown rates in small laboratory animals. The A-V dilution model was therefore tested in this thesis to calculate in vivo protein breakdown rates.

\section{References}

1. Schoenheimer RS, Rutner D. Rittenberg D. Studies in protein metabolism; metabolic activity of body proteins investigated with 1-feucine containing 2 isotopes. J Biol Chem 1939;130:730-2.

2. Cuthbertson $D P$. Observations on the disturbance of metabolism produced by injury of the limb. $Q$ J Med 1939:1:233-46.

3. Wolfe RR, editor. Tracers in Melabolic Research. New York: Alan R. Liss Inc: 1992.

4. Wateriow JC, Garlick PJ, Milward DJ, editors. Protein turnover in mammalian tissues and in the whole body. Amsterdam: North Holland Publishing Company: 1978.

5. Kopple JD. Uses and limitations of the balance technique. J Parenter Enteral Nutr 1987:11:79S$85 S$.

6. Golden M, Waterlow JC, Picou D. The relationship between dietary intake, weight change, nitrogerı balance, and protein turnover in man. Am J Clin Nutr 1977;30:1345-8.

7. Stryer L, editor. Biochemistry. 3rd ed. New York: Freeman and Company; 1988.

8. Katz J, Okajima F, Chenoweth M. Dunn A. The determination of lactate turnover in vivo with $3 \mathrm{H}$ and $14 \mathrm{C}$-labelled lactate. The significance of sites of tracer administration and sampling. Biochem J 1981:194:513-24.

9. Okajima F, Chenoweth M, Rognstad R, Dunn A, Katz J. Metabolism of $3 \mathrm{H} *$ and 14C-labelled lactate in starved rats. Biochem J 1981;19:4:525-40.

10. Golden S, Chenoweth M. Dunn A, Okajima F, Katz. J. Metabolism of tritium- and 14C-labeled alanine in rats. Am J Physiol 1981;241:E121-8.

11. Katz J. On the determination of turnover in vivo with tracers. Am J Physiol 1992;263:E417-E424.

12. Sacca L. Toffolo G, Cobelli C. V-A and A-V modes in whole body and regional kinetics: domain of validity from a physiological model. Am J Physiol 1992;263:E597-E606.

13. Picou D, Taylor Roberts T. The measurement of total protein synthesis and catabolism and nitrogen turnover in infants in different nutritional states and receiving different amounts of dietary protein. Clin Sci 1969;36:283-96. 
14. Fryburg DA. Barrett EJ. Growth hormone acutely stimulates skeletal muscle but not whole-body protein synthesis in humans. Metabolism 1993,42:1223-1227.

15. Matthews DE, Marano MA, Campbell RG. Splanchnic bed utilization of leucine and phenylatanine in humans. Am J Physiol 1993;264:E109-E118.

16. Fryburg DA, Barrett EJ, Louard RJ, Gelfand RA. Effects of starvation on human muscle protein metabolism and its response to insulin. Am J Physiol 1990;259:E477-E482.

17. Krempf M, Hoerr RA, Marks L, Young VR. Phenylalanine flux in adult men: estimates with different tracers and route of administration. Metabolism 1990:39:560-562.

18. Sugden PH, Fuller SJ. Regulation of protein turnover in skeletal and cardiac muscle. Biochem J 1991:273:21-37.

19. Rennie MJ. Smith K. Watt PW. Measurement of human tissue protein synthesis: an optimal approach. Am J Physiol 1994;266:E298-E307.

20. Chinkes DL, Klein S, Zhang XJ, Wolfe RR. Infusion of labeled KIC is more accurate than labeled leucine to determine human muscle protein synthesis. Am J Physiol 1996;270:E67-71.

21. Obled C, Barre F, Millward DJ, Arnal M. Whole body protein synthesis: studies with different amino acids in the rat. Am J Physiol 1989;257:E639-46.

22. Thompson GN, Pacy PJ, Merritt H, Ford GC, Read MA, Cheng KN, Halliday D. Rapid measurement of whole body and forearm protein turnover using a $[2 \mathrm{H} 5]$ phenylalanine model. $\mathrm{Am}$ J Physiol 1989;256:E631-E639.

23. Halliday D. McKeran RO. Measurement of muscle protein synthetic rate from serial muscle biopsies and total body protein turnover in man by continuous intravenous infusion of L-(alpha15N)lysine. Clin Sci Mol Med 1975;49:581-90.

24. Wolf RF. Pearlstone DB, Newman E, Heslin MJ, Gonenne A. Burt ME, Brennan MF. Growth hormone and insulin reverse net whole body and skeletal muscle protein catabolism in cancer patients. Ann Surg 1992;216:280-8.

25. Parry-Billings $M$, Newshoime EA. The possible role of glutamine substrate cycles in skeletal muscle. Biochem J 1991;279:327-328.

26. Newsholme EA, Parry-Billings $M$. Some evidence for the existence of substrate cycles and their utility in advivo. Biochem J 1992;285:340.

27. Newsholme EA. Substrate cycles in metabolic regulation and in heat generation. Biochem Soc Symp 1976;41:61-109.

28. Loftfield RB, Harris A. Participation of free amino acids in protein synthesis. J Biol Chem 1956;219:151-159.

29. Waterlow JC, Stephen JM. Adaptation of the rat to a low-protein diet: the effect of a reduced protein intake on the pattern of incorporation of L-[14C] fysine. Br J Nutr 1966;20:461-84.

30. Waterlow JC. Stephen JM. The effect of low protein diets on the tum-over rates of serums, liver and muscle proteins in the rat, measured by continuous infusion of L-[14C]lysine. Clin Sci 1968:35:287-305.

31. Smith K, Rennie MJ. Protein turnover and amino acid metabolism in human skeletal muscle. Baillieres Clin Endocrinol Metab 1990;4:461-499.

32. Garlick PJ, McNurlan MA, Essen P, Wemerman J. Measurement of tissue protein synthesis rates in vivo: a critical analysis of contrasting methods. Am J Physiol 1994;266:E287-E297.

33. Chikenji T, Elwyn DH, Kinney JM. Protein synthesis rates in rat muscle and skin based on LysyltRNA radioactivity. J Surg Res 1983;34:68-82.

34. Biolo G, Chinkes D. Zhang XJ, Wolfe RR. A new model to determine in vivo the relationship between amino acid transmembrane transport and protein kinetics in muscle. J Parenter Enteral Nutr 1992; 16:305-315. 
35. Garlick PJ, McNurlan A, Preedy VR. A rapid and convenient technique for measuring the rate of protein syrithesis in tissues by injection of [3H]phenylalanine. Biochem J 1980;192:719-723.

36. McNulan MA, Tomkins AM, Garlick PJ. The effect of starvation on the rate of protein synthesis in rat liver and small intestine. Biochem J 1979;178:373-379.

37. McNurtan MA, Garlick PJ. Protein synthesis in liver and small intestine in protein deprivation and diabetes. Am J Physiol 1981;241:E238-E245.

38. Preedy VR, Gariick PJ. Response of muscle protein synthesis to parenteral administration of arnino acicl mixtures in growing rats. J Parenter Enteral Nutr 1993;17;113-118.

39. Baillie AGS, Garlick PJ. Attenuated responses of muscle protein synthesis to fasting and insulin in adult female rats. Am J Physiol 1991;262:E1-E5.

40. Preedy VR, Garlick PJ. The influence of restraint and infusion on rates of muscle protein synthesis in the rat. Biochem $\mathrm{J} 1988 ; 521: 577-580$.

41. Baillie AG, Garlick PJ. Responses of protein synthesis in different skeletal muscles to fasting and insulin in rats. Am J Physiol 1991;260:E891-6.

42. Ballmer PE, McNurlan MA, Grant I, Garlick PJ. Responses of tissue protein synthesis to nutrient intake in rats exposed to interleukin-1 beta or turpentine. Clin Sci Colch 1993;85:337-42.

43. Chinkes DL, Rosenblatt $\mathrm{J}$, Wolfe RR. Assessment of the mathematical issues involved in measuring the fractional synthesis rate of protein using the flooding dose technique. Clin Sci Colch 1993;84:177-183.

44. Smith K, Babura JM, Watt PW, Scrimgeour CM, Rennie MJ. Flooding with L-[1-13C]leucine stimulates human muscle protein incorporation of continuously infused L-[1-13C] valine. Am J Physiol 1992;262:E372-E376.

45. Tourian A Goddard J, Puck $\Pi$. Phenylalanine hydroxylase activity in mammalian cells. J Cell Physiol 1969;73:159-170.

46. Goodman MN, McElaney MA, Ruderman NB. Adaptation to prolonged starvation in the rat: curtailment of skeletal muscle proteolysis. Am J Physiol 1981;241:E321-E327.

47. Goodman MN. Tumor necrosis factor induces skeletal muscle protein breakdown in rats. Am J Physiol 1991;260:E727-30.

48. Shinnick FL. Harper AE. Branched-chain amino acid oxidation by isolated rat tissue preparations. Biochim Biophys Acta 1976:437:477-86.

49. Warren RS, Jeevanandam M, Brennan MF. Comparison of hepatic protein synthesis in vivo versus in vitro in the tumor-bearing rat. J Surg Res 1987;42:43-50.

50. Warren RS. Jeevanandam M, Brennan MF. Protein synthesis in the tumor-influenced hepatocyte. Surgery 1985:98:275-82.

51. Seglen PO. Solhein AE, Grinde B, Gordon PB, Schwarze PE, Gjessing Rm, Poli A Amino acid control of protein synthessis and degradation in isolated rat hepatocytes. Ann N Y Acad Sci 1980;349:1-17.

52. Barrett EJ, Revkin JH, Young LH, Zaret BL, Jacob R, Gelfand RA. An isotopic method for measurement of muscle protein synthesis and degradation in vivo. Biochem J 1987;245:223-228.

53. Jefferson LS, Li JB, Rannels SR. Regulation by insulin of amino acid release and protein turnover in the perfused rat hemicorpus. J Biol Chem 1977;252:1476-1483.

54. Gelfand FA. Glickman MG, Castellino P, Louard RJ, DeFronzo RA, Measurement of L-[1* 14C]Leucine kinetics in splanchnic and leg tissues in humans. Diabetes 1988;37:1365-1372.

55. Crompton LA, Lomax MA. Hindlimb protein turnover and muscle protein synthesis in lambs: a comparison of techniques. Br J Nutr 1992;69:345-358.

56. Cheng KIN, Pacy PJ, Dworzak F, Ford GC, Halliday D. Influence of fasting on leucine and muscle protein metabolism across the human forearm determined using $L-[1-13 C, 15 N]$ leucine as the tracer. Clin Sci Colch 1987;73:241-246. 

Stimulation of muscle protein synthesis by long-term insulin infusion in severely burned patients. Ann Surg 1995;222(3):283-97.

58. Gelfand RA, Barrett EJ. Effect of physiologic hyperinsulinemia on skeletal muscle protein synthesis and breakdown in man. J Clin Invest 1987;80:1-6.

59. Biolo G, Maggi SP, Williams BD, Tipton KD, Wolfe RR. Increased rates of muscle protein turnover and amino acid transport after resistance exercise in humans. Am J Physiol 1995;268:E514-20.

60. Biolo G, Fleming RY, Maggi SP, Wolfe RR. Transmembrane transport and intracellular kinetics of amino acids in human skeletal muscle. Am J Physiol 1995;268:E75-84.

61. Biolo G, Zhang XJ, Wolfe RR. Role of membrane transport in interorgan amino acid flow between muscle and small intestine. Metabolism 1995;44(6):719-24.

62. Heeneman S, Deutz NEP. The effect of 4 days methionine sulfoximine administration on net muscle protein breakdown in rats. Clin Nutrition 1993;12:182-190.

63. Heeneman S, Deutz NEP. Effects of decreased glutamine supply on gut and liver metabolism in vivo in rats. Clin Sci Colch 1993;85:437-444

64. Dejong CHC, Deutz NEP. Soeters PB, Renal ammonia and giutamine metabolism during liver insufficiency- induced hyperammonemia in the rat. J Clin Invest 1993;92:2834-2840.

65. Dejong CHC, Kampman MT, Deutz NEP, Soeters PB. Altered glutamine metabolism in rat portal drained viscera and hindquarter during hyperammonemia. Gastroenterology 1992;102:936-948.

66. Dejong CHC, Deutz NEP, Soeters PB. Intestinal glutamine and ammonia metabolism during chronic hyperammonaemia induced by liver insufficiency. Gut 1993;34:1112-9.

67. Lowell BB, Ruderman NB, Goodman MN. Regulation of myofibrillar protein degradation in rat skeletal muscle during brief and prolonged starvation. Metabolism 1986;35:1121-1127.

68. Benson DW, Foley Nelson T, Chance WT, Zhang FS, James JH, Fischer JE. Decreased myofibrillar protein breakdown following treatment with clenbuterol. J Surg Res 1991:50:1-5.

69. Lundholm K. Bennegard K. Eden E, Svaninger G, Emery PW, Rennie MJ. Efflux of 3methylhistidine from the leg in cancer patients who experience weight loss. Cancer Res 1982;42:4807-4811.

70. Rennie MJ, Bennegard K, Eden E, Emery PW. Lundholm K. Urinary excretion and efflux from the leg of 3-methylhistidine before and after major surgical operation. Metabolism 1984;33:250-256.

71. Norton JA, Shamberger R, Stein TP, Milne GW, Brennan MF. The influence of tumor-bearing on protein metabolism in the rat. J Surg Res 1981;30:456-462.

72. Lowry SF, Horowitz GD, Jeevanandam M, Legaspi A, Brennan MF. Whole-body protein breakdown and 3-methylhistidine excretion during brief fasting, starvation, and intravenous repletion in man. Ann Surg 1985;202:21-27.

73. Sjolin J, Stjemstrom H. Friman G, Larsson J, Wahren J. Total and net muscle protein breakdown in infection determined by amino acid fluxes. Am J Physiol 1990;258:E856-E863.

74. Young VR, Alexis SD, Baliga BS, Munro HN, Muecke W. Metabolism of administered 3methylhistidine. Lack of muscle transfer ribonucleic acid charging and quantitative excretion as 3methylhistidine and its $\mathrm{N}$-acetyl derivative. J Biol Chem 1972;247:3592-600.

75. Tiao G, Fagan JM, Samuels N, James JH, Hudson K, Lieberman M, Fischer JE, Hasselgren PO. Sepsis stimulates nonlysosomal, energy-dependent proteolysis and increases ubiquitin mRNA levels in rat skeletal muscle. J Clin Invest 1994;94:2255-64.

76. Finley RJ, Inculet RI, Pace R, Holliday R, Rose C, Duff JH, Groves AC, Woolf LI. Major operative trauma increases peripheral amino acid release during the steady-state infusion of total parenteral nutrition in man. Surgery 1986:99:491-500. 
77. Long CL, Birkhahn RH, Geiger JW, Betts JE, Schiller WR, Blakemore WS. Urinary excretion of 3methylhistidine: an assessment of muscle protein catabolism in adult normal subjects and during malnutrition, sepsis, and skeletal trauma. Metabolism 1981;30:765-76.

78. Emery PW, Lovell L, Rennie MJ. Protein synthesis measured in vivo in muscle and liver of cachectic tumor bearing mice. Cancer Res 1984;44:2779-2784.

79. Norton JA, Shamberger R, Stein TP, Milne GW, Brennan MF. The influence of tumor-bearing on protein metabolism in the rat. J Surg Res 1981;30:456-462.

80. Millward DJ, Bates PC. 3-Methylhistidine tumover in the whole body, and the contribution of skeletal muscle and intestine to urinary 3-methylhistidine excretion in the adult rat. Biochem $\mathrm{J}$ 1983;214:607-15.

81. Emery PW, Cotellessa L, Holness M, Egan C, Rennie MJ. Different patterns of protein tumover in skeletal and gastrointestinal smooth muscle and the production of $\mathbf{N}$ tau-methylhistidine during fasting in the rat. Biosci Rep 1986;6:143-53.

82. Mjaaland M, Unneberg K, Larsson J, Nilsson L, Revhaug A. Growth hormone after abdominal surgery attenuated forearm glutamine, alanine, 3-methylhistidine, and total amino acid efflux in patients receiving total parenteral nutrition. Ann Surg 1993;217:413-22.

83. Rathmacher JA, Flakoll PJ, Nissen SL. A compartmental model of 3-methylhistidine metabolism in humans. Am J Physiol 1995;269:E193-8. 


\title{
MUSCLE PROTEIN AND AMINO ACID TURNOVER IN RATS IN VIVO: EFFECTS OF SHORT-TERM AND PROLONGED STARVATION.
}

\author{
I. de Blaauw, N.E.P. Deutz, M.F. von Meyenfeldt \\ Clinical Science (1996), 90:457-466
}

\begin{abstract}
Protein loss in muscle can be caused by decreased protein synthesis, increased breakdown or both. In small animals the tracer incorporation technique is mostly used to measure protein synthesis but for degradation measurements in vitro or ex vivo settings are required. In human and large animal studies the arteriovenous dilution technique is used because it enables the measurement of synthesis and breakdown rates simultaneously. The applicability in small animals has not yet been proven. We used a starvation model to compare both techniques.

A primed constant infusion of $\mathrm{L}-\left[2,6-{ }^{3} \mathrm{H}\right]$-phenylalanine was given to male Lewis rats after 16, 40,64 and 112 hours starvation. Protein synthesis rates of the gastrocnemius muscle was measured by the incorporation technique and compared with hindquarter protein turnover calculated in a two and three compartment arteriovenous dilution model.

Whole body phenylalanine rate of appearance decreased from $456 \pm 32$ after 16 hours to $334 \pm 34\left(\mathrm{nmol} \times 100 \mathrm{~g} \mathrm{bw}^{-1} \times \mathrm{min}^{-1}\right)$ after 112 hours starvation. Protein synthesis rates of the gastrocnemius muscle measured by the tracer incorporation technique decreased from $3.6 \pm 0.4$ after 16 hours starvation to $2.2 \pm 0.3$ after 64 hours starvation and $1.8 \pm 0.4$ (\%/day) after 112 hours starvation. Hindquarter protein breakdown, calculated with the tracer dilution model, increased after 112 hours starvation from $28 \pm 12$ to $77 \pm 15\left(\mathrm{nmol} \times 100 \mathrm{~g} \mathrm{bw}^{-1} \times \mathrm{min}^{-1}\right)$. Using the tracer dilution model, however, the calculated protein synthesis rate across the hindquarter also increased after prolonged starvation $\left(29 \pm 7\right.$ and $68 \pm 16 \mathrm{nmol} \times 100 \mathrm{~g} \mathrm{bw}^{-1} \times \mathrm{min}^{-1}$ after 16 and 112 hours, respectively). In conjunction with this, calculated bidirectional
\end{abstract}


membrane transport rates were also enhanced. Using valine and glutamine as tracer, the enhanced amino acid turnover rates were confirmed.

In conclusion, our results show that during short periods of starvation both methods give similar results. After prolonged starvation, however, an opposite change in disappearance rate and protein synthesis rate was observed. Assumptions made to the calculate protein turnover using the arteriovenous model may account for the discrepancy and care must be taken with the interpretation when using only one model in anaesthetized small animals.

Introduction

The presence of disease is often associated with a spontaneous decrease of food intake. Although the exact role of the decreased food intake in the development of severe metabolic disorders such as cachexia is not well defined, some authors consider it the most important determinant $(1,2)$.

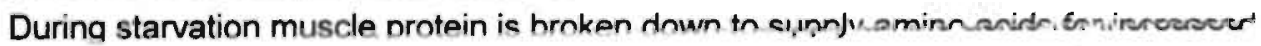
oxidation and gluconeogenesis in the liver (3). During short periods of starvation decreased protein synthesis rates lead to the observed net muscle protein loss $(4,5$, 6). When starvation is prolonged increased protein breakdown rates are suggested to be the determining factors $(5,7-10)$. Information on protein breakdown rates in these studies was derived from hindquarter perfusions $(7,8)$, incubated muscle studies (10) or from indirect measurements $(5,9)$ but never from direct measurements in vivo.

For several years the arteriovenous (A-V) dilution technique has been used to measure protein breakdown rates in vivo simultaneously with synthesis rates (11-13). The protein synthesis rates calculated with the A-V model correlated well with fractional synthetic rates (FSR\%) measured by the incorporation model (11-15) However, the A$\checkmark$ dilution method has mostly been applied in human and large animal studies. In contrast to the smaller animal studies, a human study indicated that protein loss during short starvation $(60 \mathrm{~h})$ was mainly due to increased proteolysis with an unchanged protein synthesis rate (16). Data in vivo in small animals on both protein breakdown and synthesis rates using the A-V dilution model are not available but may provide a better understanding of the possible discrepancy between in vivo human and animal studies ex vivo.

Thus, the effects in vivo of short ( 16 and $40 \mathrm{~h}$ ) and prolonged starvation ( 64 and 112. h) on muscle protein turnover were studied in rats. Protein synthesis rates, calculated with the A-V dilution method across the hindquarter were compared with the FSR $\%$ of the gastrocnemius muscle measured by the tracer incorporation technique. Three 


\section{Materials and methods}

\section{Animals.}

Male Lewis rats (280-350 g) obtained from the Centralized Animal Facilities of the University of Limburg (Maastricht, The Netherlands) were used for the stucly. During the experiment, rats were individually housed in metabolic cages taking into account an adaptation period of four days before the experiment. Rats were given standard laboratory rat chow (SRMA 1210, Hopefarms, Woerden, The Netherlands) and water ad libitum. They were subject to standard 12 hour light-dark cycle periods $07: 30$ to 19:30 hours), whereas room temperature was maintained at $25^{\circ} \mathrm{C}$. The experiments were performed in accordance with the recommendations of the Guide for the Care andi Use of Laboratory Animals (17) and approved by the Ethics Committee of Animal Research of the University of Limburg.

\section{Experimental groups}

Rats ( $n=10$ per group) were randomly divided into five groups. The first group fasted for $16 \mathrm{~h}$ (control group), the second group $40 \mathrm{~h}$, the third $64 \mathrm{~h}$ and the fourth $112 \mathrm{~h}$ before sampling. A fifth group was added as a second control group for possible effects due to prolonged housing in metabolic cages. These rats were housed in metabolic cages for $112 \mathrm{~h}$, but only fasted overnight before sampling.

\section{Study procedure}

Rats were randomly assigned to metabolic cages and weighed daily at $08: 00$ hours. All infusion and sampling experiments were performed as described previously (1821). In brief, under ether (Chempropack BV, Dordrecht, The Netherlands) anaesthesia and at constant, pre-anesthesia body temperature, a laparotomy was performed. The right renal vein, a tertiary branch of the mesenteric vein, the portal vein, the hepatic vein, the inferior vena cava and the aorta (just above the iliac bifurcation) were cannulated using a 25-gauge needle fixed in a Silastic tube (Silastic Medical Grade tubing $0.051 \mathrm{~cm}$ ID, 0.094 OD, Dow Corning Corporation, Medical Products, Midland, MO, USA) and fixed with cyanoacrylate (Cyanolit 201, Het Rubberhuis, Maastricht, The Netherlands). The right carotid artery was next catheterized (Intramedic Polyethylene Tubing PE 50, $0.051 \mathrm{~cm} \mathrm{ID,} 0.094 \mathrm{~cm}$ OD, Clay Adams, Parsipany, NY, USA). The complete procedure took approximately 40 minutes. Liver, Portal Drained Viscera 
(PDV) and hindquarter metabolism was measured simultaneously. Liver and PDV results are discussed in chapter 4.

For flow measurements, the indicator dilution method with para-aminohippuric acid (PAH) was used ( $\mathrm{pH} 7.4$, iso-osmolar, Sigma A 1422, St Louis, MI, USA). A primed $(0.15 \mathrm{ml} / 100 \mathrm{~g} \mathrm{bw}, 50 \mathrm{mmol} / \mathrm{L})$ constant infusion $\left(0.75 \mathrm{ml} \times 100 \mathrm{~g} \mathrm{bw}^{-1} \times \mathrm{h}^{-1}, 5 \mathrm{mmol} / \mathrm{L}\right)$ of PAH was simultaneously infused in the mesenteric vein and the aorta, using a Minipuls 3 Peristaltic Pump (Gilson Med. Electr. Inc., Villiers-le-Bel, France).

To study protein turnover and amino acid membrane transport kinetics, L-[2,6$\left.{ }^{3} \mathrm{H}\right]$-phenylalanine $\left({ }^{3} \mathrm{H}-\mathrm{Phe}\right.$, Sigma P 6053, St Louis, USA), L- $\left[3,4{ }^{3} \mathrm{H}\right]$-glutamine $\left({ }^{3} \mathrm{H}-\right.$ GIn, NEN DuPont, NET-551, Mechelen, Belgium) and L-[3,4- $\left.{ }^{3} \mathrm{H}\right]-$ valine $\left({ }^{3} \mathrm{H}-\mathrm{Val}\right.$, Amersham Int plc, TRK533, Buckinghamshire, UK) were used as tracers. A primed (1 $\mu \mathrm{Ci} / 100 \mathrm{~g} \mathrm{bw})$ constant infusion $\left(1 \mu \mathrm{Ci} \times 100 \mathrm{~g} \mathrm{bw}^{-1} \times \mathrm{h}^{-1}\right)$ was given into the right renal vein.

In a pilot experiment, steady state conditions necessary to measure protein turnover were measured (Fig. 1). At 30 minutes, isotopic steady state had been reached at both $16-h$ and $112-h$ starved rats.

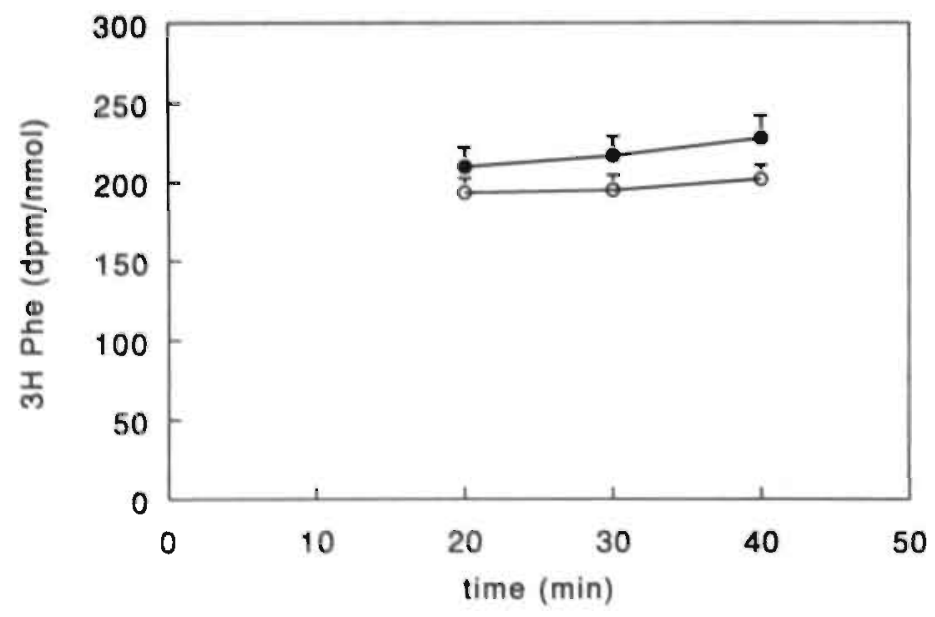

Figure 1. Auterial steady state conditions of ${ }^{3} \mathrm{H}-$ Phe during a primed constant infusion. Values are mean \pm SEM. O After 16 hours starvation $(n=4)$ After 112 hours starvation $(n=5)$. 


\section{Sampling procedure}

Blood (1.2 ml per catheter) was sampled from the hepatic vein, portal vein, inferior caval vein and carotid artery at a maximum rate of approximately $300 \mu / \mathrm{min}$. All blood was collected in heparinized cups (Lithiurn-Heparin Micro-sample container CB100, Sarstedt, FRG) on ice. The right gastrocnemius muscle was then dissected free, immediately freeze clamped, placed in liquid nitrogen and stored at $-80^{\circ} \mathrm{C}$ until further analysis.

For PAH determinations, $50 \mu \mathrm{l}$ of heparinized blood was added to $500 \mu \mathrm{l}$ trichloroacetic acid GR 10\% (TCA 10\% w/v, Merck 807, Darmstadt, Germany). vortexed and centrifuged at $8900 \mathrm{~g}$ at $4^{\circ} \mathrm{C}$ (Hettich Universac $30 \mathrm{RF}$. Tuttlingen Germany). The supernatant was frozen in liquid nitrogen and stored at $-80^{\circ} \mathrm{C}$ until further analysis. For hematocrit determinations a micro-hematocrit tube (Moduiohm 88302, Herlev, Denmark) was filled with heparinized blood and centrifuged at $10000 \mathrm{~g}$ at room temperature (Micro Hematocrit Centrifuge, Hawksley LTD, 891481, UK). Hematocrit was read with a Micro Hematocrit Reader (Hawksley Ltd, UK). Plasma was obtained by whole blood centrifugation at $8900 \mathrm{~g}$ at $4^{\circ} \mathrm{C}$ for 5 minutes. For glucose and lactate determinations, $200 \mu \mathrm{l}$ plasma was vortexed with $20 \mu \mathrm{l}$ of $50 \%$ TCA, put into liquid nitrogen and stored at $-80^{\circ} \mathrm{C}$. For plasma amino acid determinations $200 \mu \mathrm{l}$ plasma was added to $8 \mathrm{mg}$ 5-sulfosalicylic acid (SSA 5\%, Brunschwig, 10346, Amsterdam, The Netherlands) for deproteinization, vortexed, frozen in liquid nitrogen and stored at $-80^{\circ} \mathrm{C}$.

\section{Biochemical analysis}

Plasma glucose, lactate and PAH were determined spectrophotometrically on a Cobas Mira S (Roche Diagnostica, Hoffman-La Roche, Basel, Switzerland) by standard enzymatic methods, using commercially available kits as described previously $(19,21)$. Standard plasma amino acids were determined by fully automated high performance liquid chromatography (HPLC) using 2-3 mmol/L spherisorb ODS II packing material and pre-column derivatization with ortho-phthaldialdehyde as described previously (22).

To determine plasma amino acid specific activity (SA), plasma was fractionated on an ion exchange column using a technique adapted from a previously described method $(23,24)$. In short, deproteinized plasma $(50 \mu)$ ) was passed over the cation exchange resin column (Gold-column, $200 \mathrm{~mm}-4.6 \mathrm{~mm}$, Ultropac 8 resin packing, 8 $\mathrm{mm}-0.5 \mathrm{~mm}, \mathrm{~N}^{\circ} 4310-142$. Pharmacia LKB, Uppsala, Sweden) at a flow rate of 0.425 $\mathrm{ml} / \mathrm{min}$ and a total running time of 79 minutes. A $1.0 \mathrm{~mol} / \mathrm{L}$ lithium citrate buffer $(\mathrm{pH}$ 3.45) was used as eluent for 39 minutes. The next 6 minutes a lithium hydroxide solution $(12.6 \mathrm{~g} / \mathrm{L})$ was eluted whereafter the eluent reversed to the previous for the 
remaining run. The column was maintained at $59^{\circ} \mathrm{C}$ during the first 30 minutes, heated to $79^{\circ} \mathrm{C}$ in a column oven (Mistral, Spark Holland, Emmen, The Netherlands) for 10 minutes and brought back to $59^{\circ} \mathrm{C}$ henceforth. For detection of the amino acids, a UVdetector was used (UV-M II detector, $254 \mathrm{~nm}$ filter, Pharmacia LKB, Uppsala, Sweden) and the fractions $(2 \mathrm{ml}$ ) were collected in $6 \mathrm{ml}$ miniature vials (Packard Instruments BV, Groningen, The Netherlands) placed in a fraction collector (Helifrac, Pharmacia LKB). Amino acid concentrations in the fractions were determined by HPLC as described previously and no overlap between phenylalanine and tyrosine was observed (22). The recovery of each amino acid was determined and found to be $>95 \%$. Formula 989 (6 $\mathrm{ml}$, NEN Research Products, $\mathrm{N}^{\circ}$ NEF 989, Boston, USA) was added as scintillation cocktail and the sample was counted in a automatic Liquid Scintillation System (Beckmann Instruments Inc., LS 3801, USA).

For the determination of tissue free amino acid concentrations and SA, muscle tissue was pulverized using a mortar and pestle precooled in liquid nitrogen. For amino acid determinations the tissue was further homogenized and deproteinized using an Ultra-Turrax (Omni 10001, N $\mathrm{N}^{\circ}$ 10-0427, Waterbury, CT, USA). Approximately $100 \mathrm{mg}$ tissue was added to $500 \mu \mathrm{JSA} 5 \%$ with norvaline $0.5 \mathrm{mmol} / \mathrm{L}(\mathrm{BDH} 10346$ ) as an internal standard. The homogenate was frozen in liquid nitrogen and stored at $-80^{\circ} \mathrm{C}$ until further determinations.

To determine the tissue dry weight approximately $200 \mathrm{mg}$ pulverized tissue was freeze dried for $24 \mathrm{~h}$ in a Speedvac (type SC200, Savant Instruments Inc., Farmingdale, NY, USA) connected with a refrigerated condensation trap (type RT 400, Savant Instruments Inc.).

For the determination of the amino acid composition of tissue protein and the incorporation of radioactive phenylalanine and tyrosine in protein, the pellet of the tissue homogenate was used. The pellet was washed three times with milliQ distilled water at $4^{\circ} \mathrm{C}$ and then freeze dried in the Speedvac. The freeze dried acid non-soluble proteins were hydrolyzed in $2 \mathrm{ml}, 6 \mathrm{~mol} / \mathrm{L} \mathrm{HCl}$ (Merck, $\mathrm{N}^{\circ} 923$ ), at $110^{\circ} \mathrm{C}$ for 18 hours in a vacuum sustained tube. Protein amino acid analysis and $\mathrm{SA}$ determinations were analyzed as described above, after the carbon particles were removed by a $0.22 \mu \mathrm{m}$ micro filter (Millipore, GSWP 01300, Molsheim, France).

Calculations and tracer models

\section{Hindquarter plasma flow, substrate flux and muscle concentrations}

Plasma flow across the hindquarter was measured using the PAH indicator dilution method as described previously (19-21). Hindquarter substrate fluxes are calculated by multiplying the inferior vena caval - arterial concentration differences by the mean 
hindquarter plasma flow of the group and are expressed in $\mathrm{nmol} \times 100 \mathrm{~g} \mathrm{bw}^{-1} \times \mathrm{min}^{-1}$. As amino acid erythrocyte transport is khown to be slow in comparison with plasma transport, plasma flow instead of blood flow was used in this study (25). A positive flux indicates net release, a negative flux reflects a net uptake. $\alpha$-Amino-nitrogen ( $\alpha$-AN) was calculated as the sum of the individual amino acids measured (22).

Tissue concentrations of amino acids are expressed in $\mathrm{mmol} / \mathrm{L}$ and derived by the multiplication of tissue homogenate amino acid concentration (mmol/kg wet weight) and the percentage tissue water content.

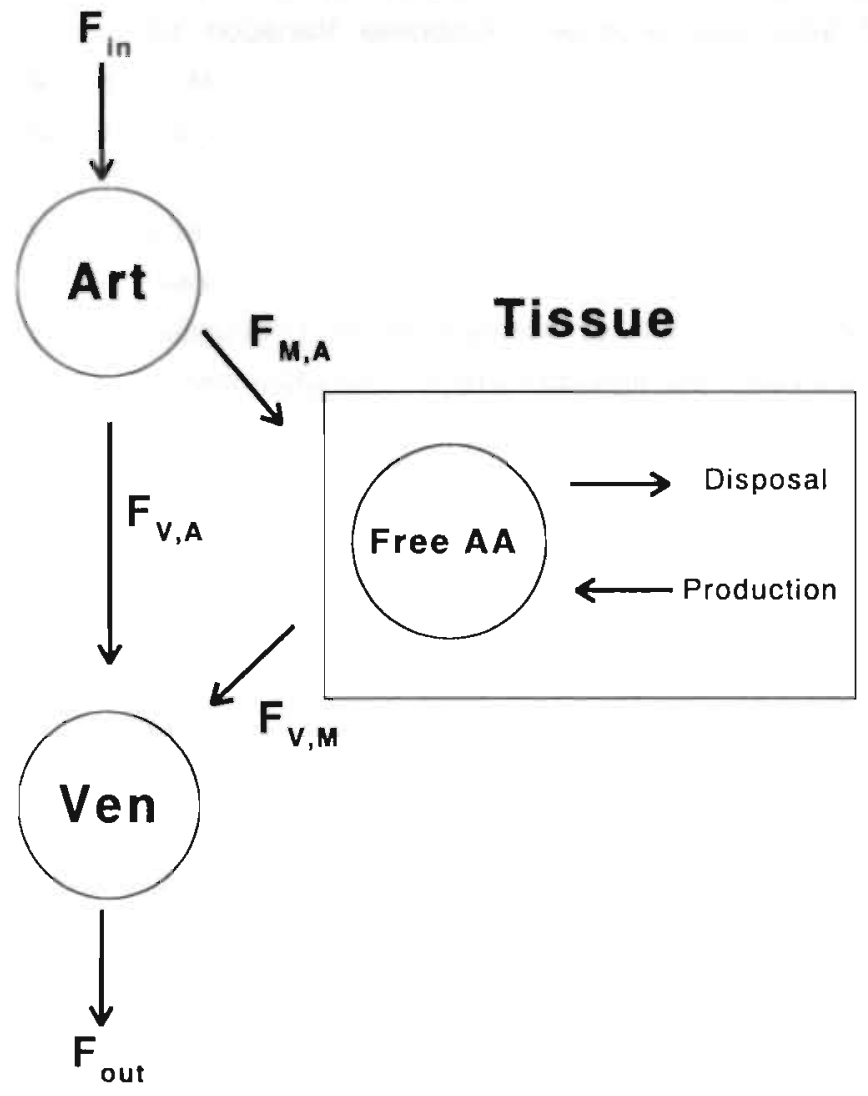

Figure 2. Three compartment model to describe in vivo membrane transpoit and protein kinetics in hindquarter muscle. (17) Amino acids enter the hindquarter via the arterial pool $\left(F_{i n}\right)$ and leave via the venous pool ( $F_{\text {ow }}$ ). Membrane transport rates from the arterial pool to the intracellular free amino acid pool $\left(F_{m . a}\right)$, from the intracellular pool to the venous pool $\left(F_{v, m}\right)$ and direct $A-V$ shunting $\left(F_{v, 0}\right)$, are calculated as described in methods. Intracellular disposal (D) and production (P) of free aminc acids are calculated simultaneously with membrane transport rates and is for phenylalanine directly related to respectively protein synthesis and breakdown.

\section{Protein tumover}

To estimate whole body protein turnover, whole body rate of appearance (Ra) of phenylalanine was calculated by dividing the venous infusion rate of ${ }^{3} \mathrm{H}$-Phe by the arterial SA at steady state (12). Whole body rate of appearance is expressed in $\mathrm{nmol} x$ $100 \mathrm{~g} \mathrm{bw}^{-1} \times \mathrm{min}^{-1}$. 
Hindquarter muscle protein turnover rates were calculated using a two compartment model as first described by Barrett et al. (11). Hindquarter rate of appearance (Ra) and rate of disappearance (Rd) are calculated by the venous dilution of ${ }^{3} \mathrm{H}-\mathrm{Phe}$ and the $\mathrm{A}$ $\checkmark$ net balance of phenylalanine. Knowing the phenylalanine content in muscle protein enables to transform $\mathrm{Ra}$ and $\mathrm{Rd}$ into protein breakdown and protein synthesis rates as in muscle the metabolic fate of phenylalanine is limited to protein synthesis and breakdown $(11,12,26)$.

Recently a three compartment model (Fig. 2) was introduced by Biolo and coworkers (14-17). Adding the third compartment not only makes it possible to calculate protein turnover in vivo but also plasma-tissue membrane transport rates and metabolic shunting of amino acids. Plasma-tissue membrane transport rates are calculated as the amino acid flux in vivo from the arterial pool to the intracellular muscle pool $\left(F_{m, a}\right)$ and from the intracellular pool to the venous pool $\left(F_{v, m}\right)$. Metabolic shunting can be derived from the flux entering the venous pool from the arterial pool bypassing the intracellular free amino acid pool $\left(F_{v, a}\right)$. Protein synthesis rate is simultaneously calculated from the intracellular disposal (D) of phenylalanine and protein breakdown rate from the intracellular production $(P)$ of phenylalanine.

Simultaneous with calculations in two or three compartment models, protein synthesis rates were also calculated by the incorporation of ${ }^{3} \mathrm{H}$-Phe into acid nonsoluble protein and expressed as Fractional Synthetic Rate per day (FSR\%) $(12,27)$. This is equal to the rate of increase of SA in acid in-soluble protein divided by the area under the curve of the precursor pool SA. The area under the curve is calculated as the integration of the arterial specific activity of phenylalanine over the 40 minutes infusion time.

Labeling of the charged tRNA pool reflects the true precursor pool SA which should be used to calculate protein synthesis $(12,14)$. Arterial $S A$ is an overestimate of the actual precursor pool SA and the calculated protein synthesis rates with arterial SA as precursor pool labeling will give the lower bound of protein synthesis rates. Using intracellular free phenylalanine $S A$ in the calculation of protein synthesis underestimates the actual precursor pool SA and will give the upper bound of protein synthesis rates. Both upper and lower bounds of protein turnover are given as it is the best estimate of the true value $(12,14)$. For comparison upper and lower bounds of disposal and production are also calculated using intracellular and arterial SA as precursor pool labeling (14-17).

\section{Statistical analysis}

Results are presented as mean \pm SEM. Effects of time was tested by Oneway ANOVA with post hoc individual group comparison by the Student-Newman-Keuls test (28). Significance from zero was tested by the Wilcoxon test. In the second experiment 
significance was tested by Students $t$-test. Significance was considered present at $p<0.05$.

Results

All data concerning plasma and tissue concentrations and specific activities were not significantly different between control group 1 and 5 . Therefore, the results of these groups were pooled to obtain one control group. Overnight fasted rats lost $5.4 \pm 0.3 \%$ of the initial body weight. Weight loss increased to $10.1 \pm 0.3 \%, 12.8 \pm 0.5 \%$ and 17.5 $\pm 1.1 \%$ after respectively 40,64 and 112 hours starvation. The decrease in body weight seems to arrest between 40 and 64 hours starvation.

\section{Arterial and intracellular concentrations}

Glucose and lactate concentrations (Table 1) were relatively high. This has previously been described to be an effect of ether anaesthesia (29). Glucose concentrations increased slightly after prolonged starvation. Arterial concentrations of glutamine, the main plasma nitrogen transporter, and phenylalanine remained unchanged after short and prolonged starvation. Tyrosine concentrations, however, decreased after prolonged starvation. The sum of all amino acids ( $\alpha$-AN) remained unchanged. All data were in agreement with previously reported values (20).

Table 1. Arterial concentrations. Values are mean \pm SEM. Arterial concentrations for glucose and lactate in mmol/L, for amino acids in $\mu \mathrm{mol} / \mathrm{L}$. $\alpha$-AN is the sum of all amino acids (21). Statistical analysis by Oneway ANOVA and Student-Newman-Keuls test for comparison of individual groups $(p<0.05)$ a vs $16 \mathrm{~h}$, b vs $40 h, c$ vs $64 h, d$ vs $112 h, n s=$ not significant.

\begin{tabular}{|c|c|c|c|c|c|c|c|c|c|c|c|}
\hline \multirow[b]{2}{*}{ Glucose } & \multicolumn{3}{|c|}{$16 \mathrm{~h}$} & \multicolumn{3}{|c|}{$40 \mathrm{~h}$} & \multicolumn{2}{|r|}{$64 \mathrm{~h}$} & \multicolumn{2}{|r|}{$112 \mathrm{~h}$} & \multirow{2}{*}{$\begin{array}{l}\text { ANOVA } \\
\text { p value } \\
0.007\end{array}$} \\
\hline & 11.7 & \pm & 0.4 & 11.8 & \pm & 0.4 & 13.7 & $\pm 0.5^{a, b, a}$ & 12.1 & \pm 0.7 & \\
\hline Lactate & 7.9 & & 0.7 & 9.5 & \pm & 0.7 & 9.5 & \pm 0.5 & 9.3 & \pm 0.7 & ns \\
\hline Glutamine & 634 & \pm & 20 & 686 & \pm & 37 & 636 & \pm 30 & 644 & \pm 30 & ns \\
\hline Tyrosine & 88 & \pm & 6 & 94 & \pm & 6 & 74 & \pm 3 & 75 & \pm & 0.03 \\
\hline Phenylalanine & 62 & \pm & 4 & 66 & \pm & 6 & 58 & \pm 4 & 63 & \pm & ns \\
\hline$\alpha-A N$ & 3005 & & 175 & 3241 & & 219 & 3005 & \pm 179 & 3085 & \pm 117 & ns \\
\hline
\end{tabular}


Table 2. Hindquarter plasma flow and fluxes. Values are mean \pm SEM. Plasma flow is expressed in $\mathrm{ml} x$ $100 \mathrm{~g} \mathrm{bw}^{-1} \times \mathrm{min}^{-1}$ and substrate fluxes in $\mathrm{nmol} \times 100 \mathrm{~g} \mathrm{bw}^{-1} \times \mathrm{min}^{-1}$, except total amino acids $(\alpha-A N)$ in umol $\times 100 \mathrm{~g} \mathrm{bw}^{-1} \times \mathrm{min}^{-1}$. Flux was calculated by multiplying the group mean plasma flow and A-V concentration differences. Effects of time by Oneway ANOVA and Student-Newman-Keuls test for comparison of individual groups ( $p<0.05$ ): "vs 16 hours, ${ }^{b}$ vs 40 hours, ${ }^{c}$ vs 64 hours, ${ }^{d}$ vs 112 hours. ns=not significant. Individual groups were tested for significance from zero by Wilcoxon test: ${ }^{5}$ not significantly different from zero.

\begin{tabular}{|c|c|c|c|c|c|c|c|c|c|c|}
\hline & & $16 \mathrm{~h}$ & & & $40 \mathrm{~h}$ & & $64 \mathrm{~h}$ & & $112 \mathrm{~h}$ & $\begin{array}{l}\text { ANOVA } \\
\text { p value }\end{array}$ \\
\hline Plasma flow & 1.4 & \pm & 0.3 & 1.8 & 0.5 & 2.0 & \pm 1.0 & 1.9 & \pm 0.5 & ns \\
\hline Glucose & -1322 & \pm & 350 & -1843 & $\pm \quad 567$ & -3034 & \pm 813 & -1083 & \pm 467 & ns \\
\hline Lactate & 70 & \pm & $57^{5}$ & 347 & $\pm 922^{5}$ & 466 & \pm 444 & 2599 & $\pm 571^{c .5}$ & 5 ns \\
\hline Glutamine & 89 & \pm & 25 & 73 & $\pm 60^{5}$ & 270 & $\pm 43^{a b}$ & 337 & $\pm 73^{\mathrm{a}, \mathrm{b}}$ & 0.002 \\
\hline Tyrosine & -4.5 & \pm & $3.6^{5}$ & -2.6 & $\pm 5.4^{5}$ & 4.3 & $\pm 4.5^{5}$ & 10.1 & \pm 5.0 & 0.05 \\
\hline Phenylalanine & -1.9 & \pm & $2.5^{5}$ & 0.9 & $\pm 4.8^{5}$ & 5.2 & $\pm 3.4^{5}$ & 9.0 & \pm 2.0 & ns \\
\hline$\alpha-A N$ & 122 & \pm & $120^{5}$ & 184 & $\pm 229^{5}$ & 498 & \pm 195 & 857 & $\pm 161^{a, b}$ & 0.02 \\
\hline
\end{tabular}

Table 3. Intracellular muscle tissue amino acid concentrations and water content of gastrocnemius muscle. Values are mean \pm SEM. Water content is expressed as percentage water in wet weight, concentrations in $\mu \mathrm{mol} / \mathrm{kg}$ wet weight, except $\alpha$-AN in mmol/kg wet weight. Statistical analysis by Oneway ANOVA and Student-Newman-Keuls test for comparison of individual groups $\left(p<0.05\right.$ ): "vs 16 hours, ${ }^{b}$ vs 40 hours, "vs 64 hours, " vs 112 hours. ns=not significant.

$\begin{array}{llll}16 \mathrm{~h} & 40 \mathrm{~h} & 64 \mathrm{~h} & \text { ANOVA } \\ \text { p value }\end{array}$

\begin{tabular}{|c|c|c|c|c|c|c|c|c|c|c|}
\hline Water \% & 81.0 & \pm 0.5 & 81.0 & \pm & 0.2 & 81.1 & \pm 0.2 & 80.5 & \pm 0.2 & ns \\
\hline Glutamine & 2817 & \pm 96 & 3373 & \pm & 2.06 a.c & 2739 & \pm 116 & 3037 & \pm 171 & 0.01 \\
\hline Tyrosine & 167 & \pm 5 & 226 & \pm & $13^{\text {acd }}$ & 149 & \pm 6 & 160 & \pm 8 & $<0.001$ \\
\hline Phenylalanine & 93 & \pm 5 & 113 & \pm & $4^{2 c c}$ & 90 & $t$ & 103 & \pm & 0.006 \\
\hline$\alpha-A N$ & 30.5 & \pm 1.4 & 35.5 & \pm & 3.9 & 29.0 & \pm 1.0 & 34.1 & \pm 1.3 & ns \\
\hline
\end{tabular}


Hindquarter plasma flow, fluxes and muscle tissue concentrations

Plasma flow (Table 2) across the hindquarter did not change significantly in time. Although glucose uptake across the hindquarter seemed to increase to a maximum at $64 \mathrm{~h}$ starvation, the uptake was not significantly different between the groups. Lactate release also tended to increase with a maximum at $112 \mathrm{~h}$ of starvation. The release of glutamine and total $\alpha$-AN by the hindquarter increased progressively in time, suggestive for increased net protein breakdown. In line with this, tyrosine release also increased and phenylalanine showed a similar trend after prolonged starvation.

The tissue water content of the gastrocnemius muscle (Table 3) was not significantly different between the groups. Glutamine, phenylalanine, tyrosine and $\alpha$ AN concentrations were all increased at $40 \mathrm{~h}$ of starvation and decreased to control values after 64 and $112 \mathrm{~h}$ starvation.

Table 4. Whole body Ra of phenylalanine; hindquarter Ra, Rd disposal and production of phenylalanine. Values are mean \pm SEM and expressed in $\mathrm{nmol} \times 100 \mathrm{~g} \mathrm{bw}^{-1} \times \mathrm{min}^{-1}$. Statistical analysis by Oneway ANOVA and Student-Newman-Keuls test for comparison of individual groups ( $p<0.05$ ): vs 16 hours, "vs 40 hours, " vs 64 hours, " vs 112 hours.

$\begin{array}{llll}\text { 16h } & \text { ANOVA } \\ \text { p value }\end{array}$

Whole body

$\begin{array}{llllllllllll}\mathrm{Ra} & 456 \pm 32 & 450 \pm 31 & 348 & \pm & 30 & 334 & \pm & 54 & 0.03\end{array}$

Hindquarter

$\begin{array}{llllllllllllll}\text { Ra } & 28 & \pm & 12 & 8 & \pm & 6 & 77 & \pm & 34 & 77 & \pm & 15 & 0.03 \\ \text { Rd } & 29 & \pm & 7 & 7 & \pm & 9 & 71 & \pm & 36 & 68 & \pm & 16 & 0.05\end{array}$

Production

\begin{tabular}{|c|c|c|c|c|c|c|c|c|c|c|c|c|}
\hline Upper bound & 23 & \pm 11 & 11 & \pm & 8 & 72 & \pm & $28^{\circ}$ & 74 & \pm & 14 & 0.01 \\
\hline Lower bound & 16 & \pm 6 & 6 & \pm & 5 & 37 & \pm & 12 & 48 & \pm & $8^{a \cdot b}$ & 0.01 \\
\hline \multicolumn{13}{|l|}{ Disposal } \\
\hline Upper bound & 24 & 13 & 10 & \pm & 12 & 66 & \pm & 30 & 65 & \pm & 15 & 0.06 \\
\hline Lower bound & 17 & \pm 6 & 5 & \pm & 8 & 32 & \pm & 14 & 39 & \pm & $8^{\circ t}$ & 0.04 \\
\hline
\end{tabular}




\section{Protein tumover}

Whole body phenylalanine Ra (Table 4) of the control group was, per $100 \mathrm{~g} \mathrm{bw}$, in agreement with literature data (30). As observed previously, whole body Ra decreased significantly after 64 and $112 \mathrm{~h}$ starvation (31).

Across the hindquarter, however, the $\mathrm{Ra}$ and $\mathrm{Rd}$ of phenylalanine (Table 4) increased after 64 and $112 \mathrm{~h}$ starvation indicating enhancement of muscle protein breakdown and synthesis. The largest variability was observed at $64 \mathrm{~h}$ - suggestive of a transitional phase.

For comparison, we also calculated intracellular production and disposal of phenylalanine in a three compartment model (14-17). Lower bounds are calculated with the arterial SA as precursor pool SA, upper bounds are calculated with the intracellular free amino acid SA as precursor pool labeling $(14,17)$. Upper bounds of phenylalanine production and disposal gave the same pattern as $\mathrm{Rd}$ and $\mathrm{Ra}$ and were of comparable magnitude. Upper and lower bound of intracellular phenylalanine production increased with increasing duration of starvation. The lower bound of intracellular disposal also increased after prolonged starvation.
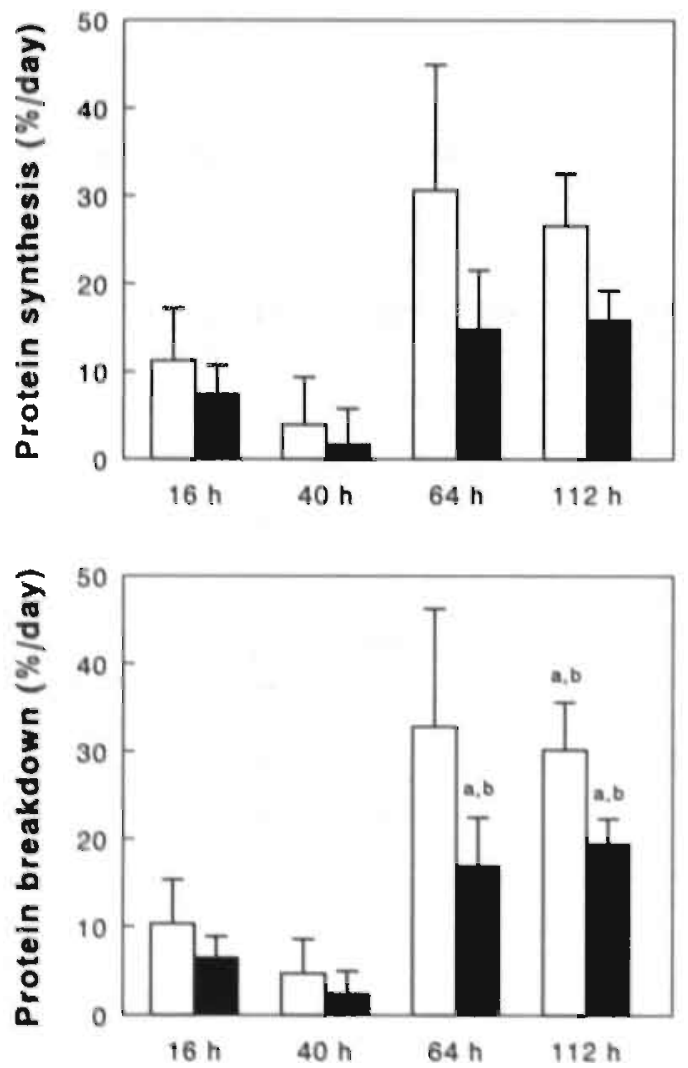

Figure 3. Protein synthesis and protein breakdown rates in hindquarter muscle after short and prolonged starvation measured with the A-V dilution model. Values are mean \pm SEM and expressed $\%$ per day. $\square$ Upper bounds, Lower bounds. The upper bounds are calculated with intracellular free SA as precursor pool SA, the lower bounds are calculated with arterial SA. as precursor pool SA. Statistical analysis by Oneway ANOVA: protein synthesis upper bound: $p=0.10$. protein synthesis lower bound: $p=0.05$, protein breakdown upper bound: $p=0.02$, protein breakdown lower bound: $p=0.004$. Student-Newman-Keuls test for comparison of individual groups ( $p<0.05)$ : " vs 16 hours, "vs 40 hours, "vs 64 hours, ${ }^{\circ}$ vs 112 hours. 
Protein synthesis and breakdown rates derived from the A-V dilution data of phenylalanine are given as fractional synthetic rate and fractional breakdown rate in Fig. 3. Both upper and lower bounds of fractional breakdown rates in muscle increased after prolonged starvation. The lower bound of the fractional synthetic rates calculated with the $\mathrm{A}-\mathrm{V}$ dilution model also increased after prolonged starvation. In contrast, upper and lower bounds of fractional synthetic rates calculated by incorporation of ${ }^{3} \mathrm{H}-\mathrm{Ph}$ in acid non-soluble proteins (Fig. 4), decreasedi significantly after 64 and $112 \mathrm{~h}$ starvation.

\section{Membrane transport and A-V shunting}

Using the three compartment model both inward $\left(F_{m, a}\right)$ and outward $\left(F_{v, m}\right)$ phenylalanine plasma-tissue membrane transport (Fig. 5) remained unchanged at 40 $\mathrm{h}$, but increased significantly after 64 and $112 \mathrm{~h}$ starvation. Metabolic shunting $\left(\mathrm{F}_{\mathrm{v}, \mathrm{a}}\right)$ increased after $40 \mathrm{~h}$ whereafter it decreased to approximately zero after $112 \mathrm{~h}$ starvation.

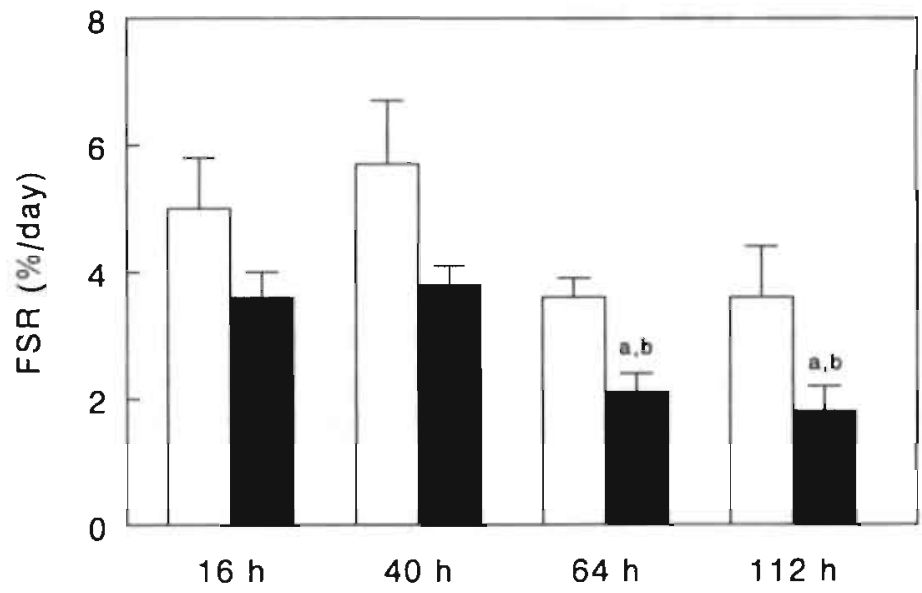

Figure 4. Fractional synthetic rate (FSR\%) of acid non-soluble proteins in gastrocnemius muscle measured by the incorporation technique. Values are mean \pm SEM and expressed as \% muscle protein per day. $\square$ Upper bounds, $\square$ Lower bounds. The upper bounds are calculated with intracellular free SA as precursor pool SA, the lower bounds are calculated with arterial SA as precursor pool SA. Statistical analysis by Oneway ANOVA: upper bound: $p=0.22$, lower bound: $p=0.006$. Student-Newman-Keuls test for comparison of individual groups $\left(p<0.05\right.$ ): " vs 16 hours, ${ }^{b}$ vs 40 hours, ${ }^{c}$ vs 64 hours: ${ }^{a}$ vs 112 hours. 


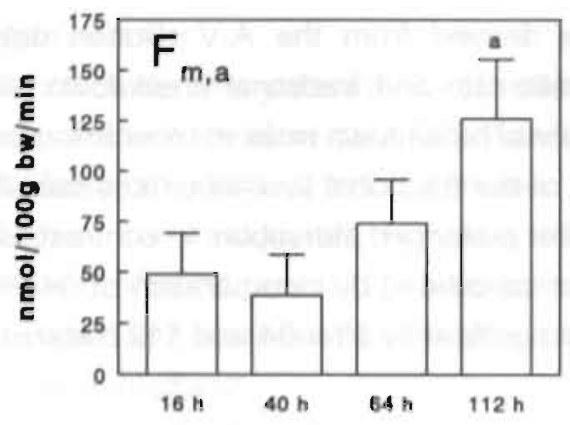

Figure 5. Plasma-muscle membrane transport rates of phenylalanine after short and prolonged starvation. Values are mean \pm SEM. Statistical analysis by Oneway ANOVA: $F_{\text {m.al }}$ ( inward arterial-tissue membrane transport rate) $p=0.01 ; F_{v m}$ (outward tissuevenous transport rate) $p=0.01 ; F_{v, a}$ (metabolic shunting) $p=0.04$. Student-Newman-Keuls lest for comparison of individual groups (p<0.05): a vs 16 hours, ${ }^{\circ}$ vs 40 hours, ${ }^{c}$ vs 64 hours, ${ }^{d}$ vs 112 hours.
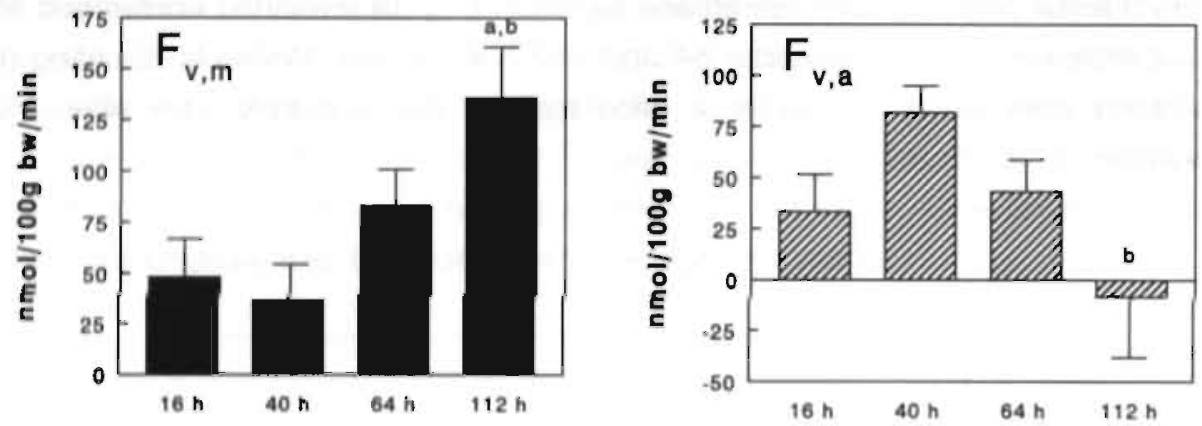

Table 5. Hindquarter Ra and Rd glutamine and valine after 16 hours and 112 hours starvation. In a second experiment glutamine, valine and phenylalanine turnover were tested simultaneously. Values are mean \pm SEM and expressed in $\mathrm{nmol} \times 100 \mathrm{~g} \mathrm{bw}^{-1} \times \mathrm{min}^{-1}$. Statistical analysis by Students $t$-test.

$16 \mathrm{~h}$

$112 \mathrm{~h}$

p value

\section{Glutamine}

Ra

Rd

Valine

Ra

Rd

Phenylalanine

$\mathrm{Ra}$

Rd

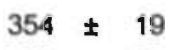

$276 \pm 29$

$33 \pm 9$

$41 \pm 6$

$21 \pm 4$

$16 \pm 3$

\section{$1068 \pm 88$}

$753 \pm 60$

$94 \pm 8$

$90 \pm 8$

$53 \pm 7$

$39 \pm 5$
$<0.001$

0.001

0.001

0.003

0.004 


\section{Hindquarter amino acid tumover}

To test whether the increased turnover rates after prolonged starvation was only specific for phenylalanine, we also measured tumover rates of glutamine and the branched chain amino acid valine in a second experiment (Table 5). Hindquarter muscle turnover of glutamine and valine both increased after prolonged starvation. It appears that prolonged starvation induces an increased turnover of most amino acids. In the second experiment prolonged starvation increased phenylalanine turnover to a similar extend as in the first experiment, thus making the results reproducible.

\section{Discussion}

The A-V dilution model was introduced to measure protein synthesis and breakdown rates simultaneously and proven to be comparable to the incorporation technique in human and large animal studies under several circumstances $(11,12,14$, 15). The technique is similar to the one we and others use in hindquarter $A-V$ substrate flux studies in small animals $(19,21,29,32-35)$. We therefore tested the applicability of the model and the effects of short and prolonged starvation in rats undergoing standard procedures used in flux measurements.

Owing to a net protein breakdown of muscle, phenylalanine and total amino acid efflux increased when starvation proceeded. The increased net protein breakdown of muscle during starvation should be reflected by the difference between Ra and Rd or production and disposal. The concentration of phenylalanine in muscle protein is approximately $230 \mathrm{nmol} / \mathrm{mg}$ (data not shown) and rat hindquarter dry weight is approximately $3300 \mathrm{mg} / 100 \mathrm{~g}$ bw (35). Assuming whole body weight loss to be proportional to hindquarter protein loss, an $18 \%$ weight loss as we observed after 112 $\mathrm{h}$ starvation, should lead to an efflux of approximately $20 \mathrm{nmol}$ phenylalanine $\times 100 \mathrm{~g}$ $\mathrm{bw}^{-1} \times \mathrm{min}^{-1}$. Net fluxes of phenylalanine calculated after 40,64 and $112 \mathrm{~h}$ starvation, however, only became significant from zero in the $112 \mathrm{~h}$ starved group with a maximum of $9.0 \mathrm{nmol} \times 100 \mathrm{~g} \mathrm{bw}^{-1} \times \mathrm{min}^{-1}$. Although part of the weight loss can be accounted for by loss of lipids and carbohydrates not resulting in a release of phenylalanine, the flux calculated was far below the theoretical release. Also, the coefficient of variance of $\mathrm{Ra}$ and $\mathrm{Rd}$ (or production and disposal) was $12-20 \%$ and too large to allow this size of differences between protein breakdown and synthesis to become significant. We therefore conclude that flux and protein turnover measured by the A-V dilution model can only be applied to evaluate acute metabolic changes which exceed protein loss of at least $4 \%$ per day or changes in Ra and Rd of at least $20 \%$. 
Protein breakdown rates we calculated with this model tripled after prolonged starvation and are similar to indirectly estimated breakdown rates described previously (37). The rapid enhancement of proteolysis observed after 4-5 days' starvation in the current study has also been observed in ex vivo studies. Prolonged starvation of rats induces secondary lysosome formation with marked autophagy of muscle after 4-6 days (37). This increase has also been referred to as being an emergency response of an end-stage starvation $(7,37)$.

In this end-stage starvation (112 $\mathrm{h}$ starved group) protein synthesis rates measured by the incorporation method decreased with approximately $50 \%$, in agreement with literature data $(5,7)$. In contrast, protein synthesis rates measured by the A-V dilution model almost tripled. This increase was independent of the use of a two- or a threecompartment model. Protein synthesis rates were similar in the post-absorptive group using either one of the models but diverged after prolonged starvation. Because the dilution of labeled phenylalanine by protein breakdown seen during prolonged starvation was not reflected by a similar increase of the net phenylalanine efflux, phenylalanine produced by protein breakdown must have been reused according to A$V$ modelling. Thus, the incorporation technique and the A-V dilution model in rats do not seem to measure the same metabolic events after extreme starvation. The reason for this discrepancy is not known but may be the result of the different assumptions underlying both models.

The tracer incorporation method is straightforward and measures synthesis of muscle proteins which precipitate in TCA. The A-V dilution model measures the turnover of phenylalanine across the hindquarter which is presumed to be for $85-90 \%$ a reflection of muscle protein turnover (14). Although stripping the skin had no influence on amino acid flux in hindquarter perfusion studies (38), various other studies have shown that skin and bone have high protein tumover rates and that the nonmuscle component of the hindquarter is more active in protein synthesis than is muscle $(39,40)$. However, 2 days' starvation also reduced protein synthesis rates of skin and bone (measured by the tracer incorporation technique) (40) and therefore protein synthesis of non-muscle tissue in hindquarter cannot explain the increased Rd (and disposal) after prolonged starvation.

Phenylalanine is used as tracer because in muscle this amino acid is only used for protein synthesis and production only originates from protein breakdown (11, 12, 26). Alternative routes are unknown in muscle. The discrepancy of FSR\% and Rd may therefore be that each method measures synthesis of different protein pools. The acid insoluble protein pool measured by the incorporation model contains the larger structural proteins in muscle. Smaller peptides remain soluble and are not part of the measurement $(6,41)$. In contrast, protein synthesis rate reflected by the A-V dilution model measures synthesis of all peptides and proteins across the hindquarter. 
However, not only is the acid soluble pool approximately 100 -fold smaller than the acid insoluble pool, but it has also been observed previously that the turnover of proteins is generally proportionally to its size (42). The only proteins with a rapid turnover are those which are incorrectly made (42). In line with this is the observation that $40 \%$ of newly synthesized collagen proteins are degraded before being released (43). It is however, unlikely that the turnover of this small, acid soluble, incorrectly made, protein pool is responsible for the tripled disappearance rate of phenylalanine. The increased turnover of glutamine and valine observed in the second experiment suggest that the turnover rate of all amino acids calculated with the A-V dilution model increased regardless of the rate of protein synthesis. It appears that in the rat after prolonged

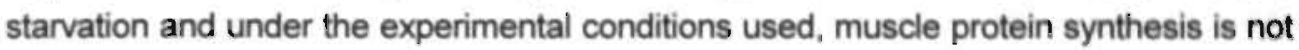
measurable with the $\mathrm{A}-\mathrm{V}$ dilution model.

Using the three compartment model plasma-tissue membrane transport rates in vivo were measured. The observed magnitude of membrane transport in vivo was in the same range reported previously as initial transport rates in rat muscle (44) and in perfused rat hindquarter estimated at physiological amino acid concentrations (45). This suggests that the in vivo method we used to measure amino acid membrane transport is in agreement with the scarce literature data.

Short starvation of 40 hours led to no significant change in metabolic shunting or bidirectional membrane transport rates of phenylalanine. When starvation proceeded, shunting of phenylalanine reduced to approximately zero and bidirectional membrane transport rates of phenylalanine significantly increased. These changes indicate that the increased muscle amino acid tumover was not only an increased intracellular tumover but was also related to an enhancement of membrane transport rates. Although analysis via which transport system and how this occurred was not subject of the present study, we must assume that the increased phenylalanine membrane transport rates is System L carrier mediated (45). System L is a high-capacity, lowaffinity carrier system (45). Its activity in vitro has been linked to the availability of leucine for protein synthesis (46). In our study arterial leucine did not change significantly during starvation but intracellular leucine concentration in the $64 \mathrm{~h}$ starved rats was almost half of the concentration observed in control rats (data not shown). Thus, in vivo, leucine availability may have been the initiating factor to increase System $\mathrm{L}$ amino acid membrane transport activity. Prolonged starvation increases glucagon, glucocorticoid, growth hormone and thyroxine $\left(T_{4}\right)$ levels and decreases insulin and triodothyronine $\left(T_{3}\right)$ concentrations $(3,9)$. System $L$ transport system is in vitro relatively insensitive for hormonal changes (except for thyroid hormones) $(45,46)$ but has recently been shown in vivo to be sensitive to e.g. insulin (47). In vivo changes in 
the sensitivity to these hormones or other plasma factors, may thus be involved in the regulation of amino acid membrane transport rates (3).

In conclusion, our results show that the A-V dilution model is applicable to measure protein turnover and amino acid plasma-tissue membrane transport in muscle in overnight fasted and briefly starved rats. However, after prolonged starvation, endstage proteolysis resulted in a discrepancy of amino acid disappearance rate into muscle tissue and the actual protein synthesis rate measured by the incorporation technique. Care must be taken with the interpretation when using only one model in anaesthetized small animals.

\section{Acknowledgements}

The authors wish to thank H.M.H. van Eijk and D.R. Rooyakkers for analytical help. This research was supported by grant 900-562-125 from the Netherlands Organization for Scientific Research (N.W.O.).

\section{References}

1 Kern KA, Norton JA. Cancer cachexia 1988; J Parenter Enter Nutr 12: 286-298.

2 Bozzetti F. Effects of artificial nutrition on the nutritional status of cancer patients. J Parenter Enter Nutr 1989: 13: 406-420.

3 Sugden MC, Holness MJ, Palmer TN. Fuel selection and carbon flux during the starved-to-fed transition. Biochem J 1989: 263: 313-323.

4 Stirewalt WS, Low RB. Slaiby SM. Insulin sensitivity and responsiveness of epithrochlearis and soleus muscles from fed and starved rats. Biochem J 1985; 227: 355-362.

5 Jepson MM, Pell JM, Bates PC, Millward DJ. The effects of endotoxaemia on protein metabolism in skeletal muscle and liver of fed and fasted rats. Biochem J 1986; 235: 329-336.

6 Lundholm K, Karlberg I, Ekman L. Eclstrom S. Schersten T. Evaluation of anorexia as the cause: of altered protein synthesis in skeletal muscles from non-growing mice with sarcoma. Cancer Res 1981: 41: 1989-1996.

7 Goodman MN, McE:laney MA, Ruderman NB. Adaptation to prolonged starvation in the rat: curtailment of skeletal muscle proteolysis. Am J Physiol 1981; 241: E321-E327.

8 Lowell BB, Ruderman NB, Goodman MN. Regulation of myofibrillar protein degradation in rat skeletal muscle during brief and prolonged starvation. Metabolism 1986; 35: 1121-1127.

9. Goodman MN, Larsen PR, Kaplan MM, Aoki TT, Young VIR, Ruderman NB. Starvation in the rat. II. Effect of age and obesity on protein sparing and fuel metabolism. Am J Physiol 1980; 239: E277-E286.

10 Kadowaki M. Harada N, Takahashi S. Noguchi T. Naito $H$. Differential regulation of the degradation of myofibrillar and total proteins in skeletal muscle of rats: Effects of streptozotocininduced diabetes, dietary protein and starvation. J Nutr 1989; 119: 471-477.

11 Barrett EJ, Revkin JH. Young LH, Zaret BL, Jacob R, Gelfand RA An isotopic method for measurement of muscle protein synthesis and degradation in vivo. Biochem 1 1987; 245: 223-228. 
12 Wolfe RR. Radioactive and stable isotope tracers in biomedicine. Principles and practice of kinetic analysis, 1992; Wiley-Liss, New York, U.S.A.

13 Thompson GN, Pacy PJ, Merritt H, Ford GC, Read MA, Cheng KN, Halliday D. Rapid measurement of whole body and forearm protein turnover using a [2H5]phenylalanine model. Am J Physiol 1989;256: E631-E639.

14 Biolo G, Flemming RYD, Maggi SP, Wolfe RR. Transmembrane transport and intracellular kinetics of amino acids in human skeletal muscle. Am J Physiol 1995; 268: E75-E84.

15 Biolo G, Maggi SP. Williams BD. Tipton KD, Wolfe RR. Increased rates of muscle protein turnover and amino acid transport after resistance exercise in humans. Am J Physiol 1995; 268: E514E520.

16 Fryburg D.A., E.J Barrett, R.J. Louard, R.A. Gelfand. Effects of starvation on human muscle protein metabolism and its response to insulin. Am J Physiol 1990; 259: E477-E482.

17 Biolo G, Chinkes D, Zhang XJ, Wolfe RR. A new model to deermine in vivo the reiationship between amino acid transmembrane transport and protein kinetics in muscle. J Parent Enteral Nutr 1992; 16:305-315.

18 Guide for the care and use of laboratory animals 1986; EEC publication 86/609.

19 Heeneman S, Deutz NEP. Effects of decreased glutamine supply on gut andi liver metabolism in vivo in rats. Clin Sci 1993; 85 : 437-444.

20 Dejong CHC, Deutz NEP. Soeters PB. Renal ammonia and glutamine metabolism duringl liver insufficiency-induced hyperammonemia in the rat. J Clin Invest 1993; 92: 2834-2840.

21 Dejong $\mathrm{CHC}$, Deutz NEP. Soeters PB. Inter-organ nitrogen exchange during prolonged starvation in the rat. J Clin Nutr Gastroenterol 1991; 6: 176-183.

22 Van Eijk $\mathrm{HMH}_{2}$ Rooyackers DR, Deutz NEP. Rapid routine determination of amino acids in plasma by high-performance liquid chromatography with a $2-3 \mathrm{~mm}$ Spherisorb ODS II column. J Chromatogr 1993; 620: 143-148.

23 Lecavalier L, Horber FF. Haymond MW. Determination of plasma concentrations and $3 \mathrm{H}$-specific activity of phenylalanine in plasma using high-performance liquid chromatography. J Chromatogr 1989; 491: 410-417.

24 van Eijk, HM, Huinck, MP, Rooyakkers, DR, Deutz, NEP. Automated simultaneous isolation and quantitation of labeled amino acid fractions from plasma and tissue by lon-exchange chromatography. J Chromatogr 1994; 660: 251-257.

25 Schaefer A, Piquard F, Haberey $P$. The effects of changes in plasma amino acid concentrations on erythrocyte amino acid content. Clin Biochem 1990; 23, 237-240.

26 Tourian A, Goddard J, Puck $\Pi$. Phenylalanine hydroxylase activity in mammalian cells. J Cell Physiol 1969; 73: 159-170.

27 Millward DJ, Garlick PJ, James WPT, Sender PM, Waterlow JC Ed: Cole DJA, Boorman KN, Buttery PJ, Lewis D, Neale RJ, Swan H. Protein turnover. Protein Metabolism and Nutrition 1976; 49-69.

28 Norusis MJ ed. SPSS/PC+ V4.0 BASE MANUAL for the IBM PC/XT/AT and PS/2 1989; SPSS Inc, Chicago, USA.

29 Kimura RE, LaPine TR, Johnston J, llich JZ. The effect of fasting on rat portal venous and aortic blood glucose, lactate, alanine, and glutamine. Ped Res 1988; 23; 241-244.

30 Moldawer LL, Kawamura I, Bistrian BR, Blackbum GL. The contribution of phenylalanine to tyrosine metabolism in vivo. Studies in the post-absorptive and phenylalanine-loaded rat. Biochem J 1983; 210: 811-827. 
31 Rose D, Horowitz GD, Jeevanandam M, Brennan MP. Shires GT, Lowry SF. Whole body protein kinetics during acute starvation and intravenous refeeding in normal man. Fed Proc 1983; 42: 4558.

32 Kimura RE, LaPine TR, Gooch WM. Portal venous and aortic glucose and lactate changes in a chronically catheterized rat. Ped Res 1988; 23: 235-240.

33 Chen MK, Espat NJ, Bland KI, Copeland EM, Souba WW. Influence of progressive tumor growth on glutamine melabolism in skeletal muscle and kidney. Ann Surg 1993; 217: 655-667.

34 Welbourne TC. Effect of metabolic acidosis on hindquarter glutamine and alanine release. Metabolism 1986; 35: 614-618.

35 Ruderman NB, Houghton CRS, Hems R Evaluation of the isolated perfused rat hindquarter for the study of muscle metabolism. Biochem J 1971; 124: 639-651.

36 Parrilla R. Flux of metabolic fuels during starvation in the rat. Pflügers Arch $1978 ; 374: 3-7$.

37 Milward DJ, Garlick PJ, Nnanyelugo DO, Waterlow JC. The relative importance of muscle protein synthesis and breakdown in the regulation of muscle mass. Biochem J 1976; 156:185-188.

38 Ruderman NB, Berger $\mathrm{M}$. The formation of glutamine and alanine in skeletal muscle. J Biol Chem $1974 ; 249,5500-5506$.

39 Preedy, VR, Garlick, P.J. Rates of protein synthesis in skin and bone, and their importance in the assessment of protein degradation in the perfused rat hemicorpus. Biochem $\mathrm{J} \mathrm{1981;194}$ 373-376.

40 Preedy, VR, McNurlan, MA, Garlick, PJ.. Protein synthesis in skin and bone of the young rat. Br J Nutr 1983; 49, 517-523.

41 Hubbard RW. Chambers JG, Sanchez A. Amino acid analysis of plasma: studies in sample preparation. J Chromatogr 1988: 431: 163-169.

42 Dice JF, Dehlinger PJ, Schimke RT. Studies on the correlation between size and the relative degradation rate of soluble proteins. J Biol Chem 1973; 248:4220-4228.

43 Bienkowski RS. Intracellular degradation of newly synthesized secretory proteins. Biochem J 1983: 214: 1-10.

44 Banos G, Daniel PM, Moorhouse SR, Pratt OE. The movement of amino acids between blood and skeletal muscle in the rat. J Physiol 1973; 235: 450-475.

45 Hundal HS, Rennie MJ, Watt PW. Characteristics of acidic, basic and neutral amino acid transport in the perfused rat hindlimb. J Physiol 1989; 408: 93-114.

46 Shotwell MA, Kilberg MS, Oxender DL. The regulation of neutral amino acid transport in mammalian cells. Biochim Biophys Acta 1983; 737: 267-284.

47 Sakurai Y, Aarsland A. Herndon DN, Chinkes DL. Pierre E, Nguyen TT. Patterson BW, Wolfe RR. Stimulation of muscle protein synthesis by long-term insulin infusion in severely burned patients. Ann Surg 1995; 222 3: 283-297. 


\title{
IN VIVO AMINO ACID METABOLISM OF GUT AND LIVER DURING SHORT AND PROLONGED STARVATION
}

\author{
1. de Blaauw, N.E.P. Deutz, M.F. von Meyenfeldt \\ Am J Physiol (1996), 33: G298-G306
}

\begin{abstract}
During starvation splanchnic organs are proportionally more affected by protein loss than other organs. Amino acid membrane transport is one of the regulating mechanisms of protein turnover but until now in vivo data are lacking. To study in vivo phenylalanine and tyrosine membrane transport and protein turnover in splanchnic organs, a primed continuous infusion of $\mathrm{L}-\left[2,6-{ }^{3} \mathrm{H}\right] \mathrm{Phenylalanine}$ was given to control rats (postabsorptive) and after short (40 hours) and prolonged (112 hours) starvation. Data were analyzed using a three compartment model previously used in muscle membrane transport studies.

Inward and outward amino acid plasma-tissue membrane transport rates in both the liver and gut were upregulated after prolonged starvation. Metabolic shunting of phenylalanine and tyrosine increased in the gut but decreased to zero in the liver after prolonged starvation. In conjunction with this, gut and liver protein turnover increased after prolonged starvation. In the liver the net uptake of gluconeogenic precursors also increased, indicative for increased gluconeogenesis. The observed changes in amino acid metabolism in both splanchnic organs after prolonged starvation, may reflect an adaptation of the gut and liver to nutritional deprivation and could be of benefit during refeeding.
\end{abstract}

\section{Introduction}

During starvation net protein loss in splanchnic organs (gut and liver) is substantially more severe than in muscle tissue $(19,40)$. The effects of starvation on splanchnic organs seems contradictory to the observed functional adaptations related to amino 
acid and protein metabolism. In the gut, active transport of nutrients in and out of the lumen increase after starvation $(3,18)$. In the liver, starvation also leads to an upregulation of metabolic processes aimed at enhanced ketogenesis and gluconeogenesis $(34,36,37)$. This appears to be related to enhanced amino acid membrane transport by hepatocytes $(14,20,21,28,39)$. However, all previously mentioned membrane transport studies of the gut and liver were performed in vitro or ex vivo because manipulation can be performed under controlled conditions. In addition, in vivo studies are more difficult to perform (39). Recently, several studies in large animals were published in which in vivo membrane transport rates in hindquarter muscle and gut were measured using a primed constant infusion of radioactive (or stable isotope) tracers $(4,7,10,44)$. Similar operative and sampling procedures have been used by our group and others to measure amino acid interorgan metabolism in rats $(12,13,22,38)$. We therefore aimed to study the applicability and validity of this tracer model to measure in vivo gut and liver membrane transport activity in rats and relate these parameters to protein turnover and the net uptake or release of gluconeogenic precursors. The effects of short and prolonged starvation were studied as these circumstances often accompany disease and pathophysiological events.

Materials and Methods

\section{Animals}

Male Lewis rats $(200-300 \mathrm{~g})$ obtained from the Centralized Animal Facilities (University of Limburg, Maastricht, the Netherlands) were used for this study. During the experiment, rats were individually housed in metabolic cages after an adaptation period of 4 days prior to the experiment. Water intake was ad libitum. They were subject to standard 12 hour light-dark cycle periods (7:30 A.M. to 7:30 P.M.), whereas room temperature was maintained at $25^{\circ} \mathrm{C}$. The experiments were performed in accordance with the recommendations of the Guide for the Care and Use of Laboratory Animals (17) and approved by the Ethical Committee of Animal Research of the University of Limburg.

\section{Experiment 1}

The first experiment was performed to study metabolic steady state conditions necessary for in vivo membrane transport studies. As prolonged starvation may influence vital organ functioning and stability of steady state conditions, rats $(n=10$ ) were studied in control conditions (overnight fasted) and in conditions of extreme fasting (112 hours) 


\section{Experiment 2}

In the second experiment rats $(n=40)$ were randomly divided into four groups. The first group fasted overnight (16 hours) as control group. A second group fasted for 40 hours (short starvation) and a third group 112 hours (prolonged starvation) prior to sampling. A fourth group was added as a second control group for possible effects due to prolonged housing in metabolic cages. These rats were housed in metabolic cages for 112 hours, yet only fasted overnight prior to sampling.

\section{Study and sampling procedures}

The experimental conditions were similar in both experiments. Rats were randomly put in metabolic cages and weighted daily at 8:00 A.M. All infusion and sampling experiments were performed as described previously (12, 13, Chapter 3 ). In brief, under ether (Chempropack BV. Dordrecht, NL) anesthesia and at constant, preanesthesia body temperature, a laparotomy was performed. The right renal vein, a tertiary branch of the mesenteric vein, the portal vein, the hepatic vein, the inferior caval vein and the aorta were cannulated using a 25 gauge needle fixed in a Silastic tube (Silastic Medical Grade tubing $0.051 \mathrm{~cm}$ ID, 0.094 OD, Dow Corning Corporation, Medical Products, Midland, MO, USA) and fixed with cyano-acrylate (Cyanolit 201, Het Rubberhuis, Maastricht, The Netherlands). Next, the right carotid artery was catheterized (Intramedic Polyethylene Tubing PE 50, $0.051 \mathrm{~cm} \mathrm{ID,} 0.094 \mathrm{~cm}$ OD, Clay Adams, Parsipany, NY, USA). The complete procedure took approximately 40 minutes. Liver, Portal Drained Viscera (PDV) and hindquarter metabolism were measured simultaneously. The results of hindquarter metabolism are discussed in Chapter 3.

For flow measurements, the indicator dilution method with para-aminohippuric acid (PAH) was used as described in detail in chapter 3. To study in vivo plasma-tissue membrane transport and protein kinetics, a primed constant infusion of L- $\left[2,6-{ }^{3} \mathrm{H}\right] \mathrm{Phenylalanine}\left({ }^{3} \mathrm{H}-\mathrm{Phe}\right.$ ) (Sigma P 6053, St Louis, USA) was given in the renal vein as described in chapter 3 .

In the first experiment we verified whether the infusion time of 40 minutes was sufficient to reach isotopic steady state concentrations for ${ }^{3} \mathrm{H}-\mathrm{Phe}$ and $\mathrm{L}-\left[2,6{ }^{3} \mathrm{H}\right] \mathrm{Ty}$ yrosine $\left({ }^{3} \mathrm{H}-\mathrm{Tyr}\right)$. Arterial blood $(0.6 \mathrm{ml}$ per sample) was sampled 20,30 and 40 minutes after the bolus of ${ }^{3} \mathrm{H}$-Phenylalanine was given. In the second experiment blood (1.2 $\mathrm{ml}$ per catheter) was sampled from the hepatic vein, portal vein, inferior caval vein and carotid artery at a maximum rate of approximately $300 \mu \mathrm{L} / \mathrm{min}$. Withdrawing this amount of blood simultaneously will cause hypovolemia and therefore precludes measuring amino acid and protein metabolism at multiple time points as in the first experiment. All blood was collected in heparinized cups (Lithium-Heparin Micro-sample container CB100, Sarstedt, FRG) on ice. Hereafter, a $1 \mathrm{~cm}$ piece of 
jejunum, approximately $1 \mathrm{~cm}$ distal of Treitz ligament, and the left liver lobe were dissected free, directly freeze-clamped, put in liquid nitrogen and stored at $-80^{\circ} \mathrm{C}$ until further analysis.

For PAH determinations, $50 \mu \mathrm{L}$ heparinized blood was added to $500 \mu \mathrm{L}$ Trichloroacetic acid GR 10\% (w/v) (TCA, Merck 807, Darmstadt, FRG), vortexed and centrifuged at $8.900 \mathrm{~g}$ at $4^{\circ} \mathrm{C}$ (Hettich Universac $30 \mathrm{RF}$, Tuttlingen, Germany). The supernatant was frozen in liquid nitrogen and stored at $-80^{\circ} \mathrm{C}$ until further analysis. For hematocrit determinations a micro-hematocrit tube (Modulohm 88302, Herlev, Denmark) was filled with heparinized blood and centrifuged at $10,000 \mathrm{~g}$ at room temperature (Micro Hematocrit Centrifuge, Hawksley LTD, 891481, UK). Hematocrit was read with a Micro Hematocrit Reader (Hawksley Ltd, UK). Plasma was obtained by whole blood centrifugation at $8,900 \mathrm{~g}$ at $4^{\circ} \mathrm{C}$ for 5 minutes. For glucose, lactate, urea and ammonia determinations, $200 \mu \mathrm{L}$ plasma was vortexed with $20 \mu \mathrm{L}$ TCA $50 \%$, put into liquid nitrogen and stored at $-80^{\circ} \mathrm{C}$. For plasma amino acid determinations 200 $\mu \mathrm{L}$ plasma was added to $8 \mathrm{mg}$ 5-Sulfosalicylic acid (SSA 5\%) (Brunschwig, 10346, Amsterdam, NL) for deproteinization, vortexed, frozen in liquid nitrogen and stored at $80^{\circ} \mathrm{C}$.

\section{Biochemical analysis}

Acid base homeostasis, $\mathrm{PO}_{2}$ an $\mathrm{PCO}_{2}$ were immediately determined using a Automatic Blood Gas System (AVL List, 993, Graz, Austria). Alanine aminotransferase (ALAT), aspartate aminotransferase (ASAT), $\gamma$-glutamyl transferase ( $\gamma$ GT) and creatinine were determined in serum using standard procedures. Plasma glucose, lactate, ammonia, urea and PAH were determined spectrophotometrically on a Cobas Mira S (Roche Diagnostica, Hoffman-La Roche, Basel, Switzerland) by standard enzymatic methods, using commercially available kits as described previously $(12,13)$. Standard plasma amino acids were determined by fully automated high performance liquid chromatography (HPLC) using 2-3 $\mu \mathrm{M}$ spherisorb ODS II packing material and pre-column derivatization with o-phthaldialdehyde as described previously (42). To determine plasma phenylalanine and tyrosine specific activity (SA), plasma was isolated on an ion exchange column using a technique adapted from a method described previously ( 16 , see also chapter 3 ).

For the determination of tissue amino acid concentrations and SA, tissue was pulverized using a mortar and pestle precooled in liquid nitrogen. For amino acid determinations the tissue was further homogenized and deproteinized using an UltraTurrax (Omni 10001, $\mathrm{N}^{\circ}$ 10-0.427, Waterbury, CT, USA). Approximately $100 \mathrm{mg}$ tissue was added to $500 \mu \mathrm{l} \mathrm{SSA} 5 \%$ with norvaline $0.5 \mathrm{mMl}(\mathrm{BDH} 10346)$ as an internal standard. The homogenate was frozen in liquid nitrogen and stored at $-80^{\circ} \mathrm{C}$ until further determinations. 
To determine the tissue dry weight approximately $200 \mathrm{mg}$ pulverized tissue was freeze dried for 24 hours in a Speedvac (type SC200, Savant Instruments inc., Farmingdale NY, USA) connected with a refrigerated condensation trap (type RT 400, Savant Instruments Inc., Farmingdale NY, USA).

\section{Calculations}

\section{Plasma flow, substrate fluxes andi intracellular concentrations}

Plasma flow across the PDV and liver was calculated using PAH in the indicator dilution method as has been extensively described previously $(12,13)$. PDV substrate fluxes are calculated by multiplying the portal venous-arterial concentrations differences with the mean PDV plasma flow of the group and are expressed in $\mathrm{nmol} / 100 \mathrm{~g} \mathrm{bw} / \mathrm{min}$. Splanchnic organ flux was calculated by multiplying the hepatic plasma flow with hepatic vein-arterial concentration differences. Liver flux was calculated by subtracting PDV flux from the splanchnic flux as described previously $(12,13)$. A positive flux indicates net release, a negative flux reflects a net uptake. $\alpha$-Amino-nitrogen ( $\alpha$-AN) was calculated as the sum of the individual amino acids measured (42). Tissue concentrations of amino acids are expressed in $\mu \mathrm{M}$ and derived by dividing the tissue homogenate amino acid concentration ( $\mu \mathrm{mol} / \mathrm{kg}$ wet weight) by the percentage tissue water.

\section{Membrane transport rates and protein tumover}

Three compartment modelling was used to calculate plasma-tissue membrane transport rates and protein tumover $(4,7,10,44)$. The model divides an organ in two vascular compartments and a tissue compartment (see chapter 2 pp 56-58 and figure 5; chapter 3, figure 2). Inward plasma-tissue membrane transport rates $\left(\mathrm{F}_{\mathrm{t}, \mathrm{a}}\right)$ are calculated as the in vivo amino acid flux from the afferent vascular pool into the intracellular free amino acid pool. Outward plasma-tissue membrane transport rates $\left(F_{v, t}\right)$ are calculated as flux from the intracellular pool to the efferent venous pool. Metabolic shunting $\left(F_{v, a}\right)$ of amino acids is described as the substrate flux from the arterial pool entering the organ straight into the venous pool. Across the PDV both ${ }^{3} \mathrm{H}-$ Phe and ${ }^{3} \mathrm{H}$-Tyr were used to calculate protein turnover. PDV production $(P)$ of phenylalanine and tyrosine reflects the intracellular amount of amino acid produced by protein breakdown and by intraluminal absorption of amino acids. Disposal (D) of phenylalanine and tyrosine in the gut reflects protein synthesis.

Similar as in flux calculations, liver membrane transport values are derived from subtracting PDV values from splanchnic organ membrane transport rates. Disposal of phenylalanine in the liver reflects protein synthesis and hydroxylation to tyrosine (41). 
Disposal was calculated by dividing tracer net balance (nb) across the liver by the intracellular specific activity of phenylalanine. Tracer net balance can be calculated by subtracting PDV tracer net balance from splanchnic organ net balance. Phenylalanine hydroxylation to tyrosine was calculated from the liver phenylalanine net uptake multiplied by the ratio of hepatic venous tyrosine SA and the SA of phenylalanine entering the liver (9). This has to be corrected for the dilution of hepatic venous tyrosine SA by liver protein breakdown. Subtraction of hydroxylation from liver disposal (D) reflects the phenylalanine used for protein synthesis only. Liver phenylalanine production $(P)$ only originates from protein breakdown and can be calculated by subtractıng liver phenylalanine tracee net balance from liver phenylalanine disposal.

\section{Statistical analysis.}

Results are presented as mean \pm SEM. For statistical analysis the Mann-Whitney $U$ test (non-parametric) was used to compare group differences (33). Significance was considered present at $\mathrm{p}<0.05$.

\section{Results}

\section{Experiment 1}

ALAT, ASAT, $\gamma$ GT and creatinine (Table 1) were all within normal ranges (27). The serum enzyme activities indicate that liver and kidney functioning were normal after both 16 and 112 hours starvation. It confirms previous studies that the starvation period used in our model does not induce major organ failure $(15,26)$. This was also confirmed by the maintenance of acid base homeostasis between 20 and 40 minutes of the operative procedure (Figure 1). Arterial pH, bicarbonate and base excess were maintained at steady state and were not different befween rats starving for 16 hours or 112 hours. Also, arterial $\mathrm{PcO}_{2}, \mathrm{PO}_{2}$ and $\mathrm{O}_{2}$ hemoglobin saturation remained constant during the procedure in both groups of rats.

As illustrated in Table 1, metabolic and isotopic steady state conditions were present between 20 and 40 minutes after the start of the procedure. Arterial concentrations and specific activity of phenylalanine and tyrosine were constant between 20 and 40 minutes indicating conditions that allow the calculation of amino acid and protein turnover across the gut and the liver. Whole body protein turnover, calculated by the whole body Appearance Rate of phenylalanine, was significantly lower measured at multiple time points. The variation of the calculated turnover was similar at all three time points in both 16 hours and 112 hours starved rats. Moreover, the difference between whole body protein turnover of 16 hours and 112 hours starved rats was reproducible at the three time points. 
Table 1. Liver and kidney functioning and steady-state conditions. Values are mean \pm SEM. ALAT, ASAT, YGT concentrations are in IUn, creatinine, phenylalanine and tyrosine concentrations in $\mathrm{mM}$, specific activity is in dpm/nmol, protein tumover in nmol x $100 \mathrm{~g} \mathrm{bw} \mathrm{x} \mathrm{minute.} \mathrm{Blood} \mathrm{was} \mathrm{sampled} 20,30$ and 40 minutes after the start of the operative procedure to determine metabolic and isotopic steady state and the reproducibility of amino acid concentration and specific activity measurements in 16- and 112-h starved rats. Liver and kidney functioning was determined by serum enzymatic activity of ALAT, ASAT, yGT and creatinine.

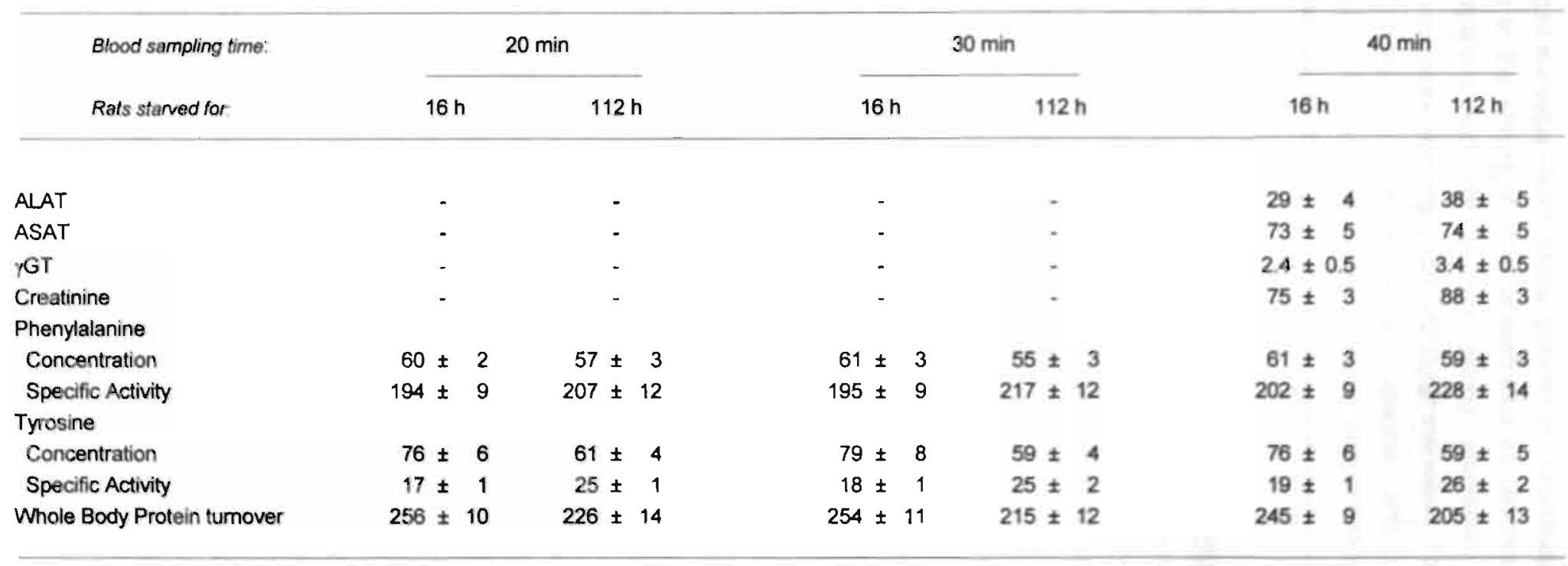



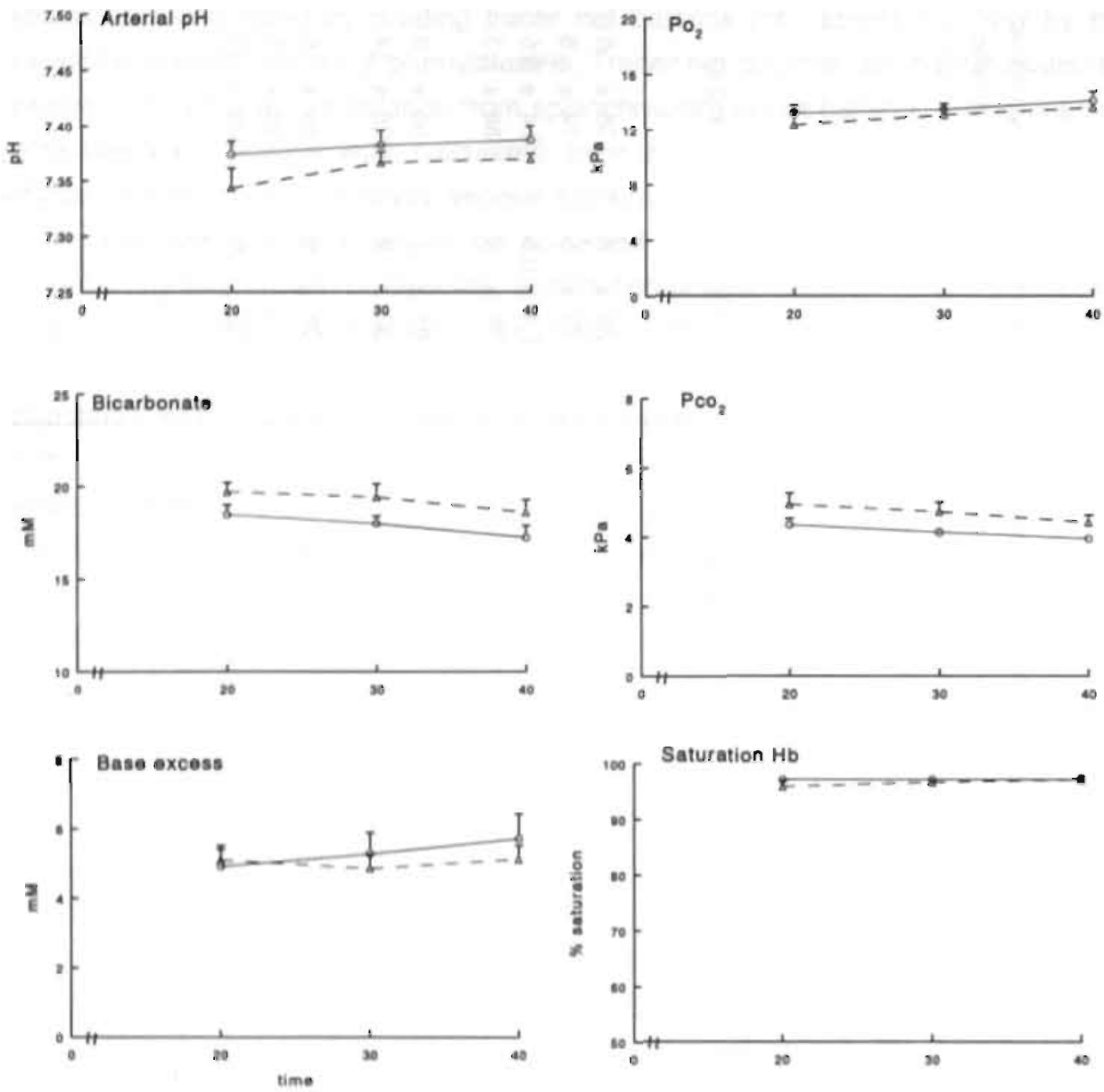

Figure 1. Acid base homeostasis, arterial $\mathrm{pO}_{2}, \mathrm{pCO}_{2}$ and hemoglobin $\mathrm{O}_{2}$ saturation to determine steady' state conditions after 16 hours $(O)$ and 112 hours $(\triangleright)$ starvation. Multiple samples were taken 20,30 and 40 minutes after the start of the operative procedure.

\section{Experiment 2}

Plasma and tissue amino acid concentrations and specific activities were not significantly different between control group 1 and 4 and the results of these groups were pooled.

Rat body weight decreased $5.4 \pm 0.3 \%$ after 16 hours starvation, $10.1 \pm 0.3 \%$ after 40 hours and $17.5 \pm 1.1 \%$ after 112 hours starvation. Arterial concentrations of ammonia (Table 2) did not change in time whereas urea concentrations decreased 
only slightly after prolonged starvation. Both arterial glucose and lactate concentrations were relatively high due to the effects of ether anaesthesia as described previously (22). Glucose concentrations did not change during starvation but lactate concentrations tended to increase after short and prolonged starvation. Total $\alpha-\mathrm{AN}$, the main plasma nitrogen transporters glutamine and alanine, and phenylalanine concentrations remained unchanged over time. Tyrosine concentrations, however, decreased after prolonged starvation.

\section{Intracellular concentrations}

Water content (Table 3) of the jejunum increased slightly after prolonged starvation. The intracellular tyrosine concentration increased significantly after short starvation. Other amino acid concentrations showed a similar trend. Liver intracellular water content remained unchanged. Intracellular amino acid concentrations showed no significant changes except for glutamate that increased.

Table 2. Arterial substrate concentrations after 16 hours, 40 hours and 112 hours starvalion. Values are mean \pm SEM. Arterial concentrations for glucose, lactate and urea in $\mathrm{mM}$. for ammonia and amino acids in $\mu \mathrm{M}$. $\alpha$-AN is the sum of all amino acids (42). Mann-Whitney $U$ : vs 16 hours: " $p<0.05$.

Time after starvation, $h$

$16 \quad 40 \quad 112$

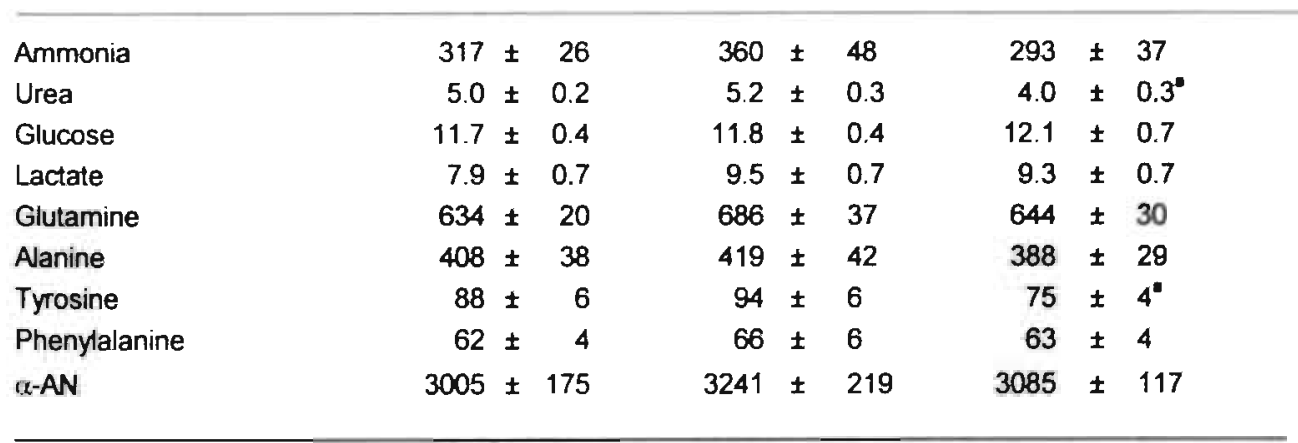


Table 3. Intracellular jejunal and liver tissue amino acid concentrations and water content. Values are mean \pm SEM. Water content is expressed as percentage water in wet weight, concentrations in $\mu$ mole/kg wet weight, except $\alpha$-AN in mmol/kg wet weight. Mann-Whitney $U$. vs 16 hours: ${ }^{a} p<0.05,{ }^{b} p<0.01,{ }^{c}$ $p<0.001$, vs 40 hours ${ }^{\circ} p<0.05$, ${ }^{\circ} p<0.01,{ }^{1} p<0.001$.

Time after starvation, $\mathrm{h}$

$16 \quad 40 \quad 112$

\begin{tabular}{|c|c|c|c|c|c|c|c|c|}
\hline \multicolumn{9}{|l|}{ Jejunum } \\
\hline Water \% & 75.8 & \pm 0.3 & 75.9 & \pm & 0.8 & 78.5 & \pm & $0.5 c$ \\
\hline Glutamate & 3611 & \pm 295 & 4761 & \pm & $535^{a}$ & 3906 & \pm & 552 \\
\hline Glutamine & 1171 & $\pm \quad 56$ & 1235 & \pm & 79 & 1007 & \pm & 110 \\
\hline Alanine & 2244 & \pm 149 & 2659 & \pm & 286 & 2273 & \pm & 182 \\
\hline Tyrosine & 206 & $\pm \quad 17$ & 314 & \pm & $44^{b}$ & 194 & \pm & 26 \\
\hline Phenylalanine & 155 & 22 & 198 & \pm & 46 & 171 & \pm & 28 \\
\hline$\alpha-\mathrm{AN}$ & 26.0 & 1.7 & 29.0 & \pm & 1.7 & 26.9 & \pm & 2.3 \\
\hline \multicolumn{9}{|l|}{ Liver } \\
\hline Water \% & 71.1 & \pm 0.3 & 70.3 & \pm & 0.3 & 70.7 & \pm & 0.5 \\
\hline Glutamate & 3048 & \pm 200 & 3378 & \pm & 417 & 3566 & \pm & $304^{d}$ \\
\hline Glutamine & 3418 & \pm 209 & 4062 & \pm & 291 & 3123 & \pm & 407 \\
\hline Alanine & 3554 & \pm 272 & 3421 & \pm & 219 & 4347 & \pm & 371 \\
\hline Tyrosine & 101 & $\pm \quad 19$ & 65 & \pm & 25 & 68 & \pm & 17 \\
\hline Phenylalanine & 90 & \pm & 80 & \pm & 9 & 93 & \pm & 5 \\
\hline$\alpha-A N$ & 26.3 & 0.9 & 24.5 & \pm & 1.5 & 26.1 & \pm & 1.4 \\
\hline
\end{tabular}

POV and liver plasma flow and substrate fluxes

Plasma flow (Table 4) of both the gut and liver remained unchanged. Ammonia production by the PDV increased after short and prolonged starvation, albeit not significantly because of a concomitant increase of the variation. Ammonia net uptake by the liver increased in conjunction with increased urea production.

Gut glucose consumption increased, although not significantly. In the liver glucose production tended to increase and lactate consumption increased during short and prolonged starvation indicating increased gluconeogenesis.

The PDV flux of both nitrogen carriers glutamine and alanine remained consistent; glutamine being net consumed and alanine being net produced. In the liver both amino acids were aiready consumed in the postabsorptive control rats. Alanine uptake, a known gluconeogenic amino acid, almost doubled after short and prolonged starvation. 
The small uptake of phenylalanine and tyrosine by the gut in the postabsorptive state remained similar after short and prolonged starvation. Across the liver phenylalanine and tyrosine consumption increased during starvation. Total $\alpha$-AN flux of the PDV remained unchanged during the starvation periods but again showed a greater variation when starvation proceeded. In the liver, however, total $\alpha$-AN uptake was higher at 40 and 112 hours of starvation.

Table 4. PDV and Liver plasma flow and substrate fluxes. Values are mean \pm SEM. Plasma flow is expressed in m/100 g bw/min, substrate fluxes in nmol/100 g bw/min. Flux was calculated by multiplying the group mean plasma flow and $A-V$ concentration differences. Mann-Whitney $U$ : vs 16 hours: " $p<0.05$. ${ }^{\mathrm{b}} \mathrm{p}<0.01,{ }^{\mathrm{c}} \mathrm{p}<0.001$, vs 40 hours ${ }^{\circ} \mathrm{p}<0.05$, ${ }^{\mathrm{P}} \mathrm{p}<0.01$, $\mathrm{p}<<0.001$.

Time after starvation, $\mathrm{h}$

$16 \quad 40$

PDV

$\begin{array}{lrrrrrr}\text { Plasma flow } & 1.9 \pm & 0.3 & 1.6 \pm & 0.7 & 2.5 \pm & 0.8 \\ \text { Ammonia } & 69 \pm & 80 & 516 \pm & 294 & 590 \pm & 458 \\ \text { Glucose } & -639 \pm & 627 & -2303 \pm & \pm 15 & -2261 \pm & 858 \\ \text { Lactate } & -1972 \pm & 885 & -2860 \pm 1094 & -1913 \pm & 977 \\ \text { Glutamate } & 9 \pm & 10 & 63 \pm & 92 & 93 \pm & 53 \\ \text { Glutamine } & -427 \pm & 71 & -437 \pm & 42 & -454 \pm & 86 \\ \text { Alanine } & 260 \pm & 57 & 451 \pm 115 & 480 \pm & 123 \\ \text { Tyrosine } & -15 \pm & 4 & 7 \pm & 13 & -10 \pm & 10 \\ \text { Phenylalanine } & -10 \pm & 3 & 13 \pm & 14 & -1 \pm & 15 \\ \text { a-AN } & -199 \pm & 109 & 544 \pm & 457 & 385 \pm & 444 \\ \text { Liver } & & & & & & \\ \text { Plasma flow } & 2.5 \pm & 0.3 & 3.1 \pm & 0.7 & 3.3 \pm & 0.8 \\ \text { Ammonia } & -244 \pm & 103 & -1273 \pm & 328 & -883 \pm & 625 \\ \text { Urea } & 504 \pm & 224 & 672 \pm & 203 & 1895 \pm & 884 \\ \text { Glucose } & 809 \pm & 1236 & 4899 \pm 1260 & 2116 \pm & 1811 \\ \text { Lactate } & -2797 \pm & 746 & -9580 \pm 1594 & -5683 \pm & 2384 \\ \text { Glutamate } & 115 \pm & 59 & 107 \pm & 84 & -214 \pm & 116 \\ \text { Glutamine } & -98 \pm & 80 & -219 \pm & 54 & -262 \pm & 84 \\ \text { Alanine } & -203 \pm & 95 & -569 \pm 155 & -502 \pm & 256 \\ \text { Tyrosine } & -9 \pm & 8 & -42 \pm & 12 & -34 \pm & 13 \\ \text { Phenylalanine } & -6 \pm & 8 & -40 \pm & 15 & -51 \pm & 13 \\ \alpha \text {-AN } & -561 \pm & 246 & -1806 \pm & 414 & -2239 \pm & 756\end{array}$


Table 5. Gut plasma-tissue membrane transport rates of phenylalanine and tyrosine. Values are mean \pm SEM and are expressed in nmol/100 g bw/min. $F_{\mathrm{L}:}$ : arterial-tissue transport rate; $F_{\mathrm{v}:}$ : tissue-portal vein transport rate; $F_{v, a}$ : metabolic shunting of amino acid. Mann-Whitney $U:$ vs 16 hours: $p<0.05,{ }^{\circ} p<0.01,{ }^{\circ}$ $p<0.001$, vs 40 hours ${ }^{\circ} p<0.05,{ }^{\circ} p<0.01,{ }^{\prime} p<0.001$.

Time after starvation, $\mathrm{h}$

$16 \quad 40 \quad 112$

\begin{tabular}{|c|c|c|c|c|c|}
\hline \multicolumn{6}{|c|}{ Phenylalanine } \\
\hline$F_{t a}$ & 36 & \pm & 39 & \pm & $75 \pm 12$ \\
\hline$F_{v, 1}$ & 37 & $t$ & 56 & \pm 13 & $94 \pm 10^{c . d}$ \\
\hline$F_{v, i n}$ & 61 & \pm & 61 & \pm 3 & $76 \pm 3$ \\
\hline \multicolumn{6}{|c|}{ Tyrosine } \\
\hline$F_{\mathrm{ta}}$ & 42 & \pm & 60 & \pm 11 & $72 \pm 10$ \\
\hline$F_{v, 1}$ & 31 & \pm 4 & 58 & $\pm 3^{6}$ & $62 \pm 9$ \\
\hline$F_{v, a}$ & 89 & \pm 13 & 94 & \pm & $126 \pm 11$ \\
\hline
\end{tabular}

Table 6. Liver plasma-tissue membrane transport rates of phenylalanine and tyrosine. Values are mean \pm SEM and are expressed in nmol/100 g bw/min. $F_{\mathrm{La}}$ : arterial and portal venous-tissue transport rate; $F_{\mathrm{v}: \mathrm{i}}$ tissue-hepatic vein transport rate; $F_{v, a}$ metabolic shunting of amino acid. Mann-Whitney $U$ : vs 16 hours: " $p<0.05,{ }^{b} p<0.01$, vs 40 hours ${ }^{\circ} p<0.05$.

Time after starvation, $\mathrm{h}$

\section{Phenylaianine}

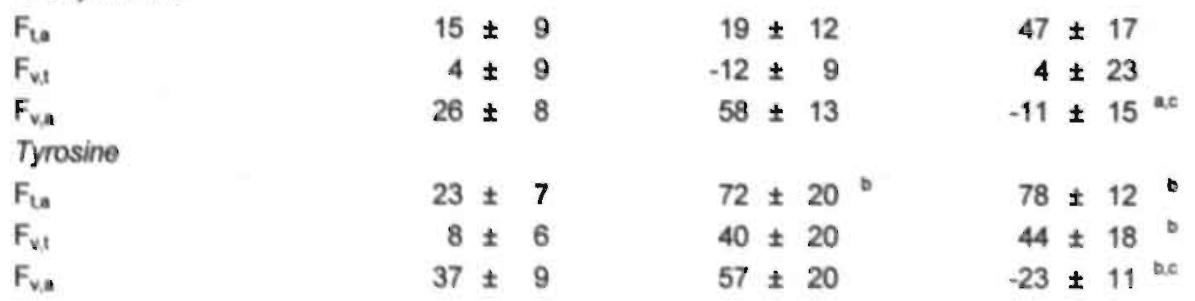


The plasma-tissue membrane transport rates (Table 5) of phenylalanine and tyrosine in the gut increased progressively in both inward $\left(F_{t, a}\right)$ and outward $\left(F_{v, t}\right)$ direction during starvation. In the gut metabolic shunting of tyrosine also increased after prolonged starvation. Shunting of phenylalanine $\left(F_{\mathrm{v}, \mathrm{a}}\right)$ increased after prolonged starvation when compared to short starvation.

In the liver phenylalanine inward and outward plasma-tissue membrane transport rates (Table 6) remained unchanged although inward transport rates tended to increase after prolonged starvation. Tyrosine membrane transport rates in the liver increased in both directions after 40 hours and 112 hours starvation. Shunting of phenylalanine and tyrosine in the liver showed a similar pattern with a rapid drop to zero after prolonged starvation.

\section{Gut and liver protein tumover}

Production (protein breakdown) and disposal (protein synthesis) of phenylalanine and tyrosine (Table 7) in the PDV increased after 112 hours of starvation. Liver phenylalanine production and total intracellular disposal (Table 8) also increased after prolonged starvation. The hydroxylation of phenylalanine to tyrosine by the liver did not change during short and prolonged starvation and varied between the 26 (112 hours) to $43 \%$ ( 16 hours) of total disposal. Therefore, phenylalanine disposal used for protein synthesis had to be increased after 112 hours starvation.

Table 7. POV disposal (protein synthesis) and production (protein breakdown) of phenylalanine and tyrosine. Values are mean \pm SEM and expressed in nmol/100 g bw/min. Mann-Whitney U: vs 16 hours. " $p<0.05,{ }^{b} p<0.01$.

Time after starvation, $h$

$16 \quad 40 \quad 112$

\section{Phenylalanine}

Disposal

Production

Tyrosine

Disposal

Production
$81 \pm 16$

$82 \pm 16$

$101 \pm 14$

$89 \pm 14$
$80 \pm 41$
$90 \pm 35$

$126 \pm 37$

$123 \pm 30$.
$169 \pm 64^{\circ}$

$207 \pm 59^{\circ}$

$158 \pm 33$

$148 \pm 37$. 
Table 8. Liver phenylalanine disposal (protein synthesis and hydroxylation), production (protein breakdown) and hydroxylation rate of phenylalanine into tyrosine. Values are mean \pm SEM and expressed in nmol/100 g bw/min. Mann-Whitney U: vs 16 hours: "p<0.01, vs 40 hours ${ }^{b} p<0.05$.

\begin{tabular}{lrrr}
\hline & \multicolumn{3}{c}{ Time after starvation, $h$} \\
\cline { 2 - 4 } & 16 & 40 & 112 \\
\hline Disposal & $28 \pm 10$ & $69 \pm 30$ & $126 \pm 351^{4, b}$ \\
$\begin{array}{l}\text { Production } \\
\text { Hydroxylation }\end{array}$ & $16 \pm 10$ & $38 \pm 25$ & $82 \pm 28$ \\
\hline & $12 \pm 6$ & $21 \pm 10$ & $34 \pm 16$ \\
\hline
\end{tabular}

Discussion

During stanvation the lack of supply of nutrients through the enteral route will force the gut to extract a substantial greater proportion of amino acids from arterial plasma. Liver metabolism must adapt to starvation by supplying other organs with glucose and specific amino acids during a state of overall nutrient scarcity. Glucose is produced by an increased liver gluconeogenesis $(34,36)$ and for this process amino acids originate from intracellular protein breakdown or from an increased amino acid uptake from the plasma pool.

All studies on amino acid membrane transport are either performed in vitro or in ex vivo perfusion models. We used a three compartment model $(4,7,10,44)$ to calculate in vivo plasma-tissue membrane transport rates. Steady state conditions necessary to use the model were verified in the first experiment. The operative procedure has been used for organ flux measurements before $\{12,13,22,38)$ and we confirmed the presence of both isotopic and metabolic steady state conditions between 20 and 40 minutes after the start of the operative procedure. In addition, the experiment showed that amino acid concentrations and specific activity measurements were not affected by the experimental procedure itself. The small size of the animals preclucde repeated measurements and left us with single point observations in the second experiment. The reproducibility in the first experiment, however, suggest the second experiment to yield valid results.

The second experiment shows an increase in phenylalanine and tyrosine plasmatissue membrane transport rates of the gut after prolonged starvation. In conjunction with this, gut protein turnover also increases. In the liver prolonged starvation induces an increase of tyrosine membrane transport rates in both directions. Phenylalanine membrane transport rates remain unchanged although the inward membrane transport 
rate tended to increase after prolonged starvation. Liver protein turnover also increased. Similarly, we observed an increase in liver ureagenesis and an increase in the uptake of gluconeogenic precursors. Although in both the gut and liver membrane transport rates were increased, no increase in the net release of phenylalanine was observed.

Amino acids are transported across the cell membrane by several transport systems with overlapping substrate specificity $(11,21)$. Phenylalanine and tyrosine are mainly transported by System L (L1 and L2) $(21,35)$. Most amino acid membrane transport systems are responsive to hormonal changes and to deprivation of amino acids but System $L$ is generally considered not to be responsive to nutritional deprivation $(1,11$, 20). We observed decreased arterial tyrosine concentrations in relation to increased membrane transport rates of both phenylalanine and tyrosine. The decreased arterial tyrosine concentrations could have upregulated the System $L$ transport of both phenylalanine and tyrosine. However, in vitro studies have also shown that the System $\mathrm{L}$ amino acids can use other transport systems to enter the cell (1). The increase in amino acid membrane transport observed in our study may be the result of other transport system activity more sensitive to amino acid deprivation. The use of an in vivo three compartment model cannot differentiate between different transport systems but measures the total transport rate of amino acids irrespective of the carrier system used.

The maximum in vitro transport rates $\left(V_{\max }\right)$ in hepatocytes ranges from $0.6 \mathrm{nmol} / \mathrm{mg}$ protein/min for L1 to $3 \mathrm{nmol} / \mathrm{mg}$ protein/min for L2 (35). This would give in vivo maximum transport rates of 300 to $1600 \mathrm{nmol} / 100 \mathrm{~g} \mathrm{bw} / \mathrm{min}$ assuming the rat liver to contain $500 \mathrm{mg}$ protein $/ 100 \mathrm{~g}$ bw in rats (25). The intracellular and arterial concentrations of phenylalanine observed in our study are approximately $5 \%$ of the $\mathrm{K}_{\mathrm{m}}$ values of $\mathrm{L} 1$ and $\mathrm{L} 2$. The theoretical transport rates deducted from in vitro data would thus be between 15 and $80 \mathrm{nmol} / 100 \mathrm{~g} \mathrm{bw} / \mathrm{min}$, which is in the same range we observed. The transport rates are also in the same range as were found in muscle tissue (4). The three compartment model therefore appears to be applicable to measure in vivo membrane transport rates in the gut and liver.

Protein turnover of both organs increased simultaneously with amino acid membrane transport. A net protein loss of gut and liver which is generally observed duning starvation $(19,40)$ should be reflected in the difference between the production and the disposal or in the net release of phenylalanine or tyrosine by these organs. In our study production and disposal of the liver and gut were not significantly different in any group and were in balance at any specific moment. In the gut our measurement of protein breakdown may be confounded by the intraluminal digestion of protein from bacteria, exfoliated cells and secreted enzymes. Protein breakdown will therefore be overestimated in this model as suggested previously by Biolo et al (7). Estimation of 
protein synthesis is not affected by intraluminal digestion and absorption of proteins because the specific activity of the precursor pool (intracellular free amino acid pool) is measured directly. However, it also appears that the A-V dilution model in the rat is not accurate enough to measure the difference between protein synthesis and breakdown in splanchnic organs. In the assumption that the rat liver contains $500 \mathrm{mg}$ protein/100 $\mathrm{g}$ bw ( $\approx 175 \times 10^{3} \mathrm{nmol}$ phenylalanine) (43), a net protein loss of the liver of $20 \%$ per day $(8,31)$ will produce an estimated release of $25 \mathrm{nmol}$ phenylalanine/min. Although the difference between production and disposal using the A-V dilution model increased from 12 (16 hours starvation) to $44 \mathrm{nmol}$ phenylalanine $/ 100 \mathrm{~g}$ bw/min after 112 hours starvation, this difference did not become significant using the A-V dilution model due to the observed variance. Therefore, production and disposal should each be considered as independent, separate parameters during the different periods of starvation. The variation in the in vivo data is too large to make the model applicable to detect net differences between protein synthesis and breakdown during starvation.

The in vivo protein breakdown rates in both splanchnic organs are in agreement with existing in vitro and ex vivo literature data $(23,24,31)$. Rat liver perfusion and perfused hepatocyte studies have shown that starvation induces non-specific (intralysosomal) breakdown of mainly long lived structural proteins $(29,30,31)$. The (extralysosomal) breakdown of short lived and abnormal proteins which normally account for approximately one third of total proteolysis, however, is not influenced by starvation (29). Therefore, when starvation proceeds the short lived protein pool will become more prominent and may have a substantially greater part in the total tumover of proteins. We hypothesize that the increase in total liver protein turnover we measured in our in vivo study may reflect a high turnover of these proteins.

Contradiction exists with one other in vivo study on effects of starvation on protein synthesis in the gut and liver of the rat (25). In this study the incorporation of a radiolabeled amino acid in structural proteins (mostly acid non-soluble) was studied to calculate protein synthesis. A possible explanation could be that the smaller, short lived, soluble proteins of both splanchnic organs are excluded using incorporation studies. In addition, the liver produces mostly secretory proteins. Although this problem is thought to be circumvented by shortening the infusion period of the tracer, it is possible that only part of these proteins are measured by the incorporation technique (25). A-V dilution models measure the intracellular production and disposal of amino acids and reflect the turnover of all proteins. This makes these models, in respect to protein synthesis, not fully comparable with incorporation models especially in metabolic stress, as good correlations have been observed in muscle under physiological conditions $(5,6)$. Further studies will be necessary to test whether both methods measure protein synthesis of the same proteins in splanchnic organs. 
In conclusion, our results show that under steady state conditions the three compartment model is applicable to study in vivo amino acid membrane transport and protein turnover in the rat liver and gut. Starvation leads to enhanced in vivo membrane transport of phenylalanine and tyrosine in the gut and of tyrosine in the liver. This occurs in conjunction with an increased splanchnic protein turnover. The increased amino acid membrane transport and protein turnover could be an in vivo adaptive process to nutritional deprivation which then should be of benefit during refeeding as previously suggested by Newsholme (32). In view of this hypothesis, higher turnover rates of proteins amplify the control of protein metabolism and make metabolic processes more efficient when food is no longer restricted.

\section{Acknowledgements}

The authors wish to thank Mr. H.M.H. van Eijk and Mr. D.R. Rooyakkers for analytical help and A.J. Meijer Ph.D. for carefully reading the manuscript and for suggestions given. This research was supported by grant 900-562-125 from the Netherlands Organization for Scientific Research (NWO).

References

1 Allen SJ, Pierro A, Cope L, Macleod A, Howard CV, Van Velzen D, Lloyd DA, Davidson DC. Glutamine-supplemented parenteral nutrition in a child with short bowel syndrome. J Pediatr Gastroenterol Nutr 1993; 17: 329-332

2 Barrett EJ, Revkin JH, Young LH, Zarel BL, Jacob R, Geliand RA. An isotopic methud for measurement of muscle protein synthesis and degradation in vivo. Bioch J 1987: 245: 223-228.

3 Bierhoff ML. Levine GM. Luminal and metabolic regulation of jejunal amino acid absorption in the rat. Gastroenterology 1988; 95: 63-68.

4 Biolo $G$, Chinkes D, Zhang $X J$, Wolfe RR. A new model to determine in vivo the relationship between amino acid transmembrane transport and protein kinetics in muscle. J Parenter Enter Nutr 1992; 16: 305-315.

5 Biolo G, Flemming RYD, Maggi SP, Wolfe RR. Transmembrane transport and intracellular kinetics of amino acids in human skeletal muscle 1995. Am J Physiol 1995; 31: E75-E84.

6 Biolo G. Maggi SP, Williams BD, Tipton KD, Wolfe RR. Increased rates of muscle protein tumover and amino acid transport after resistance exercise in humans. Am J Physiol 1995; 31: E514-E520.

7 Biolo G, Zhang XJ. Wolfe RR. Role of membrane transport in interorgan amino acid flow between muscle and small intestine. Metabolism 1995; 44 6: 719-724.

8 Blommaart PJE. Regulation of hepatic protein tumover in the perinatal period of the rat. Thesis, 1994: Univ of Amsterdam, The Netherlands.

9 Chien PFW, Smith K, Watt PW, Schrimgeour CM, Taylor DJ, Rennie MJ. Protein turnover in the human fetus studied at term using stable isotope tracer amino acids. Am J Physiol 1993; 265: E31. E35.

10 Chinkes DL, Zhang XJ, Romijn JA, Sakurai Y. Wolfe RR. Measurement of pyruvate and lactate kinetics across the hindlimb and gut in anesthesized dogs. Am J Physiol 1994: 267: E.174-E182. 
Collarini EJ, Oxender DL. Mechaniswms of transport of amino acids across membranes. Ann Rev Nutr 1987; $7: 75-90$.

12 Dejing CHC. Deutz NEP, Soeters PB. Renal ammonia and glutamine metabolism during liver insufficiency-induced hyperammonemia in the rath. J Clin Invest 1993; 92: 2834-2840.

13 Dejong CHC, Kampman MT, Deutz. NEP, Soeters PB. Altered glutamine metabolism in rat portal drained viscera and hindquarter during hyperammonemia. Gastroenterol 1992; 102: 936-948.

14 Espat NJ, Copeland EM, Souba WW. Influence of fasting on glutamine transport in rat liver. J Parenter Enter Nutr 1993; 7: 493-500.

15 Felig P. Owen OE, Wahren J, Cahill GF Jr. Amino acid metabolism during prolonged starvation. J Clin Invest 1969; 48: 584-594.

16 Grunau JA, Swiader JM. Chromatography of 99 amino acids in other ninhydrinreactive compounds in the pickering lithium gradient system. J Chromatogr 1992; 594: 165-171.

17 Guide for the care and use of laboratory animals 1986; EEC publication 86/609.

18 Hindmarsh JT, Kilby D, Ross B, Wiseman G. Further studies on intestinal active transport during semistarvation. J Physiol 1987:188: 207-218.

19 Ju JS, Nasset ES. Changes in total nitrogen content of some abdominal viscera in fasting and realimentalion. J Nutr 1959; 68: 633-645.

20 Kelley DS, Potter VR. Regulation of amino acid transport systems by amino acid depletion and supplementation in monolayer cultures of rat hepatocytes. J Biol Chem 1978; 253: 9009-9017.

21 Kilberg MS. Amino acid transport in isolated rat hepatocytes. J Membrane Biol 1982; 69: 1-12.

22 Kimura RE, LaPine TR, Johnston J, llich JZ. The effect of fasting on rat portal venous and aortic blood glucose, lactate, alanine, and glutamine. Ped Res. 1988; 23: 241-244.

23 Lardeux BR, Mortimore GE. Amino acid and hormonal control of macromolecular tumover in pertused rat liver. J Biol Chem 1987; 262: 14514-14519.

24 Leverve XM, Caro LHP, Plomp PJAM, Meijer AJ. Control of proteolysis in perifused rat hepatocytes. FEBS Lett 1987; 2:19: 455-458:

25 McNulan MA, Tomkins AM, Garlick PJ. The effect of starvation on the rate of protein synthesis in rat liver and small intestine. Biochem J 1979:178: 373-379.

Meikle AW. Klain GJ. Effect of fasting and fasting-refeeding on conversion of leucine into $\mathrm{CO} 2$ and lipids in rats. Am J Physiol 1972; 222:1246-1250.

27 Melby EC, Altman NH ed. Handbook of laboratory animal science vol II 1974; CRC PRESS, Inc, Cleveland Ohio, USA.

28 Moreno $A$, Lobaton CD. Oxender DL. Regulation of almino acid transport system $L$ by amino acid availability in CHO-K1 cells. A special role for leucine. Biochen Biophys Acta 1985; 819: 27'1-274.

Mortimore GE, Poso AR. Intracellular protein catabolism ancl its control during nutrient deprivation and supply. Ann Rev Nutr 1987; 7: 539-564.

30 Mortimore GE, Lardeux BR, Adams. CE. Regulation of microautophagy and basal protein turnover in. rat liver. J Biol Chem 1988; 263: 2506-2512.

31 Mortimore GE, Wert JJ, Adams CE. Modulation of the amino acid control of hepatic protein degradation by caloric deprivation. J Biol Chem 1988; 263: 19545-19551.

32 Newsholme EA. Substrate cycles in metabolic regulation and in heat generation. Biochem Soc Symp 1976; 41: 61-109.

33 Norusis MJ ed. SPSS/PC+ V4.0 BASE MANUAL for the IBM PCXTIAT and PS/2. 1989; SPSS Inc, Chicago, USA

34 Remesy C. Demigne C. Changes, in availability of glucogenic and ketogenic substrates and liver metabolism in fed and starved rats. Ann Nutr Metab 1983; 27: 57-70.

35 Salter M, Knowles RG, Pogson Cl. Transport of the aromatic amino acids into isolated rat liver cells. Biochem J 1986; 233: 499-506. 
36 Siw Eriksson L, Olsson M, Bjorkman O. Splanchnic metabolism of amino acids in healthy subjects: effect of 60 hours of fasting. Metabol 1988; 37: 1159-1162.

37 Souba WW, Smith RJ, Wilmore DW. Glutamine metabolism by the intestinal tract. JPEN 1985; 9 : 608-617.

38 Souba $\mathbf{W W}$, Strebel FR, Bull JM, Copeland EM, Teagtmeyer $\mathrm{H}$, Cleary $\mathrm{K}$. Interorgan glutamine metabolism in the tumor-bearing rat. J Surg Res 1988; 44: 720-726.

39 Souba WW, Pacitti AJ. How amino acids get into cells: Mechanisms, models, menus and mediators. J Parenter Enter Nutr 1992; 16: 569-578.

40 Steiner M, Bourges HR, Freedman LS, Gray SJ. Effect of starvation on the tissue composition of the small intestine in the rat. Am J Physiol 1968; 215: 75-77.

41 Tourian A, Goddard J, Puck TT. Phenylalanine hydroxylaseactivity in mammalian cells. J Celi Physiol 1969; 73: 159-170.

42. Van Eijk HMH, Rooyackers DR, Deutz NEP. Rapid routine determination of amino acids in plasma by high-performance liquid chromatography with a 2-3 um Spherisorb ODS II column. J Chromatography 1993; 620: 143-148.

43 Ward FW. Mortimore GE. Compartmentation of intracellular amino acids in rat liver. J Biol. Chem. 1978; 253:3581-3587.

44 Wolfe RR. Radioactive and stable isotope tracers in biomedicine. Principles and practice of kinetic analysis 1992; Wiley-Liss, New York, U.S.A. pp 397-398. 


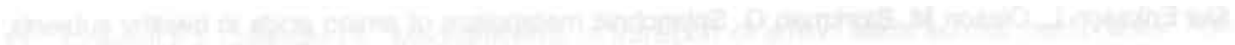

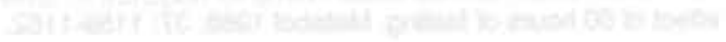

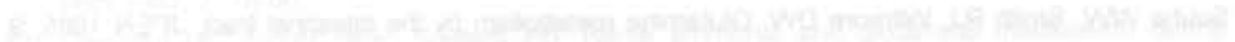
-

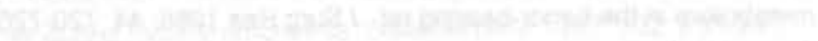

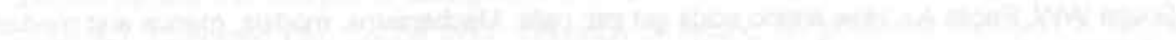

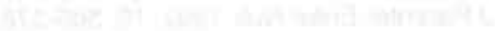
-

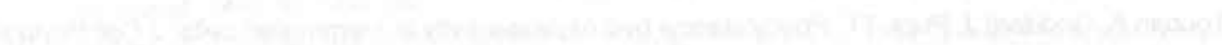




\title{
INCREASED WHOLE BODY PROTEIN AND GLUTAMINE TURNOVER \\ IN ADVANCED CANCER IS NOT MATCHED BY AN INCREASED MUSCLE PROTEIN AND GLUTAMINE TURNOVER
}

\author{
1. de Blaauw, N.E.P. Deutz, M.F. von Meyenfeldt \\ Submitted
}

\begin{abstract}
In the progress of cancer major disturbances in protein and glutamine metabolism have been observed. Muscle is the major protein pool and glutamine source in the body. Aim of this study was to investigate whether changes in whole body protein and glutamine turnover, induced by cancer, are matched by similar changes in regional muscle metabolism.

A MCA sarcoma was implanted subcutaneously in female Lewis rats. Rats were studied bearing small (5-15\% of body weight) or large (15-30\% of body weight) tumor loads and compared with sham implanted free fed and pairfed controls. Body composition was determined by the distribution of an i.p. bolus of ${ }^{3} \mathrm{H}_{2} \mathrm{O}$. Under anesthesia a primed constant infusion of $L-\left[2,6-{ }^{3} \mathrm{H}\right]$ phenylalanine and $\mathrm{L}$ $\left[3,4-{ }^{3} \mathrm{H}\right]$ glutamine was given and at steady state, whole body, hindquarter muscle and tumor protein and glutamine turnover were calculated using compartment modeling.

No anorexia occurred and a small decrease in host carcass weight was observed mainly by decreased fat mass. Whole body protein turnover increased from $115 \pm 14$ ( $\mathrm{nmol} \times 100 \mathrm{gr}$. body weight ${ }^{-1} \times \mathrm{min}^{-1}$ ) in free fed control rats to $239 \pm 29$ in the large tumor bearing rats. Net tumor protein synthesis accounted for $28 \pm 1$ and $49 \pm 1$ $\mathrm{nmol} \times 100 \mathrm{gr}$. body weight ${ }^{-1} \times \mathrm{min}^{-1}$. Muscle protein turnover increased in the small tumor bearing group but decreased again in the large tumor bearing rats. Whole body glutamine turnover remained unchanged in the small tumor bearing animals (2481 \pm 248 and $1996 \pm 268 \mathrm{nmol} \times 100 \mathrm{gr}$. body weight ${ }^{-1} \times$ min $^{-1}$ in control and small tumor bearing rats, respectively) and increased by $25 \%$ in the large tumor bearing animals. In contrast, muscle glutamine turnover more than doubled in the small tumor bearing group but returned to control values in the large tumor bearing animals.
\end{abstract}


The current study shows that in the presence of a small tumor whole body protein turnover increases and that this was in part related to protein turnover of the tumor. Muscle protein breakdown increased in these rats with a concomitant increase in glutamine production from the hindquarter. In animals bearing larger tumors whole body glutamine turnover increased. This increase, however, was only for a small part caused by tumor metabolism. Muscle glutamine turnover even decreased. Therefore, the increase in whole body glutamine turnover appears to be caused by increased turnover in visceral organs.

Introduction

Glutamine, a nonessential amino acid, is the most abundant free amino acid in the body (1). In case of severe illness, e.g. trauma and sepsis, glutamine pools become depleted $(2,3)$. Recent studies suggest that glutamine supplementation in depleted patients is of benefit to the functioning of vital organs thereby improving clinical outcome (4-6). It has been hypothesized that one of the pathophysiological mechanisms of protein catabolism may be that under specific conditions the amount of glutamine needed becomes greater than the body can produce $(3,7)$. Glutamine thus becomes "conditionally" essential.

The major source for glutamine production is skeletal muscle. Muscle contains approximately half of the free amino acid pool and this amino acid pool consists for more than $60 \%$ of glutamine (8). In muscle, glutamine is produced from protein breakdown and from ammonia and glutamate (9). It serves as a non-toxic nitrogen shuttle to carry nitrogen from peripheral tissue to gut and liver (10). Gut and liver can hydrolyze the terminal amide group of glutamine and use the remaining $\alpha$-amino group for the production of various amino acids or use the carbon skeleton as energy source (11). The liver can also use the carbon skeleton for gluconeogenesis (11).

During growth of a malignant tumor, interorgan glutamine metabolism becomes disturbed. This has been related to the development of cancer cachexia (11). Glutamine consumption of tumor cells $(12,13)$ and activation of the immune system (14) have been suggested to lead to decreased arterial glutamine concentrations. These studies, however, have also shown that although glutamine production from hindquarter muscle increases during tumor growth, arterial glutamine concentrations decrease (15). It has therefore been suggested that the increased glutamine release by muscle was insufficient and that this may be one of the regulating factors of protein catabolism in other organs typical of cancer cachexia.

To test this hypothesis we stoichometrically compared in vivo whole body glutamine turnover with the actual in vivo glutamine turnover of muscle and tumor tissue in a well established cancer model. In addition, whole body, muscle and tumor 
protein turnover were determined to relate changes in glutamine metabolism to protein catabolism.

\section{Materials and mothods}

\section{Animals}

After an adaptation period of 3 days, female Lewis rats (200-225 g. Centralized Animal Facilities, University of Limburg, Maastricht, NL) were individually housed in metabolic cages to monitor body weight and food intake. Rats were given standard laboratory rat chow (SRMA 1210, Hopefarms, Woerden, NL) and subjected to standard 12 hour light-dark cycie periods (7:30 A.M. to 7:30 P.M.) with room temperature maintained at $25^{\circ} \mathrm{C}$ The experiments were performed in accordance with the recommendations of the Guide for the Care and Use of Laboratory Animals (16) and approved by the Ethical Committee of Animal Research of the University of Limburg.

\section{Tumor and study groups}

The tumor was induced by injecting $10 \mathrm{mg}$ methylcholanthrene (MCA, Sigma W6501) subcutaneously (17). Afterwards, the tumor was maintained in vivo by serially transplanting tissue suspensions through a $18 \mathrm{G}$ needle. MCA tumors are often used in metabolic studies in Fisher 344 rats $(12,15,18)$ and are known for their rapid growth, invasion of local tissue and absence of metastatic potential (19). Small tumor bearing rats (ST) were studied when the tumor was $5-15 \%$ of the host body weight, large tumor bearing rats (LT) when the tumor was $15-30 \%$ of the host body weight. To avoid effects of time (e.g. duration of stay in metabolic cages), tumor tissue was transplanted bilateral on the back in the ST group, whereas it was quadruple implanted in the LT group. Control rats were sham implanted with saline. Tumor growth was monitored by measuring two orthogonal dimensions and by calculating the volume assuming the tumor to be a prolate spheroid (20). Although a pilot study indicated that food intake remained unchanged in tumor bearing rats. studies by others have repeatedly shown that MCA tumors induce anorexia when the tumor becomes large $(19,21)$. We therefore included a free fed and pairfed control group.

\section{Experimental procedures}

In a first experiment changes in body composition were determined. Postabsorptive rats $(n=30)$ were given an intraperitoneal bolus of ${ }^{3} \mathrm{H}_{2} \mathrm{O}$ (Amersham, $\mathrm{UK}, 0.1 \mu \mathrm{Ci} / \mathrm{ml}, 1 \mathrm{ml} / 100 \mathrm{gr}$. body weight). After 120 minutes blood was sampled from the orbital plexus. Plasma ${ }^{3} \mathrm{H}_{2} \mathrm{O}$ was determined as described previously (22). The distribution volume of ${ }^{3} \mathrm{H}_{2} \mathrm{O}$ (Total Body Water, TBW) was computed for each rat 
as the ratio between the dose injected and the activity (dpm/ $\mathrm{ml}$ plasma water) of ${ }^{3} \mathrm{H}_{2} \mathrm{O}$ at steady state. Lean body mass (LBM) of carcass and tumor was calculated from TBW divided by 0.83 (23-25). Fat free mass was determined by subtracting LBM from total body weight. Subtracting tumor weight from LBM will give an estimation of carcass lean body mass.

In a second experiment protein and glutamine metabolism were studied in free fed control, pairfed control, small tumor bearing and large tumor bearing rats $(n=40)$ as described previously $(26,27$, chapter $2,3,4)$. In brief, postabsorptive, under ether anesthesia and at constant body temperature, a laparotomy was performed. The right renal vein, the inferior caval vein and the aorta were cannulated with Silastic tube $(0.051 \mathrm{~cm}$ inner diameter, 0.094 outer diameter). The right carotid artery was catheterized with a PE canula $(0.051 \mathrm{~cm} \mathrm{ID}, 0.094 \mathrm{~cm}$ OD). For flow measurements, the indicator dilution method with para-aminohippuric acid (PAH) was used. A primed constant infusion was givern in the distal aorta just above the bifurcation. The priming dose was $0.15 \mathrm{ml} / 100 \mathrm{gr}$. body weight $(50 \mathrm{mM})$ and the infusion rate was $0.75 \mathrm{ml} \times 100 \mathrm{gr}$. body weight ${ }^{-1} \times \mathrm{h}^{-1}(5 \mathrm{mM})$. To study whole body and hindquarter muscle protein and glutamine turnover, a primed constant infusion of L-[2,6${ }^{3} \mathrm{H}$ ]phenylalanine (Sigma P 6053, St. Louis, USA) and L-[3,4- $\left.{ }^{3} \mathrm{H}\right]$ glutamine (NEN, NET 551, Groningen, The Netherlands) was given in the renal vein (priming dose: 1 $\mu \mathrm{Cl} / 100 \mathrm{gr}$. bw; infusion rate: $1 \mu \mathrm{Ci} \times 100 \mathrm{gr}$. $\left.\mathrm{bw}^{-1} \times \mathrm{min}^{-1}\right)$. The time to reach isotopic steady state conditions was first determined in a pilot study.

\section{Sampling procedure}

Blood (1.5 ml per catheter) was simultaneously sampled after $\mathbf{4 0}$ minutes infusion from the inferior caval vein and carotid artery at a rate of approximately $500 \mu \mathrm{l} / \mathrm{min}$. This is the minimal infusion period previously shown to be necessary to reach isotopic steady state conditions $(28,29$, chapter 3,4$))$. All blood was collected in heparinized cups (Lithium-Heparin, CB100, Sarstedt, FRG) on ice. Hereafter, the right gastrocnemius muscle was dissected free, directly freeze-clamped, put in liquid nitrogen and stored at $-80^{\circ} \mathrm{C}$ until further analysis. For PAH determinations, $50 \mu \mathrm{l}$ heparinized blood was added to $500 \mu \mathrm{I} \mathrm{TCAA} \mathrm{(10 \%} \mathrm{w/v,} \mathrm{Merck} \mathrm{807.} \mathrm{Darmstadt,} \mathrm{FRG),}$ vortexed and centrifuged at $8,900 \mathrm{~g}$ at $4^{\circ} \mathrm{C}$. The supernatant was frozen in liquid nitrogen and stored at $-80^{\circ} \mathrm{C}$ until further analysis. For hematocrit determinations a micro hematocrit tube was filled with heparinized blood and centrifuged at $10,000 \mathrm{~g}$ at room temperature. Hematocrit was read with a Micro Hematocrit Reader (Hawksley Ltd, UK). Plasma was obtained by whole blood centrifugation at $8.900 \mathrm{~g}$ at $4^{\circ} \mathrm{C}$ for 5 minutes. For ammonia determinations, $500 \mu$ plasma was vortexed with 50 $\mu \mathrm{l}$ TCA $50 \%$, put into liquid nitrogen and stored at $-80^{\circ} \mathrm{C}$. For plasma amino acid 
determinations $300 \mu \mathrm{l}$ plasma was added to $12 \mathrm{mg}$ 5-sulfosalicylic acid (Brunschwig, 10346, Amsterdam, NL) for deproteinization, vortexed, frozen in liquid nitrogen and stored at $-80^{\circ} \mathrm{C}$.

\section{Biochemical analysis}

Plasma ammonia and PAH were determined spectrophotometrically on a Cobas Mira S (Roche Diagnostica, Hoffman-La Roche, Basel, Switzerland) by standard enzymatic methods, using commercially available kits as described previously $(26,27)$. Standard plasma amino acids were determined by fully automated HPLC (30). To determine plasma phenylalanine, glutamine and tyrosine specific activity (SA), plasma was isolated on a cation exchange resin column as described previously (31). For the determination of tissue ammonia, polyamines, amino acid concentration and specific activity, tissue was pulverized using a mortar and pestle precooled in liquid nitrogen. The tissue was further homogenized and deproteinized in a Mini-Beadbeater (Biospec products, Bartlesville USA). Approximately $100 \mathrm{mg}$ tissue was added to $400 \mu \mathrm{l} \mathrm{SSA} 5 \%$, with $300 \mathrm{gr}$. glass beads (diameter $1 \mathrm{~mm}$, Biospeck Products) and beaten for 30 seconds. The homogenate was centrifuged at $4^{\circ} \mathrm{C}$ at $11,000 \mathrm{~g}$ and the supernatant frozen in liquid nitrogen and stored at $-80^{\circ} \mathrm{C}$ until further determinations. To determine tissue dry weight and water content approximately $200 \mathrm{mg}$ pulverized tissue was freeze dried for 24 hours in a Speedvac (SC200, Savant Instruments Inc., Farmingdale NY, USA) connected with a refrigerated condensation trap (type RT 400, Savant Instruments Inc.). Polyamine concentrations in the tumor were determined on HPLC as described previously (32). Phenylalanine content in tumor proteins were determined by gas phase hydrolysis of tumor proteins by $\mathrm{HCl}$ for 6 hours at $150^{\circ} \mathrm{C}$.

\section{Calculations}

Hindquarter plasma flow and substrate fluxes

Plasma flow across the hindquarter was calculated using PAH in the indicator dilution method described previously $(26,27)$. Substrate fluxes are calculated by multiplying the venous-arterial concentration differences with the mean hindquarter plasma flow of the group and are expressed in nmol $\times 100 \mathrm{~g}$ body weight ${ }^{-1} \times \mathrm{min}^{-1}$. A positive flux indicates net release, a negative flux reflects a net uptake. $\alpha$-Aminonitrogen ( $\alpha-\mathrm{AN}$ ) was calculated as the sum of the individual amino acids measured, excluding taurine and $\alpha$-amino butyric acid (30). Branched chain amino acids (BCAA) are the sum of valine, leucine and isoleucine. Tissue concentrations of amino acids 
are expressed in $\mu \mathrm{mol} / \mathrm{l}$ and derived by dividing tissue homogenate amino acid concentration ( $\mu \mathrm{mol} / \mathrm{kg}$ wet weight) by tissue water content.

\section{Glutamine and protein turnover}

Whole body glutamine and phenylalanine rate of appearance ( $R a)$ were calculated from the arterial dilution of the tracer amino acid at steady state (33, chapter 2) and is expressed in nmol $\times 100 \mathrm{gr}$. body weight ${ }^{-1} \times \mathrm{min}^{-1}$. The turnover of the essential amino acid phenylalanine is used to reflect whole body protein turnover. Hydroxylation (HDX) of phenylalanine can be calculated from the relative SA of phenylalanine and tyrosine and their relative content in whole body protein (33, chapter 2) and reflects, in steady state conditions, the oxidation rate of amino acids (33). In steady state whole body Ra equals whole body Rd and by subtracting HDX from whole body $R d$ phenylalanine whole body $R d$ used for protein synthesis $\left(R_{d_{\text {protein }}}\right.$ synthesis) is obtained. Glutamine, being a non-essential amino acid, can be produced by protein breakdown and, non-protein derived, by the transamidation of glutamate. Knowing the relative amino acid content of phenylalanine and glutamine in body proteins (34) makes it possible to calculate glutamine Ra derived from protein breakdown and non-protein derived glutamine Ra.

Hindquarter muscle phenylalanine and glutamine turnover are calculated from the arterial-venous dilution of the tracer amino acids across the hindquarter calculated in a two compartment model (35, chapter 2 ). This will give phenylalanine and glutamine Rate of Appearance (Ra) and Disappearance (Rd) across the hindquarter. Ra of phenylalanine reflects protein breakdown and Rd protein synthesis as the only fate of phenylalanine in muscle is protein $(33,35)$. Hindquarter $\mathrm{Ra}$ and $\mathrm{Rd}$ are expressed as $\mathrm{nmol} \times 100 \mathrm{gr}$. carcass weight ${ }^{-1} \times \mathrm{min}^{-1}$ because hindquarter mass is more related to carcass weight than total body weight (which exists for $0-30 \%$ of tumor mass). The hindquarter consists of several tissue compartments but muscle generally accounts for $80-90 \%$ of total hindquarter protein turnover (36). To relate the hindquarter muscle compartment with the whole body muscle compartment we considered that hindquarter muscle comprises approximately $50 \%$ of the total muscle pool of the body (37).

\section{Tumor protein and glutamine tumover}

Because no single artery and vein are present to measure glutarnine and protein turnover across the tumor only estimates can be made. Net protein synthesis of the tumor in both small tumor bearing animals (double implantation) and large turnor bearing animals (quadruple implantation) is calculated after a polynomal curve fit was made to characterize turnor growth (Fig. 1). The tumor growth rate 1 day prior to 
the measurements was determined per minute and multiplied by the amount of phenylalanine present in tumor proteins determined after hydrolysis of tumor tissue:

$$
1 \quad 100
$$

Protein synthesis $=\Delta \mathrm{T} \times$ Protphe $\times\left(\frac{}{24 \times 60}\right) \times\left(\frac{-}{\mathrm{bw}}\right)$

where $\Delta \mathrm{T}$ is increase in tumor mass from day $19-20$ (mg dry weight), Protphe the phenylalanine content in tumor protein ( $\mathrm{nmol} / \mathrm{mg}$ dry weight), bw the body weight. Tumor protein synthesis is thus expressed as nmol phenylalanine $\times 100 \mathrm{gr}$. body weight ${ }^{-1} \times$ min $^{-1}$. It is emphasized that this is net protein synthesis in the tumor and that the actual turnover of proteins in the tumor is higher.

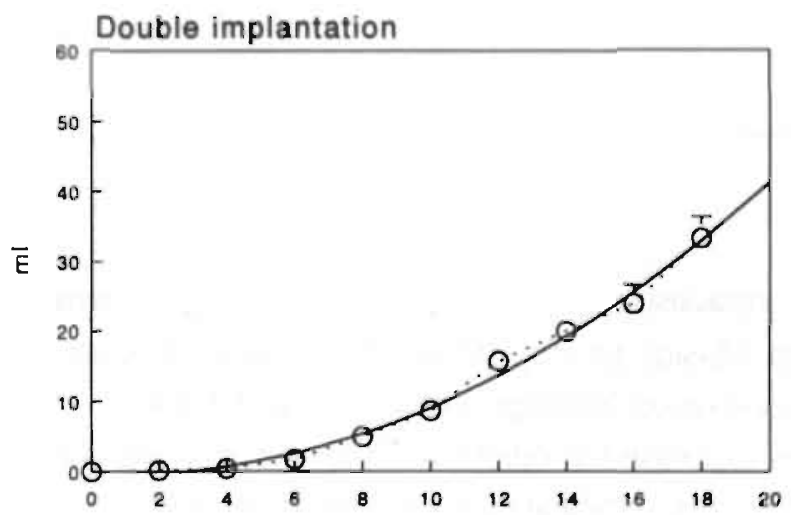

Figure 1. Growth curve of MCA tumor which was double implanted ( 0 ) in the small tumor bearing group (ST) or quadruple implanted $(\bullet)$ in the large tumor bearing group (LT). Linear least square regression analysis was used to determine the following coefficients in polynomal curves:

ST: $Y=0.65-1.3 X+0.46 X^{2}$, Square root of coefficient of determinations (Rval) = 0.99;

LT: $Y=1.10-2.16 X+0.76 X^{2}$, Rval $=$ 0.99 .

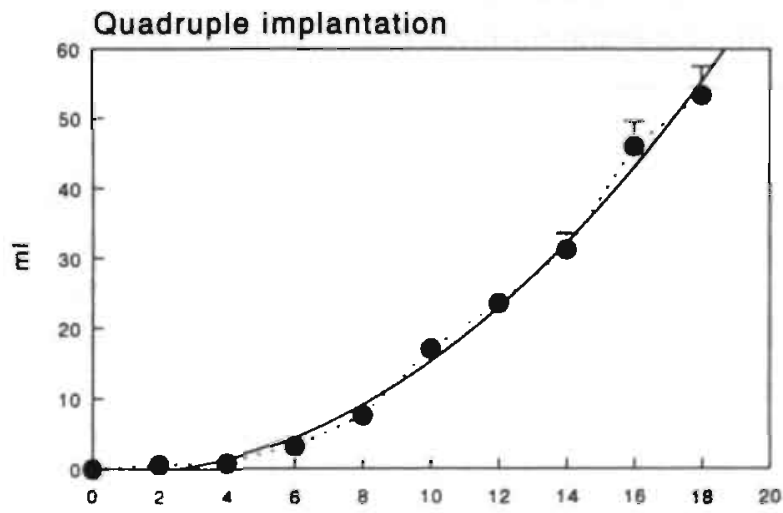


Upper and lower bounds of tumor glutamine turnover were determined. After starting the primed constant infusion of ${ }^{3} \mathrm{H}-\mathrm{GIn}$, the SA of intracellular glutamine can change by two possible mechanisms: 1 ) if the arterial plasma pool exchanges rapidly with the intracellular tumor pool an immediate steady state will be present of which the magnitude will depend on the arterial steady state SA and the (unlabeled) intracellular glutamine production; 2) if the exchange with the intracellular pool is relatively low, or not present at all, the intracellular SA will increase from zero at a slow rate during constant infusion as steady state is not obtained. In the first situation glutamine turnover can be determined by the relative change in the SA of glutamate, the product of intracellular glutamine breakdown, in relation to the intracellular SA of glutarnine. Glutamine turnover is thus calculated as the percentage of glutamine metabolized to glutamate. This is similar to the incorporation technique used to determine protein synthesis and will give the fractional turnover of glutamine. Multiplied with the total intracellular glutamine pool of the tumor, glutamine turnover is calculated in $\mathrm{nmol} / \mathrm{min}$. In formula:

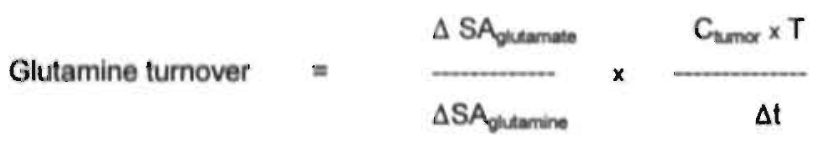

$\Delta \mathrm{SA}_{\text {givtamate. glutamine }}$ are increases in intracellular tumor specific activity of glutamate and glutamine (dpm/nmol) during the infusion period, $\Delta t$ the infusion time (minutes), $\mathrm{C}_{\text {tumor }}$ the intracellular glutamine concentration (nmol/gr. wet weight) and $\mathrm{T}$ the tumor mass in gram. Glutamine turnover is expressed in $\mathrm{nmol} / \mathrm{min}$. However, this will only be true if the intracellular glutamine SA was immediately almost similar as the activity measured at the end of the experiment. Glutamine turnover thus underestimates the actual turnover and the calculated value can be considered a lower bound of glutamine turnover in the tumor.

If the second mechanism is true, the SA of intracellular ${ }^{3} \mathrm{H}-\mathrm{G}$ In starts at zero and rises linearly during the experiment depending on the relative glutamine turnover and the constant arterial steady state SA. The fractional turnover can thus be determined by dividing the ratio of arterial and intracellular $\mathrm{SA}$ of ${ }^{3} \mathrm{H}-\mathrm{Gin}$ by the infusion time and multiplying this with the total intracellular glutamine pool. In formula:

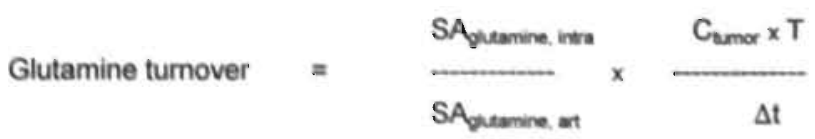


$\triangle \mathrm{SA}_{\text {glutamine, an }}$ is the increase in arterial glutamine $\mathrm{SA}$ at steady state $(\mathrm{dpm} / \mathrm{nmol})$ and $\mathrm{SA}_{\text {glutamine, intra }}$ the intracellular glutamine $\mathrm{SA}$ (dpm/nmol). Glutamine turnover is thus calculated as uptake by tumor tissue from the arterial blood and the turnover calculated in this manner can be considered an upper bound of intracellular glutamine turnover of the tumor.

\section{Statistical analysis}

Results are presented as mean I SEM. Oneway ANOVA was used to test significance. Individual group comparison was performed by post hoc testing with Student-Newman-Keuls. Significance from zero was tested by the Wilcoxon test. Significance was considered present at $p<0.05$. Data were analyzed using the Statistical Package for Social Sciences (SPSS, (38)).

\section{Results}

Food intake and body composition

Food intake of small and large tumor bearing rats did not decrease during the study period and was not different from free fed or pairfed control rats (Fig. 2). Carcass weight (total body weight minus tumor weight) were equal in all three groups (Table 1). Fat mass was reduced in large tumor bearing rats.

\section{Arterial concentrations}

Arterial ammonia (Table 2) was not significantly different in both tumor bearing groups. Glutamine concentrations decreased with increasing tumor load whereas glutamate concentrations remained unchanged. The concentration of alanine, phenylalanine, branched chain amino acids and total amino acid concentration increased in the small tumor bearing animal. Alanine and total arterial amino acid concentrations were also increased in large tumor bearing animals.

Whole body protein and glutamine tumover

In a pilot experiment steady state conditions were determined. Steady state conditions were present after 30 minutes infusion of ${ }^{3} \mathrm{H}$-glutamine and ${ }^{3} \mathrm{H}$ phenylalanine (Fig. 3). During the infusion of ${ }^{3} \mathrm{H}$-phenylalanine, steady state conditions were also achieved for ${ }^{3} \mathrm{H}$-tyrosine. For further studies a minimal infusion time of 40 minutes was employed. 

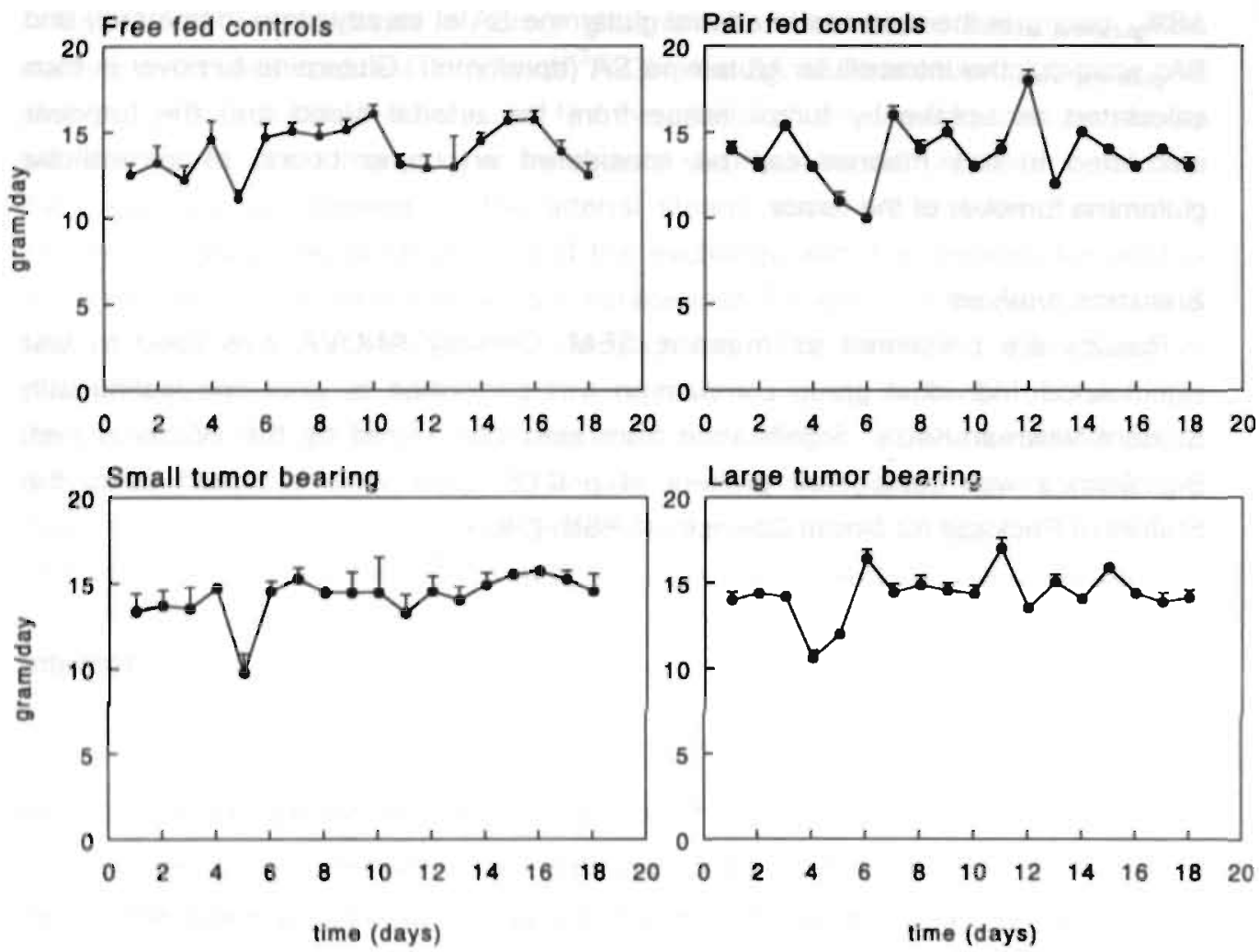

Figure 2. Food intake of free fed control (upper left), pairfed control (upper right), small tumor bearing (lower left) and large tumor bearing (lower right) rats. No significant changes in food intake between different groups.

Table 1. General characteristics of control and tumor bearing rats of the first experiment. Values are mean \pm SEM (grams). Statistical analysis by Oneway ANOVA with post hoc testing by StudentNewman-Keuls: " $p<0.05$ versus free fed control group; " $p<0.05$ versus small tumor bearing group.

FF control

\section{Body composition}

Body weight

Tumor weight

$\%$ of bw

Carcass weight

FFM carcass

Fat mass carcass

$190 \pm 3$
-
$190 \pm 3$
$159 \pm 2$
$30 \pm 2$

Small tumor

Large tumor

$\begin{array}{rll}196 & \pm & 5 \\ 16 & \pm & 2 \\ 8 & \pm & 1 \\ 181 & \pm & 5 \\ 159 & \pm & 3 \\ 26 & \pm & 3\end{array}$

$\begin{array}{rll}226 & \pm & 5 \\ 43 & \pm & 3 \\ 16 & \pm & 1 \\ 184 & \pm & 4 \\ 166 & \pm & 4 \\ 18 & \pm & 2\end{array}$


Table 2. Arterial concentrations of ammonia and amino acids. Values are mean \pm SEM ( $\mu \mathrm{mol} /$ ). Statistical analysis by Oneway ANOVA with post hoc testing by Student-Newman-Keuls: "p<0.05 versus free fed control group: " $p<0.05$ versus pairfed control group; $" \mathrm{p}<0.05$ versus small tumor bearing group.

\begin{tabular}{|c|c|c|c|c|c|c|c|c|}
\hline \multirow[b]{2}{*}{ Ammonia } & FF control & PF control & \multicolumn{3}{|c|}{ Small tumor } & \multicolumn{3}{|c|}{ Large tumor } \\
\hline & $186 \pm 23$ & $204 \pm 13$ & $232 \pm$ & 35 & & 205 & \pm & 17 \\
\hline Glutamine & $643 \pm 13$ & $642 \pm 33$ & $605 \pm$ & 24 & & 567 & \pm & $16^{*}$ \\
\hline Glutamate & $107 \pm 10$ & $99 \pm 2$ & $130 \pm$ & 23 & & 117 & \pm & 6 \\
\hline Alanine & $226 \pm 43$ & $221 \pm 23$ & $385 \pm$ & 63 & a & 464 & \pm & $58^{a, b}$ \\
\hline Phenylalanine & $53 \pm 2$ & $54 \pm 1$ & $75 \pm$ & 4 & $a b$ & 74 & \pm & $3^{a, b}$ \\
\hline BCAA & $271 \pm 18$ & $\pm \quad 9$ & $349 \pm$ & 23 & a.b.c & 293 & \pm & 13 \\
\hline$\alpha-\mathrm{AN}$ & $2655 \pm 72$ & $2489 \pm 32$ & $3253 \pm$ & 226 & $a . b$ & 3018 & \pm & $94^{\circ}$ \\
\hline
\end{tabular}

Table 3. Whole body phenylalanine and glutamine turnover. Values are mean \pm SEM and in $n m o l$ $100 \mathrm{gr}^{\text {. body weight }} \mathrm{x} \mathrm{min}^{-1}$. Statistical analysis by Oneway ANOVA with post hoc testing by Student Newman Keuls; " $p<0.05$ versus free fed control group; $" p<0.05$ versus pair fed control group; ${ }^{\circ} p<0.05$ versus small tumor bearing group.

\begin{tabular}{|c|c|c|c|c|c|c|c|c|c|}
\hline \multirow{2}{*}{ Phenylalanine } & \multicolumn{2}{|c|}{ FF control } & \multicolumn{2}{|c|}{ PF control } & \multicolumn{2}{|c|}{ Small tumor } & \multicolumn{3}{|c|}{ Large tumor } \\
\hline & & & & & & & & & \\
\hline Ra & 115 & \pm 14 & 132 & \pm 15 & 202 & \pm 50 & 239 & \pm & $29^{\circ}$ \\
\hline Hydroxylation & 18 & \pm 43 & 26 & \pm 5 & 37 & \pm 16 & 56 & \pm & $16^{\prime \prime}$ \\
\hline Rd (protein synthesis) & 98 & \pm 13 & 106 & \pm 15 & 176 & \pm 40 & 184 & \pm & $25{ }^{\prime \prime}$ \\
\hline \multicolumn{10}{|l|}{ Glutamine } \\
\hline $\mathrm{Ra}$ (total) & 2481 & \pm 248 & 2073 & \pm 264 & 1996 & \pm 268 & 3081 & 1 & $215^{a, b, c}$ \\
\hline Ra (protein derived) & 356 & \pm 29 & 323 & \pm 39 & 498 & \pm 122 & 586 & & 73 " \\
\hline Ra (non-protein derived) & d) 2125 & \pm 228 & 1750 & \pm 243 & 1498 & \pm 285 & 2528 & \pm & $177^{-a b . c}$ \\
\hline
\end{tabular}


groups. Phenylalanine and BCAA concentrations increased in both tumor bearing groups, whereas intracellular alanine concentration increased in the large tumor bearing rats. The total intracellular amino acid concentration was not significantly different between the groups.

Hindquarter plasma flow (Table 5) did not differ significantly between the groups although the mean values were higher in both tumor bearing groups. Ammonia efflux tended to increase in the small tumor bearing group but this did not become significant. The net release of glutamine, phenylalanine and the sum of all amino acids increased in the small tumor bearing group and decreased again in the large tumor bearing rats.

Hindquarter $\mathrm{Ra}$ and $\mathrm{Rd}$ were not significantly different between the groups (Fig.4, upper panel). Changes in Ra and Rdi between the groups are within the detection limits of the A-V dilution method to measure protein turnover rates as previously described by us (28). However, the difference between phenylalanine Ra and Rd increased in the small tumor bearing group indicating an increased net protein breakdown. In the large tumor bearing group the difference between $\mathrm{Ra}$ and $\mathrm{Rd}$ decreased to control values, indicating no net, measurable, protein breakdown.

Hindquarter glutamine $\mathrm{Ra}$ increased significantly compared to hindquarter $\mathrm{Rd}$ resulting in an increased net glutamine release in the small tumor bearing animals (Fig 4, lower panel).

Table 4. Gastrocnemius water content and amino acid concentrations. Values are mean \pm SEM and expressed as umol/. Statistical analysis by Oneway ANOVA with post hoc testing by Student-NewmanKeuls: " $p<0.05$ versus free fed control group; " $p<0.05$ versus pair fed control group.

\begin{tabular}{|c|c|c|c|c|c|c|c|c|}
\hline \multirow[b]{2}{*}{$\% \mathrm{H}_{2} \mathrm{O}$} & \multicolumn{2}{|c|}{ FF control } & \multicolumn{2}{|c|}{ PF control } & \multicolumn{2}{|c|}{ Small tumor } & \multicolumn{2}{|c|}{ Large tumor } \\
\hline & 74.0 & \pm 1.0 & 72.7 & \pm 1.0 & 74.5 & \pm 0.4 & 75.1 & \pm 0.4 \\
\hline Glutamine & 4617 & \pm 132 & 4949 & \pm 281 & 3484 & \pm 188 & 3882 & $\pm 357^{b}$ \\
\hline Glutamate & 691 & \pm 108 & 742 & \pm 84 & 537 & \pm 56 & 829 & \pm 137 \\
\hline Alanine & 965 & \pm 178 & 787 & \pm 58 & 1253 & \pm 135 & 1326 & $\pm 135^{\circ}$ \\
\hline Phenylalanine & 108 & \pm 6 & 106 & \pm 4 & 146 & $\pm 11 \cdot b$ & 152 & $\pm \quad 5^{a b}$ \\
\hline BCAA & 555 & \pm 78 & 418 & \pm 33 & 696 & $\pm 64^{\circ}$ & 663 & $\pm 42^{\circ}$ \\
\hline$\alpha-\mathrm{AN}$ & 24317 & \pm 588 & 23430 & \pm 736 & 21246 & \pm 757 & 21363 & \pm 1087 \\
\hline
\end{tabular}



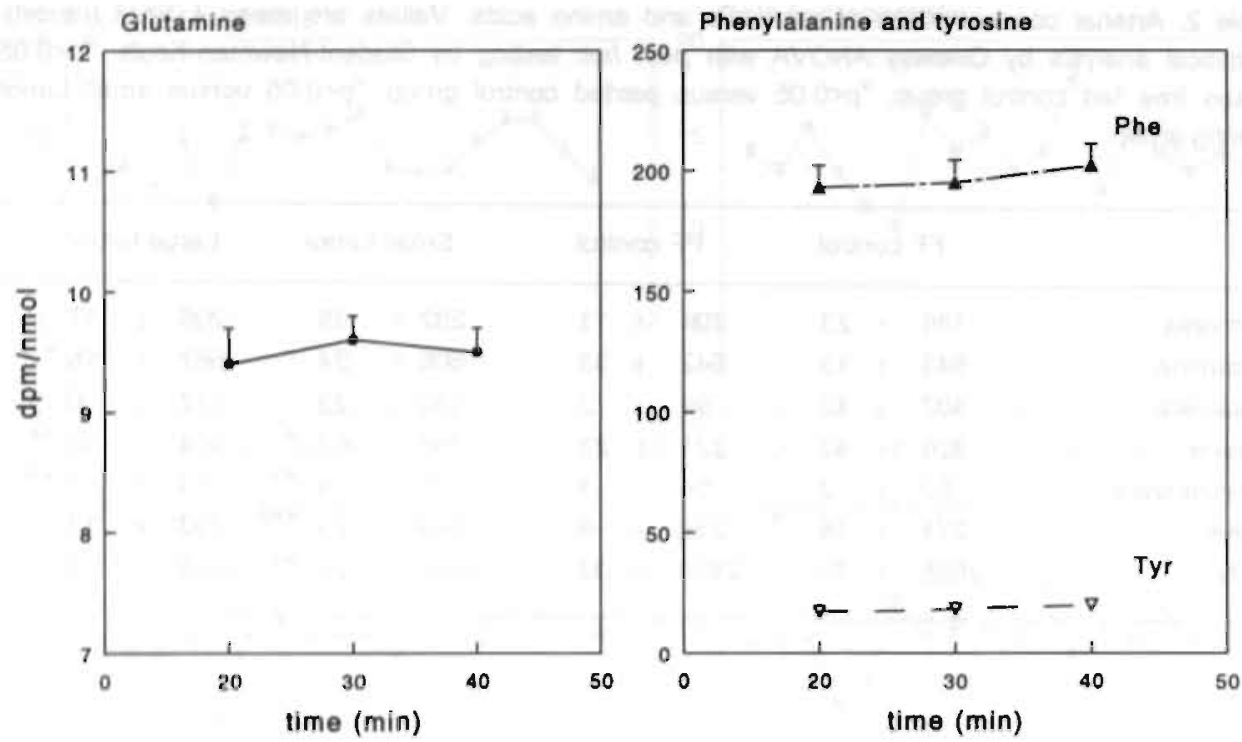

Figure 3. Arterial specific activities of amino acids after a primed constant infusion of ${ }^{3} \mathrm{H}$-glutamine and ${ }^{3} \mathrm{H}$-phenylalanine. Steady state conditions were reached within 30 minutes after the priming bolus was given. Note that the phenylalanine hydroxylation product ${ }^{3} \mathrm{H}$-tyrosine also reaches steady state conditions.

Whole body phenylalanine Ra (Table 3 ) increased in the small tumor bearing animals although this did not become significant. In the large tumor bearing animals whole body phenylalanine Ra increased. Hydroxylation and whole body protein synthesis rate ( $R d_{\text {protein synthesis }}$ ) were also increased in the large tumor bearing rats.

Whole body glutamine Ra remained unchanged in the small tumor bearing rats but increasecl by approximately $25 \%$ in the large tumor bearing group compared to the free fed controls. Compared to the pair fed controls the increase was approximately $48 \%$. In all groups most of the glutamine appearance rate was nonprotein derived. The increase in whole body glutamine turnover in large tumor bearing rats was also mostly non-protein derived.

\section{Hindquarter muscle metabolism}

Intracellular water of muscle (Table 4) remained unchanged. The intracellular concentration of glutamine was decreased to a similar extent in small and large tumor bearing rats. Intracellular glutamate was not significantly different between the 
In the large tumor bearing group glutamine Ra decreased to control values. However, glutamine Rd was reduced to zero resulting in a net efflux of glutamine from the hindquarter.

\section{Tumor growth and metabolism}

Intracellular water of tumor tissue was higher than of muscie but similar in small and large tumors (Table 6). Intracellular ammonia concentration increased in large tumors compared to small tumors. Intracellular glutamine concentrations in tumor tissue was much lower than in muscle whereas intracellular glutamate concentrations were higher than in muscle, indicating net consumption of glutamine and production of glutamate by tumor cells. Alanine concentrations were also remarkably high in tumor tissue compared to muscle tissue. High BCAA concentrations were also observed in tumor tissue. Glutamine, glutamate, alanine and total amino acid concentrations were decreased in the large tumors compared to the smaller tumors.

Between day 19 and 20 small tumors and large tumors increased by $3.7 \mathrm{ml}$ and $6.1 \mathrm{ml}$, respectively (Table 7 , Fig.1). Small tumors had an estimated protein synthesis rate of $28 \pm 0.4 \mathrm{nmol}$ phenylalanine $\times 100 \mathrm{gr}^{\text {. body weight }}{ }^{-1} \times$ min $^{-1}$ whereas large tumors had an approximate synthesis rate of $49 \pm 1.2 \mathrm{nmol}$ phenylalanine $x$ $100 \mathrm{gr}$. body weight ${ }^{-1} \times \mathrm{min}^{-1}$.

Table 6. Tumor ammonia and amino acid concentrations. Values are mean \pm SEM ( $\mu \mathrm{mol} / \mathrm{h})$. Statistical analysis between small and large tumors by Mann Whitney $U$ test: " $p<0.05,{ }^{b} p<0.01$.

\begin{tabular}{|c|c|c|c|c|c|c|}
\hline \multirow[b]{2}{*}{$\mathrm{H}_{2} \mathrm{O} \%$} & \multicolumn{3}{|c|}{ Small tumor } & \multicolumn{3}{|c|}{ Large tumor } \\
\hline & 86.0 & \pm & 1.1 & 89.7 & \pm & 0.5 \\
\hline Ammonia & 2298 & \pm & 320 & 2871 & \pm & 567 \\
\hline Glutamine & 2084 & \pm & 149 & 1516 & \pm & 99 \\
\hline Glutamate & 3870 & \pm & 235 & 2923 & \pm & 203 \\
\hline Alanine & 6540 & \pm & 445 & 4860 & \pm & 521 \\
\hline Phenylalanine & 192 & \pm & 12 & 196 & $t$ & 30 \\
\hline BCAA & 1347 & \pm & 106 & 1187 & \pm & 144 \\
\hline$\alpha-A N$ & 12837 & \pm & 811 & 11135 & \pm & 817 \\
\hline
\end{tabular}


Table 7. Calculated tumor protein and glutamine turnover. Values are mean \pm SEM. Protein tumover is calculated from the growth curve (Fig 1). Maximal glutamine turnover is determined by the arterial and intracellular glutamine SA ratio, the minimal tumover rate by the ratio of the intracellular SA of glutamine and glutamate. Statistical analysis between small and large tumors by Mann Whitney $U$ test: $p<0.05,{ }^{b} p<0.001$.

Small tumor

\section{Proteln turnover}

Tumor weight (gr.)

Tumor growth (ml/day)

Concentration (nmol Phe/mg dw)

Turnover Phe (nmol/100 gr.bw/min)
$26 \pm 3$ 3.7

$187 \pm 5$

$28 \pm 0.5$

$6.1 \pm 2.7$

$0.6 \pm 0.1$

$53 \pm 6$

$2.0 \pm 0.8$

$1016 \pm 295$

$471 \pm 14$

$0.51 \pm 0.01$

$296 \pm 87$

$132 \pm 39$
Large tumor
$52 \pm 4^{b}$ 6.1

$187 \pm 5$

$49 \pm 1.2$

\section{Glutemine turnover}

Glutarnate SA (dpm/nmol)

Glutarnine pool ( $\mu \mathrm{mol}$ )

Upper bound

Glutamine turnover (\%)

Glutarnine turnover (nmolimin)

Turnover (nmol/100 gr. bw/min)

\section{Lower bound}

Glutamine turnover (\%)

Glutamine turnover ( $\mathrm{nmol} / \mathrm{min}$ )

Turnover (nmol/100 gr. bw/min)

C $132 \pm 39$

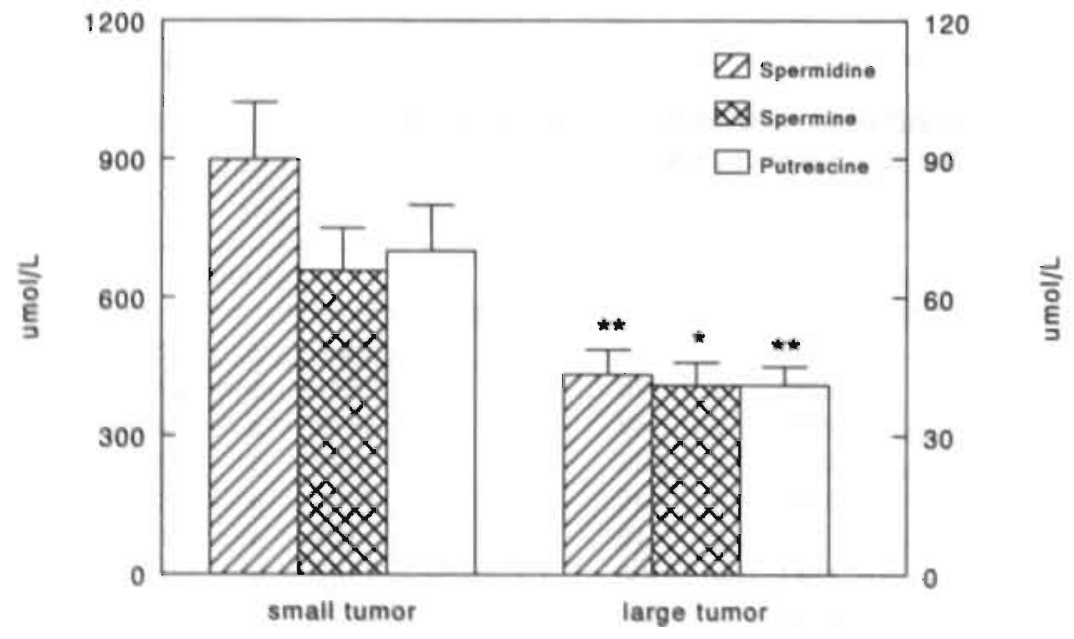

Figure 5. Intracellular polyamine concentrations in tumor tissue. Values are mean \pm SEM and expressed as $\mu \mathrm{mol} /$. Statistical analysis by Mann Whitney $U: " p<0.05,{ }^{*} p<0.01$. Right axis: spermine and spermidine, left axis: putrescine. 
Table 5. Hindquarter plasma flow and ammonia and amino acid fluxes. Values are mean \pm SEM. Flow in $\mathrm{ml} \times 100 \mathrm{~g}$ carcass weight $\mathrm{t}^{-1} \times \mathrm{min}^{-1}$, flux in $\mathrm{nmol} \times 100 \mathrm{gr}$. carcass weight $\mathrm{x} \mathrm{min}^{-1}$. A negative flux reflects net uptake and a positive flux reflects net release. Statistical analysis by Oneway ANOVA with post hoc individual group comparison by Student-Newman-Keuls: " $p<0.05$ versus free fed control group: "p<0.05 versus pair fed control group; ${ }^{c} p<0.05$ versus large tumor bearing group. Wilcoxon test: p $<0.05$, not significant from zero.

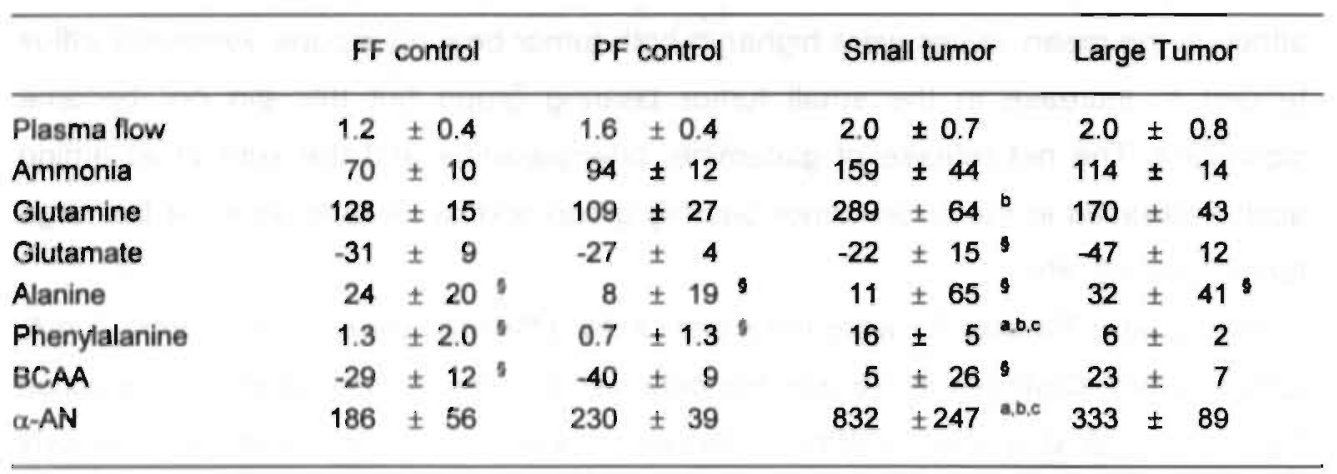
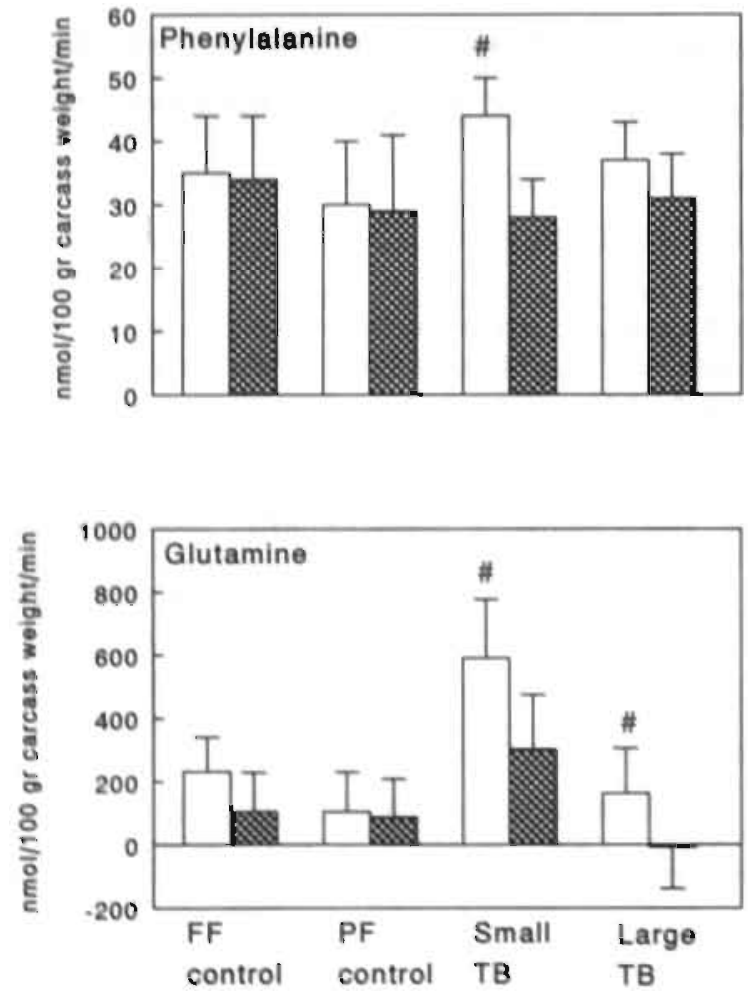

Figure 4. Hindquarter protein and glutamine turnover in control (free fed and pairfed). small tumor bearing and large turnor bearing rats. Data are mean $\pm S E M . \square R a,=R d$

Top: protein lurnciver expressed as $\mathrm{nmol}$ phenylalanine/100 $\mathrm{gr}$. carcass weight/min.

Bottum: glutarnine turnover expressed in nmol glutamine/ $100 \mathrm{gr}$. carcass weight/min.

Statistical Analysis between different groups by Oneway ANOVA: no significant changes. Mann Whitney $U$ for significant difference between $\mathrm{Ra}$ and $\mathrm{Rd}$ within group: $p<0.05$. 


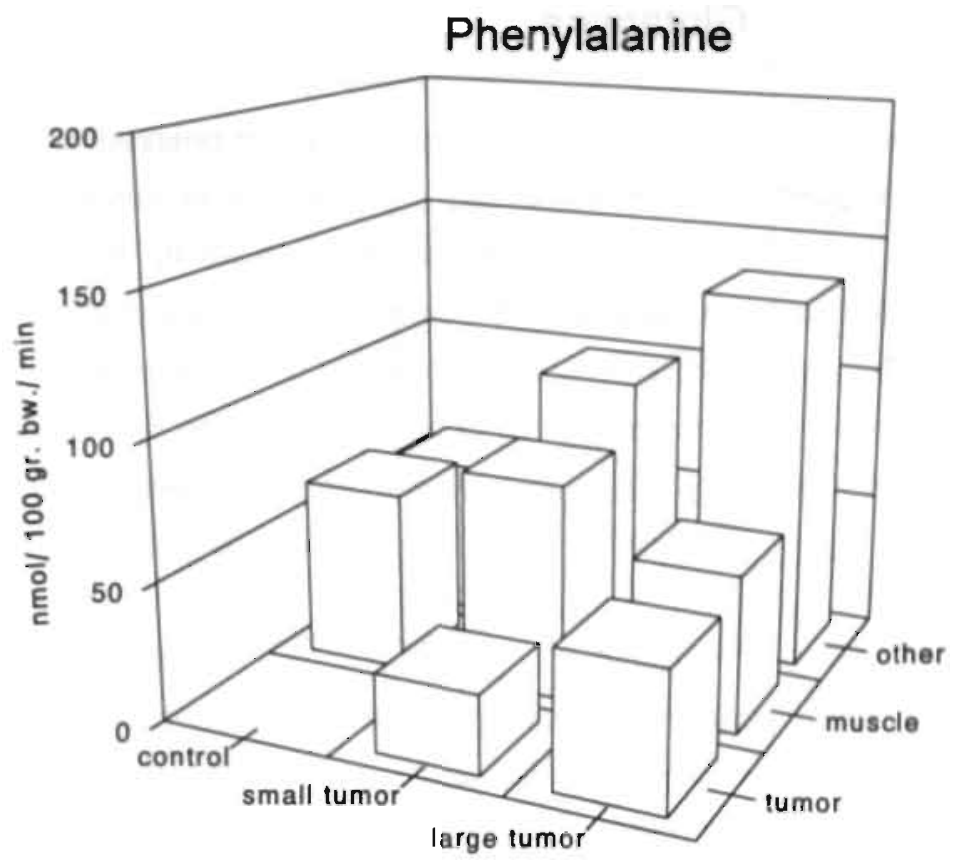

Figure 6A. Relative effects of small and large tumors on whole body protein turnover. Whole body protein tumover is subdivided in the turnover of three compartments, turnor, muscle and other. All values are in $\mathrm{nmol} \times 100 \mathrm{gr}$. body weight ${ }^{-1} \times$ min $^{-1}$. Whole body muscle compartment is calculated by assuming hindquarter muscle to be $50 \%$ of total muscle mass of the body $(6,54)$. Control values are the averages of the free fed and pairfed control groups. For further explanation see text results.

The upper bound of glutamine turnover in small tumors was $1016 \pm 295 \mathrm{nmol} / \mathrm{min}$ whereas the lower bound was $296 \pm 87 \mathrm{nmol} / \mathrm{min}$. Although large tumnors had twice the mass the upper and lower bounds were in the same range (upper bound: $779 \pm$ $196 \mathrm{nmol} / \mathrm{min}$, lower bound: $471 \pm 112 \mathrm{nmol} / \mathrm{min}$ ) suggesting that these tumors are metabolically relatively less active per gram tissue. This was confirmed by the intracellular polyamine concentrations. Polyamine concentrations are indicators for cellular proliferation and differentiation $(39,40)$. Putrescine, spermine and spermidine concentrations all decreased in the large tumors compared to the smaller ones (Fig. $5)$.

A summary of the contributions of tumor and muscle tissue to whole body protein and glutamine metabolism is given in Fig. 6A and 6B. For these calculations hindquarter muscle is assumed to be approximately $50 \%$ of the total body muscle mass and both muscle and tumor tumover rates are all adjusted to turnover rates per 


\section{Glutamine}

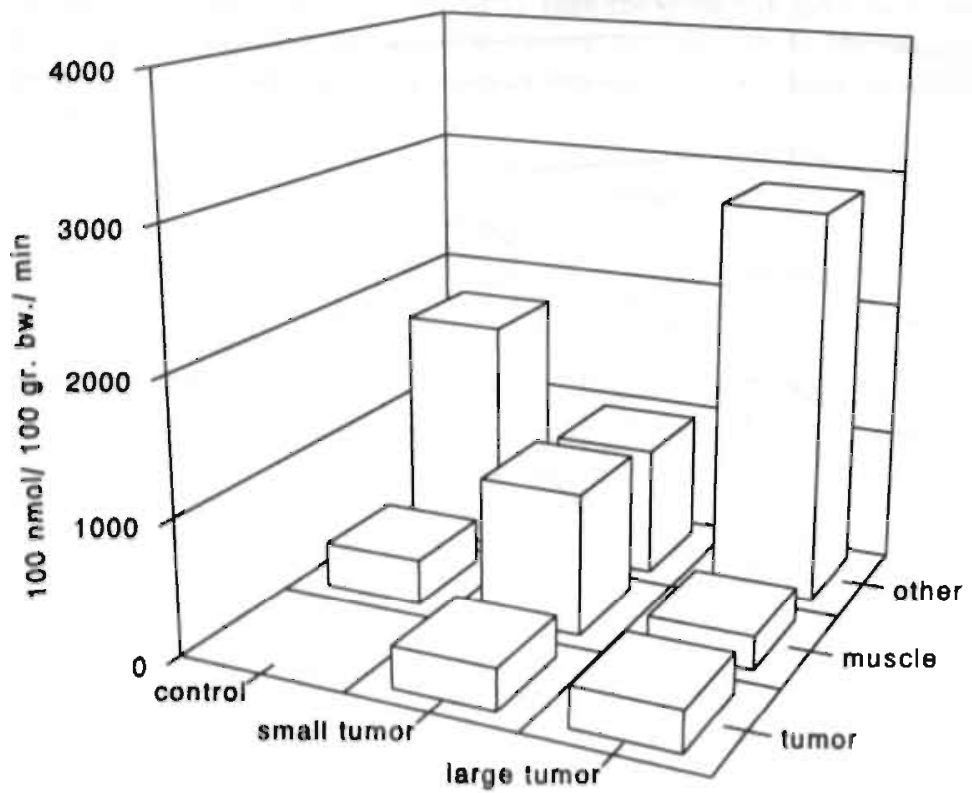

Figure 6B. Relative effects of small and large tumors on whole body glutamine tumover. Whole body glutamine turnover is subdivided in the turnover of three compartments, tumor, muscle and other. All values are in $\mathrm{nmol} \times 100 \mathrm{gr}$. body weight ${ }^{-1} \times$ min $^{-1}$. Whole body muscle compartment is calculated by assuming hindquarter muscle to be $50 \%$ of total muscle mass of the body $(6.54)$. Control values are the averages of the free fed and pairfed control groups. For further explanation see text results.

$100 \mathrm{gr}$. body weight. Control data are the average of free fed and pairfed data. Muscle tissue decreasingly contributes to whole body protein turnover of large tumor bearing rats (Fig. 6A). The contribution of non-muscle non-tumor tissue increased in small tumor bearing rats and increased further when the tumor became large. Tumor tissue protein synthesis determines $16 \%$ and $27 \%$ of whole body protein synthesis in small tumor bearing and large tumor bearing rats, respectively.

Changes in glutamine turnover are to a great extent similar (Fig. 6B). Muscle contributes approximately $16 \%$ to whole body turnover in control rats. Although whole body glutamine turnover remains the same in small tumor bearing rats (Table 3 ), the relative contribution of muscle increases to approximately $45 \%$. In large tumor bearing rats, when whole body glutamine turnover increased by $25-48 \%$ compared to free fed and pairfed controls (Table 3), the relative contribution of muscle decreased to $7 \%$ and other organs predominate whole body glutamine Ra. 
To understand the alterations in glutamine and protein metabolism observed in cancer, turnover studies were performed at whole body and at regional muscle levels. The rat MCA tumor model was used because this model has been used previously to study cancer metabolism related to anorexia and cachexia $(12,14)$. The tumor did not induce anorexia in our rats. Therefore, the metabolic changes observed can only be attributed to the presence of the tumor. However, as nutrient intake remained the same, nutrient delivery to, and metabolism of non-tumor tissues must have been changed.

\section{Protein metabolism}

Tumor bearing rats had increased whole body protein turnover rates, thus mimicking observations in other tumor bearing rat models $(41,42)$ and cancer patients $(43,44)$. However, the current study shows that changes in whole body protein turnover in animal models are in part caused by tumor protein turnover. In the current study net protein synthesis of the tumor was calculated. The actual turnover of tumor proteins is probably higher. An indication of the actual protein turnover can be derived from the intracellular specific activity of phenylalanine in tumor. This was approximately $2-3 \%$ of the arterial specific activity (data not shown). In muscle tissue this was approximately $8-10 \%$ of arterial specific activity. This indicates that the intracellular dilution of ${ }^{3} \mathrm{H}$-phenylalanine by protein breakdown at steady state was approxirnately 4 time higher than in muscle and that protein turnover is also higher than in muscle. However, for accurate measurements plasma flow across the tumor is needed.

In small tumor bearing rats protein turnover rates of non-tumor; non-muscle tissue increased and this increased further in the large tumor bearing animals. Organs responsible for the increased protein turnover in MCA tumor bearing rats are visceral organs like the liver, spleen and immune cells. These organs and cells are known to increase their protein synthesis rates due to the acute phase response $(21,45,46)$. In the large tumor bearing rats, part of the increased turnover of phenylalanine was due to an increased hydroxylation rate indicating increased amino acid oxidation in these 
animals. Increased oxidation of amino acids could have occurred in visceral organs of the host but possibly also to a large extent in tumor tissue.

Regional measurements of muscle protein turnover in the hindquarter showed increased turnover rates in small tumor bearing rats resulting in net protein breakdown. Muscle wasting of tumor bearing rats is characterized by increased loss of the non-soluble myofibrillar proteins whereas the amount of sarcoplasmatic soluble proteins even increases slightly (47). The A-V dilution method measures protein turnover of both the soluble sarcoplasmatic and the myofibriliar protein pool in muscle. Therefore, changes in the higher turnover rate of the soluble pool in muscle may have overshadowed changes in the myofibrillar compartment and the effect of increasing tumor loads on myofibrillar proteins may have been underestimated. However, irrespective of the different turnover rates of the different protein pools in muscle, an increased net breakdown of myofribillar proteins should also result in a net phenylalanine release. The observed increase in net release of phenylalanine in the small tumor bearing rats is thus probably a reflection of net protein breakdown of myofibrillar proteins.

Protein turnover and net breakdown returned to control values in large tumor bearing rats. This is consistent with a previous study by Chen et al (15). It therefore appears that muscle tissue was exhausted in the large tumor bearing rats as was postulated previously by Souba (14). This exhaustion appears to be of particular importance for glutamine because it is the major amino acid released by muscle protein breakdown (48).

\section{Glutamine metabolism}

The importance of glutamine was also shown in the current study by the $25-48 \%$ increase in whole body glutamine turnover in large tumor bearing rats. The increased whole body glutamine turnover indicates that both production and consumption are increased. Figure 5 shows that tumor tissue is only for a small part responsible for the increased glutamine consumption. The uptake of glutamine by tumor tissue has previously been estimated to be approximately $15 \mathrm{nmol} \times \mathrm{gr}$. tumor ${ }^{-1} \times \mathrm{min}^{-1}$ which is in the same range as measured in the current study (49). Although tumor mass was approximately double in large tumor bearing rats compared to small tumor bearing rats, glutamine turnover did not increase as much. We therefore also measured tissue polyamine concentrations as indicator for tissue proliferation. The decreased 
polyamine concentrations and, per gram tissue, decreased giutamine turnover of tumor tissue in large tumor bearing rats, indicate that these tumors have become less metabolically active. This could be related to the size of the tumors. The growth rate of the quadruple implanted tumors were only $164 \%$ of the double implanted and not twice the rate as expected. The quadruple implanted tumors in larger tumor bearing rats appear to exhaust the host more rapidly and hereby inhibit its own nutrient delivery.

Other major glutamine consuming organs are the kidney, gut and immune cells. However, previous studies in MCA tumor bearing rats showed that net glutamine consumption by both the kidney and gut did not increase but remained unchanged and decreased, respectively $(15,50,51)$. Glutamine consumption of lymphocytes has been estimated to be $200-300 \mathrm{nmol} \times 100 \mathrm{gr}$. body weight ${ }^{-1} \times$ min $^{-1}(52)$. Increased amounts of leukocytes and activation of the immune cells, which increase glutamine consumption by approximately $50 \%(53)$, can thus theorefically explain a major part of the increased whole body glutamine consumption.

Glutamine turnover and production of hindquarter muscle increased in small tumor bearing rats but this decreased in the large tumor bearing rats relative to the increased whole body glutamine turnover. The liver and lungs are both other major contributors to glutamine production. Studies with MCA tumor bearing rats also showed that the liver can become an organ of net glutamine release as the tumor grows (54). In another study by the same group, however, very large tumors appear to induce an increased uptake of glutamine rather than release by the liver $(14,55)$. The effects of increasing tumor loads on lung glutamine metabolism have not been described but previous studies have shown increased glutamine synthetase activity in lungs with concomitant net glutamine production in cases of metabolic stress $(56,57)$. It therefore seems reasonable to assume that whole body glutamine metabolism is increasingly affected by liver and lung glutamine production as the tumor grows.

Tumor growth was associated with decreased intracellular glutamine concentrations in muscle. The production of glutamine from protein breakdown can only account for a small amount of the total glutamine efflux. Assuming the ratio of phenyialanine and glutamine present in protein to be approximateiy $1: 3(34)$, the net glutamine production from protein breakdown in the small tumor bearing group would be $132 \mathrm{nmol} \times 100 \mathrm{gr}$. body weight ${ }^{-1} \times \mathrm{min}^{-1}$. Thus, most of the observed increase in 
glutamine production observed in small tumor bearing rats, is a result of increased amidation of glutamate. The uptake of glutamate remained unchanged in the small tumor bearing group. Besides protein breakdown, muscle can produce glutamate by the transamination of $\alpha$-ketoglutarate or branched chain amino acids (valine, leucine and isoleucine) (10). The increased intracellular branched chain amino acid concentrations and unchanged glutamate concentrations indicate that there was no shortage of glutamine precursors. It thus appears that the decreased intracellular glutamine concentrations are not as much the resultant of decreased glutamine synthesis from its precursors but more of an increased glutamine release from muscle tissue. This is in agreement with the hypothesis postulated by Rennie that decreased intracellular glutamine concentration associated with catabolic diseases, such as sepsis and diabetes, is not regulated by its production but by increased membrane transport rates (58). It is further in agreement with a previous study demonstrating an increased glutamine efflux from muscle of tumor bearing rats associated with the presence of increased intracellular glutamine synthetase mRNA (15).

Glutamine membrane transport and glutamine efflux from the hindquarter are to a great extent hormonally controlled by glucocorticoids (59-61). Furthermore, hypercortisolemia, induced in healthy volunteers, increases whole body glutamine turnover by approximately $40 \%$ which is in the same range as observed in the current study. Increased glucocorticoid concentrations and increased urinary excretion of cortisol have been observed in cancer patients (62) and in several tumor bearing animals $(63,64)$ and may thus have regulated the metabolic changes observed in our tumor bearing rats. However, increased concentrations of most other stress hormones have also been observed in MCA tumor bearing rats in conjunction with increased levels, of several catabolic cytokines $(46,65,66)$. The complex interplay of these hormones and cytokines in respect to the regulations of the metabolic disturbances of the tumor bearing rat is beyond the scope of the current study.

The increased whole body glutamine turnover rates should also be seen in the perspective of other metabolic pathways. Glutamine has a key role in intermediary metabolism as non-toxic interorgan ammonia carrier but also as a major gluconeogenic precursor (67). Moreover, the interaction goes both ways as approximately $13 \%$ of glutamine carbon skeletons are derived from glucose (68). If we further consider that the glucose pool and turnover is approximately a six fold 
higher than glutamine turnover and glucose turnover increases by $55 \%$ in large MCA turnor bearing rats $(69)$, it seems plausible that this also affects glutamine turnover. However, the exact quantitative influence of changes in glucose metabolism on glutamine metabolism of tumor bearing rats was not part of the current study and needs further research.

In summary, the current study shows that in the presence of a small tumor whole body protein turnover increases and that this was in part related to protein synthesis of the tumor. Muscle protein breakdown increased in these rats with a concomitant increase in glutamine production from the hindquarter. In animals bearing larger tumors whole body glutamine turnover increased. This increase, however, was only for a small part caused by tumor metabolism. Muscle glutamine turnover even decreased. Therefore, the increase in whole body glutamine turnover appears to be caused by increased turnover in visceral organs.

\section{Acknowledgments}

The authors wish to thank Mr. HMH van Eijk and Mr. DR Rooyakkers for excellent analytical help.

\section{References}

1. Smith RJ. Glutamine metabolism and its physiologic importance. J Parenter Enteral Nutr $1990 ; 14: 40$ S-4S.

2. Bland $\mathrm{PW}$. Whiting CV. Antigen processing by isolated rat intestinal villus enterocytes. Immunology 1989;68:497-502.

3. Lacey JM, Wilmore DW. Is glutamine a conditionally essential amino acid? Nutr Rev 1990;48:297309.

4. Ziegler TR, Young LS, Benfell K, Scheltinga M, Hortos K, Bye R, Morrow FD, Jacobs DO, Smith

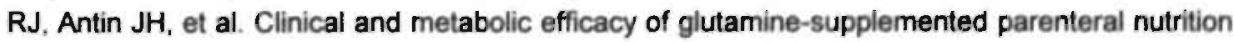
after bone marrow transplantation. Ann Intern Med 1992;116:821-828

5. Van der Hulst RRWJ. Kreel BK, von Meyenfeldt MF, Brummer RJM, Arends JW, Deutz NEP, Soeters PB. Glutamine and the preservation of gut integrity. Lancet 1993:341:1363-5.

6. Tremel H, Kienle B, Weileman LS, Stehle P, Furst P. Glutamine dipeptide-supplemented parenteral nutrition maintains intestinal function in critically ill. Gastroenterologyi 1994;107:1595601.

7. Gore DC, Jahoor F. Glutamine kinetics in burn patients. Comparison with hormonally induced stress in volunteers. Arch Surg 1994;129:1318-23.

8. Bergstrom J, Furst P. Noree LO, Vinnars E. Intracellular free amino acid concentration in human muscle tissue. J Appl Physiol 1974;36:693-7. 
9. Garber AJ, Kart IE, Kipnis DM. Alanine and glutamine synthesis and release from skeletal muscle II. The precursor role of amino acids in alanine and glutamine synthesis. J Biol Chem 1976;251:836-43.

10. Lund $\mathrm{P}$. Williamson $\mathrm{DH}$. Inter-tissue nitrogen fluxes. Br Med Bull 1985;41:251-256

11. Souba WW. Glutamine: a key substrate for the splanchnic bed. Annu Rev Nutr 1991;11:285-308.

12. Fischer JE, Chance WT. Total parenteral nutrition, glutamine, and tumor growth. J Parenter Enteral Nutr 1990;14:86S-9S.

13. Sauer LA, Webster, Stayman, III J, Dauchy RT. Amino acid, glucose, and lactic acid utilization in vivo by rat tumors. Cancer Res 1982;42:4090-7.

14. Souba WW. Glutamine and Cancer. Ann Surg 1993;218:715-28.

15. Chen MK, Espat NJ, Bland KI, Copeland EM, Souba WW. Influence of progressive tumor growth on glutamine metabolism in skeletal muscle and kidney. Ann Surg 1993;217:655-67.

16. Waldegrave W, Chairman Council of Eoropean Community. Guide for the care and use of laboratory animals. European Community 1986; Publication 86/609, Brussels, Belgium.

17. Boyland $\mathrm{E}$, Warren $\mathrm{FL}$. The induction of tumours by methylcholanthrene in two strains of mice. $J$ Path Bact 1937;45:171-7.

18. Burt ME, Lowry SF, Gorschboth C, Brennan MF. Metabolic alterations in a noncachectic animal tumor system. Cancer 1981;47:2138-46.

19. Popp MB, Morrison SD, Brennan MF. Total parenteral nutrition in a methylcholanthrene-induced rat sarcoma model Cancer Treat Rep 1981;65(5):137-43.

20. Morrison SD. In vivo estimation of size of experimental tumors. J Natl Cancer Inst 1983;71:407408

21. Warren RS, Jeevanandam M, Brennan MF. Protein synthesis in the tumor-influenced hepatocyte. Surgery 1985;98:275-82.

22. Del Prato S, Bonadonna RC, Bonora E, Gulli G, Solini A Shank M, Defronzo RA. Characterization of cellular defects of insulin action in type 2 (non-insulin- dependent) diabetes mellitus. J Clin Invest 1993;91:484-94.

23. Kaibara A, Yoshida S, Yamasaki K, Ishibashi N, Kakegawa T. Effect of glutamine and chemotherapy on protein metabolism in tumor- bearing rats. J Surg Res 1994;57:143-9.

24. Yasumura S, Glaros D, Kalef-Ezra J, Xatzikonstantinou J, LoMonte AF, Yeh JK, Moore RI. Distribution of body water in rats. In: Advances in in vivo body compostition studies. Eds: Yasumura $\mathrm{S}$ et ai. Plenum press, New York 1990.

25. Culebras JM. Fitzpatrick GF. Brennan MF, Boyden CM, Moore FD. Total body water and the exchangeable hydrogen II. A review of comparative data from animals based on isotope difution and desiccation with a report of new data from the rat. Am J Physiol 1977;232:R60-R65.

26. Dejong CHC, Deutz NEP. Soeters PB. Renal ammonia and glutarnine metabolism during liver insufficiency-induced hyperammonemia in the rat. $\mathrm{J}$ Clin Invesi 1993;92:2834-2840.

27. Dejong CHC, Kampman MT. Deutz NEP. Soeters PB. Altered glutamine metabolism in rat portal drained viscera and hindquarter during hyperammonemia. Gastroenterology 1992; 102:936-48.

28. de Blaauw I, Deutz NEP, von Meyenfeldt MF. In vivo protein and amino acid turnover in rats: effects of short-term and prolonged starvation. Clin Sci Colch 1996:90:457-66.

29. de Blaauw !. Deutz. NEP, von Meyenfeldt MF. In vivo amino acid metabolism of gut and liver during short and prolonged starvation. Am J Physiol 1996;270(33):G298-306.

30. van Eijk HMH, Rooyackers DR, Deutz NEP. Rapid routine determination of amino acids in plasma by high-performance liquid chromatography with a 2-3 um Spherisorb ODS II column. J Chromatogr 1993;620:143-148. 
31. van Eijk HMH, Huinck MP, Rooyakkers DR, Deutz NEP. Automated simultaneous isolation and quantitation of labeled amino acid fractions from plasma and tissue by ion-exchange chromatography. J Chromatogr B Biomed Appl 1994;660:251-7.

32. van Eijk HMH, Rooyakkers DR, Deutz NEP. Automated determination of polyamines by High Performance Liquid Chromatography with simple sample preparation. J Chromatogr 1996, in press.

33. Thompson GN, Pacy PJ, Merritt H, Ford GC, Read MA, Cheng KN, Halliday D. Rapid measurement of whole body and forearm protein turnover using a [2H5]phenylalanine model. Am J Physiol 1989;256:E631-639.

34. Kominz DR, Hough A, Symonds P, Laki K. The amino acid composition of actin, myosin, fropomyosin and the meromyosins. Arch Biochem Biophys 1954:50:148-159

35. Barrett EJ, Revkin JH, Young LH, Zaret BL, Jacob R, Gelfand RA. An isotopic method for measurement of muscle protein synthesis and degradation in viva. Biochem $\mathrm{J} 1987 ; 245: 223-8$

36. Biolo G, Fleming RY, Maggi SP, Wolfe RR. Transmembrane transport and intracellular kinetics of amino acids in human skeletal muscle. Am J Physiol 1995;268:E75-84.

37. Souba WW, Smith RJ, Wilmore DW. Glutamine metabolism by the intestinal tract. J Parenter Enteral Nutr 1985;9:608-17

38. Norusis MJ. SPSS/PC+V4.0 BASE MANUAL for the IBM PC/XT/AT and PS/2. SPSS Inc; 1989. Chicago, IL, USA.

39. Janne J, Poso H, Raina A. Polyamines in rapid growth and cancer. Biochim Biophys Acta 1978;473:241-93.

40. McCormack SA, Johnson LR. Role of polyamines in gastrointestinal mucosal growh. Am J Physiol 1991:260:G795-G806.

41. Kawamura I, Moldawer LL, Keenan RA, Batist G, Botha, Jr A, Bistrian BR, Blackburn GL. Altered amino acid kinetics in rats with progressive fumor growth. Cancer Res 1982;42:824-9.

42. Norton JA, Shamberger R, Stein TP, Milne GW, Brennan MF. The influence of tumor-bearing on protein metabolism in the rat. J Surg Res 1981;30:456-32.

43. Fearon $\mathrm{KCH}$, Hansell DT, Preston T, Plumb JA, Davies J, Shapiro D, Shenkin A, Calman KC, Bums HJG. Influence of whole body protein turnover rate on resting energy expenditure in patients with cancer. Cancer Res 1988;48:2590-5.

44. Heber D, Chlebowski RT, Ishibashi DE, Herrold JN, Block JB. Abnormalities in glucose and protein metabolism in noncachectic lung cancer patients. Cancer Res 1982;42:4815-9.

45. Radcliffe JD, Fontanez IN, Morrow $\mathrm{S}$. The effect of a methylcholanthrene-induced sarcoma on the protein status of fischer rats. Nutr Res 1986;6:539-47.

46. Stovroff MC, Fraker DL, Norton JA. Cachectin activity in the serum of cachectic, tumour-bearing rats. Arch Surg 1989;124:94-9.

47. Clark CM, Goodlad GA. Depletion of proteins of phasic and tonic muscles in tumour-bearing rats. Eur J Cancer 1971;7:3-9.

48. Ruderman NB, Berger M. The formation of glutamine and alanine in skeletal muscle. $J$ Biol Chem 1974:249:5500-6.

49. Chen MK, Austgen TR, Klimberg VS, Copeland, III EM, Souba WW. Tumor glutamine use exceeds intestinal glutamine use in cachectic tumor- bearing rats. Surg Forum 1990;41:12-14.

50. Clarke JTR, Bier DM. The conversion of phenylalanine to tyrosine in man. Direct measurement by continuous intravenous tracer infusions of L-[ring-2H5] phenylalanine and L- [1-13C] tyrosine in the postabsorptive state. Metabolism 1982;31:999-1005.

51. Souba WW, Klimberg VS, Salloum RMI, Sitren H, Bland KI, Copeland EM. Tumor modulation of intestinal glutaminase activity. FASEB J 1990;A1042. 
52. Newsholme EA, Crabtree B, Ardawi MS. Glutamine metabolism in lymphocytes: its biochemical. physiological and clinical importance. Q J Exp Physiol 1985;70:473-89.

53. Ardawi MS, Newsholme EA. Glutamine metabolism in lymphocytes of the rat. Biochem J $1983 ; 212: 835-42$.

54. Souba WW, Strebel FR, Bull JM, Copeland EM, Teagtmeyer H, Cleary K. Interorgan glutamine metabolism in the tumor-bearing rat. J Surg Res 1988;44:720-6.

55. Dudrick PS, Inoue Y, Espat NJ, Souba WW. Na(+)-dependent glutamine transport in the liver of tumour-bearing rats. Surg Oncol 1993;2:205-15.

56. Austgen TR, Chen MK, Salloum RM, Souba WW. Glutamine metabolism by the endotoxin-injured lung. J Trauma 1991;31:1068-74.

57. Sarantos $P$, Howard $D$, Souba $W W$. Dexamethasone regulates glutamine synthetase expression in rat lung. Metabolism 1993;42:795-800.

58. Rennie MJ, Tadros L, Khogali S, Ahmed A, Taylor PM. Glutamine transport and its metabolic effects. J Nutr 1894;124:1503S-8S.

59. Leighton B, Parry Billings $M$, Dimitriadis G, Bond J, Newsholme EA, DaCosta C, Foot EA. Physiological glucocorticoid levels regulate glutamine and insulin-mediated glucose metabolism in skeietal muscle of the rat. Studies with RU 486 (mifepristone). Biochem J 1991;274:187-92.

60. Hundal HS, Babij P, Taylor PM, Watt PW, Rennie MJ. Effects of corticosteroid on the transport and metabolism of glutamine in rat skeletal muscle. Biochim Biophys Acta 1991:1092:376-383.

61. Millward DJ, Jepson MM, Omer A. Muscle glutamine concentration and protein turnover in vivo in malnutrition and in endoloxemia. Metabolism 1989;38:6-13.

62. Drott $C$, Svaninger $G$, Lundholm $\mathrm{K}$. Increased urinary excretion of cortisol and catecholami-NES in malnourished cancer patients. Ann Surg 1988;208:645-50.

63. Tessitore L. Costelli $\mathrm{P}$, Baccino FM. Humoral mediation for cachexia in tumour-bearing rats. $\mathrm{Br} \mathrm{J}$ Cancer 1993;67:15-23.

64. Tessitore L, Costelli P. Baccino FM. Pharmacological interterence with tissue hypercatabolism in tumour bearing rats. Biochem J 1994:299:71-8.

65. Bartlett DL. Charland SL. Torosian MH. Reversal of tumor-associated hyperglucagonemia as treatment for cancer cachexia. Surgery 1995;118:87-97.

66. Smith BK, Conn CA, Kluger MJ. Experimental cachexia: effects of MCA sarcoma in the Fischer rat. Am J Physiol 1993;265:E376-38.4.

67. Nurjhan N. Bucci A, Perriello G, Stumvoll M, Dailey G, Bier DM, Toft I, Jenssen TG, Gerich JE. Glutamine: a major gluconeogenic precursor and vehicle for interorgan carbon transport in man. J Clin Invest 1995; 95:272-7.

68. Perriello G, Jorde R, Nurjhan N. Stumvoll M, Dailey G, Jenssen T, Bier DM, Gerich JE. Estimation of glucose-alanine-lactate-glutamine cycles in postabsorptive humans: role of skeletal muscle. Am J Physiol 1995;269:E443-50.

69. Singh J, Grigor MR. Thompson MP. Glucose homeostasis in rats bearing a transplantable sarcoma. Cancer Res 1980;40:1699-706. 


\title{
GLUTAMINE DEPLETION AND INCREASED GUT PERMEABILITY IN NON-ANORECTIC, NON-WEIGHT LOSING TUMOR BEARING RATS
}

\author{
1. de Blaauw, N.E.P. Deutz, M.F. von Meyenfeldt \\ Gastroenterology, in press
}

Abstract

Glutamine is an essential amino acid for rapidly dividing cells such as enterocytes. The progress of cancer is associated with a decrease of arterial and muscle glutamine concentrations. Objectives were to test whether increasing tumor loads affect gut intracellular glutamine handling, protein turnover and gut absorptive and barrier function. Tumor bearing rats were studied with a tumor load of $5-15 \%$ or $15-30 \%$ of body weight. Portal drained visceral net uptake or release of energy substrates, amino acids and intestinal protein turnover were studied. Gut absorptive capacity and permeability was assessed by the urinary recovery of 3-O-methyl-D-glucose or Lactulose/Rhamnose (L/R) ratio after an oral gavage.

In tumor bearing rats the net uptake of energy substrates (ketones, glutamine) and net protein synthesis increased across the portal drained viscera while mucosal glutamine concentrations decreased. Absorptive capacity remained unchanged in both tumor bearing groups. The LR ratio, however, increased with increasing tumor load indicating loss of gut barrier function. This was not related to changes in villus height, crypt depth or changes in mucosal cell populations but to decreased intracellular polyamine concentrations.

In conclusion, the presence of a MCA tumor leads to altered mucosal glutamine metabolism and loss of gut barrier function possibly related to disturbed proliferation or differentiation of enterocytes. 
In cancer disease wasting of body mass negatively affects clinical outcome of therapeutic interventions (1). Anorexia and changes in host intermediary metabolism result in progressive weight loss and, if left unresolved, inevitably result in host death (2). In this respect, gut functioning has a central role in the cancer bearing host. Adequate digestion and absorption of nutrients is necessary to supply the host. Moreover, due to its high turnover of cells, the gut must retain specific nutrients for its own use. The amino acid glutamine is a preferential energy substrate for enterocytes and is essential for nucleotide production $(3,4)$. If glutamine is insufficiently available, the gut appears to lose its barrier function against luminal bacteria, endotoxins and other toxic products (5). In extreme catabolic diseases, e.g. burn injury or sepsis, loss of gut barrier functioning has been suggested to become the axis of an amplification loop with ongoing catabolism and death as final result (6-11).

The progress of cancer has been associated with depletion of arterial and muscle intracellular glutamine pools $(12,13)$. Furthermore, decreased net glutamine uptake by portal drained viscera was observed in cancer bearing rodents (14) which was associated with a fall in mucosal glutaminase activity (15). It appears that the gut is compromised in the utilization of its major energy substrate and this may influence its functioning. Objectives of the present study are to test whether increasing tumor loads affect intracellular glutamine handling and protein turnover in portal drained viscera and whether they also affect gut absorption capacity or barrier function.

Materials and methods

\section{Animals and tumor model}

Female Lewis rats $(200-225 \mathrm{~g}$. Centralized Animal Facilities, University of Limburg. Maastricht, NL) were individually housed in metabolic cages during the experiment after an adaptation period of 3 days. Rats were given standard laboratory rat chow (SRMA 1210, Hopefarms, Woerden, NL) and subjected to standard 12 hour light-dark cycle periods (7:30 A.M. to 7:30 P.M.) with room temperature maintained at $25^{\circ} \mathrm{C}$. The experiments were performed in accordance with the recommendations of the Guide for the Care and Use of Laboratory Animals (16) and approved by the E:thical Committee of Animal Research of the University of Limburg.

A subcutaneous methylcholanthrene (MCA) induced fibro sarcoma (12, 17, $18,19)$ was used as cancer model (17). MCA tumors are often used in metabolic studies and are known for its rapid growth, invasion of local tissue and absence of metastatic potential $(12,18,19)$. Rats $(n=40)$ were randomly divided into four groups: 
a small tumor bearing group (ST), a large tumor bearing group (LT), a pairfed control group and a control group fed ad libitum. In the ST group the tumor was allowed to grow until it reached $5-15 \%$ of the host body weight. In the LT group the tumor grew to $15-30 \%$ of the host body weight. Tumor tissue was transplanted bilaterally on the back in the ST group, whereas it was quadruple implanted in the LT group. Control rats were sham implanted with saline. Tumor growth was monitored by measuring two orthogonal dimensions and by calculating the volume assuming the tumor to be a prolate spheroid (20). Tumor size, body weight and food intake were monitored daily.

\section{Experiment 1}

Metabolic experiments were performed as described previously $(21,22$, see in detail chapter 2 and 4 ). In brief, under ether anesthesia, the right renal vein, a tertiary branch of the mesenteric vein, the portal vein and the carotid artery were cannulated with a silastic or PE tube and fixed with cyano-acrylate. For flow measurements, the indicator dilution method with para-aminohippuric acid infused in the mesenteric vein was used. To study protein and glutamine turnover, a primed constant infusion of $\mathrm{L}-\left[2,6 \cdot{ }^{3} \mathrm{H}\right]$ phenylalanine and $\mathrm{L}-\left[3,4-{ }^{3} \mathrm{H}\right] \mathrm{glutamine}$ given in the right renal vein. The priming dose and infusion rate were $1 \mu \mathrm{Ci} \times 100 \mathrm{~g} \mathrm{bw}^{-1}$ and $1 \mu \mathrm{Ci} \times 100 \mathrm{~g} \mathrm{bw}^{-1} \times \mathrm{h}^{-1}$ respectively. Blood was simultaneosly sampled from the portal vein and carotid artery and collected in heparinized cups on ice. Hereafter, $1 \mathrm{~cm}$ jejunal tissue approximately $10 \mathrm{~cm}$ beyond Treitz ligament was dissected free, directly freezeclamped, put in liquid nitrogen and stored at $-80^{\circ} \mathrm{C}$ until further analysis.

For PAH determinations, $50 \mu$ heparinized blood was added to $500 \mu \mathrm{L}$ TCA GR $10 \%$, vortexed, centrifuged at $8,900 \mathrm{~g}$ at $4^{\circ} \mathrm{C}$, the supernatant stored at $-80^{\circ} \mathrm{C}$ after snap freezing with liquid nitrogen. For hematocrit determinations a micro-hematocrit tube was filled with heparinized blood and centrifuged at $10,000 \mathrm{~g}$ at room temperature. Hematocrit was read with a Micro Hematocrit Reader. Plasma was obtained by whole blood centrifugation at $8,900 \mathrm{~g}$ at $4^{\circ} \mathrm{C}$ for 5 minutes. For ammonia, urea, glucose, lactate and ketone (ß-hydroxybutyrate, acetoacetate) determinations, $500 \mu \mathrm{l}$ plasma was vortexed with $20 \mu \mathrm{l}$ TCA $50 \%$, put into liquid nitrogen and stored at $-80^{\circ} \mathrm{C}$. For plasma amino acid determinations and amino acid specific activities, $300 \mu \mathrm{l}$ plasma was added to $12 \mathrm{mg}$ 5-sulfosalicylic acid for deproteinization, vortexed, frozen in liquid nitrogen and stored at $-80^{\circ} \mathrm{C}$.

\section{Experiment 2}

Gut absorptive and barrier functioning was examined in a second experiment. As no anorexia was observed in the first experiment, all groups were freely fed. On day $0,6,12$, and 18 after tumor implantation an oral dose ( $1 \mathrm{ml}$, iso-osmolar) of lactulose 
( $292 \mathrm{mmol} / \mathrm{L}$, Centrafarm 15211381, Etten-Leur, NL), L-rhamnose (10 mmol/L, Janssen Chimica 1740845, Geel, Belgium) and 3-O-methyl-D-glucose $(5.5 \mathrm{mmol} / \mathrm{L}$, Sigma M4879, Geel, Belgium) was given at 8:00 AM. The dosage of lactulose was relatively low compared to previous studies because the sensitivity of the HPLC determination is very high (23). Using this dosage no diarrhea was observed. Urine was collected for 10 hours in a flask containing $6 \mathrm{~N} \mathrm{HCl}$ to prevent bacterial overgrowth. Previous to the oral gavage, 12 hour urine was collected to test for the presence of sugars in native urine. No lactulose, L-rhamnose or 3-O-methyl-Dglucose was present. Urinary recovery of the three sugars was calculated as follows: the volume of urine collected was multiplied with the concentration of the sugar. This product was divided by the oral intake. Permeability of the gut was assessed by the ratio of the recovery of lactulose and L-rhamnose. This has previously been shown to be a better parameter than using lactulose recovery alone. Incomplete doses, reduced recovery, altered intestinal dilution, altered transit time, altered body distribution and renal clearance have similar effects on both recoveries and thus do not influence the ratio (24).

After sacrifice, small parts of the jejunum (10 $\mathrm{cm}$ beyond Treitz ligament) were excised and fixed in formaldehyde for 24 hours. Tissue was embedded in paraffin and oriented so that transverse sections of the jejunum were obtained. Sections (5 $\mu \mathrm{m}$ ) were cut using a microtome (Leica J1130, Rijswijk, NL) and stained with standard haematoxyline-eosine. Villus height and crypt depth were measured using a Jandel Video Analysis System (Erkath, Germany) as described previously (5). Only crypt-villus units were included which had a continuity from the crypt bottom to villus tip. Means of villus heights and crypt depths were obtained after at least 10 measurements each of three different jejunal tissue specimens. Measurements were performed by two independent observers and all slides were coded so that the observer was unaware from which group of rats the sections originated. Intraobserver and interobserver variance for these measurements were $3 \%$ and $7 \%$. respectively (5).

Intraepithelial lymphocytes were stained in formalin fixed, paraffin embedded tissue sections with anti-CD3 polyclonal antibodies (DAKO A452, Glostrup. Danmark) as described previously (25). Intraepithelial $\mathrm{CD}^{+}$positive cells seen in the epithelial morphological regions of the villus-crypt were counted in ten high powerfield of each section and screened for the relative number of $\mathrm{CD} 3^{+}$positive cells and enterocytes respectively (25). $\mathrm{CD}^{*}$ positive cells are expressed as percentage of enterocytes. 


\section{Biochemical analysis}

Plasma ammonia, urea, glucose, lactate, $\beta$-hydroxybutyrate, acetoacetate and PAH were determined spectrophotometrically on a Cobas Mira S (Roche Diagnostica, Hoffman-La Roche, Basel, Switzerland) by standard enzymatic methods, using commercially available kits as described previously $(21,26)$. Standard plasma amino acids were determined by fully automated high performance liquid chromatography (HPLC) as described previously (27). To determine plasma phenylalanine and glutamine specific activity (SA), plasma was isolated on a cation exchange resin column as described previously (28). For the determination of tissue ammonia, polyamine and amino acid concentrations, tissue was pulverized using a mortar and pestie precooled in liquid nitrogen. The tissue was further homogenized and deproteinized in a Mini-Beadbeater (Biospec products, Bartlesville USA). Approximately $100 \mathrm{mg}$ tissue was added to $400 \mu \mathrm{l} \mathrm{SSA} 5 \%$, with $300 \mathrm{mg}$ glass beads (diameter $1 \mathrm{~mm}$, Biospeck Products) and beaten for 30 seconds. The homogenate was centrifuged at $4^{\circ} \mathrm{C}$ at $1,100 \mathrm{~g}$ and the supernatant frozen in liquid nitrogen and stored at $-80^{\circ} \mathrm{C}$ until further determinations. To determine tissue dry weight and water content approximately $200 \mathrm{mg}$ pulverized tissue was freeze dried for 24 hours in a Speedvac (SC200, Savant Instruments Inc., Farmingdale NY, USA) connected with a refrigerated condensation trap (type RT 400, Savant Instruments Inc.).

Concentrations of intestinal polyamines putrescine, spermidine and spermine were determined by HPLC (29). Urine lactulose, L-rhamnose and 3-O-methyl-Dglucose were determined by routine HPLC after derivatization with FMOC-hydrazine (23).

\section{Calculations}

Plasma flow across the portal drained viscera (PDV) was calculated using PAH in the indicator dilution method described previously $(21,26$, chapter 4$)$. Substrate fluxes are calculated by multiplying the venous-arterial concentration differences with the mean portal plasma flow of the group and are expressed in $n$ mol $\times 100 \mathrm{~g} \mathrm{bw}^{-1} \times$ $\min ^{-1}$. A positive flux indicates net release, a negative flux reflects a net uptake. Fractional extraction of amino acids were calculated by dividing the difference between arterial and portal venous concentrations by arterial concentrations. It is expressed as percentage of the arterial concentration. $\alpha$-Amino-nitrogen was calculated as the sum of the individual amino acids measured (27), branched chain amino acids (BCAA) as the sum of valine, leucine, isoleucine and ketones as the sum of $\beta$-hydroxybutyrate and acetoacetate. Tissue concentrations of amino acids are expressed in $\mu \mathrm{mol} / \mathrm{L}$ and derived by dividing the tissue homogenate amino acid concentration ( $\mu \mathrm{mol} / \mathrm{kg}$ wet weight) by tissue water content. 
PDV glutamine and phenylalanine turnover can be calculated from the arterialvenous dilution of the tracer amino acids across the PDV calculated in a three compartment model $(22,30$, see in detail chapter 2$)$. Intracellular phenylalanine and glutamine disposal (D) and production (P) can thus be calculated together with in vivo membrane transport rates and metabolic shunting of amino acids. Intracellular disposal of phenylalanine is a reflection of protein synthesis and intracellular production of phenylalanine reflects protein breakdown as the gut has very low hydroxylase activity (31).

\section{Statistical analysis}

Results are presented as mean \pm SEM. The Mann Whitney $U$ test corrected with the Bonferroni procedure was used to test significance between control and tumor bearing groups (32). Multiple time parameters in experiment 2 were analyzed with two-way ANOVA in which time and the presence of a tumor were the main effects. Significance was considered present at $p<0.05$.

Results

Food intake of tumor bearing rats did not decrease during the study period and was not different from control rats (33, see also chapter 5, fig. 2). Therefore, the results of the pairfed and the freely fed control groups in the first experiment were pooled.

Table 1. Arterial ammonia and amino acid concentrations in control, small and large tumor bearing rats. Vaiues are presented in $\mu \mathrm{mol} / \mathrm{L}$ (mean $\pm \mathrm{SEM}$ ). Mann Whitney $U$ nonparametric test versus control group: " $p<0.05$, ${ }^{b} p<0.01,{ }^{c} p<0.001$.

\begin{tabular}{|c|c|c|c|c|c|c|c|c|}
\hline \multirow[b]{2}{*}{ Ammonia } & \multicolumn{2}{|c|}{ Control } & \multicolumn{3}{|c|}{ Small tumor } & \multicolumn{3}{|c|}{ Large tumor } \\
\hline & 195 & \pm 13 & 232 & \pm & 35 & 205 & \pm & 17 \\
\hline Glutamine & 642 & \pm 17 & 605 & \pm & 24 & 567 & \pm & $16^{\circ}$ \\
\hline Glutamate & 109 & \pm 6 & 130 & \pm & 23 & 117 & $t$ & 6 \\
\hline Citrulline & 43 & \pm 2 & 41 & \pm & 2 & 42. & \pm & 2 \\
\hline Alanine & 224 & \pm 24 & 385 & \pm & $63^{\circ}$ & 464 & \pm & $58^{\circ}$ \\
\hline Phenylalanine & 53 & \pm 2 & 75 & \pm & $4^{c}$ & 74 & \pm & $3^{c}$ \\
\hline BCAA & 255 & \pm 11 & 349 & \pm & $23^{\circ}$ & 293 & \pm & $13 \cdot$ \\
\hline$\alpha-$ Amino-nitrogen & 2727 & \pm 51 & 3598 & \pm & $269^{b}$ & 3420 & \pm & $101^{c}$ \\
\hline
\end{tabular}


Table 2. Mucosal concentrations of ammonia and amino acid. Values in $\mu$ mol/L (mean \pm SEM) except $\mathrm{H}_{2} \mathrm{O}$ in \%. Mann Whitney $U$ nonparametric test versus control group: " $p<0.05,{ }^{\mathrm{D}} \mathrm{p}<0.01,{ }^{\mathrm{C}} \mathrm{p}<0.001$.

\begin{tabular}{|c|c|c|c|c|c|c|c|c|c|}
\hline \multirow[b]{2}{*}{$\mathrm{H}_{2} \mathrm{O}(\%)$} & \multicolumn{3}{|c|}{ Control } & \multicolumn{3}{|c|}{ Small tumor } & \multicolumn{3}{|c|}{ Large tumor } \\
\hline & 72.6 & $t$ & 0.7 & 74.5 & \pm & 1.0 & 75.0 & \pm 0.6 & - \\
\hline Ammonia & 3942 & \pm & 314 & 3478 & \pm & 336 & 3042 & \pm 196 & b \\
\hline Glutamine & 1796 & \pm & 110 & 1410 & \pm & 97 • & 1209 & \pm 102 & e \\
\hline Glutamate & 5611 & \pm & 285 & 4806 & \pm & $169^{b}$ & 4129 & \pm 240 & e \\
\hline Aspartate & 896 & \pm & 59 & 701 & \pm & 78 * & 596 & $\pm \quad 91$ & b \\
\hline Citrulline & 251 & \pm & 10 & 223 & \pm & 14 & 182 & 10 & c \\
\hline Alanine & 2487 & \pm & 154 & 2378 & \pm & 223 & 2042 & \pm 184 & * \\
\hline Phenylalanine & 906 & \pm & 131 & 681 & \pm & 98 & 481 & $\begin{array}{r}+86 \\
\end{array}$ & ○ \\
\hline BCAA & 3703 & \pm & 479 & 2811 & \pm & 442 & 2042 & \pm 383 & - \\
\hline$\alpha$-Amino-nitrogen & 38359 & \pm & 1501 & 34578 & \pm & 1470 & 30021 & \pm 1152 & c \\
\hline
\end{tabular}

\section{Intestinal metabolism}

Most arterial amino acids increased in both tumor bearing rats with the exception of glutamine which decreased (Table 1). In contrast, mucosal amino acid concentrations of the gut decreased dramatically with increasing tumor load (Table 2). The mean plasma flow across the portal drained viscera, which under normal conditions reflects intestinal flow, increased substantially but not significantly $(p=0.08$, Table 3$)$. This increase may have remained undetected by the variation (type II error). Glucose, lactate, ketones and glutamine are the major energy substrates of the gut. The uptake of glucose and lactate remained unchanged whereas the uptake of ketones and glutamine increased in the large tumor bearing rats. Ammonia, alanine and citrulline are major end products of gut glutamine consumption. The release of ammonia and alanine increased confirming the increased use of glutamine by portal drained organs. Citrulline release tended to increase $(p=0.08$ ). To look more specifically into intestinal glutamine turnover and in vivo membrane transport rates ${ }^{3} \mathrm{H}$-glutamine was infused. In the large tumor bearing animals, both the ingoing $\left(F_{\text {in }}\right)$ and outgoing $\left(F_{\text {out }}\right)$ amount of glutamine increased in the portal drained viscera. This resulted in a doubling of both inward and outward glutamine membrane transport rates (Table 4). Intracellular glutarnine turnover (disposal and production) also increased which resulted in the increased flux (uptake) of glutamine by portal drained organs in large tumor bearing rats.

Protein kinetics of portal drained viscera are calculated by the intracellular disposal of phenylalanine (protein synthesis) and production (protein breakdown). Although in small tumor bearing rats more phenylalanine entered the ingoing pool of 
Table 3. PDV plasma flow, ammonia and amino acid fluxes. Values are presented in nmol $\times 100 \mathrm{~g} \mathrm{bw}^{-1}$ $x$ min $^{-1}$ (mean \pm SEM). $(-)$ reflects net uptake, $(+)$ reflects net release of a substrate. Mann Whitney $U$ nonparametric test versus control group: " $p<0.05,{ }^{b} p<0.01$, ${ }^{c} p<0.001$.

\begin{tabular}{|c|c|c|c|c|c|c|c|c|c|}
\hline \multirow[b]{2}{*}{ Flow } & \multicolumn{2}{|c|}{ Control } & \multicolumn{3}{|c|}{ Small tumor } & \multicolumn{4}{|c|}{ Large tumor } \\
\hline & 0.9 & \pm 0.2 & 1.3 & \pm & 0.4 & 2.8 & \pm & 0.7 & \\
\hline Glucose & -659 & \pm 174 & -550 & \pm & 200 & -770 & \pm & 279 & \\
\hline Lactate & -596 & \pm 160 & 603 & \pm & $361^{c}$ & -739 & \pm & 515 & $\sigma$ \\
\hline Ketones & -63 & \pm 10 & -99 & \pm & 18 & -219 & \pm & 49 & 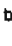 \\
\hline Ammonia & 154 & \pm 45 & 184 & \pm & 35 & 352 & \pm & 72 & b \\
\hline Glutamine & -284 & $\pm \quad 31$ & -299 & \pm & 29 & -574 & \pm & 77 & c \\
\hline Glutamate & 15 & \pm 6 & 5 & \pm & 5 & -22 & \pm & 13 & c \\
\hline Citrulline & 29 & \pm 5 & 30 & \pm & 4 & 51 & \pm & 9 & \\
\hline Alanine & 149 & \pm 29 & 174 & \pm & 32 & 274 & \pm & 52 & $\cdot$ \\
\hline Phenylalanine & -4 & \pm 2 & -2 & \pm & 3 & -10 & \pm & 4 & - \\
\hline$B C A A$ & 2 & \pm 7 & -0.5 & \pm & 14 & -19 & \pm & 30 & \\
\hline$\alpha$-Amino-nitrogen & -119 & \pm 62 & -148 & \pm & 85 & -456 & \pm & 151 & \\
\hline
\end{tabular}

Table 4. PDV glutamine extraction, turnover and intracellular kinetics. All data are presented in nmol glutamine $\times 100 \mathrm{~g} \mathrm{bw}^{-1} \times \mathrm{min}^{-1}$ except extraction \% of arterial concentration (mean $\pm \mathrm{SEM}$ ). $\mathrm{F}_{\text {in }}$ is the amount of glutamine entering the PDV through arterial plasma as described in chapter 2 (Fig. 5, page 56, equation 12-20), $F_{\text {out }}$ is the amount of giutamine leaving PDV by the portal vein, $F_{i, a}$ is inward directed plasma tissue membrane transport, $F_{p j}$ is outward directed plasma tissue membrane transport, $F_{p, a}$ is metabolic shunting, disposal of glutamine reflects intracellular glutamine consumption whereas production reflects intracellular production. Mann Whitney $U$ nonparametric test versus control group: " $p<0.05, " p<0.01,{ }^{\circ} p<0.001$.

\begin{tabular}{|c|c|c|c|c|c|c|c|c|c|c|}
\hline \multirow[b]{2}{*}{ Glutamine extraction } & \multicolumn{3}{|c|}{ Control } & \multicolumn{3}{|c|}{ Small tumor } & \multicolumn{4}{|c|}{ Large tumor } \\
\hline & 39 & \pm & 4 & 38 & \pm & 4 & 36 & \pm & 3 & \\
\hline$F_{\text {in }}$ & 732 & \pm & 52. & 784 & \pm & 30 & 1587 & \pm & 44 & e \\
\hline Fout & 448 & \pm & 47 & 485 & \pm & 43 & 1015 & \pm & 36 & e. \\
\hline$F_{i, a}$ & 848 & \pm & 146 & 639 & \pm & 121 & 1691 & \pm & 306 & • \\
\hline $\mathrm{F}_{\mathrm{pd}}$ & 565 & \pm & 154 & 339 & \pm & 106 & 1119 & \pm & 320 & a \\
\hline$F_{p, n}$ & -116 & \pm & 130 & 145 & \pm & 146 & -102 & \pm & 320 & \\
\hline Disposal & 476 & \pm & 59 & 435 & \pm & 36 & 968 & \pm & 88 & c \\
\hline Production & 192 & \pm & 46 & 136 & \pm & 8 & 395 & \pm & 77 & - \\
\hline Flux & -284 & \pm & 31 & .299 & \pm & 29 & -574 & \pm & 77 & e \\
\hline
\end{tabular}


Table 5. PDV protein turnover and intracellular kinetics. All data are presented in nmol glutamine $\times 100$ $\mathrm{g} \mathrm{bw}^{-1} \times \mathrm{min}^{-1}$ (mean $\pm \mathrm{SEM}$ ). $\mathrm{F}_{\mathrm{h}}$ is the amount of glutamine entering the PDV through arterial plasma, $F_{a u}$ is the amount of glutamine leaving PDV by the portal vein, $F_{j, a}$ is inward directed plasma tissue membrane transport, $F_{p j}$ is outward directed plasma tissue membrane transport, $F_{p, a}$ is metabolic shunting. disposal of glutamine reflects intracellular glutamine consumption whereas production reflects intracellular production 2 (see in detail, chapter 2, page 56, fig 5, equation 12-20). Mann Whitney $U$ nonparametric test versus control group: " $p<0.05,{ }^{b} p<0,01,{ }^{\circ} p<0,001$.

\begin{tabular}{|c|c|c|c|c|c|c|c|c|c|}
\hline \multirow[b]{2}{*}{$F_{i n}$} & \multicolumn{2}{|c|}{ Control } & \multicolumn{3}{|c|}{ Small tumor } & \multicolumn{4}{|c|}{ Large tumor } \\
\hline & 61 & 4 & 98 & \pm & $6^{c}$ & 207 & \pm & 7 & c \\
\hline$F_{\text {out }}$ & 57 & 4 & 96 & \pm & $9^{\circ}$ & 197 & \pm & 7 & e \\
\hline$F_{i a}$ & 25 & 3 & 29 & \pm & 7 & 79 & \pm & 11 & c \\
\hline$F_{P J}$ & 22 & \pm & 29 & \pm & 8 & 69 & \pm & 11 & e \\
\hline$F_{p . a}$ & 35 & \pm 3 & 69 & \pm & $6^{c}$ & 128 & \pm & 10 & c \\
\hline Disposal & 299 & \pm 52 & 177 & \pm & 37 & 168 & \pm & 36 & " \\
\hline Production & 295 & \pm 52 & 176 & \pm & 38 & 158 & \pm & 36 & - \\
\hline Flux & -4 & \pm 2 & -2 & \pm & 3 & -10 & \pm & 4 & b \\
\hline
\end{tabular}

the portal drained viscera $\left(F_{\text {in }}\right)$, this did not result in increased membrane transport rates into the cell but did increase metabolic shunting of phenylalanine (Table 5).

In large tumor bearing rats the ingoing $\left(F_{\text {in }}\right)$ and outgoing phenylalanine increased $\left(F_{\text {out }}\right)$ compared to control and small tumor bearing rats. This resulted in increased inward membrane transport rates, outward membrane transport rates and metabolic shunting. Protein turnover (both breakdown and synthesis) decreased in the large tumor bearing rats. Phenylalanine flux (difference protein breakdown and synthesis), however, increased in the large tumor bearing animals indicating net protein breakdown.

\section{Intestinal function}

3-O-Methyl-D-glucose recovery in urine was not significantly different over time between the different groups. Lactulose recovery of small and large tumor bearing rats increased compared to control rats. L-Rhamnose recovery was similar in all groups at the different time points. The lactulose/L-rhamnose ratio increased in both tumor bearing rats compared to control rats indicating gut barrier loss with increasing tumor loads (Fig. 1).

To test whether this was due to villus atrophy we merasured villus height and crypt depth (Table 7). Both villus height and crypt depth, however, remained unchanged in both tumor bearing rats. The increased permeability may also be explained by 
alterations in mucosal cell populations (24), in particular increasing amounts of inflammatory cells or its mediators. Therefore the relative amount of intraepithelial lymphocytes were counted. The percentage intraepithelial lymphocytes, however, remained unchanged in the small tumor bearing rats and decreased in the large tumor bearing rats.

Finally, we measured intestinal polyamine concentrations (Table 8) as an indicator of enterocyte cell proliferation and differentiation (34). Intracellular putrescine, spermidine and spermine concentrations decreased significantly in the large tumor bearing rats. Furthermore, the molar ratio of spermidine to spermine, an indicator of cell growth under a variety of circumstances (35), decreased in the large tumor bearing rats

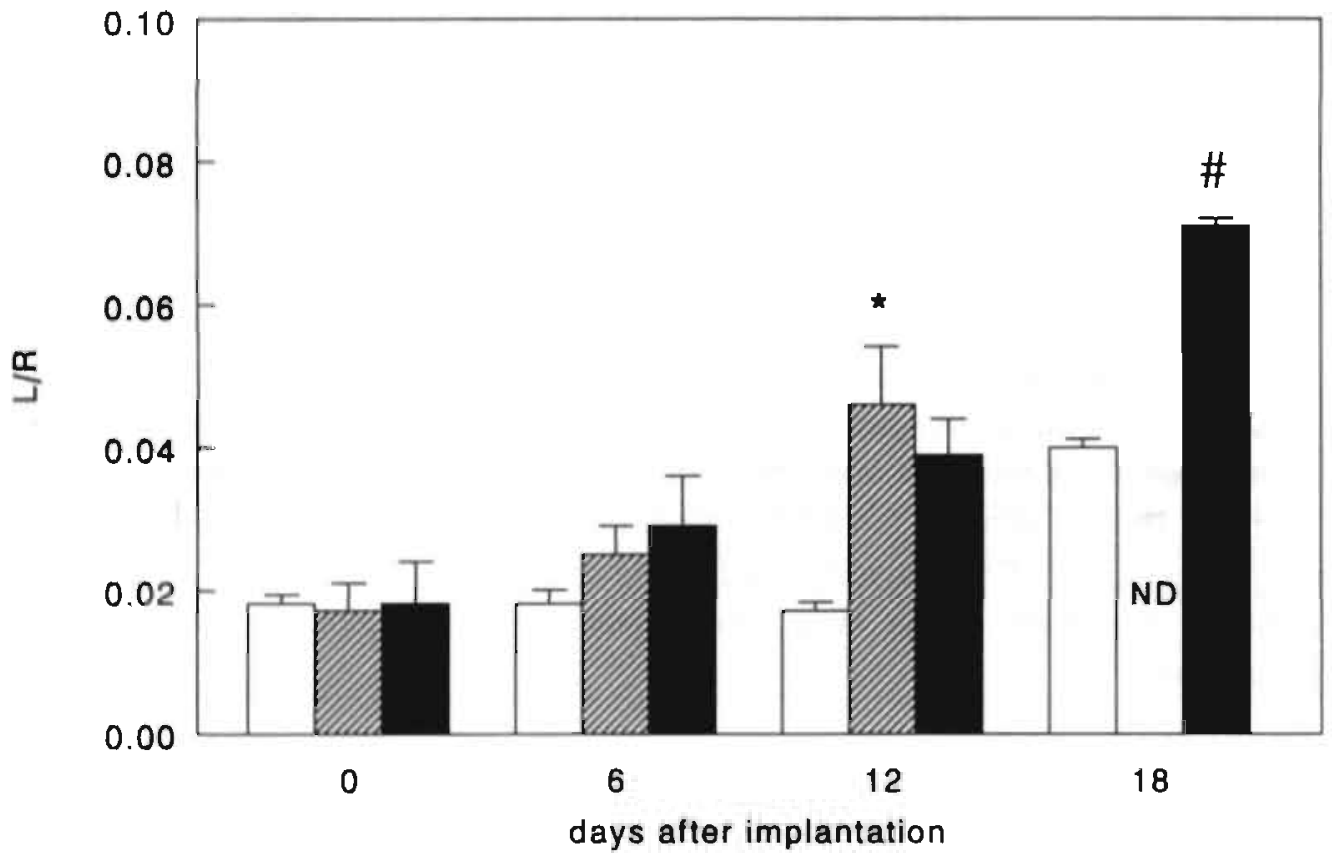

Figure 1. Ratio of urinary recovery of lactulose and L-rhamnose after an oral iso-osmolar dose (mean \pm SEM). $\square$ Control group. Small tumor bearing group, I Large tumor bearing group. Statistica! analysis by two-way ANOVA (effects of group): Control versus small TB group." $p<0.001$; Control versus large TB group: \# $p<0.001$. ND=not determined 
Table 6. Urinary recovery of an oral dose of lactulose, thamnose and 3-O-methyl-D-glucose in control, small and large tumor bearing animals. Values are urinary recovery of an iso-osmolar oral dose after 12 hours and expressed in $\%$ of the oral dose (mean \pm SEM). nd: not determined. Statistical analysis by two way ANOVA: control versus small tumor bearing rats: $p<0.001$; control versus large tumor bearing rats: \# $p<0.001$.

Control

\section{3-0-methyl-D-Glucose}

\section{Day 0}

Day 6

Day 12

Day 18

\section{Lactulose}

Day 0

Day 6

Day 12

Day 18

\section{L-Rhamnose}

\section{Day 0}

Day 6

Day 12

Day 18

$\begin{array}{rrr}76 & \pm 3 \\ 83 & \pm \\ 71 & \pm \\ 72 & \pm \\ 7 & 10\end{array}$

$0.15 \pm 0.01$

$0.18 \pm 0.02$

$0.14 \pm 0.01$

$0.26 \pm 0.08$
Small tumor

$62 \pm 14$

$84 \pm 5$

$92 \pm 12$

nd

Large tumor

$\begin{array}{rrrrrr}7.8 & \pm 0.4 & 10.7 & \pm 1.3 & 9.1 & \pm 1.0 \\ 10.3 & \pm 0.6 & 11.2 & \pm 1.1 & 9.6 & \pm 1.5 \\ 7.8 & \pm 0.5 & 7.1 & \pm 0.8 & 6.5 \pm & \pm .6 \\ 6.8 & \pm 0.9 & & \text { nd } & & 7.5 \pm 0.7\end{array}$

Table 7. Villus height, crypt depth and percentile intra-epithelial lymphocytes in control, smali and large tumor bearing animals. Villus height, crypt depth are in $\mu$ m (mean \pm SEM). IEL are the relativo intraepithelial iymphocytes in the gut villus as percentage of enterocytes. Mann Whitney $U$ nonparametric test versus control group: " $p<0.05$.

\begin{tabular}{lrrrrrrrrr}
\hline & \multicolumn{1}{c}{ Control } & Small tumor & Large tumor \\
\hline Villus height & 418 & \pm & 12 & 409 & \pm & 26 & 432 & \pm 18 \\
Crypt depth & 194 & \pm & 12 & 197 & \pm & 14 & 199 & \pm & 14 \\
IEL & 21 & \pm & 2 & 22 & \pm & 2 & 16 & \pm & 2 \\
\hline
\end{tabular}


Table 8. Intracellular polyamine concentrations in the jejunum. Values are in $\mu \mathrm{mol} / \mathrm{L}$ except spermidine/spermine which is the ratio of the two polyamines (mean $\pm S E M$ ). Mann Whitney $U$ versus control group: " $p<0.05,{ }^{b} p<0.01$.

\begin{tabular}{lrrrrr}
\hline & \multicolumn{1}{c}{ Control } & \multicolumn{2}{c}{ Small tumor } & \multicolumn{2}{c}{ Large tumor } \\
\hline Putrescine & $163 \pm 40$ & $153 \pm$ & 19 & $126 \pm 12$ \\
Spermidine & $3816 \pm 537$ & $3368 \pm 545$ & $2095 \pm 237$ \\
Spermine & $1708 \pm 337$ & $1439 \pm 252$ & $1077 \pm 141$ \\
Spermidine/spermine & $2.3 \pm 0.1$ & $2.4 \pm 0.1$ & $1.9 \pm 0.1$ \\
\hline
\end{tabular}

Discussion

Glutamine is an important respiratory fuel and nucleotide precursor for the gastrointestinal tract $(3,4,36)$. Disturbances in glutamine metabolism have been observed previously in MCA tumor bearing rats (12,37-39). In particular depletion of arterial and intracellular muscle glutamine pools have been observed $(12,38)$ which were associated with decreased gut glutaminase activity in tumor bearing rats (15). In the current study arterial and intestinal intracellular glutamine also decreased with increasing tumor loads. In contrast, inward directed glutamine membrane transport rates and intracellular glutamine disposal increased in the portal drained viscera.

Endproducts of glutamine metabolism in the gut are ammonia (38\%), citrulline $(28 \%)$ and alanine $(24 \%)(3,36)$. Net release of these products increased simultaneously with the increased intracellular disposal of glutamine suggesting enhanced metabolism of glutamine by the gut. However, the increased consumption of glutamine by portal drained viscera also includes uptake by other organs drained by the portal vein, e.g. the spleen. Lymphocytes present in the spleen are also avid consumers of glutamine and in cancer bearing rats both growth of the spleen as activation of lymphocytes have been observed (40-43). However, the metabolic enclproducts of glutamine by rat lymphocytes are glutamate and aspartate instead of alanine and citrulline $(36,44)$. We therefore postulate that the increased glutamine turnover in PDV in the large tumor bearing rats is a reflection of enhanced intracellular glutamine metabolism in enterocytes.

Protein turnover measured by the A-V dilution of ${ }^{3} \mathrm{H}$-phenylalanine across the portal drained viscera has several methodological problems $(22,45)$. It is recognized that intracellular disposal reflects protein synthesis but the intracellular production of 
phenylalanine is a compilation of intracellular protein breakdown and the breakdown of proteins in the gut lumen (exfoliated cells, enzymes, bacterial proteins) $(22,45)$. We observed decreased intestinal protein turnover and decreased protein synthesis rates in large tumor bearing rats. The decreased protein turnover did not result in villus atrophy or cryptal changes but was related to decreased mucosal polyamine concentrations.

Decreased mucosal polyamine concentrations have previously been associated with disturbed maturation at the villus tip $(34,46)$. Moreover, polyamine concentrations are associated to intestinal cell growth. In this respect, polyamines have been shown to regulate the expression of growth related genes and have been related to the stabilization of cell membranes (34). Therefore, reduced polyamine concentrations could be related to loosening of tight junctions between enterocytes which could have caused the decreased gut barrier function we observed in cancer bearing rats.

Loss of gut barrier function became apparent in both turnor bearing rats by the increased lactulose/L-rhamnose ratio. The ratio of urinary recovery of lactulose and L-rhamnose reflects the ability of two macromolecules with different sizes to permeate the gut barrier. Although the precise anatomic intestinal permeation route of lactulose and L-rhamnose is unclear (47), L-rhamnose can permeate the mucosal barrier at a higher rate than lactulose due to better accessibility and size differences (47-49). The changes in the lactulose/L-rhamnose ratio observed in cancer were mostly due to increased recoveries of lactulose with no significant changes in Lrhamnose recoveries. This is in agreement with the observed unchanged villus height and crypt depth which would have decreased L-rhamnose (and 3-O-methyl-D. glucose) recovery $(2.4,50)$. It indicates that the tight junctions may be dynamic and have opened as a (patho)physiological response in these tumor bearing rats (49). A similar response has been suggested to cause increased permeability during intestinal inflammation (49). Urinary lactulose recovery in control rats was slightly lower than the normal range of results $(0.4 \%-1 \%)$ found by others $(51,52)$, possibly due to the fact that we used iso-osmolar solutions instead of the hyperosmolar solutions used by others.

Bacterial translocation has been described in tumor bearing rats and mice $(15,39)$. This has previously been related to increased permeability of macromolecules such as lactulose $(6,7,53)$. The suggested relation is questionable as bacteria and endotoxins are far too large to pass through the same pores as lactulose. Only peptides, either bacterial or nutritional, of the same size (maximal $1.1 \mathrm{~nm}$ ) can be expected to pass the intestinal barrier in the tumor bearing rats. Increased permeability for these macromolecules is, however, generally assumed to be pathophysiological and harmful for host body function (24). 
Decreased gut barrier function has also been related to intestinal inflammation (54-57), atrophy of intestinal villi $(58,59)$ and decreased availability of arterial glutamine to the gut $(5,48)$. We observed no increase in inflammatory cells, no villus atrophy but depletion of arterial and intracellular glutamine was present in tumor bearing rats. In line with this, addition of glutamine to parenteral nutrition has previously been shown to improve intestinal barrier function, in both rats and man, as measured by the permeability of sugar probes $(5,48)$. Also, in rats, parenteral glutamine suppletion reversed bacterial translocation and reversed the decreased gut IgA production induced by TPN (60). Impaired glutamine turnover in tumor bearing rats may thus be at the basis of the reduced gut barrier function.

Both the increased glutamine turnover and decreased mucosal polyamine concentrations could be related to the functional loss of the intestine. Recently, in vitro enterocyte polyamine production was also found to be glutamine concentration dependent (61). Therefore, we hypothesize that in cancer bearing rats, the increased glutamine turnover resulted in depletion of glutamine pools with concomitant decreased intestinal polyamine production which consequently induced loss of cell membrane stability with loss of gut barrier function for macromolecules.

In conclusion, this study shows that the presence of a MCA tumor leads to and an increased intracellular glutamine turnover with intracellular glutamine depletion. Although absorption remains intact, the gut loses its barrier function without morphological changes in villus height and crypt depth. Increased loss of gut barrier function is possibly related to disturbed growth or differentiation of enterocytes. The chronic loss of gut barrier to these macromolecules could be of harm to the cancer bearing host and be an important factor in the etiology of, gut associated, morbidity observed in cancer.

\section{Acknowledgments}

The authors wish to thank Mr. HMH van Eijk, Mr. DR Rooyakkers and Mrs B Gerdts, MD for technical and analytical help.

\section{References}

1. Dempsey DT, Mullen JL, Buzby GP. The link, between nutritional status, and clinical outcome: can nutritional intervention modify it? Am J Clin Nutr 1988;47:352-6.

2. Kem KA, Norton JA. Cancer cachexia. J Parenter Enteral Nutr 1988;12:286-298.

3. Windmueller HG, Spaeth AE. Respiratory fuels and nitrogen metabolism in vivo in small intestine of fecl rats. J Biol Chem 1980;255:107-112.

4. Souba WW. Glutamine: a key substrate for the splanchnic bed. Annu Rev Nutr 1991;11:285-308.

5. Van der Hulst RRWJ, Kreel BK, Meyenfeldt MF, Brummer RJM, Arends JW, Deutz NEP, Soeters PB. Giutamine and the preservation of gut integrity. Lancet 1993;341:1363-1365. 
6. Ziegler TR, Smith RJ, O'Dwyer ST, Demling RH, Wilmore DW. Increased intestinal permeability associated with infection in burn patients. Arch Surg 1988;123:1313-1319.

7. O'Dwyer ST, Michie HR, Zlegler TR, Revhaug A, Smith RJ, Wilmore DW. A single dose of endotoxin increases intestinal permeability in healthy humans. Arch Surg 1988;123:1459-1464.

8. Shou J, Motyka LE, Daly JM. Intestinal microbial translocation: immunologic consequences and effects of interleukin-4. Surgery 1994;116:868-76.

9. Mobrahan S. Glutamine: A conditionally essential nutrient or another nutritional puzzle. Nutr Rev 1992;50:331-333.

10. Yao YM, Bahrami S, Leichtfried G, Redl H, Schlag G. Pathogenesis of hemorrhage-induced bacteria/endotoxin translocation in rats. Effects of recombinant bactericidal/permeabilityincreasing protein. Ann Surg 1995;221:398-405.

11. Pape HC, Dwenger A, Regel G, Aufm"Kolck M, Gollub F, Wisner D, Sturm JA, Tscherne H. Increased gut permeability after multiple trauma. Br J Surg 1994;81:850-2.

12. Chen MK, Espat NJ, Bland KI, Copeland EM, Souba WW. Influence of progressive tumor growth on glutamine metabolism in skeletal muscle and kidney. Ann Surg 1993;217:655-667,

13. de Blaauw I, Deutz NEP, von Meyenfeldt MF. Increased whole body glutamine turnover in cancer is not matched by increased hindquarter glutamine release. Gastroenterology 1995;108(4):A722.

14. Chen MK, Austgen TR, Klimberg VS, Copeland, III EM, Souba WW. Tumor glutamine use exceeds intestinal glutamine use in cachectic tumor- bearing rats. Surg Forum 1990;41:12-14 .

15. Souba WW. Klimberg VS, Salloum RM, Sitren H, Bland KI, Copeland EM. Tumor modulation of intestinal glutaminase activity. FASEB J 1990:A1042.

16. Waldegrave W, Chairman Council of Eoropean Community. Guide for the care and use of laboratory animals. European Community 1986; Publication, 86/609: Brussels, Belgium.

17. Boyland $\mathrm{E}$, Warren FL. The induction of tumours by methylcholanthrene in two strains of mice. J Path Bact 1937;45:171-177.

18. Popp MB, Morrison SD, Brennan MF. Total parenteral nutrition in a methylcholanthrene-induced rat sarcoma model. Cancer Treat Rep 1981;65(Suppl 5):137-43.

19. Burt ME, Lowry SF, Gorschboth C, Brennan MF. Metabolic alterations in a noncachectic animal tumor system. Cancer 1981;47:2138-2146.

20. Morrison SD. In vivo estimation of size of experimental tumors. J Natt Cancer Inst 1983;71:407408.

21. Dejong CHC, Kampman MT, Deutz NEP, Soeters PB. Altered glutamine metabolism in rat portal drained viscera and hindquarter during hyperammonemia. Gastroenterology 1992;102:936-248.

22. de Blaauw I, Deutz NEP, von Meyenfeldt MF. In vivo amino acid metabolism of gut and liver during short and prolongecl stanvation. Am J Physiol 1996;270(33):G298-306.

23. Rooyakkers DR, van EIjk HMH, Deutz NEP. Simple and sensitive multi sugar probe gut permeability test using HPLC with fluorescence labeling. J Chromatogr 1996;730:99-105.

24. Travis S. Menzies I. Intestinal permeability: functional assessment and significance. Clin Sci 1992;82:471-488.

25. McDermott MR, Horsewood P, Clark DA, Bienenstock J. T lymphocytes in the intestinal epithelium and lamina propria of mice. Immunology 1986;57:213-8.

26. Dejong CHC, Deutz NEP, Soeters PB. Renal ammonia and glutamine metabolism during liver insufficiency- induced hyperammonemia in the rat. J Clin Invest 1993:92:2834-2840.

27. van Eijk HMH, Rooyackers DR, Deutz NEP. Rapid routine determination of amino acids in plasma by high-performance liquid chromatography with a 2-3 um Spherisorb ODS II column. J Chromatogr 1993;620:143-148. 
28. van Eijk HMH, Huinck MP, Rooyakkers DR. Deutz NEP. Automated simultaneous isolation and quantitation of labeled amino acid fractions from plasma and tissue by ion-exchange chromatography. J Chromatogr B Biomed Appl 1994;660:251-7.

29. van Eijk HMH, Rooyakkers DR, Deutz NEP. Automated determination of polyamines by High Performance Liquid Chromatography with simple sample preparation. J Chromatogr 1996 in press.

30. Biolo G, Fleming RY, Maggi SP, Wolfe RR. Transmembrane transport and intracellular kinetics of amino acids in human skeletal muscle. Am J Physiol 1995;268:E75-84.

31. Tourian A, Goddard J, Puck $T T$. Phenylalanine hydroxylase activity in mammalian cells. J Cell Physiol 1969;73:159-170.

32. Norusis MJ. SPSS/PC+ V4.0 BASE MANUAL for the IBM PCIXTIAT and PS/2. SPSS Inc, 1989; Chicago, IL, USA

33. de Blaauw I, Deutz NEP, von Meyenfeldt MF. Glutamine depletion and increased gut permeability in non-anorectic, non weight losing tumor bearing rats. Gastroenterology 1995;108(4):A721.

34. McCormack SA, Johnson LR. Role of polyamines in gastrointestinal mucosal growh. Am J Physiol 1991;260:G795-G806.

35. Janne J, Poso H, Raina A. Polyamines in rapid growth and cancer. Biochım Biophys Acta 1978;473:241-93.

36. Windmueller HG, Spaeth AE. Intestinal metabolism of glutamine and glutamate from the lumen as compared to glutamine from blood. Arch Biochem Biophys 1975:171:662-672.

37. Chance WT, Cao $L_{i}$ KIm MW, Nelson JL, Fischer JE. Reduction of tumor growth following treatment with a glutamine antimetabolite. Life Sci 1988;42:87-94.

38. Fischer JE, Chance WT. Total parenteral nutrition, glutamine, and tumor growth. JPEN J Parenter Enteral Nutr 1990;14:86S-9S.

39. Souba WW. Glutamine and Cancer. Ann Surg 1993:218:715-728.

40. Radeliffe JD, Fontanez IN, Morrow S. The effect of a methyicholanthrene-induced sarcoma on the protein status of fischer rats. Nutr Res 1986;6:539-547.

41. Tessitore L, Costelli P, Baccino FM. Humoral mediation for cachexia in tumour-bearing rats. $\mathrm{Br} \mathrm{J}$ Cancer 1993;67:15-23.

42. Sinith BK, Conn CA, Kluger MJ. Experimental cachexia: effects of MCA sarcoma in the Fischer rat. Am J Physiol 1993;265:E376-R384.

43. Stovroff MC, Fraker DL, Norton JA. Cachectin activity in the serum of cachectic, tumour-bearing rats. Arch Surg 1989:124:94-99.

44. Ardaw MS, Newsholme EA. Glutamine metabolism in lymphocytes of the rat. Biochem J $1983 ; 212: 835-42$.

45. Biolo G. Zhang XJ. Wolfe RR. Role of membrane transport in interorgan amino acid flow between muscle and small intestine. Metabolism 1995;44(6):719-24.

46. Cynober. Can arginine and ornithine support gut functions? Gut 1994; Suppl 1:\$42-\$45.

47. Bjarnason I, MacPherson A, Hollander D. Intestinal permeability: an overview. Gastroenterology 1995:108:1566-81.

48. Li J, Langkamp Henken B, Suzuki K, Stahlgren LH. Glutamine prevents parenteral nutritioninduced increases in intestinal permeability. J Parenter Enteral Nutr 1994;18:303-7.

49. Helton WS. The pathophysiologic significance of alterations, in intestinal permeability induced by' total parenteral nutrition and glutamine. J Parenter Enteral Nutr 1994;18:289-90.

50. Meikle AW, Klain GJ. Effect of fasting and fasting-refeeding on conversion of leucine into CO 2 and lipids in rats. Am J Physiol 1972;222:1246-50.

51. Delahunty T. Hollander D. A comparison of intestinal permeability between humans and three common laboratory animals. Comp Biochem Physiol A 1987;86:565-7. 
52. Fradkin A, Yahav J, Diver Haber A, Zemer D, Jonas A. Colchicine induces enhanced intestinal permeability in the rat. Acta Physiol Scand 1995;153:249-54.

53. Fink MP, Antonsson JB, Wang H, Rothschild HR. Increased intestinal permeability in endotoxic pigs. Arch Surg 1991;126:211-218.

54. Barbuto JA, Grimes WJ, Hersh EM. Antibodies to tumor necrosis factor: a component of B cell immune responses with a role in tumor/host interaction. Cancer Immunol Immunother 1995;40:31-6.

55. Ford RP, Menzies IS, Phillips AD, Walker Smith JA, Turner MW. Intestinal sugar permeability: relationship to diarrhoeal disease and small bowel morphology. J Pediatr Gastroenterol Nutr 1985;4:568-74.

56. Cook GC, Menzies IS. Intestinal absorption and unmediated permeation of sugars in postinfective tropical malabsorption (tropical sprue). Digestion 1986;33:109-16.

57. Crowe SE, Soda K, Stanisz AM, Perdue MH. Intestinal permeability in allergic rats: nerve involvement in antigen-induced changes. Am J Physiol 1993;264:G617-23.

58. Murphy MS, Eastham EJ, Nelson R, Pearson ADJ, Laker MF. Intestinal permeability in Crohn's disease. Arch Dis Child 1989;64:321-325.

59. Menzies IS, Laker MF, Pounder R, Bull J, Heyer S, Wheeler PG, Creamer B. Abnormal intestinal permeability to sugars in villous atrophy. Lancet 1979;2:1107-9.

60. Alverdy JC. Effects of glumatine supplemented diets on immunology of the gut. J Parenter Enteral Nutr 1990;14:109S-113S.

61. Kandil HM, Argenzio RA, Chen W, Berschneider HM, Stiles AD, Westwick JK, Rippe RA, Brenner DA, Rhoads JM. L-Glutamine and Lasparagine stumulate ODC activity and prolifewration in a porcine jejunal enterocyte line. Am J Physiol 1995;32(4):G 591-9. 



\title{
HEPATIC AMINO ACID AND PROTEIN METABOLISM IN MODERATE CACHECTIC TUMOR BEARING RATS
}

\author{
L. de Blaauw, N.E.P. Deutz, W. Boers', M.F. von Meyenfeldt
}

J. Hepatology, in press

Abstract

Cancer cachexia is characterized by loss of lean body mass. Under this, condition peripheral proteins are broken down and their amino acids are transferred to visceral organs and the tumor. The liver is the principle organ in the regulation of protein and amino acid metabolism but liver amino acid kinetics in cancer are unclear. Therefore, we examined the effects of increasing tumor loads on hepatic protein tumover and amino acid handling.

A MCA-induced sarcoma was implanted subcutaneously in Lewis rats, ( $\pm 200 \mathrm{gr}$.). Rats were studied when the tumor was $5-15 \%$ or $15-30 \%$ of body weight. Control rats. were sham implanted. Under anesthesia a primed constant infusion of paraaminohippuric acid and $L-\left[3,4-{ }^{3} \mathrm{H}\right]$-valine was given to calculate hepatic substrate fluxes and protein tumover. Serum $\alpha_{2}$-macroglobulin concentration was measured to determine the acute phase response.

Carcass weight decreased approximately $10 \%$ in large tumor bearing rats $(p<0.001)$. Liver wet weight increased from $5.5 \pm 0.1$ (gr.) to $5.9 \pm 0.2$ in the small tumor bearing group and $7.3 \pm 0.3(p<0.001)$ in the large tumor bearing group with minimal changes in water content. Senum $\alpha_{2}$-macroglobulin concentration, essential and gluconeogenic amino acid uptake by the liver increased in large tumor bearing animals. This contrasted with reduced liver ammonia uptake and unchanged urea production in tumor bearing rats. In the small turnor bearing group liver protein synthesis increased whereas protein breakdown remained unchanged. In the large tumor bearing group protein synthesis also increased but protein breakdown decreased to zero.

\footnotetext{
'Department of Experimental Internal Medicine, Academical Medical Centre, Amsterdam
} 
The study shows that in tumor bearing rats, liver uptake of essential and gluconeogenic amino acids without significant increases in urea or glucose production. Synthesis of both structural and export proteins, e.g acute phase proteins, increases suggesting that the liver becomes a more efficient nitrogen sparing and active protein synthesizing organ during the growth of a malignant tumor.

Introduction

Cancer cachexia is a clinical syndrome characterized by excessive nitrogen loss and increased protein breakdown (1). Peripheral proteins are broken down and amino acids are mobilized and transferred to visceral organs and the tumor $(2,3)$. The liver is a central organ in maintaining amino acid homeostasis (4). The liver is capable to take up amino acids for the production of defense peptides and proteins, gluconeogenesis and ureagenesis (4). Defense peptides and proteins produced in response to cancer are glutathion, acute phase proteins and immune related proteins of the reticulo endothelial system, e.g. Kupffer cells (5-8). In addition, previous studies also showed that synthesis of structural proteins of the liver raised proportionally to the tumor burden to maintain and enlarge liver protein mass (9).

It has long been recognized that hepatic gluconeogenesis increases in the progress of cancer (10-14). Augmented glucose production in cancer has been demonstrated to occur from glycerol, lactate and the amino acid alanine $(11,12,15)$. Recently, glutamine has been recognized to contribute to an even larger extent to the glucose molecule carbon skeletons than alanine (16). Increased gluconeogenesis thus may be related to the depletion of glutamine observed in several other studies (5). Increased gluconeogenesis has also been held responsible for decreased plasma concentrations of other gluconeogenic amino acids, e.g. serine and threonine (17). If the carbon skeleton of amino acids is used to produce glucose, the amino group is processed to urea by the liver to be removed from the body by the kidney. For this reason, increased urea synthesis in the liver may occur in cancer explaining a large part the nitrogen loss observed. Contradictory results, however, have been reported in several animal studies. In tumor bearing mice decreased urea excretion $(18,19)$ and increased nitrogen retention $(20)$ is observed. In addition, decreased plasma concentrations of amino acids of the urea cycle were observed and suggested to reflect a diminished urea cycle activity $(17,21)$.

The present study was undertaken to evaluate the effects of increasing tumor loads in rats on liver amino acid handling. We specifically wanted to evaluate how net amino acid uptake by the liver of the tumor bearing host contributed to protein turnover, urea synthesis and net glucose release. 


\section{Animals}

Female Lewis rats (200-225 g, Centralized Animal Facilities, University of Limburg. Maastricht, NL) were individually housed in metabolic cages during the experiment after an adaptation period of 3 days. Rats were given standard laboratory rat chow ad libitum (SRMA 1210, Hopefarms, Woerden, NL) and subjected to standard 12 hour light-dark cycle periods (7:30 A.M. to 7:30 P.M.) with room temperature maintained at $25^{\circ} \mathrm{C}$. The experiments were performed in accordance with the recommendations of the Guide for the Care and Use of Laboratory Animals (22) and approved by the Ethical Committee of Animal Research of the University of Limburg.

\section{Study procedure}

Methylcholanthrene (MCA) induced sarcomas were implanted subcutaneously as described previously in chapter 5 and 6. MCA tumers are often used in metabolic studies and are known for its rapid growth, invasion of local tissue and absence of metastatic potential $(13,23,24,25,26)$.

Two studies were performed. In both experiments rats were randomly divided into three groups: a small tumor bearing group (ST), a large tumor bearing group (LT) and a control group fed ad libitum. In the ST group the tumor was allowed to grow until it reached $5-15 \%$ of the host body weight. In the LT group the tumor grew to 15 $30 \%$ of the host body weight. To avoid effects of time, tumor tissue was transplanted bilaterally on the back in the ST group, whereas it was quadruple implanted in the LT group. Control rats were sham implanted with saline. Tumor growth was monitored by measuring two orthogonal dimensions and by calculating the volume assuming the tumor to be a prolate spheroid (27). Rats were housed in metabolic cages and tumor size, body weight and food intake were monitored daily.

In a first experiment ( $n=10$ per group) the acute phase respons was determined by measuring serum $\alpha_{2}$-macroglobulin (28). Blood was obtained under ether anaesthesia by puncture of the retrobulbar venous plexus.

In a second experiment ( $n=16$ per group) liver metabolism was examined as described in chapter $4(29,30)$. In brief, under ether anesthesia and at constant, preanesthesia body temperature, a laparotomy was performed. The right renal vein, the mesenteric vein, the portal vein, the hepatic vein and the aorta were cannulated using a 25 gauge needle fixed in a Silastic tube (Silastic Medical Grade tubing 0.051 cm ID, 0.094 OD. Dow Corning Corporation, Midland, MO, USA) and fixed with 
cyano-acrylate. For flow measurements, the indicator dilution method with para-

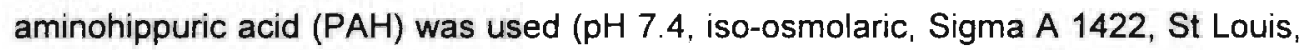
MI, USA). A primed $\left(0.15 \mathrm{ml} \times 100 \mathrm{~g} \mathrm{bw}^{-1}, 50 \mathrm{~mol} / \mathrm{L}\right)$ continuous infusion $(0.75 \mathrm{ml} \times$ $\left.100 \mathrm{~g} \mathrm{bw}^{-1} \times \mathrm{h}^{1}, 5 \mathrm{mmol} / \mathrm{L}\right)$ of PAH was infused in the mesenteric vein, using a Minipuls 3 Peristaltic Pump (Gilson Med. Electr. Inc., Villiers-le-Bel, France). A primed $\left(1 \mu \mathrm{Ci} \times 100 \mathrm{~g} \mathrm{bw}^{-1}\right)$ constant infusion $\left(1 \mu \mathrm{Ci} \times 100 \mathrm{~g} \mathrm{bw}^{-1} \times \mathrm{h}^{-1}\right)$ of $\mathrm{L}-\left[3,4-{ }^{3} \mathrm{H}\right]$ valine $\left({ }^{3} \mathrm{H}-\mathrm{Val}\right.$, Amersham Int plc, TRK533, Buckinghamshire, UK) and L$\left[3,4{ }^{3} \mathrm{H}\right] \mathrm{glutamine}\left({ }^{3} \mathrm{H}-\mathrm{Gln}\right.$, NEN NET-551, Mechelen, Belgium) was given in the right renal vein. The results concerning hepatic glutamine turnover are dicussed in a chapter 8. A minimum infusion time of 30 minutes was needed to reach steady state concentrations for $\mathrm{PAH},{ }^{3} \mathrm{H}-\mathrm{Val}$ and ${ }^{3} \mathrm{H}-\mathrm{Gln}(30)$. In experiment 2 the whole procedure took 40 minutes before blood was sampled.

\section{Sampling procedure}

In the second experiment $1.0 \mathrm{ml}$ blood was simultaneously sampled from the portal vein, hepatic vein and aorta. All blood was collected in heparinized cups on ice. Hereafter, the liver was dissected free, directly freeze-clamped, put in liquid nitrogen and stored at $-80^{\circ} \mathrm{C}$ until further analysis. For PAH determinations, $50 \mu \mathrm{l}$ heparinized blood was added to $500 \mu \mathrm{l} \mathrm{TCA} \mathrm{10 \%} \mathrm{(Merck} \mathrm{807,} \mathrm{Darmstadt,} \mathrm{Germany).}$ vortexed and centrifuged at $8,900 \mathrm{~g}$ at $4^{\circ} \mathrm{C}$ (Universac 30RF, Hettich, Tuttlingen, Germany). The supernatant was frozen in liquid nitrogen and stored at $-80^{\circ} \mathrm{C}$ until further analysis. For hematocrit determinations a micro-hematocrit tube was filled with heparinized blood and centrifuged at $10,000 \mathrm{~g}$ at room temperature. Hematocrit was read with a Micro Hematocrit Reader. Plasma was obtained by whole blood centrifugation at $8,900 \mathrm{~g}$ at $4^{\circ} \mathrm{C}$ for 5 minutes. For ammonia, urea, glucose and lactate determinations, $200 \mu$ l plasma was vortexed with $20 \mu \mathrm{lTCA} 50 \%$, put into liquid nitrogen and stored at $-80^{\circ} \mathrm{C}$. To determine plasma amino acid specific activities and concentrations, $8 \mathrm{mg}$ 5-sulfosalicylic acid (SSA) was added to $200 \mu \mathrm{l}$ plasma, vortexed, frozen in liquid nitrogen and stored at $-80^{\circ} \mathrm{C}$.

\section{Analysis}

Plasma ammonia, urea, glucose, lactate and PAH were determined spectrophotometrically on a Cobas Mira S (Roche Diagnostica, Hoffman-La Roche, Basel, Switzerland) by standard enzymatic methods, using commercially available kits as described previously $(29,31)$. Plasma amino acid concentrations and specific activity were determined by HPLC as described previously (32). Serum $\alpha_{2}$ macroglobulin was determined by single immunodiffusion using mono specific antibodies against rat $\alpha_{2}$-macroglobulin (28). For the determination of tissue ammonia, amino acid concentrations and specific activities, liver tissue was 
pulverized using a mortar and pestle precooled in liquid nitrogen. The tissue was further homogenized and deproteinized in a Mini-Beadbeater (Biospec products, Bartlesville USA). Approximately $100 \mathrm{mg}$ tissue was added to $400 \mu \mathrm{l} \mathrm{SSA} 5 \%$, with $300 \mathrm{mg}$ glass beads (diameter $1 \mathrm{~mm}$, Biospeck Products) and beaten for 30 seconds. The homogenate was centrifuged at $4^{\circ} \mathrm{C}$ at $1,100 \mathrm{~g}$ and the supernatant frozen in liquid nitrogen and stored at $-80^{\circ} \mathrm{C}$ until further determinations.

To determine tissue dry weight and water content approximately $200 \mathrm{mg}$ pulverized tissue was freeze dried for 24 hours in a Speedvac (SC200, Savant Instruments Inc., Farmingdale NY, USA) connected with a refrigerated condensation trap (Savant Instruments Inc.).

\section{Calculations}

Hepatic plasma flow, flux and intracellular concentrations

Plasma flow across liver was calculated using PAH in the indicator dilution method as described previously $(33,34)$. Splanchnic flux was calculated by multiplying the mean hepatic plasma flow with hepatic vein-arterial concentration differences. Portal drained viscera (PDV) flux is the mean PDV plasma flow multiplied with portal veinarterial concentration difference. Liver flux was calculated by subtracting PDV flux from the splanchnic flux $(33,34)$. A positive flux indicates net release, a negative flux reflects a net uptake. $\alpha$-Amino-nitrogen was calculated as the sum of the individual amino acids measured (32). Essential, non-essential and gluconeogenic amino acids are defined as described previously (35). Tissue concentrations of amino acids are expressed in $\mu \mathrm{mol} / \mathrm{L}$ and derived by dividing the tissue homogenate amino acid concentration ( $\mu \mathrm{mol} / \mathrm{kg}$ wet weight) by the tissue water content.

\section{Hepatic protein turnover}

Liver in vivo protein turnover was calculated in a three compartment model as described in detail in chapter 2 and $4(30,36)$. The three compartments involved are the following: 1) vascular afferent pool (hepatic artery and portal vein); 2) intracellular free amino acid pool; 3) vascular efferent pool (hepatic vein). Disposa! and production of valine are calculated out of and into the intracellular free amino acid pool. Disposal of valine was used to estimate liver protein synthesis as the liver has low valine transaminase activity (37). Similar, valine production can only originate from protein breakdown. Valine is used both in vitro and in vivo to measure hepatocyte protein turnover $(38,39)$.

Membrane transport rates are calculated as the amino acid flux from the afferent pool to the intracellular pool $\left(F_{L A}\right)$, the amino acid flux from the intracellular pool into 
the hepatic vein $\left(F_{L, H}\right)$ and the amino acid flux shunting from afferent vessels into the hepatic vein $\left(F_{H, A}\right)$.

\section{Statistical Analysis}

Results are presented as mean \pm SEM. The Mann Whitney $U$ test corrected with the Bonferroni procedure was used to test significance between tumor bearing groups and control group (40). Significance was considered present at $p<0.05$.

\section{Results}

\section{General response}

The presence of MCA tumors did not reduce food intake (Figure 1) while carcass weight decreased only moderately in the large tumor bearing animals (Table 1). Liver weight was unchanged in the small tumor bearing animals and increased approximately $30 \%$ in the large tumor bearing animals after 24 days. Serum $\alpha_{2}$ macroglobulin concentration raised with increasing tumor loads. In the large tumor bearing rats $\alpha_{2}$-macroglobulin concentrations were elevated comparable to those seen in response to severe acute inflammatory stimuli such as turpentine or surgical trauma $(28,41)$.
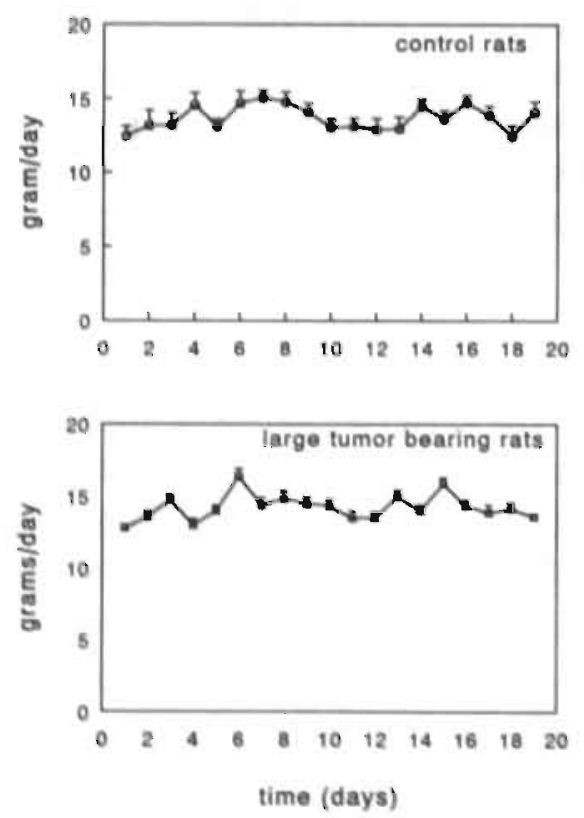

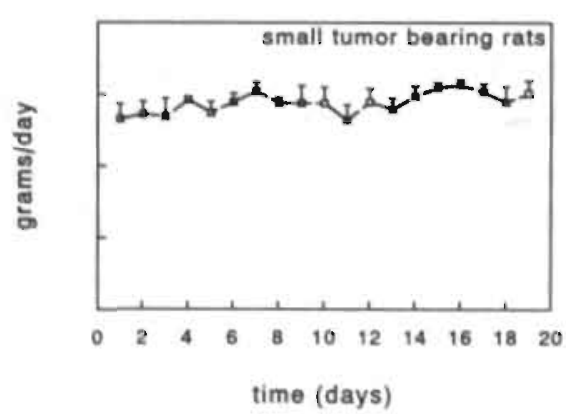

Figure 1. Food intake of control, small tumor bearing and large tumor bearing rats. All rats were fed ad libitum. No significant? changes in food intake. between different groups. 
Table 1. Tumor weight, carcass weight, liver wet weight, dry weight, intracellular water content and serum $\alpha_{2}$-macroglobuline concentrations. Values are grams (mean \pm SEM) except $\alpha_{2}$-macroglobuline $(\mu \mathrm{g} / \mathrm{ml})$ and measured at day of implantation (day 1) and day of experiment (day 24). Detection level $\alpha_{2}$-macroglobuline is $50 \mu \mathrm{g} / \mathrm{ml}$. Statistical analysis by Mann Whitney $U$ vs control group: " $p<0.05$, " $p<0.01,{ }^{c} p<0.001$.

\begin{tabular}{|c|c|c|c|c|c|c|c|c|c|c|}
\hline & \multicolumn{3}{|c|}{ Control } & & \multicolumn{2}{|c|}{ Small tumor } & & \multicolumn{2}{|c|}{ Large tumor } & \\
\hline & day & & day 24 & & day 1 & day 2 & & day 1 & day 24 & \\
\hline Tumor weight & - & & - & & - & - & & - & - & \\
\hline Carcass weight & $200 \pm$ & 4 & $200 \pm$ & 4 & $192 \pm 3$ & $198 \pm$ & 2 & $199 \pm$ & $181 \pm$ & $2^{\circ}$ \\
\hline \multicolumn{11}{|l|}{ Liver } \\
\hline Wet weight & - & & $5.5 \pm$ & 0.1 & - & $5.9 \pm$ & 0.2 & - & $7.3 \pm$ & $0.3^{\mathrm{e}}$ \\
\hline Dry weight & - & & $1.56 \pm$ & 0.10 & - & $1.54 \pm$ & 0.05 & - & $1.90 \pm$ & $0.08^{e}$ \\
\hline$\%$ Water & - & & $71.6 \pm$ & 0.5 & - & $73.9 \pm$ & 0.4 & - & $73.7 \pm$ & 0.9 \\
\hline$\alpha_{2}-$ Macroglobuline & - & & $<50$ & & - & $1019 \pm$ & $509^{a}$ & - & $5300 \pm$ & $1040^{c}$ \\
\hline
\end{tabular}

\section{Arterial concentrations}

Arterial glucose concentrations deminished in the small tumor bearing animais and decreased further in the large tumor bearing animals (Table 2). Arterial lactate concentrations increased with increasing tumor load.

An arterial hyperaminoacidemia developed in both groups of tumor bearing rats, (Fig. 2, Table 2). In the tumor bearing rats both essential and non-essential amino. acid concentrations increased. In control rats almost $30 \%$ of non-essential amino acids consisted of glutamine which proportion concentration did not change in the presence of a tumor. Concentrations of all gluconeogenic amino acids increased in tumor bearing rats.

\section{Liver intracellular concentrations}

Intracellular ammonia did not vary between controls and tumor bearing rats (Table 3). Total $\alpha$-amino acid nitrogen remained unchanged in the small tumor bearing animals but decreased in the large tumor bearing animals (Table 3, Fig. 3). However, mostly non essential amino acids decreased and of these primarily glutamine and taurine. 
Table 2. Arterial glucose, lactate, ammonia, urea and amino acid concentrations in control, small and large tumor bearing rats. Values are presented in $\mu \mathrm{mol} / \mathrm{L}$ except glucose, lactate and urea in mmol/L (mean \pm SEM). Mann Whitney $U$ vs control group: ${ }^{a} p<0.05,{ }^{b} p<0.01,{ }^{c} p<0.001$. BCAA: Branched Chain Amino Acids (leucine, isoleucine, valine). Essential amino acids in italics, gluconeogenic amino acids in bold (32).

\begin{tabular}{|c|c|c|c|c|c|c|c|}
\hline \multirow[b]{2}{*}{ Glucose } & \multicolumn{2}{|c|}{ Control } & \multicolumn{3}{|c|}{ Small tumor } & \multicolumn{2}{|c|}{ Large tumor } \\
\hline & 9.7 & \pm 0.1 & 8.7 & \pm & $0.4^{c}$ & 7.7 & $\pm 0.2^{c}$ \\
\hline Lactate & 6.4 & \pm 0.3 & 7.4 & \pm & $0.3^{c}$ & 8.4 & $\pm 0.4^{c}$ \\
\hline Arnmonia & 174 & \pm 10 & 169 & \pm & 8 & 161 & $\pm \quad 9$ \\
\hline Urea & 3.9 & \pm 0.2 & 3.9 & \pm & 0.2 & 3.8 & \pm 0.1 \\
\hline GlutamIne & 550 & \pm 25 & 577 & $t$ & 12 & 539 & $\pm \quad 28$ \\
\hline Glutamate & 62 & \pm 4 & 82 & \pm & $6=$ & 118 & $\pm 10^{c}$ \\
\hline Asparagine & 33 & \pm 2 & 43 & \pm & $1^{c}$ & 42 & $\pm \quad 2^{\circ}$ \\
\hline Serine/Histidine & 189 & \pm 15 & 235 & \pm & $7^{2}$ & 199 & $\pm \quad 11$ \\
\hline Glycine & 180 & \pm 15 & 263 & \pm & $18^{c}$ & 276 & $\pm 11^{c}$ \\
\hline Threonlne & 83 & \pm 4 & 87 & \pm & 5 & 70 & $\pm \quad 4^{\circ}$ \\
\hline Citrulline & 46 & \pm 3 & 52 & \pm & 2 & 64 & $\pm \quad 17$ \\
\hline Alanine & 321 & \pm 18 & 359 & \pm & 18 & 358 & \pm 25 \\
\hline Arginine & 118 & \pm 5 & 161 & \pm & $6^{\circ}$ & $15 \mathrm{Cl}$ & $\pm 8^{c}$ \\
\hline Taurine & 150 & \pm & 302 & \pm & $25^{c}$ & 342 & $\pm 37^{c}$ \\
\hline$\alpha$-Aminobutyric acid & 22 & \pm & 36 & \pm & $2^{c}$ & 48 & $\pm 9^{c}$ \\
\hline Tyrosine & 61 & \pm & 94 & \pm & $4^{c}$ & 113 & $\pm 31^{c}$ \\
\hline Valine & 117 & \pm & 154 & \pm & $6^{\circ}$ & 168 & $\pm 10^{c}$ \\
\hline Methionine & 45 & \pm & 53 & \pm & $1^{c}$ & 50 & $2^{a}$ \\
\hline Isoleuclne & 48 & \pm & 70 & \pm & $3^{c}$ & 72 & $4^{c}$ \\
\hline Phenylalanine & 47 & \pm & 66 & \pm & $2^{c}$ & 77 & $7^{\circ}$ \\
\hline Tryptophan & 48 & \pm & 38 & \pm & $2^{c}$ & 33 & $2^{\circ}$ \\
\hline Laucine & 73 & \pm & 102 & \pm & $4^{c}$ & 98 & $5^{c}$ \\
\hline Ornithine & 18 & \pm 2 & 37 & \pm & $3^{\circ}$ & 46 & $5^{c}$ \\
\hline Lysine & 291 & \pm 15 & 409 & \pm & $15^{\mathrm{c}}$ & 356 & $\pm 25^{b}$ \\
\hline$B C A A$ & 239 & \pm 13 & 326 & \pm & $12^{\mathrm{s}}$ & 326 & $14^{c}$ \\
\hline
\end{tabular}

Esșential amino acid concentrations either increased (histidine, valine, isoleucine, phenylalanine, leucine) or remained unchanged (threonine, methionine, tryptophan, lysine) with increasing tumor loads. The sum of essential amino acids increased in the large tumor bearing rats. The sum of gluconeogenic amino acids decreased in the small tumor bearing rats and remained reduced in the large tumor bearing rats. 
Table 3. Intracellular ammonia and amino acid concentrations in the liver of control, small and large tumor bearing rats. Values are presented in $\mu$ mol/ (mean \pm SEM). Mann Whitney $U$ vs control group: " $p<0.05$, $p<0.01$, ${ }^{e} p<0.001$. BCAA: Branched Chain Amino Acids (leucine, isoleucine, valine). Essential amino acids in italics, gluconeogenic amino acids in bold (32).

\begin{tabular}{|c|c|c|c|c|c|c|c|}
\hline \multirow[b]{2}{*}{ Arnmonia } & \multicolumn{2}{|c|}{ Control } & \multicolumn{3}{|c|}{ Small tumor } & \multicolumn{2}{|c|}{ Large tumor } \\
\hline & 1681 & \pm 133 & 1801 & \pm & 155 & 1691 & $\pm \quad 78$ \\
\hline Glutarnine & 5221 & \pm 236 & 3700 & * & $297^{\circ}$ & 3052 & $\pm 298^{\circ}$ \\
\hline Histidine & 408 & $\pm \quad 19$ & 390 & \pm & 22 & 533 & \pm 21 \\
\hline Glutamate & 5128 & \pm 237 & 5066 & \pm & 216 & 4818 & \pm 339 \\
\hline Asparagine & 68 & \pm 5 & 135 & \pm & $28^{\circ}$ & 103 & $\pm 14^{\circ}$ \\
\hline Serine & 404 & $\pm \quad 18$ & 484 & 业 & 45 & 518 & $\pm 51^{c}$ \\
\hline Glycine & 3658 & \pm 128 & 2674 & \pm & 111 & 2962 & $\pm 137^{\circ}$ \\
\hline Threonine & 758 & \pm 63 & 787 & \pm & 173 & 897 & \pm 105 \\
\hline Citrulline & 99 & $\pm \quad 7$ & 122 & \pm & $8^{*}$ & 128 & $\pm 10^{\circ}$ \\
\hline Alanine & 4243 & \pm 376 & 4452 & \pm & 294 & 4563 & \pm 322 \\
\hline Arginine & 261 & $\pm \quad 75$ & 407 & \pm & 79 & 178 & \pm 62 \\
\hline Taurine & 14006 & \pm 869 & 15962 & \pm & 1345 & 11309 & $\pm 1298^{\circ}$ \\
\hline$\alpha$-Aminobutyric acid & 102 & \pm 14 & 165 & \pm & 8 & 230 & $\pm 23^{c}$ \\
\hline Tyrosine & 161 & $\pm \quad 12$ & 163 & \pm & 8 & 201 & $11^{\circ}$ \\
\hline Valine & 238 & $\pm \quad 16$ & 267 & \pm & 15 & 288 & $21=$ \\
\hline Methionine & 133 & $\pm \quad 10$ & 127 & \pm & 11 & 146 & 19 \\
\hline Isoleucine & 118 & $\pm \quad 8$ & 136 & \pm & 8 & 141 & $9^{*}$ \\
\hline Phenylalanine & 112 & \pm & 124 & \pm & $5=$ & 136 & $7^{b}$ \\
\hline Tryptophan & 39 & \pm & 42 & \pm & 2 & 41 & 4 \\
\hline Leucine & 228 & $\pm \quad 14$ & 279 & \pm & $13^{*}$ & 284 & $17=$ \\
\hline Ornithine & 203 & $\pm \quad 12$ & 272 & \pm & $15^{\circ}$ & 326 & $27^{\circ}$ \\
\hline Lysine & 884 & \pm 88 & 966 & \pm & 155 & 830 & 47 \\
\hline$B C A A$ & 584 & \pm 28 & 682 & \pm & 37 & 713 & $35^{\circ}$ \\
\hline
\end{tabular}

Urea cycle intermediate amino acids are ornithine, citrulline and arginine. The first two increased in tumor bearing rats but arginine concentrations decreased below control values in the large tumor bearing rats.

Hepatic plasma flow and flux

Hepatic plasma flow was similar in control and both tumor bearing animals (Table 4). Glucose release decreased in small tumor bearing rats although not significantly. Lactate uptake increased in the large tumor bearing animals. In line with this, we found an increased uptake of gluconeogenic amino acids in the large tumor bearing 
Table 4. Hepatic glucose, lactate, ammonia, urea and amino acid fluxes in control, small and large tumor bearing rats. Values are presented in nmol $\times 100 \mathrm{~g} \mathrm{bw}^{-1} \times \mathrm{min}^{-1}$ (mean $\pm \mathrm{SEM}$ ). Mann Whitney $U$ vs control group: " $p<0.05,{ }^{b} p<0.01,{ }^{\circ} p<0.001$. BCAA: Branched Chain Amino Acids (leucine, isoleucine, valine). Essential amino acids in italics, gluconeogenic amino acids in bold (32).

\begin{tabular}{|c|c|c|c|c|c|c|c|c|}
\hline \multirow[b]{2}{*}{ Flow } & \multicolumn{2}{|c|}{ Control } & \multicolumn{3}{|c|}{ Small tumor } & \multicolumn{3}{|c|}{ Large tumor } \\
\hline & 2.5 & \pm 0.5 & 2.6 & \pm & 0.6 & 2.7 & \pm & 0.6 \\
\hline Glucose & 318.4 & \pm 792 & 1910 & \pm & 467 & 3310 & \pm & 487 \\
\hline Lactate & -2940 & \pm 702 & -3659 & \pm & 461 & -4235 & & $448^{3}$ \\
\hline Ammonia & -310 & \pm 36 & -160 & \pm & $32^{\circ}$ & -177 & \pm & $30^{b}$ \\
\hline Urea & 820 & \pm 169 & 456 & \pm & 81 & 521 & \pm & 57 \\
\hline GlutamIne & 112 & \pm 52 & -64 & \pm & $34^{\circ}$ & 37 & \pm & 38 \\
\hline Glutamate & -19 & \pm 15 & 108 & \pm & $28^{\circ}$ & 112 & \pm & $28^{\circ}$ \\
\hline Asparaglne & -43 & $\pm \quad 5$ & 57 & \pm & 7 & 66 & \pm & $6^{\mathrm{b}}$ \\
\hline Serine/Histidine & -115 & \pm 19 & -166 & \pm & 22 & -155 & \pm & 22 \\
\hline Glycine & -201 & \pm 33 & -184 & \pm & 27 & -262 & \pm & 30 \\
\hline Threonine & -57 & \pm 26 & -63 & \pm & 8 & -68 & \pm & 8 \\
\hline Citrulline & -42 & \pm 11 & .20 & \pm & 7 & -56 & \pm & $8^{\circ}$ \\
\hline Alanine & -396 & $\pm \quad 79$ & -321 & \pm & 63 & -545 & \pm & $52^{a}$ \\
\hline Arginine & -53 & \pm 9 & -97 & \pm & $14^{\circ}$ & -114 & \pm & $15^{b}$ \\
\hline Taurine & -52 & \pm 18 & -9 & \pm & 26 & -84 & \pm & 45 \\
\hline$\alpha$-Aminobutyric acid & -11 & \pm 3 & -3 & \pm & 3 & -7 & \pm & 4 \\
\hline Tyrosine & -22 & \pm & -18 & \pm & 7 & -31 & \pm & 10 \\
\hline Valine & 26 & \pm & 8 & \pm & 12 & -36 & \pm & $18^{c}$ \\
\hline Methionine & 1 & \pm & -22 & \pm & $7^{\circ}$ & -28 & \pm & $5^{c}$ \\
\hline Isoleucine & 13 & \pm 4 & 13 & \pm & 6 & -6 & \pm & $6^{a}$ \\
\hline Phenylalanine & -3 & \pm & -9 & \pm & 3 & -32 & \pm & $8^{\circ}$ \\
\hline Tryptophan & 4 & \pm 7 & 3 & \pm & 3 & -3 & \pm & 4 \\
\hline Leucine & 26 & \pm 14 & 17 & \pm & 8 & -19 & \pm & $13^{a}$ \\
\hline Ornithine & 3 & \pm 4 & 31 & \pm & $10^{b}$ & -2 & \pm & 12 \\
\hline Lysine & -136 & $\pm \quad 18$ & -161 & \pm & 31 & -208 & \pm & 50 \\
\hline$B C A A$ & 64 & \pm 24 & 38 & \pm & 24 & -62 & \pm & $34^{b}$ \\
\hline
\end{tabular}

rats (Table 4, Fig. 4). Alanine uptake accounted for 40 to $46 \%$ of the uptake of all gluconeogenic amino acids by the liver. The uptake of total $\alpha$-amino acids remained unchanged in the small tumor bearing rats but tended to increase in the large tumor bearing rats. This was due to an increased uptake of essential amino acids.

The uptake of non-essential amino acids also only tended to increase. Ammonia uptake decreased in both tumor bearing rats. Urea release remained unchanged in the small and large tumor bearing animals. 

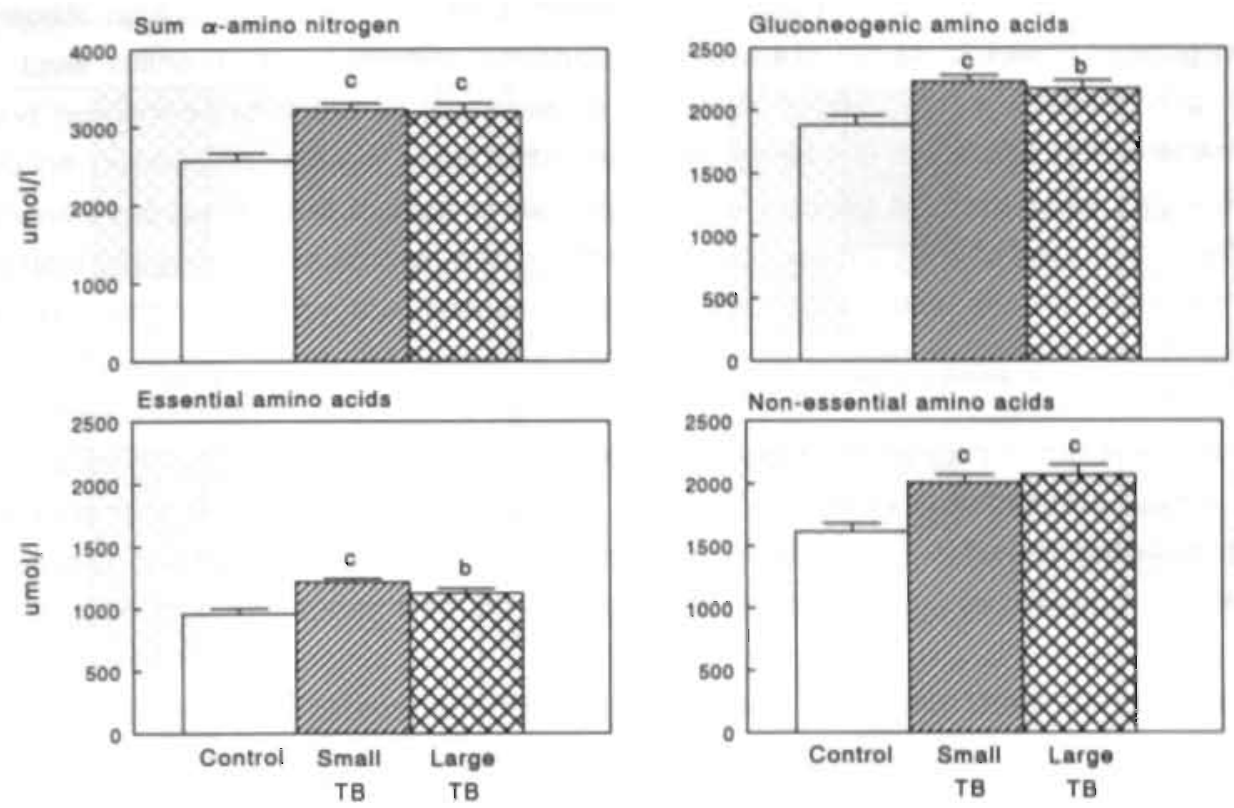

Figure 2. Arterial concentrations ( $\mu \mathrm{mol} / /$ ) of total $\alpha$-amino nitrogen (top, left), gluconeogenic amino acids (top, right), essential amino acids (bottom, left) and non essentiai amino acids (bottom, right). " $p=0.05,{ }^{b} p=0.01,{ }^{c} p=0.001$. TB = tumor bearing.
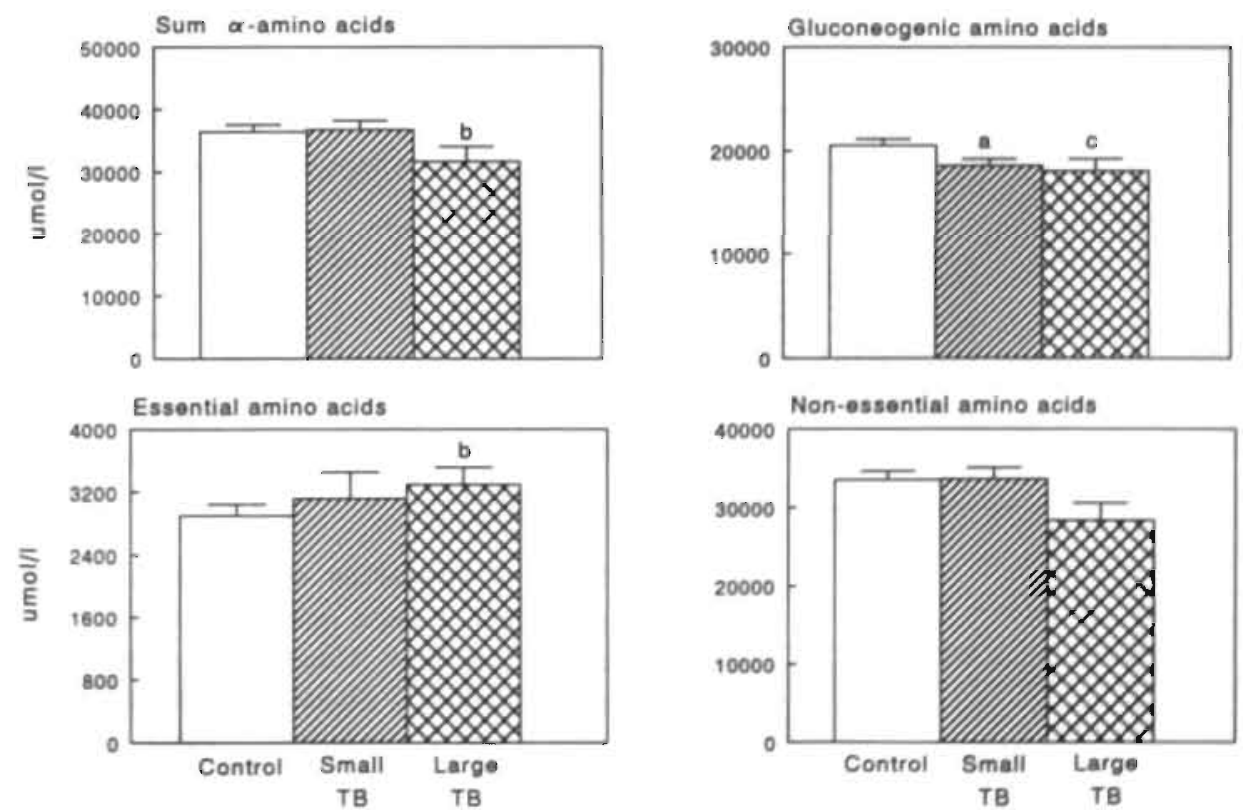

Figure 3. Intracellular concentrations ( $\mu \mathrm{mol} / \mathrm{l}$ ) of total $\alpha$-amino nitrogen (top, left), gluconeogenic amino acids (top, right), essential amino acids (bottom, left) and non essential amino acids (bottom, right). " $p=0.05,{ }^{b} p=0.01,{ }^{c} p=0.001$. TB $=$ tumor bearing. 

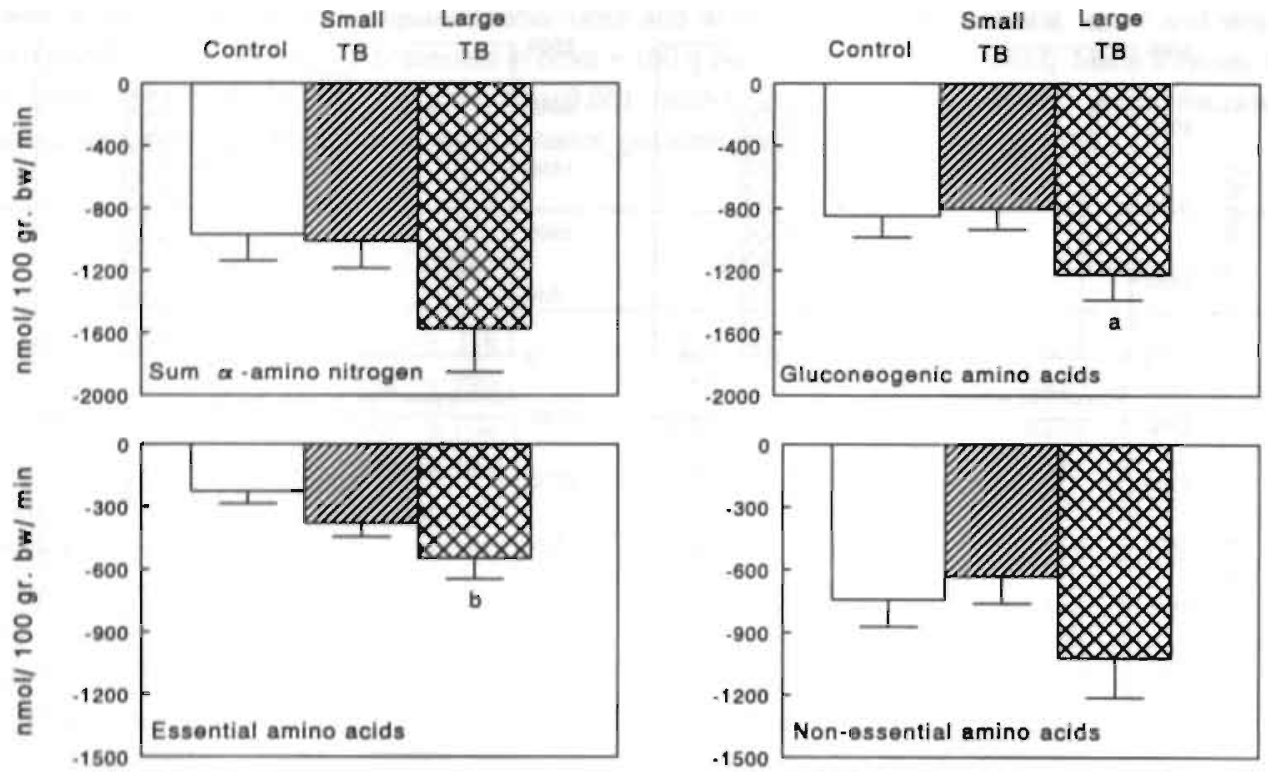

Figure 4. Fluxes of total $\alpha$-amino nitrogen (top, left). gluconeogenic amino acids (top, right), essential amino acids (bottom, left) and non essential amino acids (bottom, right) across the liver. $A$ negative flux reflects net uptake, a positive flux reflects net release of amino acids. $p=0.05,{ }^{b} p=0.01$, $p=0.001 . T B=$ tumor bearing

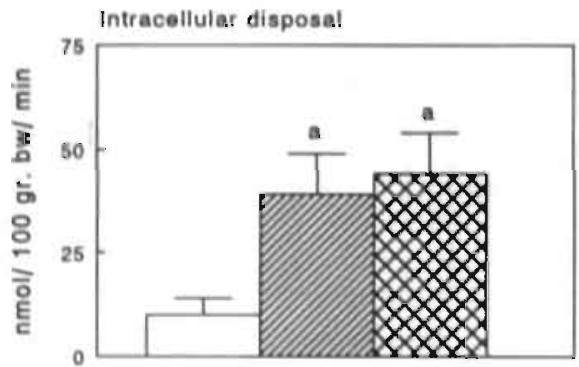

Flux valine

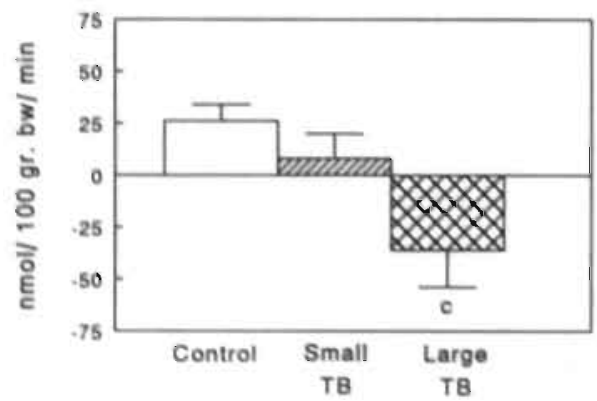

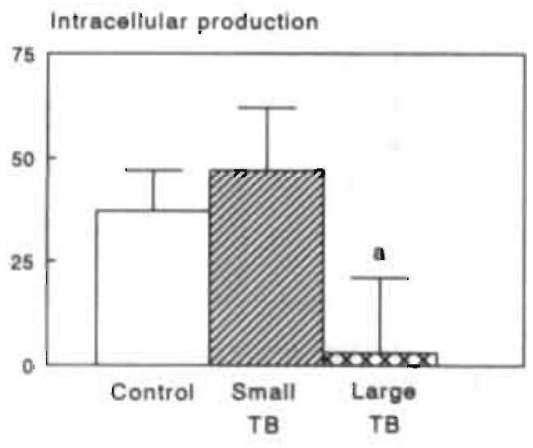

Figure 5. Intracellular disposal of valine (top). production of valine (middle) and flux of valine across the liver. Disposal of valine reflects protein synthesis whereas production of valine reflects protein breakdown. Valine fluxt is the difference between disposal and production (negative: net uptake; positive: net release). " $p=0.05$, ${ }^{b} p=0.01$, ${ }^{c} p=0.001$. TB $=$ tumor bearing. 


\section{Hepatic protein turnover and valine membrane transport}

Liver valine disposal (protein synthesis) increased in the small tumor bearing rats and remained increased at that level in the large tumor bearing animals (Fig. 5). Valine production (protein breakdown) was unchanged in the small tumor bearing animals but decreased to zero in the large tumor bearing animals. Liver valine flux (difference protein breakdown and synthesis) was thus reduced to zero in the small tumor bearing rats by the increased protein synthesis rates. In the large tumor bearing animals valine flux became negative (=net protein synthesis) by strongly decreased protein breakdown rates.

Valine inward membrane transport rates ( $\left.F_{L, A}\right)$ were unchanged in the small tumor bearing rats and increased only slightly in the large tumor bearing rats (Table 5). Outward membrane transport $\left(F_{H, L}\right)$ was not significantly different between the groups. In the large turnor bearing group valine shunting $\left(F_{H, A}\right)$ increased more than fifty percent.

To see whether plasma-amino acid membrane transport determines a large fraction of intracellular amino acid turnover, we calculated total intracellular amino acid appearance rate of valine as the sum of valine inward membrane transport plus valine production from intracellular protein breakdown ( $\left.R a_{i}, T a b l e ~ 6\right)$. Membrane transport determines $74 \%$ of all de novo appearance of valine in the free intracellular amino acid pool of control rats. Approximately $26 \%$ of intracellular amino acid appearance in the hepatocyte is determined by protein breakdown (production). In the small tumor bearing rats protein breakdown accounted for a relatively larger amount of total valine appearance rate than in control rats, whereas this decreased to zero in the large tumor bearing rats.

Table 5. Liver valine membrane transport in control, smali and large tumor bearing rats. Values are presented in nrnol valine $\times 100 \mathrm{~g} \mathrm{bw}^{-1} \times \min ^{-1}$ (mean $\pm \mathrm{SEM}$ ). $\mathrm{F}_{\mathrm{LA}}$ : inward directed membrane transport rates; $F_{H, L}$ : outward directed membrane transport; $F_{L A}$ : metabolic shunting. " $p<0.05$, ${ }^{b} p<0.01$, $p<0.001$ vs control group.

\begin{tabular}{|c|c|c|c|c|c|c|c|}
\hline \multirow[b]{2}{*}{$F_{L A}$} & Control & \multicolumn{3}{|c|}{ Șmall tumọr } & \multicolumn{3}{|c|}{ Large tumor } \\
\hline & $88 \pm 31$ & 87 & \pm & 50 & 108 & \pm & $33^{\circ}$ \\
\hline$F_{H, L}$ & $105 \pm 37$ & 95 & \pm & 56 & 71 & \pm & 42 \\
\hline$F_{H A}$ & $201 \pm 31$ & 301 & \pm & 51 & 325 & \pm & $37^{\circ}$ \\
\hline
\end{tabular}


Table 6. Total intracellular valine turnover and relative contribution of amino acid membrane transport and intracellular protein breakdown (Production). $F_{L A}$ : inward membrane transport of valine; $P$ : intracellular production from protein breakdown; $R_{a}$ : total intracellular appearance rate $\left(F_{L, A}+\right.$ production). $\mathrm{Ra}_{4}$ is in $\mathrm{nmol}$ valine $\times 100 \mathrm{~g} \mathrm{bw}^{-1} \times \mathrm{min}^{-1}, \mathrm{~F}_{\mathrm{I}, \mathrm{w}} / \mathrm{Ra}_{\mathrm{i}}$ and $\mathrm{P} / \mathrm{Ra}$, are the fractions to which membrane transport and protein breakdown contribute to total intracellular appearance rate. Statistics: vs control group: " $p<0.05,{ }^{b} p<0.01,{ }^{c} p<0.001$.

\begin{tabular}{|c|c|c|c|c|c|c|c|c|c|}
\hline \multirow[b]{2}{*}{$\mathrm{Ra}_{i}$} & \multicolumn{2}{|c|}{ Control } & \multicolumn{4}{|c|}{ Small tumor } & \multicolumn{3}{|c|}{ Large tumor } \\
\hline & 142 & \pm 40 & 180 & \pm & 71 & & 174 & \pm & 57 \\
\hline$F_{1, \omega} / R_{a_{1}}$ & 0.74 & \pm 0.07 & 0.58 & \pm & 0.06 & • & 0.97 & \pm & 0.04 \\
\hline $\mathrm{P} / \mathrm{Ra}_{\mathrm{i}}$ & 0.26 & \pm 0.07 & 0.41 & \pm & 0.06 & ฯ & 0.03 & \pm & 0.04 \\
\hline
\end{tabular}

Discussion

The liver has a dual role in the development of cancer. It regulates a great part of the intermediary metabolism, particularly related to amino acid and glucose homeostasis. It is, however, also involved in the acute phase response. Processing of amino acids by the liver in cancer therefore both serves the production of defense proteins and the maintenance of metabolic homeostasis. In our rat cancer model no anorexia was observed. The inflammatory and metabolic changes observed can thus only be attributed to the presence of the tumor. However, the unchanged nutrient intake in the presence of a tumor of $5-15 \%$ or $15-30 \%$ of the body weight must have changed nutrient delivery to non-tumor tissues with subsequent adaptations in intermediary metabolism. Net carcass weight loss was limited in this cancer model. The current study thus appears to be a reflection of metabolic changes observed in moderate cancer cachexia, e.g. early detected cancer patients with no, or hardly any, nitrogen and weight loss.

Urea production by the liver remained unchanged in both groups of tumor bearing rats although it tended to decrease $(p=0.07)$. The decrease may have remained undetected by the variation of the data (type II error). Citrulline and ornithine are intermediary amino acids of the urea cycle. In a previous study decreased arterial concentrations of these amino acids were found indicative for decreased urea cycle activity in tumor bearing rats (17). In the current study increased concentrations of these amino acids were observed in arterial plasma and, moreover, in the liver of tumor bearing rats. We feel that this is more in agreement with decreased urea cycling as intermediate substrates of the urea cycle appear not to be used. However, 
it also indicates that changes in amino acid concentrations are difficult to translate into kinetic parameters and the interpretation of only amino acid concentrations should be done with great care.

Unchanged or possibly decreased activity of the urea cycle in tumor bearing animals also explains the increased arterial amino acid concentrations. We previously showed that the presence of the tumor increases peripheral protein breakdown with an enhanced net efflux of amino acids from muscle (42). Thus, mobilization of amino acids in combination with unchanged or decreased urea cycle activity and increased arterial amino acid concentrations, directs amino acid interorgan transfer towards other tissues, e.g. immune cells and tumor tissue.

Arginine is also an intermediary amino acid of the urea cycle. The decreased intracellular arginine concentrations in large tumor bearing rats are probably not related to the urea cycle but to the production of nitric oxide: arginine is the precursor of nitric oxide and nitric oxide production by hepatocytes and Kupffer cells increases after stimulation with inflammatory mediators (8).

Two environmental stimuli are of influence on urea production in tumor bearing rats. The availability of $\alpha$-amino nitrogen is a well described factor which influences liver amino acid uptake and processing $(35,43)$. In particular low protein diets decrease the availability of amino acids for the liver (43). The uptake of amino acids by the liver thus decreases with subsequent reduced urea production. In our tumor bearing rats, however, arterial concentrations increased with increasing tumor loads suggesting a greater availability of amino acids for potential urea synthesis. Another important mechanism influencing urea synthesis is related to circulating peptides/proteins induced by the presence of the tumor. Hormones and cytokines are known to influence liver urea synthesis and protein synthesis in other stress conditions, such as burns, infection and trauma (44). Increased, decreased and unchanged insulin and glucagon levels have been observed in MCA tumor bearing rats $(38,45,46)$. In addition, increased levels of severa! cytokines, e.g. TNF $\alpha_{,}$IL.1, IL6, have been observed in the cancer bearing host (47-51). These cytokines are ali able to induce in vitro amino acid uptake by hepatocytes $(52,53)$. Involvement of IL6 is further in agreement with the general concept that it is one of the most important mediators of the acute phase response as observed in the current study $(28,51)$. The positive effects of the increased arterial amino acid concentrations on the urea cycle therefore appears to be counteracted by humoral factors. However, the exact etiology of such a nitrogen sparing mechanism by the liver in the cancer bearing host needs further research.

Increased Cori cycling and increased gluconeogenesis have been demonstrated in previous studies of sarcoma bearing rats $(15,46,54)$. In our study no changes in net glucose production were observed. This may have been caused by the negative 
effect of ether anesthesia on gluconeogenesis (55). We, however, also did not measure the exact gluconeogenesis but only the net production of glucose. This will clearly underestimate liver gluconeogenesis in particular when inflammatory cells of the liver, such as Kupffer cells, are activated and consume glucose.

Lactate and amino acids are major precursors for gluconeogenesis (56). If the carbon skeleton of amino acids is transformed to glucose, the amino group is processed to urea. Amino acids first transfer their amino group to aspartate which donates one nitrogen group to urea. The second nitrogen of urea is derived from the amide group of glutamine or free ammonia. Gluconeogenic amino acid uptake in control rats is thus more or less in balance with the nitrogen transferred to urea in control rats (Table 4, 850 versus $820 \mathrm{nmol} \times 100 \mathrm{~g} \mathrm{bw}^{-1} \times \mathrm{min}^{-1}$ ). In the small tumor bearing rats the uptake of gluconeogenic amino acids exceeds the nitrogen used for urea production by $348 \mathrm{nmol} \times 100 \mathrm{~g} \mathrm{bw}^{-1} \times \mathrm{min}^{-1}$ and this surplus increases to 705 $\mathrm{nmol} \times 100 \mathrm{~g} \mathrm{bw}^{-1} \times \mathrm{min}^{-1}$ in large tumor bearing rats. Thus, it appears that the liver prefers to use gluconeogenic amino acids for other processes, mainly protein synthesis. Acute phase protein synthesis has previously been shown to increase secondary to tumor growth (51). Serum $\alpha_{2}$-macroglobulin is one of the major acute phase proteins in the rat and is a broad spectrum protease inhibitor that can bind cytokines and regulates tissue damage and restructuring $(28,57)$. Increased levels of several cytokines, damage and necrosis of tumor are features of our tumor model and may very well explain the raised increased acute phase protein synthesis.

Protein synthesis in the hepatocyte was measured by intracellular valine disposal. This was possible as the enzyme activity of the major other metabolic route, transamination, is very low in liver tissue compared to other tissues (37). Maximal transamination of valine in the rat liver is $75 \mathrm{nmol} \times 100 \mathrm{~g} \mathrm{bw}^{-1} \times \mathrm{min}^{-1}$ and the $\mathrm{Km}_{\mathrm{m}}$ value is $1.2-2.5 \mathrm{mM}(58)$. Our in vivo intracellular valine concentrations are approximately one tenth of the $\mathrm{K}_{\mathrm{m}}$ value. Estimated in vivo transamination would thus be approximately $4 \mathrm{nmol} \times 100 \mathrm{~g} \mathrm{bw}^{-1} \times \mathrm{min}^{-1}$ which comprises almost half of the intracellular disposal of valine in control rats. However, in the tumor bearing rats this was only one tenth of total disposal and most of intracellular valine disposal can thus be accounted for by protein synthesis.

In control rats protein breakdown rates exceeded protein synthesis rates resulting in a net protein loss with a net efflux of valine. The negative protein balance of the liver in control rats is related to the experimental conditions. First, all rats are studied postabsorptively. Second, previous studies, although not all (59) suggest that ether anesthesia decreases protein synthesis rates of the liver $(60,61)$. The increased net protein synthesis rates in tumor bearing rats should thus be interpreted relative to the control rats and may in absolute terms be an underestimation of the actual protein synthesis rates. 
Liver protein synthesis is the sum of export proteins and structural proteins. Serum $\alpha_{2}$-macroglobulin is considered to be the most reactive acute phase protein exported by the liver (28). It has a turnover of approximately $8 \%$ per day and a $\mathrm{Kd}$ of 820.000 (62). Assuming plasma volume of rats to be $4 \%$ of bodyweight (62), the increased serum $\alpha_{2}$-macroglobulin concentrations in the large tumor bearing rats equals an additional production of $48 \mathrm{mg} \alpha_{2}$-macroglobuline proteins. This is approximately $27800 \mathrm{nmol}$ valine (63) over approximately 18 days or $0.5 \mathrm{nmol}$ valine $\times 100 \mathrm{gr}^{-b^{-1}}$ $x \mathrm{~min}^{-1}$. Although other acute phase proteins (e.g. haptoglobulin, coeruloplasmine, $\alpha_{1}$ acid glycoprotein) are also produced by hepatocytes in response to inflammation, the descrepancy between the calculated intracellular disposal (44 nmol $\times 100 \mathrm{gr}$. bw ${ }^{-1} \times$ $\left.\min ^{-1}\right)$ and the theoretical disposal for $\alpha_{2}$-macroglobuline $(0.5 \mathrm{nmol})$, suggest that the increased protein synthesis in majority reflects increased synthesis of structural proteins of the liver.

The increased protein synthesis in the small tumor bearing rats was not accompanied by increased membrane transport rates of valine. This indicates that changes in membrane transport activity were not involved in the regulation of liver protein synthesis. This can also be seen in the relative contribution of amino acid membrane transport and intracellular production to total intracellular amino acid turnover $\left(\mathrm{Ra}_{3}\right.$, Table 6$)$. The relative contribution of intracellular production increased at the cost of membrane transport rates in the small tumor bearing rats. In the large tumor bearing rats, however, valine production decreased to almost zero and membrane transport was still sufficiently high to supply valine for protein synthesis. The unchanged valine membrane transport despite the increased need for intracellular valine in these animals possibly indicates that amino acid membrane transport of these amino acids in our rat cancer model is working at submaximal activity. These in vivo findings are in agreement with in vitro observations on hepatocyt system $L$ membrane transport carriers. These studies show that system $L$ membrane transport carriers demonstrate a relatively high activity in hepatocytes but do not maintain large concentration differences across cell membranes (64). Furthermore, hepatic system $L$ has been shown not to play any significant role in liver amino acid turnover in the presence of altered amino acid availability due to high or low protein diets (43).

In conclusion, the study shows that in tumor bearing rats, liver uptake of essential and gluconeogenic amino acids increases. Glucose and urea production remain unchanged whereas protein synthesis of both structural and export proteins, e.g acute phase proteins, increase. These changes indicate that the liver becomes a more efficient nitrogen sparing and active protein synthesizing organ during the growth of a malignant tumor. 
The authors wish to thank Mr. HMH van Eijk, Mr. DR Rooyakkers and Mrs. H. Sala for analytical help.

\section{References}

1. Kern KA, Norton JA. Cancer cachexia. J Parenter Enteral Nutr 1988;12:286-298.

2. Norton JA, Shamberger R, Stein TP. Milne GW, Brennan MF. The influence of tumor-bearing on protein metabolism in the rat. J Surg Res 1981;30:456-462.

3. Douglas RG, Shaw JH. Metabolic effects of cancer. Br J Surg 1990;77:246-54.

4. Christensen HN. Interorgan amino acid nutrition. Physiol Rev 1982;62:1193-1233.

5. Souba WW. Glutamine and Cancer. Ann Surg 1993;218:715-728.

6. Fahr MJ, Kornbluth J, Blossom S, Schaeffer R, Klimberg VS. Harry M. Vars Research Award. Glutamine enhances immunoregulation of tumor growth. J Parenter Enteral Nutr 1994;18:471-6

7. Welbourne TC, King AB, Horton K. Enteral glutamine supports hepatic glutathione efflux during inflammation. J Nutr Biochem 1993;4:236-242

8. Billiar TR, Curran RD. Kupffer cell and hepatocyte interactions: a brief overview. J Parenter Enteral Nutr 1990;14:175S-80S.

9. Warren RS, Jeevanandam M, Brennan MF. Protein symthesis in the tumor-influenced hepatocyte. Surgery 1985:98:275-82.

10. Holroyde CP, Gabuzda TG, Putnam RC, Paul P. Reichard GA. Altered glucose metabolism in metastatic carcinoma. Cancer Res 1975;35:3710-4.

11. Lundholm K, Edstrom S, Karlberg I, Ekman L, Schersten T. Glucose turnover, gluconeogenesis from glycerol, and estimation of net glucose cycling in cancer patients. Cancer 1982:50:1142-50.

12. Inculet RI, Peacock JL, Gorschboth CM, Norton JA. Gluconeogenesis in the tumor-influenced rat hepatocyte: importance of tumor burden, lactate, insulin, and glucagon. J Natl Cancer Inst 1987:79:1039-46.

13. Burt ME, Lowry SF, Gorschboth C, Brennan MF. Metabolic alterations in a noncachectic animal tumor system. Cancer 1981:47:2138-2146.

14. Lowry SF, Foster DM, Norton JA, Berman M, Brennan MF. Glucose disposal and gluconeogenesis from alanine in tumor-bearing Fischer 344 rats. J Natl Cancer Inst 1981;66:6538.

15. Lowy SF, Foster DM, Norton JA, Berman M, Brennan MF. Glucose disposal and gluconeogenesis from alanine in tumor-bearing fischer 344 rats. J Natl Cancer Inst 1981;66:653658.

16. Nurjhan N. Bucci A, Perriello G, Stumvoll M, Dailey G, Bier DM, Tof I, Jenssen TG, Gerich JE. Glutamine: a major gluconeogenic precursor and vehicle for interorgan carbon transport in man. J Clin Invest 1995:95:272-7.

17. Chance WT, Cao L. Kim MW. Nelson JL. Fischer JE. Reduction of tumor growth following treatment with a glutamine antimetabolite. Life Sci 1988;42:87-94.

18. Ekman L. Lundholm KG. Blackburn GL, Grant JP, Young VR, editors. Amino Acids, metabolism and medical applications. London: John Wright. PSG Inc, 1983; Is the liver or the periphery limiting for hepatic utilization of amino acids in cancer-induced malnutrition, pp. 213-7.

19. Beck SA. Tisdale MJ. Nitrogen excretion in cancer cachexia and its modification by a high fat diet in mice. Cancer Res 1989;49:3800-3804.

20. Karlberg HI, Kern KA, Fischer JE. Albumin turnover in sarcoma-bearing rats in relation to cancer anorexia. Am J Surg 1983;145:95-101. 
21. Krause R, James JH, Humphrey C, Fischer JE. Plasma and brain amino acids in Walker 256 carcinosarcoma-bearing rats. Cancer Res 1979;39:3065-9.

22. Waldegrave W. Chairman Council of European Community. Guide for the care and use of laboratory animals. European Community 1986; Publication 86/609, Brussels, Belgium

23. Boyland $\mathbf{E}$, Warren FL. The induction of tumours by methylcholanthrene in two strains of mice. J Path Bact 1937;45:171-177.

24. Chen MK, Espat NJ, Bland KI, Copeland EM, Souba WW. Influence of progressive tumor growth on glutamine metabolism in skeletal muscle and kidney. Ann Surg 1993;217:655-667.

25. Popp MB, Morrison SD, Brennan MF. Total parenteral nutrition in a methyl-cholanthrene-induced rat sarcoma model. Cancer Treat Rep 1981;65(Suppl 5):137-43.

26. de Blaauw I, Deutz NEP, von Meyenfeldt MF. Glutamine depletion and increased gut permeability in non-anorectic, non weight losing tumor bearing rats. Gastroenterologyf 1995;108(4):A.721

27. Morrison SD. In vivo estimation of size of experimental tumors. J Natl Cancer Inst 1983;71:407408.

28. van Gool J, van Vugt H. Helle M, Aarden LA. The relation among stress, adrenalin, interleukin 6 and acute phase proteins in the rat. Clin Immunol Immunopathol 1990;57:200-10.

29. Dejong CHC, Kampman MT, Deutz NEP, Soeters. PB. Altered glutamine metabolism in rat portal drained viscera. and hindquarter during hyperammonemia. Gastroenterology 1992;102:936-9.48.

30. de Blaauw I, Deutz NEP, von Meyenfeldt MF. In vivo amino acid metabolism of gut and liver during short and prolonged starvation. Am J Physiol 1996;270(33):G298-306.

31. Dejong CHC, Deutz NEP. Soeters, PB. Renal ammonia and glutamine metabolism during liver insufficiency- induced hyperammonemia in the rat. J Clin Invest 1993;92:2834-2840.

32. van Eijk HMH, Huinck MP, Rooyakkers DR, Deutz NEP. Automated simultaneous isclation and quantitation of labeled amino acid fractions from plasma and tissue by ion-exchange chromatography. J Chromatogr El Biomed Appl 1994;660:251-7'.

33. Deutz NEP, Reijven PL, Athanasas G, Soeters PB. Post-operative changes in hepatic, intestinal, splenic and muscle fluxes of amino acids and ammonia in pigs. Clin Sci Colch 1992;83:607-14

34. Heeneman S, Deutz: NEP. Effects of decreased glutamine supply on gut and liver metabolism in vivo in rats. Clin Sci 1993:85:437-444.

35. Thomas JH, Gillham B. Thomas J, Gillham B, editors. Wills' Biochemical Basis of medicine. 2nd ed. London: Wright; 1989; 20, Plasma amino acid's and utilization of amino acids by tissues „p. 238-47.

36. Biolo G. Fleming RY. Magg: SP, Woife RR. Transmembrane transport and intracellular kinetics of amino acids in human skeletal muscle. Am J Physiol 1995;44 (6):E75-84.

37. Shinnick FL, Harper AE. Branched-chain amino acid oxidation by isolated rat tissue preparations. Biochim Biophys Acta 1976:437:477-86.

38. Warren RS, Jeevanandam M, Brennan MF. Comparison of hepatic protein synthesis in vivo versus in vitro in the tumor-bearing rat. J Surg Res 1987;42:43-50.

39. Seglen PO, Solhein AE, Grinde B, Gordon PB, Schwarze PE, Gjessing Rm, Poli A. Amino acid control of protein synthesis and degradation in isolated rat hepatocytes. Ann N Y Acad Sci 1980;349:1-17

40. Norusis MJ. Statistical Package for Social Sciences (SPSS)/PC+ V4.0 BASE MANUAL for the IBM PCIXT/AT and PS/2. SPSS Inc, 1989; Chicago, IL, USA.

41. Jennings G. Elia $M$. The acute-phase response to turpentine-induced abscesses in mainourished rats at different environmental temperatures. Metabolism 1992;41:141-7.

42. de Blaauw I, Deutz NEP, von Meyenfeldt MF. Increased whole body glutamine turnover in cancer is not matched by increased hindquarter glutamine release. Gastroenterology 1995;108(4):A722. 
43. Fafoumoux P, Remesy C, Demigne C. Fluxes and membrane transport of amino acids in rat liver under different protein diets. Am J Physiol 1990;259:E614-E625.

44. Heindorf HA. The hepatic catabolic stress response. Hormonal regulation of urea synthesis after surgery. Dan Med Bull 1993;40:224-234.

45. Chance WT, Muggia Sullam M, Chen MH, Murphy RF, Fischer JE. Reversal of tumor-induced biochemical abnormalities by insulin treatment in rats. J Natl Cancer Inst 1986;77:497-503.

46. Lowry SF, Norton JA, Gorschboth CM. Brennan MF. Glucose turnover and gluconeogenesis during hypocaloric glucose infusion in tumor-bearing F344 male rats. J Natl Cancer Inst 1980;64:291-296.

47. Stovroff MC, Fraker DL, Norton JA. Cachectin activity in the serum of cachectic, tumour-bearing rats. Arch Surg 1989;124:94-99.

48. Fearon $\mathrm{KCH}$, McMillan DC, Preston T, Winstanley P. Cruickshank AM, Shenkin A. Elevated circulating interleukin- 6 is associated with an acute-phase response but reduced fixed hepatic protein synthesis in patients with cancer. Ann Surg 1991;213:26-31.

49. Smith BK, Conn CA, Kluger MJ. Experimental cachexia: effects of MCA sarcoma in the Fischer rat. Am J Physiol 1993;265:E376-R384.

50. Ardawi MS. Effects of epidermal growth factor and glutamine-supplemented parenteral nutrition on the small bowel of septic rats. Clin Sci Colch 1992;82:573-80.

51. Andersson C, Gelin J, Iresjo BM, Lundholm K. Acute-phase proteins in response to tumor growth. J Surg Res 1993:55:607-14.

52. Andus T, Bauer J, Gerok W. Effects of cytokines on the liver. Hepatology 1991;13:364-375.

53. Bereta J, Kurdowska A, Koj A, Hirano T, Kishimoto T, Content J, Fiers. W. Van Damme J, Gauldie J. Different preparations of natural and recombinant human interleukin-6 (IFN-beta 2, BSF-2) similarly stimulate acute phase protein synthesis and uptake of alpha-aminoisobutyric acid by cultured rat hepatocytes. Int J Biochem 1989;21:361-6.

54. Singh J, Grigor MR. Thompson MP. Glucose homeostasis in rats bearing a transplantable sarcoma. Cancer Res 1980;40:1699-706.

55. Philippidis H. Ballard FJ. The development of gluconeogenesis in rat liver. Effects of glucagon and other. Biochem J 1970;120:385-92.

56. Hers HG, Hue L. Gluconeogenesis and related aspects of glycolysis. Annu Rev Biochem $1983 ; 52: 617-653$.

57. Jennings $\mathbf{G}$. Bourgeois $C$. Elia $M$. The magnitude of the acute phase protein response is attenuated by protein deficiency in rats. J Nutr 1992;122:1325-1331.

58. Harper AE, Miller RH, Block KP. Branched chain amino acid metabolism. Annu Rev Nutr 1984;4:409-454.

59. Sampson DA, Masor M, Jansen GR. Protein synthesis in rat tissues during lactation: no effect of diethyl ether anaesthesia. Biochem J 1984;224:681-3.

60. Bessesen A, Morland J. Effects of anaesthetics on protein synthesis in isolated rat hepatocytes: inhibition by diethyl ether in contrast to no influence by pentobarbital and fentanyl. Acta Pharmacol Toxicol Copenh 1985;57:23-9.

61. Bessesen A, Smith Kielland A, Gadeholt G, Morland J. Reduced synthesis of hepatic and plasma proteins in rats during diethyl ether anaesthesia. Acta Pharmacol Toxicoll Copenh 1984:54:241-6.

62. James WPT, Coward WA. Waterlow JC, Stephen JML, editors. Nitrogen metabolism in man. L.ondon: ASC: 1981; 37', Metabolism of plasma proteins, pp. 457-73.

63. Beitel G.J, Luft AJ, Pannucker DE, Lorscheider FL. Structural analysis of acute-phase $\alpha_{2}$ macrogiobilin. Biochem J 1986;238:359-64.

64. Kilberg MS. Amino acicl transport in isolated rat hepatocytes. J Membr Biol 1982;69:1-12. 


\title{
HEPATIC GLUTAMINE KINETICS IN CANCER
}

\author{
L. de Blaauw, N.E.P. Deutz, M.F. von Meyenfeldt
}

Submitted

\begin{abstract}
The liver plays a key role in glutamine homeostasis. Cancer cachexia is thought to be related to deteriorated glutamine metabolism. Aim of this study was to exarnine the effects of increasing tumor loads on hepatic glutamine membrane transport and intra- and intercellular glutamine tumover.

A MCA-induced sarcoma was implanted subcutaneously in Lewis rats $( \pm 200 \mathrm{~g})$. Rats were studied when the tumor was $5-15 \%$ or $15-30 \%$ of body weight. Control rats were sham implanted. Under anesthesia a primed constant infusion of para-aminohippuric acid and $\mathrm{L}-\left[3,4{ }^{3} \mathrm{H}\right]$-glutamine was given. At steady state, glutamine turnover and membrane transport rates were calculated in a three compartment model of the liver.

Carcass weight decreased approximately $10 \%$ in large tumor bearing rats. Liver wet weight increased from $5.6 \pm 0.1$ (gr.) to $5.9 \pm 0.2$ (gr.) in the small tumor bearing group to $7.3 \pm 0.3$ (gr.) in the large tumor bearing group. Arterial glutamine concentrations remained unchanged whereas hepatic intracellular glutamine concentrations decreased in both tumor bearing rats. The net balance of glutamine across the liver changed from a net release in control rats to a net uptake in the small tumor bearing group. In the large tumor bearing group glutamine balance was not different from zero. Hepatic intracellular glutamine disposal (control $198 \pm 87 \mathrm{nmol} \times 100 \mathrm{~g} \mathrm{bw}^{-1} \times$ minute ${ }^{-1}$ ) increased in the small tumor bearing group $\left(624 \pm 127 \mathrm{nmol} \times 100 \mathrm{~g} \mathrm{bw}^{-1} \times\right.$ minute $\left.{ }^{-1}\right)$ and decreased to control values in the large tumor bearing group $\left(266 \pm 59 \mathrm{nmol} \times 100 \mathrm{~g} \mathrm{bw}^{-1} \times\right.$ minute $\left.^{-1}\right)$. Increased intracellular glutamine tumover was accompanied by a net increased inward directed membrane transport rate. Normalized for the concentrations, both inward and outward membrane transport rates increased indicating increased transport activity in both
\end{abstract}


tumor bearing rats. The study shows that modulation of liver glutamine breakdown is an important determinant of glutamine handling in tumor bearing rats.

Introduction

Glutamine is the most abundant amino acid in the body and has many key metabolic functions $(1,2)$. The liver is a central organ in maintaining glutamine homeostasis as it can either produce or consume glutamine (3). Periportal hepatocytes have high glutaminase activity and can deamidate glutamine resulting in the formation of ammonia and glutamate (4). Glutamine is thus a substrate for gluconeogenesis and ureagenesis in the liver. Liver glutamine synthetase activity is mostly restricted to perivenous cells $(4,5)$. Plasma glutamate and ammonia are almost completely used for glutamine synthesis. This result is a so called intercellular glutamine cycle in the liver which normally results in neither a net uptake nor release of glutamine (6). It also makes it possible for the liver to consume or release net amounts of glutamine depending on prevailing metabolic pressure.

Plasma-tissue membrane transport represents an important step in liver glutamine metabolism. Glutamine membrane transport systems build up a plasma-tissue (cytosolic and mitochondrial) concentration gradient to enable liver glutaminase to be active near its $K_{m}(5)$. In this respect, glutamine membrane transport rates were suggested to be rate controlling in hepatic glutamine synthesis and degradation handling (4.5).

Following injury, stress or in the progress of cancer, glutamine plasma and intracellular skeletal muscle pools become depleted $(7,8)$. This has been associated with increased protein catabolism. Failure of the liver to produce sufficient glutamine was suggested to be one of the main pathophysiological mechanisms involved (2).

The present study was undertaken to evaluate the effects of an increasing tumor burden on in vivo liver glutamine membrane transport. A recently introduced in vivo model was used to simultaneously measure in vivo amino acid membrane transport rates and intracellular turnover $(9,10)$. In doing so, we also wanted to compare in vivo membrane transport rates in cancer with intracellular glutamine turnover to test whether membrane transport rates have regulating properties in vivo. 


\section{Study procedure}

The present study was simultaneously done with the study on hepatic metabolism of other amino acids and on hepatic protein turnover as described in chapter 7 . Therefore, animals, study procedure and biochemical analysis are as described on page 151-154. In brief, a methylcholanthrene (MCA) induced tumor, which is serially transplanted in our laboratory, was used to study the effects of cancer on hepatic glutamine metabolism. Female Lewis rats $(200-225 \mathrm{~g}, \mathrm{n}=48)$ were randomly divided into three groups: a small tumor bearing group (ST), a large tumor bearing group (LT) and a control group fed ad libitum. In the ST group the tumor was allowed to grow until it reached 5-15\% of the host body weight. in the LT group the turnor grew to $15-30 \%$ of the host body weight. Rats were housed in metabolic cages and tumor size, body weight and food intake were monitored daily. Food consumption of tumor bearing animals was similar to control animals until the day of measurements (see chapter 7 ).

In vivo hepatic glutamine membrane transport rates and liver glutamine turnover were calculated in a three compartment model (see figure 5, chapter 2). The three compartments involved are the following: 1) vascular afferent pool (hepatic artery and portal vein); 2) intracellular pool; 3) vascular efferent pool (hepatic vein). Disposal and production of glutamine is calculated out of and into the intracellular free amino acid pool. Membrane transport rates are calculated as the amino acid flux from the afferent pool to the intracellular pool $\left(F_{1, a}\right)$, the amino acid flux from the intracellular pool into the hepatic vein $\left(F_{i, h}\right)$ and the amino acid flux shunted from afferent vessels into the hepatic. vein $\left(F_{h, a}\right)$.

To compare intracellular glutamine kinetics between the groups all data were normalized per unit of glutamine concentration of the source pool $(11,12)$. $F_{1, \bar{a}}$ was divided by the arterial concentration, $F_{v, l}$ and disposal by the intracellular concentration. These parameters describe the volume of arterial plasma or intracellular water cleared of glutamine via inward or outward membrane transport per unit of time. Total intracellular appearance $\left(R a_{1}\right)$ is defined as the sum of $F_{1, a}$ and intracellular production (P) (11). $F_{1 . a} / R a_{1}$ expresses the fractional contribution of membrane transport to intracellular glutamine turnover relative to total glutamine turnover (12). P/Ral expresses the fractional contribution of intracellular glutamine production relative to total glutamine turnover. 
Statistical Analysis

Results are presented as mean \pm SEM. The Mann Whitney $U$ corrected with the Bonferroni procedure was used to test significance (13). Significance was considered present at $p<0.05$.

Results

Arterial, portal and intracellular concentrations

Ammonia remained unchanged in arterial plasma of both tumor bearing rats (Table 1). Portal venous ammonia concentration decreased with increasing tumor loads. Hepatic intracellular ammonia was remained unaffected by the presence of the tumors. Glutamate concentrations increased in arterial and portal venous blood of large tumor bearing animals but remained unchanged intracellularly.

Table 1. Plasma and intracellular ammonia and amino acid concentrations in control, small and large tumor bearing rats. Values are mean $\pm \operatorname{SEM}(\mu \mathrm{M})$. Mann Whitney test $U$ vs control group: $p<0.05$, ${ }^{b} p<0.01,{ }^{\circ} p<0.001$; vs small tumor bearing group: ${ }^{a} p<0.05,{ }^{\circ} p<0.01,{ }^{\prime} p<0.001$.

Conitroi

Small tumor

Large tumor

Arterial concentrations

Ammonia

Glutamate

$174 \pm 10$

$62 \pm 4$

Glutamine

$550 \pm 25$

$\begin{array}{rcc}169 & \pm & 8 \\ 82 & \pm & 6 \\ 577 & \pm & 12\end{array}$

$161 \pm 9$

Portal concentrations

Amrnonia

Glutamate

$332 \pm 19$

$86 \pm 5$

Glutamine

$263 \pm 16$

$118 \pm 10^{\mathrm{cs}}$

$539 \pm 28$

Intracellular concentrations

Ammonia

Glutamate

$1681 \pm 132$

$5128 \pm 237$

$287 \pm 11$

$77 \pm 6$

$335 \pm 15^{\circ}$

$277 \pm 12^{b}$

$114 \pm 12$.

$326 \pm 11^{\mathrm{c}}$

Glutamine

$5221 \pm 236$

$1801 \pm 155$

$5066 \pm 216$

$1691 \pm 78$

$3700 \pm 186^{\circ}$

$4819 \pm 338$

$3052 \pm 298^{c . e}$ 
Glutamine concentration remained unchanged in the arterial blood and increased in portal venous blood of both tumor bearing rats. Intracellular glutamine concentrations decreased by approximately $29 \%$ and $41 \%$ in the smail and large tumor bearing animals, respectively.

\section{Hepatic plasma flow and net flux}

Hepatic plasma flow was similar in control and both tumor bearing animals (Table 2). Ammonia uptake, decreased in both tumor bearing rats. Glutamate flux changed from zero to a net release in both tumor bearing rats. Glutamine flux changed from a net release to a net uptake in small tumor bearing rats. In large tumor bearing rats glutamine flux became not significantly different from zero.

Hepatic glutamine tumover and membrane transport rates

Intracellular giutamine disposal increased threefold in smali tumor bearing animals and decreased again in large tumor bearing animals (Table 3). Glutamine production

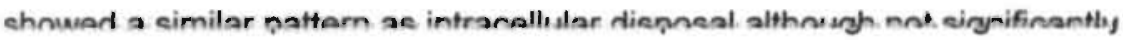

In conjunction with increased glutamine turnover, liver inward membrane transport rates $\left(F_{1, a}\right)$ increased in the small tumor bearing rats. Outward membrane transport $\left(F_{v, t}\right)$ remained unchanged in both tumor bearing rats.

Table 2. Hepatic plasma flow and fluxes of ammonia and amino acids in control, small ancl large fumor bearing rats. Plasma flow in $\mathrm{ml} \times 100 \mathrm{~g} \mathrm{bw}^{-1} \times \mathrm{min}^{-1}$. flux in $\mathrm{nmol} \times 100 \mathrm{~g} \mathrm{bw}^{-1} \times \mathrm{min}^{-1}($ mean $\pm \mathrm{SEM}$ ). Mann Whitney $U$ test vs controll group: " $p<0.05,{ }^{b} p<0.01$, ${ }^{c} p<0.001$; vs small tumor bearing group: " $p<0.05$, " $p<0.01$. ' $p<0.001$.

$\begin{array}{lrrrrrrr}\text { Flow } & 2.5 & \pm 0.5 & 2.6 & \pm & 0.6 & 2.7 & \pm 0.6 \\ \text { Ammonia } & -310 \pm 36 & -160 & \pm & 32 & -177 & \pm 30 \\ \text { Glutamate } & -19 \pm 15 & 108 & \pm & 28^{c} & 112 & \pm 28^{c} \\ \text { Glutamine } & 112 \pm 52 & -64 & \pm & 34^{*} & 37 & \pm 38\end{array}$


Table 3. Liver glutamine kinetics in control, small and large tumor bearing rats. Values are presented in $n$ mol $\times 100 \mathrm{~g} \mathrm{bw}^{-1} \times \min ^{-1}$ (mean \pm SEM). Statistical analysis by Mann Whitney $U$ test vs control group: ${ }^{a}$ $p<0.05, "{ }^{n} p<0.01,{ }^{6} p<0.001$; vs small tumor bearing group: ${ }^{d} p<0.05,{ }^{\circ} p<0.01,{ }^{\prime} p<0.001$.

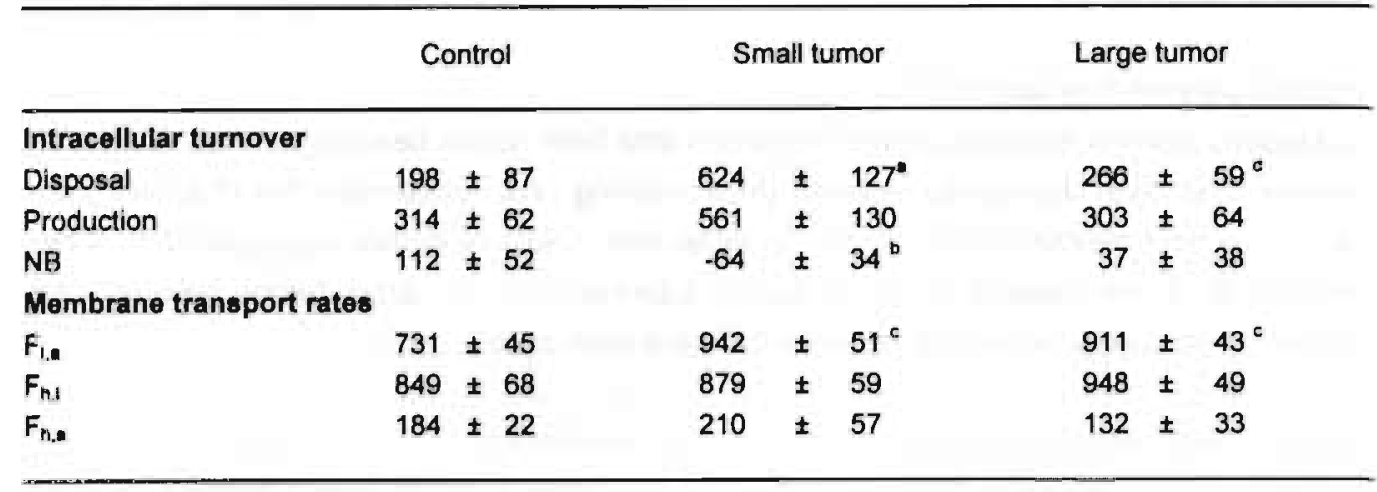

Table 4. Glutamine membrane transport system activity and intracellular disposal normalized to the concentration of source pool. Values are presented $\mathrm{ml} \times 100 \mathrm{~g} \mathrm{bw}^{-1} \times \mathrm{min}^{-1}$ (mean $\pm \mathrm{SEM}$ ). Statistical analysis by Mann Whitney $U$ test vs control group: $p<0.05,{ }^{b} p<0.01,{ }^{c} p<0.001$; vs small tumor bearing group: ${ }^{d} p<0.05, " p<0.01, ' p<0.001$.

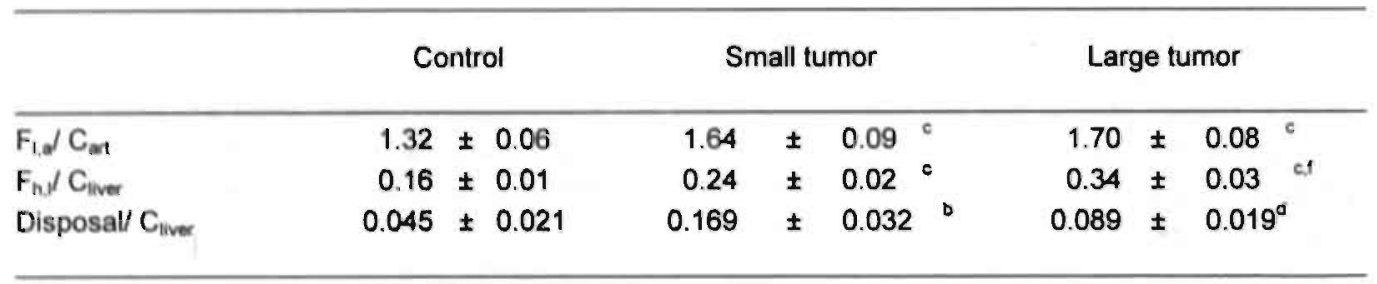

Normalization of membrane transport rates for the concentrations in the pool of origin, gives an estimate of the ability of the transport system to clear vascular or intracellular amino acid pools (transport system activity) $(11,12)$. Normalization of inward membrane transport activity shows that arterial clearance of glutamine by the liver increased approximately $24-28 \%$ in both tumor bearing rats (Table 4). Outward membrane transport normalized for the intracellular concentration (intracellular clearance of glutamine) increased in the small and large tumor bearing rats by more than $50 \%$ and $100 \%$. 
Table 5. Relationship between inward directed membrane transport rates, intracellular glutamine production and total intracellular glutamine appearance rate. $\mathrm{Ra}_{\text {, }}$ is total intracellular glutamine appearance

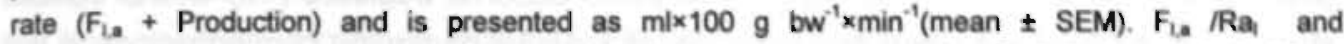
Production/Ra, are fractional rates of intracellular glutamine appearance rate. Statistical analysis by Mann Whitney $U$ test vs control group: " $p<0.05,{ }^{b} p<0.01,{ }^{\circ} p<0.001$; vs small tumor bearing group: ${ }^{d} p<0.05$. - $p<0.01$, 'p<0.001.

\begin{tabular}{|c|c|c|c|c|c|c|c|c|}
\hline \multirow[b]{2}{*}{$\mathrm{Ra}_{\mathbf{H}}$} & \multicolumn{2}{|c|}{ Control } & \multicolumn{3}{|c|}{ Small tumor } & \multicolumn{3}{|c|}{ Large tumor } \\
\hline & 1046 & \pm 94 & 1503 & \pm & 175 & 1214 & \pm & 95 \\
\hline \multicolumn{9}{|l|}{ Periportal } \\
\hline$F_{\mathbf{L}} / R_{a_{1}}$ & 0.72 & \pm 0.03 & 0.72 & \pm & 0.08 & 0.78 & \pm & 0.04 \\
\hline \multicolumn{9}{|l|}{ Perivenous } \\
\hline Production/Ra & 0.28 & \pm 0.03 & 0.28 & \pm & 0.08 & 0.21 & \pm & 0.04 \\
\hline
\end{tabular}

In controi rats total intracellular glutamine turnover ( $\left.R \mathrm{a}_{i}\right)$ was for $72 \%$ determined by arterial plasma-liver tissue glutamine membrane transport and for $28 \%$ determined by intracellular production of glutamine (Table 5). The latter fraction remained unchanged in small tumor bearing rats but tended to decrease in large tumor bearing rats making glutamine turnover in the liver of advanced tumor bearing rats more dependent on membrane transport rates.

\section{Discussion}

Cachexia is a common cause of death in advanced cancer (14). Nutritional interventions have been limited in their success because pathophysiclogical mechanisms underlying the cachectic syndrome are poorly understood. Glutamine has recently been recognized as a key amino acid in physiological interorgan amino acid exchange (1). In addition, glutamine depletion has also been associated with several catabolic disease states (7). The present study was performed to evaluate changes in hepatic glutamine handling induced by increasing tumor loads.

The tumor in the present study induced only moderate cancer cachexia (see chapter 7). No anorexia was present and carcass weight only reduced by approximately $10 \%$ in advanced cancer. Liver mass, however, increased in this rodent cancer model which has previously been described to an acute phase response to the tumor $(15,16)$. 
Furthermore, disturbed glutamine homeostasis becomes apparent in these tumor bearing rats as the bodies major glutamine pools become depleted (17). In the current study we also observed sharp decreases in intracellular glutamine concentrations in the liver of tumor bearing rats. These concentrations are highly dependent on membrane transport rates which maintain a more than tenfold plasma-tissue concentration gradient (Table 1). In the liver glutamine is exclusively and actively taken up by $\mathrm{Na}^{+}$-dependent System N (18). Intracellular glutamine breakdown, disposal in our model, by phosphatedependent mitochondrial glutaminase depends on the maintenance of intracellular and intramitochondrial glutamine concentrations by System $N(5)$.

Both disposal and System $\mathrm{N}$ inward membrane transport take place in the periportal hepatocytes which account for approximately $92 \%$ of all hepatocytes in the liver (5). The $K_{m}$ and $V_{\text {max }}$ of System $N$ are $1.3 \mathrm{mM}$ and $10 \mathrm{nmol} \times \mathrm{mg}^{-1} \times$ minute ${ }^{-1}$ respectively (19) and when considering the arterial glutamine concentrations in control rats this would give a theoretical transport rate of $1.2 \mathrm{nmol} \mathrm{x} \mathrm{mg}^{-1} \times$ minute ${ }^{-1}$ (approximately $1650 \mathrm{nmol}$ $\times 100 \mathrm{~g} \mathrm{bw}^{-1} \times$ minute $^{-1}$ ). Considering portal venous concentrations the theoretical membrane transport rate would be approximately $789 \mathrm{nmol} \times \mathrm{mg}^{\circ} \times$ minute? Membrane transport rates calculated in the three compartment model in the current study thus more closely resembles membrane transport rates from portal venous plasma into the hepatocyte.

Membrane transport rates increased in the small tumor bearing rats despite unchanged arterial glutamine concentrations. Therefore, membrane transport capacity had to increase as was shown in the normalized values (Table 4). The normalized values remained elevated in the large tumor bearing animals. Disposal of glutamine increased a threefold in the small tumor bearing rats. This is exceptional because mitochondrial glutaminase has a very high $\mathrm{K}_{\mathrm{m}}(28 \mathrm{mM})$ and glutamine breakdown is thus strictly concentration dependent. The elevated glutamine breakdown could only have been possible with elevated cytosolic-mitochondrial membrane transport rates and subsequent concentration gradients between the intracellular cytosolic pool and the mitochondrial pool. In the large tumor bearing rats glutamine disposal decreased again. This may have been due to a failure of cytosolic-mitochondrial glutamine membrane transport rates due to a further decrease in intracellular glutamine concentrations $(40 \%)$. Although plasma-tissue membrane transport capacity increased in the large tumor bearing rats, the actual transport rate did not increase sufficiently to maintain intracellular glutamine concentrations and subsequent glutamine breakdown.

Glutaminase produces both ammonia and glutamate from glutamine (20). Hepatic ammonia flux and intracellular ammonia concentrations remained unchanged in the 
small tumor bearing rats. The ammonia derived from glutamine is preferentially used for carbamoyl phosphate (urea cycle) production in the periportal cells (4). Urea flux across the liver, however, remained unchanged in both tumor bearing rats (chapter 7 , table 4). If not used for urea synthesis, ammonia could also have been transported from periportal cells to perivenous cells. Indeed, glutarnine production also increased and a large part of the ammonia produced by periportal cells was probably used for perivenous glutamine synthesis. Simultaneous breakdown and synthesis of glutamine by different cell subsets of the liver has previously been called the intercellular glutamine cycle $(5,21)$.

In vivo intercelullular glutamine kinetics and cycling calculated in the three compartment model used in the current study are summarized in figure 1. In all rats the majority of glutamine entered the intracellular pool and only a minority was directly shunted into the hepatic vein. During the increased glutamine turnover in small tumor bearing rats, glutamine membrane transport rates became of approximately the same magnitude as intracellular glutamine disposal and breakdown. However, more importantly, the model shows that a great part of glutamine entering the periportal cells (via System $\mathrm{N}$ ), was also released by these cells. The latter occurs $\mathrm{Na}^{*}$-independent via System " $n$ " which is a facilitated diffusion (22). In control rats $731 \mathrm{nmol}$ entered the periportal cells whereas only $198 \mathrm{nmol}$ were broken down (figure 1). Therefore, 533 $\mathrm{nmol}$, which is approximately $73 \%$ of the glutamine actively taken up, left periportal cells via System " $\mathrm{n}$ ".

Looking more closely in the small tumor bearing rats, this percentage decreased to $33 \%$. This means that the increase in glutamine disposal was not as much made possible by increasing System $\mathrm{N}$ membrane transport rates but more by decreasing the facilitated diffusion of glutamine by System " $n$ ". In the large tumor bearing rats, approximately $71 \%$ of glutarnine which entered periportal cells was also released by these cells as was seen in control rats.

In the large tumor bearing animals the decreased glutamine disposal rates also made the net glutamine flux of the liver approximately zero. In these animals glutamate release, one of the end products of glutamine breakdown, was still increased. If not originating from glutamine, glutamate must have been produced from aspartate or TCA cycle intermediates as has been shown in vitro (23). This would be in agreement with a recent study in which it was shown that the liver of tumor bearing rats demonstrates a progressive loss of energy generating capacity (24). 

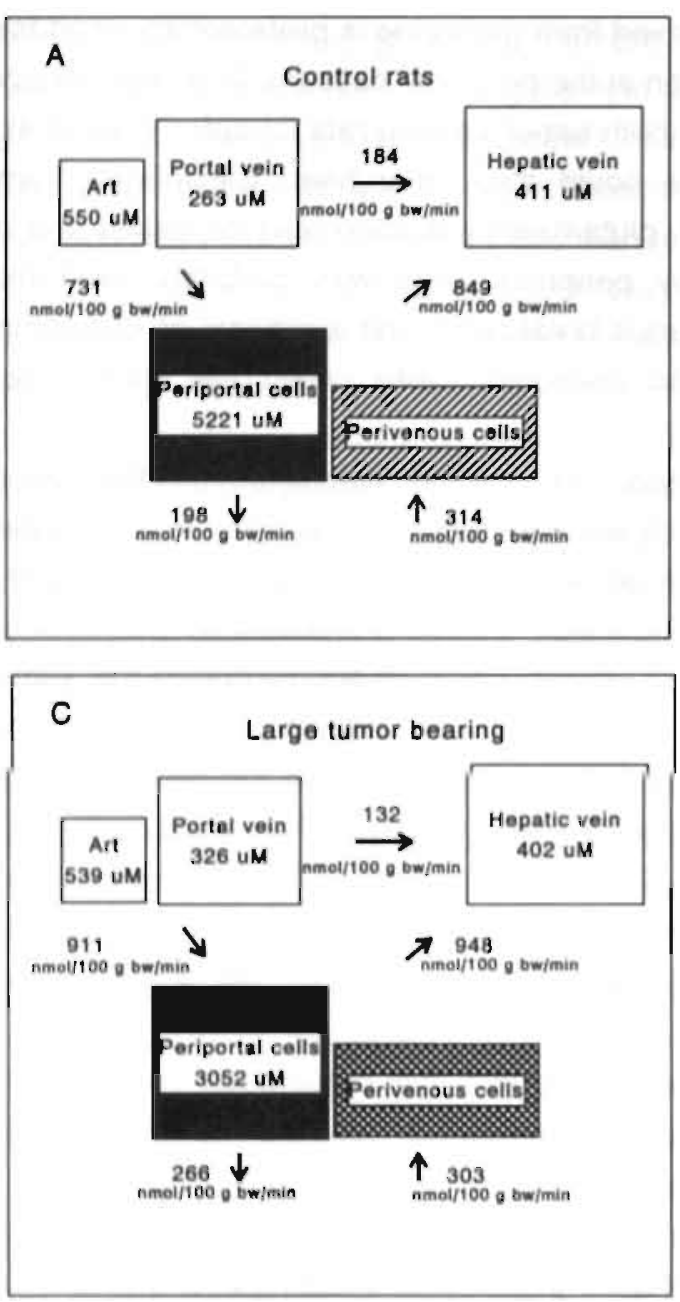

B

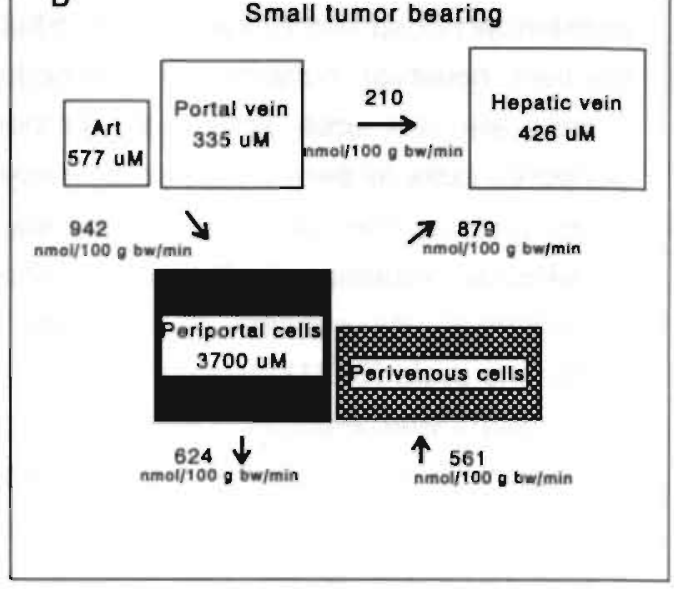

Figure 1. Glutamine kinetics in controf and tumor bearing rats. Glutamine uptake of hepatocytes involves largely $\mathrm{Na}^{*}$-dependent System $\mathrm{N}$ which is mostly active in periportal hepatocytes (32). Glutamine release by hepatocytes occurs via facilitated diffusion of System " $n$ ". Glutamine disposal or breakdown is restricted to periportal cells which containe intramitochondrial phosphate dependent glutaminase, whereas glutamine synthesis is restricted to perivenous cells containing glutamine synthetase. A control rats, B small tumor bearing rats, C large tumor bearing rats.

Glutamate is the actual energy substrate of tumor cells when they consume glutamine (25). Previous studies suggested that the high uptake of glutamine by tumor cells may not be essential to cell proliferation if sufficient other energy and anabolic precursors were supplied (26). Although in vivo uptake of glutamate by tumor cells has been observed (27), most reports show that glutamate is taken up and oxidized much 
less effectively than glutamine due to low membrane transport rates $(25,28)$. Therefore, the reason for increased glutamate release by the liver probably lies within the liver of the tumor bearing rat. It may be related to the relatively decreased perivenous glutamine production in the large tumor bearing rats or insufficient substrate oxidation as suggested previously in hepatocytes of tumor bearing rats (24).

In conclusion, our study shows that the liver changes from an organ of net release to an organ of net glutamine uptake in the presence of a small tumor. In advanced cancer glutamine consumption and production are in balance. The major changes in liver glutamine metabolism were found in glutamine disposal which was regulated by changes periportal facilitated diffusion of glutamine via System " $n$ " membrane transport rates.

\section{References}

1. Souba WW. Glutamine: a key substrate for the splanchnic bed. Annu Rev Nutr 1991;11:285-308.

2. Souba WW. Glutarnine and Cancer. Ann Surg 1993;218:715-728.

3. Haussinger D. Glutamine metabolism in the liver: overview and current concepts. Metabolism 1989;38:14-7.

4. Meijer AJ, Verhoeven AJ. Regulation of hepatic glutamine metabolism. Biochem Soc Trans 1986;14:1001-4.

5. Haussinger D. Liver glulamine metabolism. JPEN J Parenter Enteral Nutr 1990;14:56S-62S.

6. Haussinger D, Gerck W, Sies, H. Regulation of flux through glutaminase and glutamine synthetase in isolated perfused rat liver. Biochim Biophys Actal 1983;755:272-8.

7. Lacey JM, Wilmore DW. Is glutamine a conditionally essential amino acid? Nutr Rev 1990;48:297. 309.

8. Heindorff $H$, Almdal $T$, Vilstrup $H$. Effects of hysterectomy and semi-starvation on amino acid gradients across liver, muscle and gut in rats. Clin Nutrition 1990;9:253-259.

9. Biolo G. Fleming RY. Maggi SP, Wolfe RR. Transmembrane transport and intracellular kinetics of amino acids in human skeletal muscle. Am J Physiol 1995;268:E75-84.

10. de Blaauw I, Deutz NEP, von Meyenfeldt MF. In vivo amino acid metabolism of gut and liver during short and prolonged starvation. Am J Physiol 1996; 270:G1-9.

11. Biolo G, Zhang $X J$, Wolfe RR. Role of membrane transport in interorgan amino acid flow between muscle and small intestine. Metabolism 1995;44(6):719-724.

12. Biolo G, Chinkes D, Zhang XJ, Wolfe RR. A new model to determine in vivo the relationship between amino acid transmembrane transport and protein kinetics in muscle. J Parenter Enteral Nutr 1992;16:305-315.

13. Norusis MJ. SPSS/PC+ V4.0 BASE MANUAL for the IBM PC/XT/AT and PS/2. SPSS Inc, 1989; Chicago, IL, USA.

23. de Blaauw 1. Deutz NEP, von Meyenfeldt MF. Glutamine depletion and increased gut permeability in non-anorectic, non weight losing tumor bearing rats. Gastroenterology 1995;108(4):A721. 
14. Douglas RG. Shaw JH. Metabolic effects of cancer. Br J Surg 1990;77:246-54.

15. Warren RS, Jeevanandam M, Brennan MF. Comparison of hepatic protein synthesis in vivo versus in vitro in the tumor-bearing rat. J Surg Res 1987;42:43-50.

16. Andersson C, Gelin J, Iresjo BM, Lundholm K. Acute-phase proteins in response to tumor growth. J Surg Res 1993;55:607-14.

17. de Blaauw I, Deutz NEP, von Meyenfeldt MF. Increased whole body glutamine tumover in cancer is not matched by increased hindquarter glutamine release. Gastroenterology 1995;108(4):A722.

18. Kilberg MS. Amino acid transport in isolated rat hepatocytes. J Membr Biol 1982;69:1-12.

19. Jacob R, Rosenthal N, Barrett EJ. Characterization of glutamine transport by liver plasma membrane vesicles. Am J Physiol 1986;251:E509-14.

20. Lund P. Glutamine metabolism in the rat. FEBS LETTERS 1980;117:K86-92.

21. Haussinger $D$, Sies $H$, Gerok $W$. Functional hepatocyte heterogeneity in ammonia metabolism. The intercellular glutamine cycle. J Hepatol 1985;1:3-14.

22. Kilberg MS, Haussinger D. Kilberg MS, Haussinger D, editors.Mamalian amino acid transport. New York: Plenum Press; 1992;Amino acid transport in liver. p. 133-48.

23. Cooper AJ, Nieves E, Rosenspire KC, Filc DeRicco S, Gelbard AS, Brusilow SW. Short-term metabolic fate of $13 \mathrm{~N}$-labeled glutamate, alanine, and glutamine(amide) in rat liver. $\mathrm{J}$ Biol Chem 1988;263:12268-73.

24. Tsuburaya A, Blumberg D, Burt M, Brennan MF. Energy depeltion in the liver and in isolated hepatocytes of tumor-bearing animais. Journal of Surgical Research 1995;59(4):421-7.

25. Moreadith RW, Lehninger AL. The pathways of glutamate and glutamine oxidation by tumor cell mitochondria. J Biol Chem 1984;259:6215-6221.

26. McKeehan WL. Glycolysis, glutaminolysis and cell proliferation. Cell Biol Int Rep 1982;6:635-50.

27. Sauer LA, Webster, Stayman, III J, Dauchy RT. Amino acid, glucose, and lactic acid utilization in vivo by rat tumors. Cancer Res 1982;42:4090-4097.

28. Angel, Medina M, Sanchez-Jimenez F, Marques J, Rodriquez, Quesada A, Nunez de Castro I. Relevance of glutamine metabolism to tumor cell growth. Mol Cell Biochem 1992;113:1-15. 


\title{
CANCER REDUCES THE METABOLIC RESPONSE OF MUSCLE TO SURGICAL STRESS IN THE RAT
}

\author{
L. de Blaauw, N.E.P. Deutz, M.F. von Meyenfeldt
}

Submilted

\section{Abstract}

The metabolic response to surgical stress is characterized by muscle protein breakdown and mobilization of amino acids, e.g. glutarnine, from peripheral tissue to visceral organs. Cancer is related to increased whole body protein breakdown which may influence the normal metabolic response after surgery. Aim was to study the effects of cancer on postoperative peripheral muscle protein and glutamine turnover. MCA-induced sarcomas were implanted subcutaneously in female Lewis rats ( $\pm 200 \mathrm{~g}$ ). Tumor bearing rats were studied when the tumor was 5-15\% of body weight. Control rats were sham implanted. Hysterectomy was performed in control and tumor bearing rats as a standardized operative procedure. At the second postoperative day a primed constant infusion of para-aminohippuric acid, L- $\left[2,6-{ }^{3} \mathrm{H}\right]$ phenylalanine and L-[3,4${ }^{3} \mathrm{H}$ jglutamine was given to study hindquarter muscle protein tumover and glutamine kinetics.

In control rats muscle protein synthesis aimost doubled and protein breakdown increased a threefold after hysterectomy with concomitant increased outward amino acid membrane transport rates. Hysterectomy did not change protein synthesis or breakdown rates in tumor bearing rats. Muscle glutamine production, membrane transport and release increased after hysterectomy in control rats. Tumor bearing rats had depressed membrane transport rates and showed no surgical stress response related to muscle glutamine metabolism.

The present study shows that surgicai stress induces an increased mobilization of amino acids, e.g. glutamine, from muscle which does not occur in the cancer bearing state. The reduced metabolic response to surgery in the cancer bearing host may be of particular importance for the functioning of visceral organs which utilize amino acids like glutamine at a high rate after trauma. 
The metabolic response to surgical trauma is characterized by increased peripheral protein breakdown and mobilization of amino acids $(1,2)$. Amino acids are transported to visceral organs for gluconeogenesis and the acute phase response $(1,2)$. In this respect, glutamine appears to have a central role. It has long been recognized as a non-toxic ammonia or nitrogen carrier from muscle to visceral organs $(3,4)$. Furthermore, glutamine is a major gluconeogenic amino acid by which new carbon skeletons derived from proteins and amino acids are transferred to the glucose pool (5). Moreover, glutamine is essential for rapidly dividing cells, e.g. immune cells and enterocytes, as energy source and as precursor for nucleotides. It was therefore hypothesized that peripheral production of glutamine may be rate limiting and thus make glutamine conditionally essential for the functioning of the immune system, gut and liver (6-9). This has been confirmed in several clinical and animal studies in which supplementation of glutamine resulted in improvement of immune, gut and liver functioning (10-14).

Cachectic cancer patients are characterized by excessive weight loss (15). Poor nutritional status has been associated with a poor outcome of surgical treatment $(16,17)$. In animal studies, advanced cancer has been associated with decreased mobilization of glutamine suggesting that muscle tissue was exhausted in these animals $(18,19)$. An insufficient capacity of muscle to produce glutamine may have clinical impact on functioning of glutamine consuming organs like the gut, liver and the immune system of the cancer bearing host. Decreased capacity to mobilize amino acids, in particular glutamine, can impair postoperative immune function or induce loss of gut barrier function, and make cancer patients more prone to postoperative morbidity. We wanted to test this hypothesis in the cancer bearing host undergoing mild surgery.

Aim of the present study was to measure muscle amino acid efflux, in particular that of glutamine, in tumor bearing rats after a mild surgical trauma. As muscle glutamine release is related to several intracellular metabolic processes in muscle, e.g. de novo production from glutamate, membrane transport rates or intracellular protein turnover, isotope labeled amino acids were used to measure intracellular glutamine and protein kinetics in hindquarter muscle. 


\section{Animals and study groups}

Female Lewis rats (190-210 gr., Centralized Animal Facilities, University of Limburg. Maastricht, NL) were individually housed in metabolic cages during the experiment after an adaptation period of 3 days. Rats were given standard laboratory rat chow (SRMA 1210, Hopefarms, Woerden, NL) and subjected to standard 12 hour light-dark cycle periods (7:30 A.M. to 7:30 P.M.) with room temperature maintained at $25^{\circ} \mathrm{C}$. The experiments were performed in accordance with the recommenclations of the Guide for the Care and Use of Laboratory Animals (20) and approved by the Ethical Committee of Animal Research of the University of Limburg.

Rats $(n=40)$ were randomly assigned to one of the following four groups:

1) control, sham anesthesia,

2) control, hysterectomized,

3) tumor bearing, sham anesthesia.

4) tumor bearing, hysterectomized.

In the tumor bearing group a methylcholantrene (MCA) sarcoma was implanted subcutaneously. The tumor is maintained in our laboratory in vivo by serially transplanting tissue suspensions through an $18 \mathrm{G}$ needle. A MCA tumor is often used in metabolic studies and is known for its rapid growth, invasion of local tissue and absence of metastatic potential $(18,21,22)$. The tumor was allowed to grow until it reached $5-15 \%$ of the host body weight. Non-tumor bearing rats were sham implanted with saline. Tumor growth was monitored by measuring two orthogonal dimensions and by calculating the volume assuming the tumor to be a prolate spheroid (23). Tumor size, body weight and food intake were monitored daily. Carcass weight was determined by subtracting estimated tumor weight from total body weight

\section{Surgical procedure}

All rats were anaesthetized with diethyl ether (Merck 923, Darmstadt. Germany). The surgical groups were subjected to a laparotomy. The bicornuate uterus was dissected free and ligated on both sides from the ovaries with vicryl 3-0 (Ethicon, Norderstedt, Germany). Next, the uterus was ligated at the basis with vicryl 3-0 and removed from the abdomen. The abdominal wound was closed with vicryl 3-0 in two layers. The whole procedure tock approximately 10-15 minutes. This stanciard procedure has been described previously (24-26). It involves the removal of a nonessential organ and in patients the metabolic responses to this type of surgical trauma were found to correspond with findings after cholecystectomy (26). Nonoperated rats underwent sham anesthesia with diethyl ether for 15 minutes. 


\section{Study procedures}

Metabolic studies were performed postabsorptive two days after the operation or sham anesthesia. Hindquarter fluxes, protein and glutamine turnover were examined as described previously $(27,28)$ and in chapter 2,3 and 4 . In brief, under ether anesthesia and at constant, pre-anesthesia body temperature, a laparotomy was performed. The right renal vein, the aorta and caval vein (just above the bifurcation) were canulated using a 25 gauge needle fixed in a Silastic tube (Silastic Medical Grade tubing $0.051 \mathrm{~cm} \mathrm{ID}, 0.094$ OD, Dow Corning Corporation, Midland, MO, USA) and fixed with cyano-acrylate. For flow measurements, the indicator dilution method with para-aminohippuric acid $(\mathrm{PAH})$ was used $(\mathrm{pH} 7.4$, iso-osmolaric). A primed $(0.15$ $\mathrm{ml} \times 100 \mathrm{gr}$. body weight $\left.\mathrm{f}^{-1}, 50 \mathrm{mmol} / \mathrm{l}\right)$ constant infusion $(0.75 \mathrm{ml} \times 100 \mathrm{gr}$. body weight $\left.^{-1} \times \mathrm{h}^{-1}, 5 \mathrm{mmol} / \mathrm{l}\right)$ of $\mathrm{PAH}$ was infused in the aorta, using a Minipuls 3 Peristaltic Pump. For turnover studies, a primed $\left(1 \mu \mathrm{Ci} \times 100 \mathrm{gr}\right.$. body weight $\left.{ }^{-1}\right)$ constant infusion $\left(1 \mu \mathrm{Ci} \times 100 \mathrm{gr}\right.$. body weight $\left.{ }^{-1} \times \mathrm{h}^{1}\right)$ of $\mathrm{L}-\left[3,4-{ }^{3} \mathrm{H}\right]$ phenylalanine and $\mathrm{L}-\left[3,4 \cdot{ }^{3} \mathrm{H}\right] \mathrm{glutamine}$ was given in the right renal vein. $\mathrm{A}$ minimum infusion time of 30 minutes was needed to reach steady state concentrations for $\mathrm{PAH},{ }^{3} \mathrm{H}$-phenylalanine and ${ }^{3} \mathrm{H}$-glutamine as described previously $(28,29)$. The right carotid artery was canulated during the equilibrium period with PE 50 catheter (Intramedic, $0.051 \mathrm{~cm}$ ID, $0.094 \mathrm{~cm}$ OD, Clay Adams, Parispany, NY, USA). The complete procedure took approximately 40 minutes. Hindquarter measurements were simultaneously done with measurements across portal darained viscera described in chapter 10 .

Blood $(1.0 \mathrm{ml}$ per catheter) was simultaneously sampled from the caval vein and carotid artery. All blood was collected in heparinized cups on ice. Hereafter, the right gastrocnemius muscle was dissected free, weighted, directly freeze-clamped, put in liquid nitrogen and stored at $-80^{\circ} \mathrm{C}$ until further analysis.

For PAH determinations, $50 \mu \mathrm{l}$ heparinized blood was added to $500 \mu \mathrm{l}$ TCA ( $10 \%$ $w / v)$, vortexed and centrifuged at $8,900 \mathrm{~g}$ at $4^{\circ} \mathrm{C}$. The supernatant was frozen in liquid nitrogen and stored at $-80^{\circ} \mathrm{C}$ until further analysis. For hematocrit determinations a micro-hematocrit tube was filled with heparinized blood and centrifuged at $10,000 \mathrm{~g}$ at room temperature. Hematocrit was read with a Micro Hematocrit Reader. Plasma was obtained by whole blood centrifugation at $8.900 \mathrm{~g}$ at $4^{\circ} \mathrm{C}$ for 5 minutes. For ammonia, urea, glucose and lactate determinations, $200 \mu \mathrm{l}$ plasma was vortexed with $20 \mu \mathrm{lTCA} 50 \%$, put into liquid nitrogen and stored at $-80^{\circ} \mathrm{C}$. To determine plasma amino acid specific activities and concentrations, $300 \mu \mathrm{l}$ plasma was added to $12 \mathrm{mg}$ 5-sulfosalicylic acid (SSA, Brunschwig, 10346. Amsterdam, NL), vortexed, frozen in liquid nitrogen and stored at $-80^{\circ} \mathrm{C}$.

Plasma ammonia, urea, glucose, lactate and PAH were determined spectrophotometrically on a Cobas Mira S (Roche Diagnostica, Hoffman-La Roche, Basel, Switzerland) by standard enzymatic methods, using commercially available 
kits $(27,28)$. Plasma amino acid concentrations and specific activity were determined by fully automated HPLC as described previously (30). For the determination of tissue ammonia, amino acid concentrations and specific activities, muscle tissue was pulverized using a mortar and pestle precooled in liquid nitrogen. The tissue was further homogenized and deproteinized in a Mini-Beadbeater (Biospec products, Bartlesville, USA). Approximately $100 \mathrm{mg}$ tissue was added to $400 \mu \mathrm{l}$ SSA $5 \%$, with $300 \mathrm{mg}$ glass beads (diameter $1 \mathrm{~mm}$, Biospeck Products) and beaten for 30 seconds. The homogenate was centrifuged at $4^{\circ} \mathrm{C}$ at $11,000 \mathrm{~g}$ and the supernatant frozen in liquid nitrogen and stored at $-80^{\circ} \mathrm{C}$ until further determinations.

To determine tissue dry weight and water content approximately $200 \mathrm{mg}$ pulverized tissue was freeze dried for 24 hours in a Speedvac (SC200, Savant Instruments Inc., Farmingdale NY, USA) connected with a refrigerated condensation trap.

\section{Calculations:}

Hindquarter plasma flow and substrate fluxes

Plasma flow across the hindquarter was calculated using PAIH in the indicator dilution method $(27,28)$. Substrate fluxes are calculated by multiplying the venousarterial concentration differences with the mean hindquarter plasma flow of the group and are expressed in $\mathrm{nmol} \times 100 \mathrm{gr}$. body weight $\mathrm{f}^{-1} \times \mathrm{min}^{-11}$. A positive flux indicates net release, a negative flux reflects a net uptake. $\alpha$-Amino-nitrogen was calculated as the sum of the individual amino acids measured except taurine (30). The sum of essential amino acids was calculated as described previousily (31). Tissue concentrations of amino acids are expressed in $\mu \mathrm{mol} /$ and derived by dividing the tissue homogenate amino acid concentration ( $\mu \mathrm{mol} / \mathrm{kg}$ wet weight) by the tissue water content (l/kg wet weight).

\section{Protein and glutamine kinetics}

Hindquarter protein and glutamine turnover were calculated by the A-V dilution of radioactively labeled phenylalanine and glutamine across the hindquarter calculated in a three compartment model $(28,32,3,3)$. Intracellular disposal and production of phenylalanine and glutamine can thus, be derived and reflect in vivo intracellular turnover of these amino acids. Production of phenylalanine reflects protein breakdjown and disposal reflects protein syrthesis because metabolism of phenylalanine in muscle is restricted to synthesis into and breakdown from protein (34). Furthermore, glutamine and phenylalanine membrane transport rates can simultaneously be measured: $F_{m, a}$ are plasma-tissue inward directed transport rates, 
$F_{m, v}$ are plasma tissue outward directed membrane transport rates and $F_{v a}$ reflect metabolic shunting of amino acids (32).

Glutamine, being a non-essential amino acid, can be produced by protein breakdown and, non-protein derived, by the transamidation of glutamate. Knowing the relative amino acid content of phenylalanine and glutamine in protein (35) enables us to calculate glutamine production derived from protein breakdown and glutamine production which is non-protein derived (de novo synthesis).

\section{Statistical Analysis}

Results are presented as mean \pm SEM. Data were analyzed using the statistical program SPSS (36). Two way analysis of variance (ANOVA) was used to detect significant effects of tumor load, surgical trauma and the interaction between tumor load and trauma. Significant interactions suggest that the effects of surgery were not the same for control (non-tumor bearing) and tumor bearing rats. Significance from zero was tested by the Wilcoxon signed-ranks test. Significance was considered present at $p<0.05$.

Results

A hysterectomy had no influence on tumor weight (Table 1). Initial carcass weights were similar in all groups and no significant changes were observed in the preoperative period. On the second postoperative day hysterectomized control and tumor bearing rats lost approximately twice as much of their carcass weight than the sham anesthetized rats.

Food intake of control and tumor bearing rats remained unchanged in the preoperative period. Postoperative food intake decreased to approximately $20-25 \%$ in operated rats compared to sham anesthetized rats.

\section{Arterial concentrations}

Tumor bearing rats had decreased arterial glucose concentrations (Table 2). Hysterectomy had no influence on arterial glucose concentrations. The tumor bearing state and hysterectomy both increased arterial lactate concentrations while a relatively diminished increase in arterial lactate after surgery in tumor bearing rats was observed.

Surgery decreased arterial ammonia in both control rats and tumor bearing rats. Urea concentrations remained unchanged in the presence of a tumor or after hysterectomy. 


\begin{tabular}{|c|c|c|c|c|c|c|c|c|}
\hline & \multicolumn{2}{|c|}{ Control } & \multicolumn{2}{|c|}{ Tumor bearing } & \multirow[b]{2}{*}{$\mathrm{T}$} & \multicolumn{2}{|l|}{$p$ value } & \multirow[b]{2}{*}{1} \\
\hline & Sham & Hysterectomy & Sham & Hysterectomy & & S & & \\
\hline Tumor welght & - & - & $38 \pm 2$ & $32 \pm 3$ & $<0.001$ & ns & & ns \\
\hline \multicolumn{9}{|l|}{ Carcass welght } \\
\hline Initial & $195 \pm 3$ & $200 \pm 3$ & $200 \pm 3$ & $204 \pm 3$ & ns & ns & ns & \\
\hline Preoperative & $200 \pm 3$ & $205 \pm 4$ & $198 \pm 4$ & $201 \pm 4$ & ns & ns & ns & \\
\hline Postoperative (day 2) & $190 \pm 2$ & $184 \pm 4$ & $191 \pm 7$ & $180 \pm 4$ & ns & 0.02 & ns & \\
\hline \multicolumn{9}{|l|}{ Food intake } \\
\hline Initial & $18 \pm 1$ & $17 \pm 1$ & 171 & $15 \pm 2$ & ns & ns & ns & \\
\hline Preoperative & $17 \pm 1$ & $15 \pm 1$ & $17 \pm 1$ & $16 \pm 2$ & ns & ns & ns & \\
\hline Postoperative & $16 \pm 1$ & $4 \pm 2$ & $15 \pm 3$ & $3 \pm 1$ & ns & $<0.001$ & ns & \\
\hline
\end{tabular}

Table 1. Carcass weight, tumor weight and food intake during the experiment. Values are mean \pm SEM. Carcass weight is in grams, food intake in gram/day except postoperative which is in total intake after hysterectomy until the metabolic study. Statistical analysis by Two-Way ANOVA: $\mathrm{T}=$ effects of tumor load, $\mathrm{S}=$ effects of surgery, $\mathrm{I}=$ interaction of tumor load and surgery, $\mathrm{ns}=$ not significant. 


\begin{tabular}{|c|c|c|c|c|c|c|c|c|c|c|}
\hline \multirow[b]{3}{*}{ Glucose } & \multicolumn{3}{|c|}{ Control } & \multicolumn{4}{|c|}{ Tumor bearing } & \multicolumn{3}{|c|}{$p$ value } \\
\hline & \multirow{2}{*}{$\begin{array}{c}\text { Sham } \\
10.2 \pm 0.3\end{array}$} & \multicolumn{2}{|c|}{ Hysterectomy } & \multicolumn{2}{|c|}{ Sham } & \multicolumn{2}{|c|}{ Hysterectomy } & \multirow{2}{*}{$\begin{array}{c}\mathrm{T} \\
<0.001\end{array}$} & \multirow{2}{*}{$\begin{array}{l}\text { S } \\
\text { ns }\end{array}$} & \multirow{2}{*}{$\begin{array}{c}1 \\
\text { ns }\end{array}$} \\
\hline & & 10.7 & \pm 0.2 & 9.3 & \pm 0.4 & 9.1 & \pm 0.4 & & & \\
\hline Lactate & $5.2 \pm 0.4$ & 7.7 & \pm 0.3 & 7.3 & \pm 0.5 & 8.1 & \pm 0.4 & 0.001 & $<0.001$ & 0.03 \\
\hline Ammonia & $173 \pm 9$ & 129 & $\pm \quad 9$ & 147 & \pm 14 & 115 & \pm 5 & ns & 0.001 & ns \\
\hline Urea & $3.4 \pm 0.1$ & 3.5 & \pm 0.2 & 3.6 & \pm 0.3 & 3.2 & \pm 0.2 & ns & ns & ns \\
\hline$\alpha$-Amino-nitrogen & $2685 \pm 63$ & 2980 & \pm 257 & 3648 & \pm 232 & 3318 & \pm 118 & 0.001 & ns & ns \\
\hline Essential AA & $1019 \pm 35$ & 1156 & \pm 92 & 1568 & \pm 115 & 1472 & \pm 51 & $<0.001$ & ns & 0.03 \\
\hline Non-essential AA & $1665 \pm 48$ & 1823 & \pm 176 & 2382 & \pm 182 & 2040 & \pm 90 & 0.03 & ns & ns \\
\hline Glutamate & $40 \pm 3$ & 77 & $\pm \quad 20$ & 67 & $\pm \quad 5$ & 66 & $\pm \quad 5$ & ns & ns & ns \\
\hline Glutamine & $628 \pm 14$ & 535 & \pm 23 & 528 & 20 & 476 & \pm 21 & $<0.001$ & 0.004 & ns \\
\hline Alanine & $271 \pm 24$ & 480 & $\pm \quad 98$ & 542 & 76 & 564 & \pm 71 & 0.03 & ns & ns \\
\hline Branched Chain AA & $227 \pm 17$ & 257 & $\pm \quad 23$ & 302 & 26 & 284 & \pm 10 & 0.008 & ns & ns \\
\hline
\end{tabular}

Table 2. Arterial ammonia and arnino acid concentrations in control and tumor bearing rats after hysterectomy, sham operation or pair fed to operated rats. Glucose, lactate and urea in mmol/l, ammonia and amino acids in $\mu$ mol/l (mean \pm SEM). Statistical analysis by Two Way ANOVA: $T=$ effects of tumor load, $S=$ effects of surgery, $I=$ interaction between tumor load and surgery. $A A=$ amino acids. 
The presence of a tumor increased arterial $\alpha$-amino-nitrogen concentrations (both essential and non-essential) whereas hysterectomy had no effect. Glutamine and alanine are non-essential amino acids which represent approximately $30 \%$ of total arterial $\alpha$-amino-nitrogen (37). They are the most important interorgan nitrogen carriers in the body. Arterial glutamine concentrations were decreased in tumor bearing rats and decreased after hysterectomy in both tumor bearing and control rats. In contrast, arterial alanine increased in tumor bearing rats. Hysterectomy had no effect on arterial alanine. Arterial branched chain amino acid concentrations also increased in tumor bearing rats whereas hysterectomy had no effect on these concentrations.

\section{Hindquarter plasma flow and fluxes}

Hindquarter plasma flow remained unchanged between the groups (Table 3). No significant changes in glucose uptake by the hindquarter was observed. It was, however, only significantly different from zero in the tumor bearing group. Lactate release increased after hysterectomy more than a twofold in control rats while tumor bearing rats had no increase in lactate release after hysterectomy.

Ammonia release by the hindquarter, reflecting breakdown of amino acids and nucleotides (38), was not significantily different between different groups although the release became non-significant from zero after hysterectomy in tumor bearing rats. Hindquarter $\alpha$-amino-nitrogen release was increased after hysterectomy. The six-fold increase in amino acid release after surgery in control rats was attenuated by the presence of a tumor. The increased release of total amino acids after surgery was mostly due to an increased release of non-essential amino acids, again attenuated by the presence of a tumor.

Glutamine release by the hindquarter increased after hysterectomy in control rats. In tumor bearing rats glutamine release remained unchanged after surgery. Glutamate, the intracellular precursor of glutamine, was taiken up in sham control rats, hysterectomized control rats and sham tumor bearing rats while only a significant release was seen in hysterectomized tumor bearing rats. Alanine release by the hindquarter increased after surgery in both control and tumor bearing rats.

\section{Hindquarter protein and glutamine kinetics}

Intracellular disposal of phenylalanine in muscle (protein synthesis) was decreased in the presence of a turnor and did not increase in response to surgery in tumor bearing rats as in control rats (Fig. 1). Protein breakdown "measured by the intracellular production of phenylalanine, increased after hysterectomy. However, in tumor bearing rats intracellular production of phenylalanine did not increase after surgery. Phenylalanine flux, the difference between protein synthesis and protein 


\begin{tabular}{|c|c|c|c|c|c|c|c|c|c|c|}
\hline \multirow[b]{3}{*}{ Plasma flows } & \multicolumn{4}{|c|}{ Control } & \multicolumn{3}{|c|}{ Tumor bearing } & \multirow{2}{*}{\multicolumn{2}{|c|}{$\frac{p \text { value }}{\mathrm{S}}$}} & \multirow[b]{2}{*}{1} \\
\hline & \multicolumn{2}{|c|}{ Sham } & \multicolumn{2}{|c|}{ Hysterectomy } & \multicolumn{2}{|c|}{ Sham } & Hysterectomy & & & \\
\hline & 2.1 & \pm 0.4 & 4.2 & \pm 0.9 & 3.2 & \pm 1.0 & $2.6 \pm 1.0$ & ns & ns & ns \\
\hline Glucose & -505 & \pm 508 & -996 & \pm 1059 & -1989 & \pm 538 & $-361 \pm 612^{\prime}$ & ns & ns & ns \\
\hline Lactate & 2573 & \pm 182 & 6277 & \pm 724 & 4420 & \pm 622 & $3871 \pm 428$ & ns & 0.009 & $<0.001$ \\
\hline Ammonia & 165 & $\pm \quad 18$ & 188 & \pm 53 & 189 & \pm 97 & $52 \pm 27$ & ns & ns & ns \\
\hline$\alpha$-Amino-nitrogen & 297 & \pm 147 & 1739 & \pm 364 & 897 & \pm 324 & $1310 \pm 241$ & ns & 0.007 & 0.05 \\
\hline Essential AA & 38 & \pm 50 & 473 & \pm 136 & 181 & \pm 152 & $298 \pm 88$ & ns & 0.05 & ns \\
\hline Non Essential AA & 260 & \pm 105 & 1267 & \pm 235 & 716 & \pm 185 & $1012 \pm 165$ & ns & 0.002 & 0.03 \\
\hline Glutamine & 199 & $\pm \quad 41$ & 595 & \pm 73 & 346 & $\pm \quad 39$ & $389 \pm 37$ & ns & 0.001 & $<0.001$ \\
\hline Glutamate & -13 & \pm & -43 & $\pm \quad 12$ & -42 & $\pm \quad 6$ & $21 \pm 5$ & ns & ns & 0.002 \\
\hline Alanine & -21 & 10 & 203 & $\pm \quad 70$ & 191 & \pm 100 & $307 \pm 110$ & ns & 0.05 & ns \\
\hline BCAA & -65 & 14 & -8 & \pm 29 & -31 & \pm 38 & $42 \pm 27^{*}$ & ns & 0.02 & ns \\
\hline
\end{tabular}

Table 3. Hindquarter plasma flow, ammonia and amino acid fluxes. Values are presented in $\mathrm{nmol} \times 100 \mathrm{gr}^{\text {. body }} \mathrm{weight}^{-1} \times \mathrm{min}^{-1}$ except plasma flow in $\mathrm{ml} \times 100 \mathrm{gr}$. body weight ${ }^{-1} \times \mathrm{min}^{-1}$ (mean $\pm \mathrm{SEM}$ ). Statistical analysis by Two-Way ANOVA: T = effects of tumor load, $\mathrm{S}=$ effects of surgery, $\mathrm{I}$ = interaction between tumor load and surgery. Wilcoxon's test: "not significant from zero $(p<0.05)$. (-) reflects net uptake, $(+)$ reflects net release of a substrate. 
breakdown rates, increased after hysterectomy in control rats. This response was also absent in tumor bearing rats.

Phenylalanine plasma-tissue membrane transport rates were in agreement with the pattern of intracellular turnover (Fig. 2). Both surgery and the presence of a tumor did not significantly influence inward directed membrane transport rates $\left(F_{m, a}\right)$. There was, however, an opposite change after surgery in control and tumor bearing rats: control rats increased their inward membrane transport rates while tumor bearing rats decreased their transport rates in response to hysterectomy. Outward membrane transport rates $\left(F_{v, m}\right)$ were increasecl after surgery. However, no change was observed after surgery in tumor bearing rats. Metabolic shunting of phenylalanine in muscle tissue $\left(F_{v, a}\right)$ was increased in tumor bearing rats and no effect of surgery was observed. There was, however, a relative increased shunting in control rats whereas it relatively decreased after surgery in tumor bearing rats.
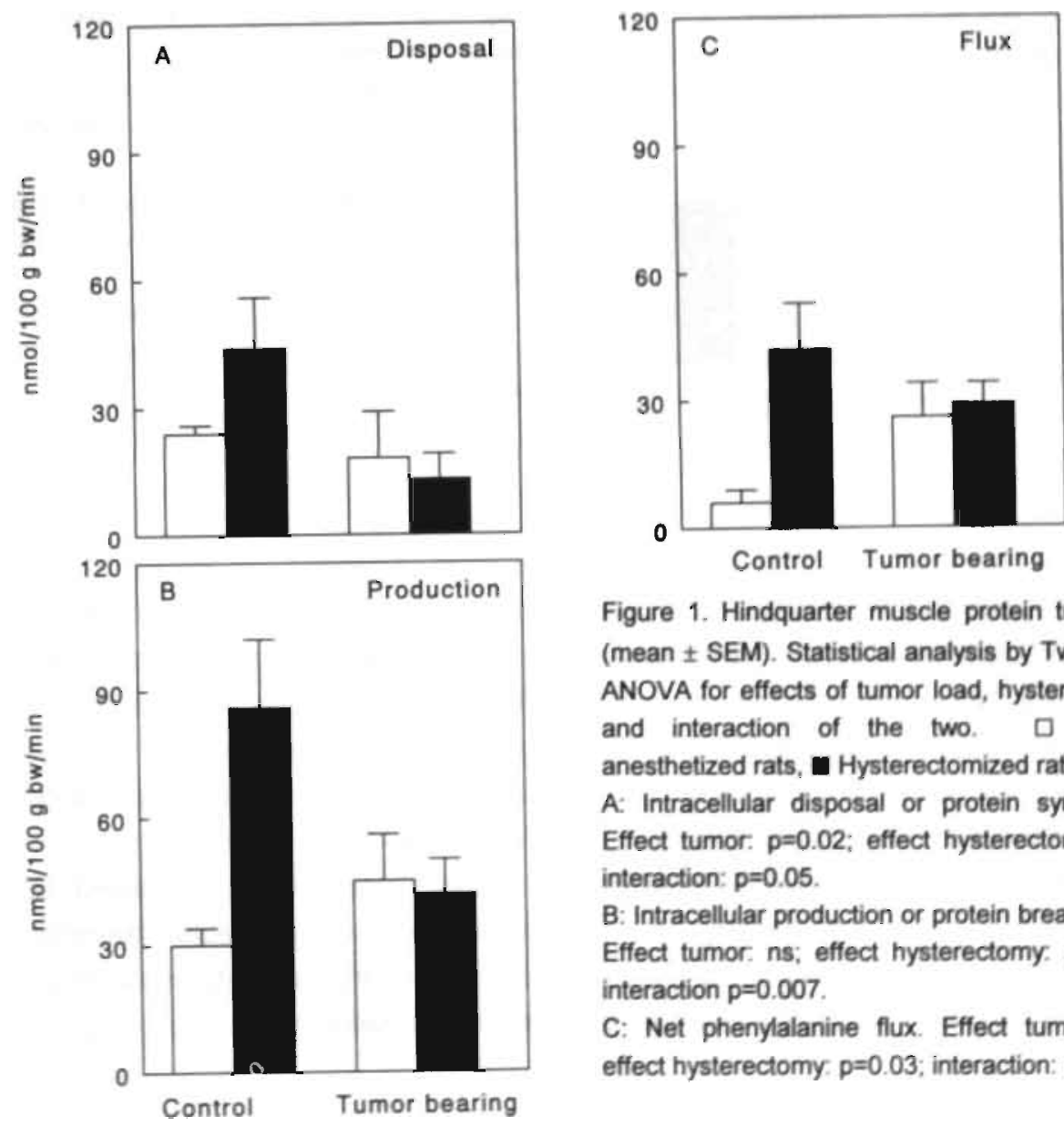

Figure 1. Hindquarter muscle protein turnover (mean \pm SEM). Statistical analysis by Two-Way ANOVA for effects of tumor load, hysterectomy and interaction of the two. $\square$ Sham anesthetized rats, $\mathbf{u}$ Hysterectomized rats.

A: Intracellular disposal or protein synthesis. Effect tumor: $p=0.02$; effect hysterectomy: ns; interaction: $p=0.05$.

B: Intracellular production or protein breakdown. Effect tumor: ns; effect hysterectomy: $p=0.03$; interaction $\mathrm{p}=0.007$.

C: Net phenylalanine flux. Effect tumor. ns; effect hysterectomy: $p=0.03$; interaction: $p=0.03$. 

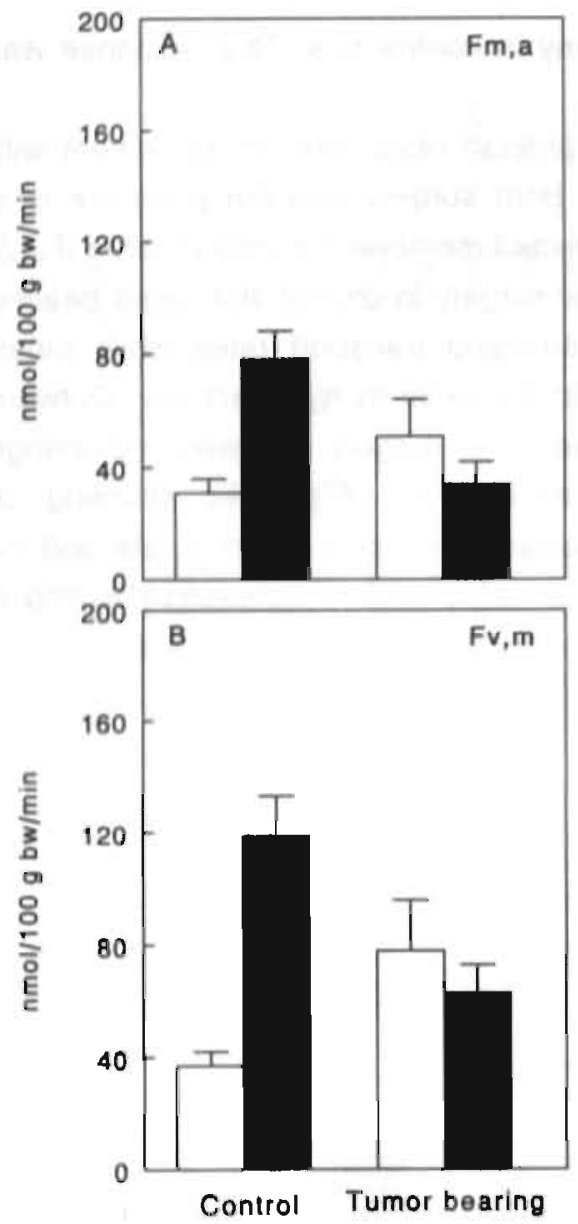

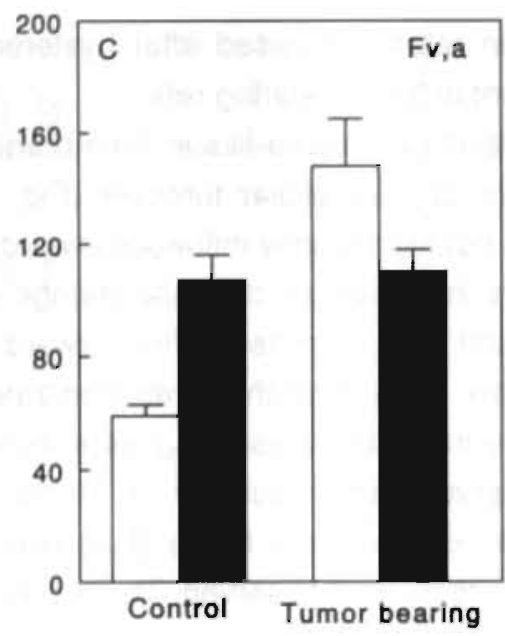

Figure 2. Phenylalanine membrane transport in muscle tissue (nmol phenylalanine $\times 100 \mathrm{gr}$. body weight $\left.{ }^{-1} \times \min ^{-1}\right)$. $\square$ Sham anesthetized rats, - Hysterectomized rats.

$A: F_{m, n}$, inward membrane transport. Effect turmoir. ns; effect hysterectomy: ns; interaction: $p=0.002$.

B: $F_{v, m}$ outward membrane transport. Effect tumor: ns; effect hysterectomy: $p=0.04$; interaction: $p=0.001$.

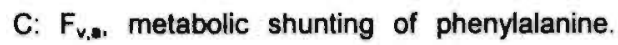
Effect tumor: $p<0.001$; effect hysterectomy: ns; interaction: $p<0.001$

Intracellular glutamine production was increased after hysterectomy in control rats (Fig. 3). Tumor bearing rats had unchanged glutamine production rates in response to surgery. No significant changes in intracellular glutamine disposal was observed after hysterectomy or due to the presence of a tumor. Glutamine release (difference between production and disposal) also increased after surgery and this response was absent in the tumor bearing state.

Glutamine inward directed membrane transport rates $\left(F_{m, a}\right)$ increased after surgery (Fig. 4). Tumor bearing rats had decreased inward directed membrane transport rates. Outward membrane transport rates $\left(F_{v, m}\right)$ increased after surgery and this response was completely attenuated in the tumor bearing rats. 

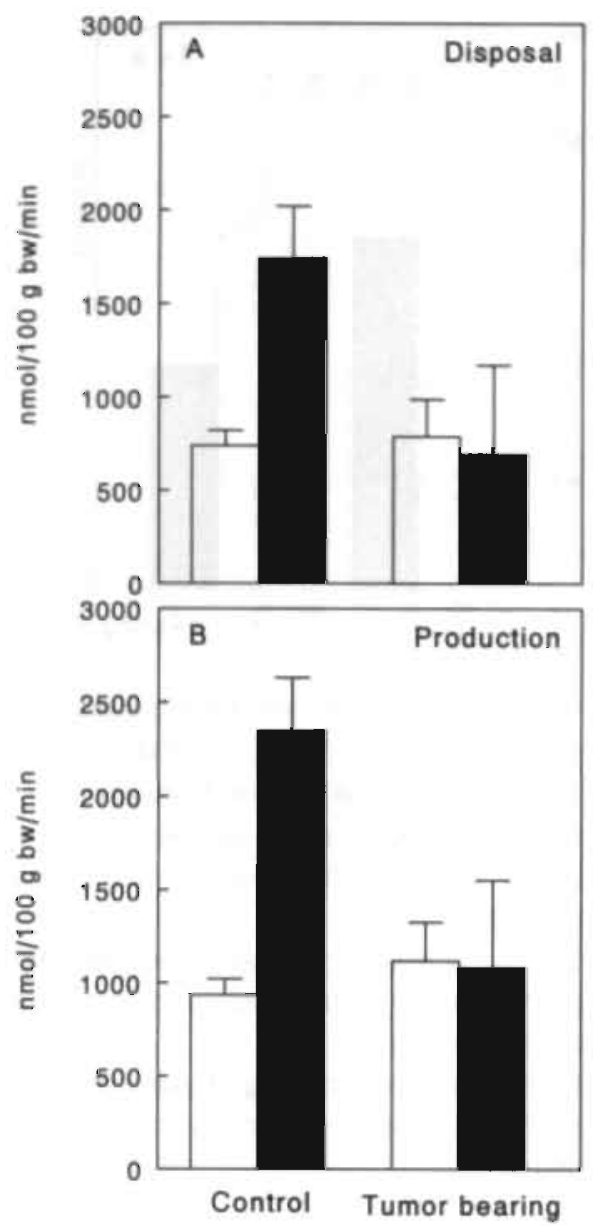

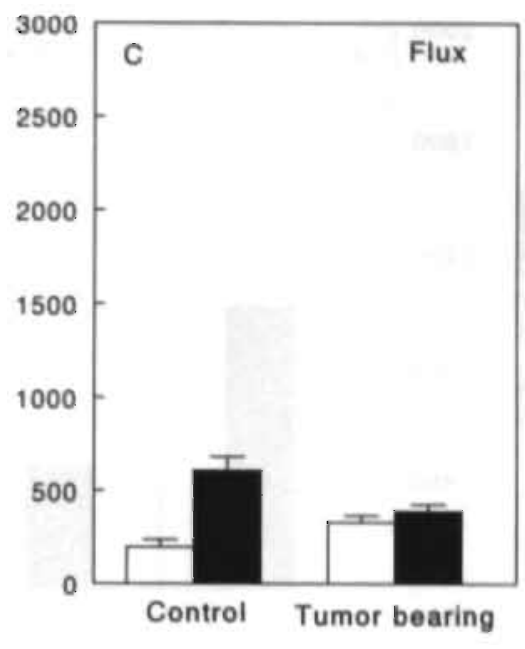

Figure 3. Hindquarter glutamine turnover. (mean \pm SEM). $\square$ Sham anesthetized rats, Hysterectomized rats.

A: Intracellular disposal or consumption. Effect tumor: ns; effect hysterectomy: ns; interaction: ns.

B: Intracellular production. Effect tumor: ns; effect hysterectomy: $p=0.05$; interaction: $p=0.01$. $C$ : Net glutamine flux. Effect tumor: ns; effect hysterectomy: $p=0.001$; interaction: $p<0.001$.

Hysterectomy or the cancer bearing state did not influence metabolic shunting of glutamine separately but there was a significant interaction between the two. In control rats shunting increased whereas a decrease was observed after surgery in tumor bearing rats.

\section{Muscle weight and intracellular concentrations}

Gastrocnemius wet weight and dry weight decreased in tumor bearing rats (Table. 4). Hysterectomy had no significant effect on muscle weight. Intracellular hydration of muscle was not different between the groups.

Intracellular ammonia remained unchanged. Total intracellular $\alpha$-amino acid concentrations were increased in tumor bearing rats. Surgery decreased intracellular 

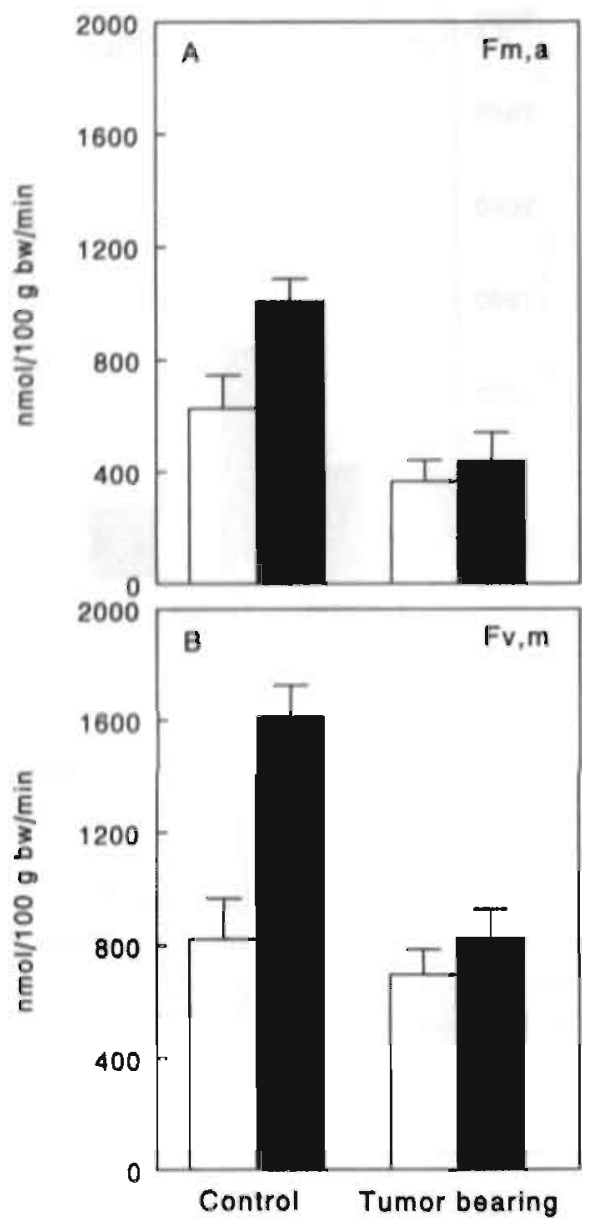

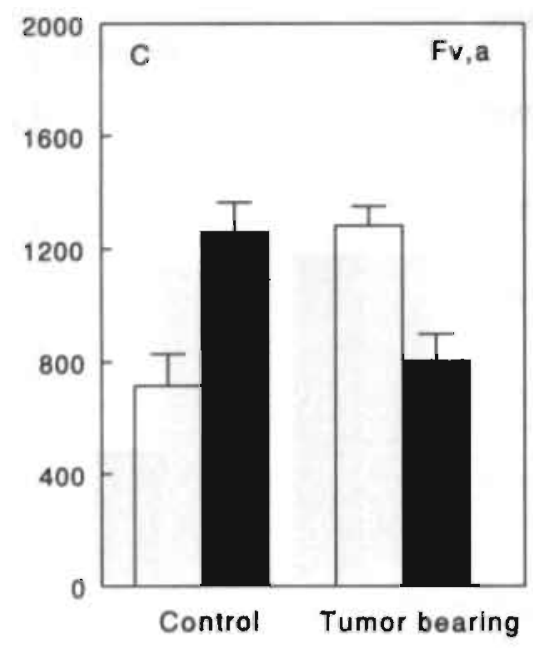

Figure 4. Glutamine membrane transport rates in muscle tissue (mean \pm SEM). $\square$ Sham anesthetized rats, $\square$ Hysterectomized rats.

A: $F_{m}$ inward membrane transport. Effect tumor: $p<0.001$; effect hysterectomy: $p=0.04$; interaction: ns.

$B$ : $F_{\text {sin }}$ outward membrane transport. Effect tumor: $p<0.001$; effect hysterectomy: $p=0.001$; interaction: $p=0.002$

C. $F_{\mathrm{va}}$, metabolic shunting of glutamine. Effect tumor: ns; effect hysterectomy: ns; interaction: $p<0.001$.

$\alpha$-amino acid concentrations to control values. The increased $\alpha$-amino acid concentration in tumor bearing rats appears to be due to increased essential and non-essential amino acid concentrations although this was not significant when measured separately.

Intracellular glutamine concentrations decreased as an effect of surgery and as an effect of cancer. Intracellular glutamate, alanine, phenylalanine and branched amino acids increased in tumor bearing rats. Intracellular phenylalanine concentrations remained unchanged after hysterectomy in tumor bearing rats while hysterectomy increased intracellular phenylalanine in control rats. 


\begin{tabular}{|c|c|c|c|c|c|c|c|c|}
\hline & \multicolumn{2}{|c|}{ Control } & \multicolumn{3}{|c|}{ Tumor bearing } & \multicolumn{3}{|c|}{$p$ value } \\
\hline & Sham & Hysterectomy & & tham & Hysterectomy & $T$ & $S$ & i \\
\hline Wet weight & $1.23 \pm 0.02$ & $1.15 \pm 0.02$ & 1.04 & \pm 0.05 & $1.04 \pm 0.05$ & $<0.001$ & ns & ns \\
\hline Dry weight & $0.295 \pm 006$ & $0.275 \pm .006$ & 0.252 & \pm .013 & $0.245 \pm 011$ & $<0.001$ & ns & ns \\
\hline $\mathrm{H}_{2} \mathrm{O} \%$ & $76.0 \pm 0.3$ & $75.9 \pm 0.2$ & 75.6 & \pm 0.3 & $76.2 \pm 0.2$ & ns & ns & ns \\
\hline Ammonia & $2515 \pm 266$ & $2235 \pm 333$ & 2235 & \pm 308 & $2319 \pm 239$ & ns & ns & ns \\
\hline$\alpha-$ Amino-nitrogen & $13421 \pm 762$ & $14526 \pm 359$ & 16345 & \pm 664 & $14646 \pm 584$ & 0.02 & ns & 0.01 \\
\hline Essential & $2008 \pm 321$ & $2596 \pm 188$ & 3236 & \pm 211 & $2533 \pm 343$ & ns & ns & ns \\
\hline Non-essential & $11161 \pm 613$ & $11930 \pm 249$ & 13109 & \pm 534 & $11831 \pm 423$ & ns & ns & ns \\
\hline Glutamine & $4179 \pm 263$ & $3910 \pm 155$ & 3718 & \pm 211 & $3324 \pm 265$ & 0.01 & 0.05 & $\mathrm{~ns}$ \\
\hline Glutamate & $899 \pm 72$ & $949 \pm 61$ & 1322 & \pm 120 & $1226 \pm 115$ & 0.02 & ns & ns \\
\hline Alanine & $1428 \pm 229$ & $2199 \pm 297$ & 3052 & \pm 493 & $2641 \pm 207$ & 0.02 & ns & ns \\
\hline Phenylalanine & $105 \pm 10$ & $134 \pm 7$ & 165 & \pm 11 & $157 \pm 9$ & 0.001 & ns & 0.05 \\
\hline BCAA & $333 \pm$ & $401 \pm 38$ & 520 & $\pm \quad 55$ & $484 \pm 37$ & 0.008 & ns & ns \\
\hline
\end{tabular}

Table 4. Gastrocnemius wet weight, dry weight, intracellular hydration, ammonia and amino acid concentrations. Weights in grams, concentrations in $\mu$ mol/ (mean \pm SEM). Statistical analysis by Two-Way ANOVA: $\mathrm{T}=$ effects of tumor load, $\mathrm{S}=$ effects, of surgery, 1 = interaction between tumer load and surgery. 


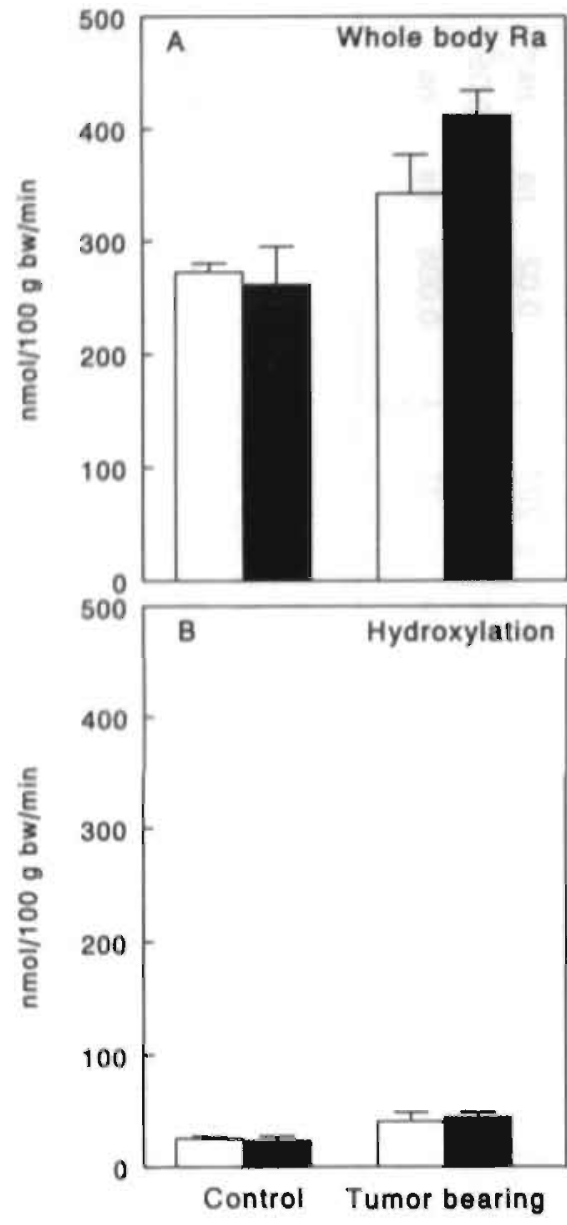

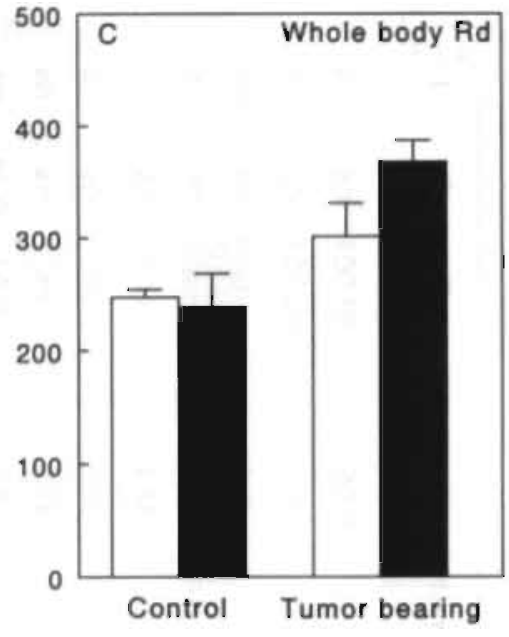

Figure 5. Whole body protein turnover in $\mathrm{nmol}$ phenylalanine $\times 100 \mathrm{gr}$, body weight $\mathrm{f}^{-1} \times \mathrm{min}^{-1}$. Sham anesthetized rats, - Hysterectomized rats.

A: Whole body Ra. Effect tumor: $p<0.001$; effect hysterectomy: ns; interaction: ns.

B. Hydroxylation rate. Effect tumor: $p=0.001$; effect hysterectomy: ns; interaction: ns.

C: Whole body Rd into protein. Effect tumor: $p=0.001$; effect hysterectomy: $n s ;$ interaction: ns.

Whole body protein and glutamine tumover

Surgery had no significant effect on whole body phenylalanine Ra (Fig. 5). Tumor bearing rats had increased whole body protein turnover rates. Phenylalanine hydroxylation, an indication of amino acid oxidation, was increased in tumor bearing rats but remained unaffected by hysterectomy. Whole body $\mathrm{Rd}$ was also only increased in tumor bearing rats.

Whole body giutamine Ra decreased in control rats in response to surgery while it increased after surgery in the presence of a tumor (Fig. 6). Glutamine Ra from protein breakdown was relatively low compared to de novo synthesis. Glutamine Ra from protein breakdown increased in tumor bearing rats. Whole body de novo glutamine synthesis was not affected by hysterectomy or the presence of a tumor but there was again an opposite response to surgery in control and tumor bearing rats. 


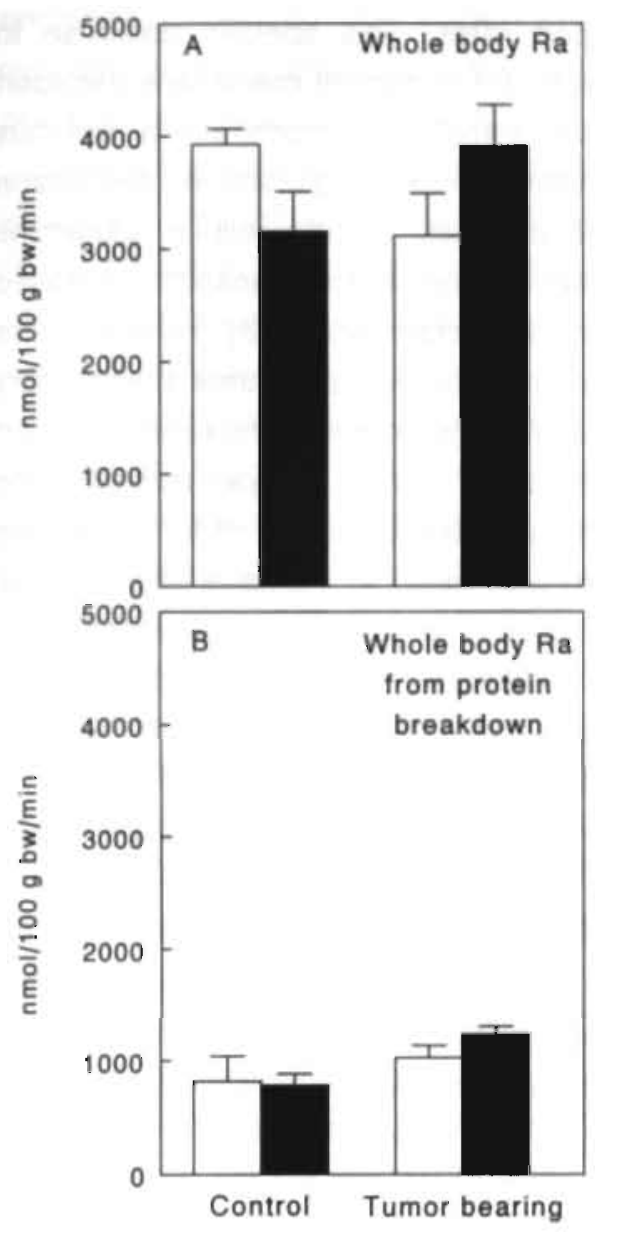

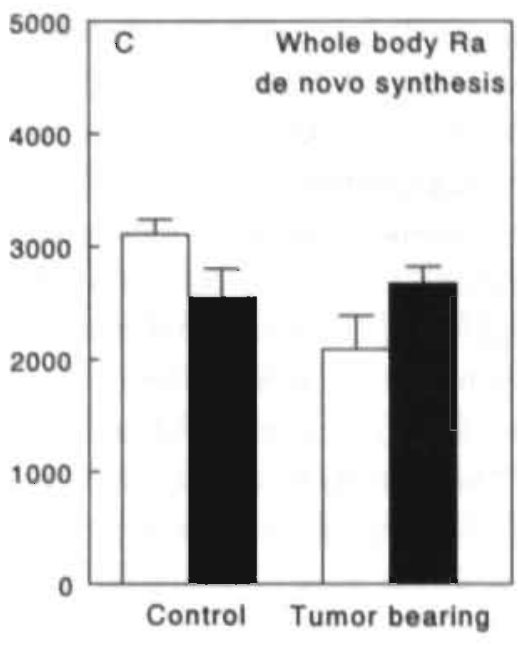

Figure 6 . Whole body glutamine turnover in $\mathrm{nmol} \times 100 \mathrm{gr}$. body weight $\mathrm{f} \mathrm{min}^{-1}$.

Sham anesthetized rats, - Hysterectomized rats.

A: Total whole body Ra. Effect tumor: ns; effect hysterectomy: ns; interaction: $\mathrm{p}=0.02$.

B: Ra from protein breakdown. Effect tumor: $p<0.001$; effect hysterectomy: ns; interaction: ns.

C: Ra, de novo. Effect tumor: ns; effect hysterectomy: $n s$; interaction: $\mathrm{p}=0.05$.

\section{Discussion}

The current study shows that after a surgical trauma muscle proteins are acutely broken down with subsequent amino acid release by the hindquarter. It also shows that the presence of cancer prohibits the normal postoperative response in muscle related to specific changes in muscle metabolism.

The amino acids glutamine and alanine, although biochemically non-essential amino acids, play dominant roles in interorgan amino acid exchange. Glutamine is also essential as major energy source and nucleotide precursor for rapidly dividing cells, e.g. immune cells and enterocytes and has been postulated to be conditionally essential in after severe trauma and metabolic stress $(6,8,9)$. Hysterectomy increased glutamine release by the hindquarter in control rats by increasing muscle 
glutamine production and membrane transport rates. This specific response to surgery was absent in tumor bearing rats. The $\mathrm{K}_{\mathrm{m}}$ for glutamine membrane transport in muscle $\left(K_{\mathrm{m}}<0.3 \mathrm{mM}\right)$ normally lies far below intracellular concentrations and thus transport approaches saturation (7). Therefore, muscle glutamine membrane transport normally remains independent of changes in intracellular glutamine concentrations (7). In the current study, glutamine membrane transport increased after surgery in control rats and this could only be accomplished by increasing the amount of transport carriers. The unchanged membrane transport rates after surgery in tumor bearing rats thus indicates an inability to increase membrane transport carriers. The inability to increase membrane transport carriers is again related to the inhibited postsurgical increase in protein synthesis rates in muscle of tumor bearing rats. Intracellular muscle glutamine production also failed to increase after surgical stress in tumor bearing rats. The decreased intracellular glutamine concentrations in these rats further suggest that glutamine synthetase capacity, which normally increases after injury $(39,40)$, had decreased. This failure by muscle to produce glutamine was also confirmed by the release of glutamate, the major precursor of glutamine in muscle, after surgery in tumor bearing rats while all other groups had an uptake of glutamate.

Glutamine release by muscle has previously been postulated to have a key role during an immune challenge as the flux generating step $(7,39)$. An impairment of glutamine release after surgery in tumor bearing rats decreases the possibility for visceral organs to increase their glutamine uptake under surgical stress which normally occurs. For instance, visceral organs (liver, spleen, gut) and immune cells increase their uptake of glutamine for gluconeogenesis and for the production of defense proteins and peptides such as glutathione (41,42). Furthermore, lymphocytes, macrophages and natural killer cells all consume glutamine at a high rate as energy source and for nucleotide production. In vitro and in vivo activation of these cells increases the consumption of glutamine $(39,43,44)$. Interestingly, an impaired acute phase response to surgical stress is observed in cancer patients (45). Therefore, a decreased nutrient supply by peripheral tissue, as measured in the current study, may have an etiologic role in this.

Although muscle glutamine production remained unchanged after surgery in the tumor bearing host, alanine release by the hindquarter increased. Alanine production in muscle is derived from pyruvate whereas the carbon skeletons of glutamine are mostly derived from protein breakdown. Pyruvate production increases with increased glycolysis. This should, however, also be accompanied by increased lactate production. The latter was increased after surgery in control rats but remained unchanged after surgery in the tumor bearing rats. Because lactate is released in much larger amounts than alanine, glycolysis in peripheral muscle must have 
remained unchanged after surgery in tumor bearing rats but only a larger fraction of pyruvate is being channeled into alanine instead of lactate. A valid reason for this phenomenon remains to be established.

The normal catabolic response to surgical stress is mediated by a range of neuroendocrine and immune responses (46). This response includes the sympathetic nervous system response, the release of counter regulatory hormones iglucagon, cortisol and adrenaline), insulin and several inflammatory mediators such as TNF $\alpha$ and IL-6. A more chronic release of these mediators has also been observed in tumor bearing rats (47). The lack of metabolic response after surgery in tumor bearing rats suggests that either the normal neuro-endocrine response is not present or that resistance to this response has been provoked by the chronic presence of the tumor. Resistance or tolerance to these mediators has been described in several human and animal studies $(24,48-50)$. The regulatory role of these mediators in the attenuated response of tumor bearing rats, however, needs further research.

Previous studies concerning postoperative protein metabolism have been contradicting. Increased $(51,52)$, unchanged $(53,54)$ and decreased $(55-57)$ whole body protein synthesis and breakdown rates have been observed. These differences are partly caused by differences in methods used to measure protein turnover and by the differences in populations that were studied. Moreover, whole body protein turnover appears to be a compilation of different protein synthesis and breakdown rates of several organs (58). Although muscle protein pool is by far the largest protein pool and whole body protein turnover is often seen as a reflection of muscle protein turnover, changes of organs with a rapid protein turnover rate, e.g. splanchnic organs, can have a larger impact on whole body turnover measurements than changes in muscle protein turnover (59). The discrepancy between whole body protein turnover and regional muscle protein turnover has previously been observed in several other studies $(60-62)$. In the current study, the postoperatively increased protein breakdown rates of peripheral muscle in control rats did not affect whole body protein turnover. Other organs thus must have decreased their protein turnover rates. We therefore feel that protein tumover of the largest protein pool in the body. muscle tissue, should be measured at regional level and not derived from whole body data under these circumstances.

In conclusion, the presence of cancer induces moderate muscle protein breakdown and decreased mobilization of amino acids, in particular of glutamine, after standard surgery. This reduced metabolic response to surgery may affect functioning of other organs supposedly to take up amino acids, e.g. glutamine, for the acute phase response. 
The authors wish to thank Mr. HMH van Eijk and Mr. DR Rooyakkers for excellent analytical help.

\section{References}

1. Newsholme EA and Leech AR. 1983. The integration of metabolism during starvation, refeeding and injury. In Biochemistry for the medical sciences. Newsholme EA and Leech AR, editors. John Wiley \& Sons, New York. 537-561.

2. Douglas RG and Shaw JHF. 1989 . Metabolic response to sepsis and trauma. Br. J. Surg. 76:115-122.

3. Duda, G. D. and P. Handler. 1958. Kinetics of ammonia metabolism in vivo. J. Biol. Chem. 232:303-314.

4. Newsholme EA and Leech AR. 1983. Metabolism of Ammonia. In Biochemistry for the Medical Science. Newsholme EA and Leech AR, editors. John Wiley \&. Sons, New York. 481-508.

5. Nurjhan, N. A. Bucci, G. Perriello, M. Stumvoll, G. Dailey, D. M. Bier, I. Toft, T. G. Jenssen, and J. E. Gerich. 1995. Glutamine: a major gluconeogenic precursor and vehicle for interorgan carbon transport in man. J. Clin. Invest. 95:272-277.

6. Rouse, K., E. Nwokedi, J. E. Woodliff, J. Epstein, and V. S. Klimberg. 1995. Glutamine enhances selectivity' of chemotherapy through changes in glutathione metabolism. Ann. Surg. 221:420-426.

7. Newshoime, E. A and M. Parry Billings. 1990. Properties of glutamine release from muscle and its importance for the immune system. JPEN. J. Parenter. Enteral. Nutr. 14:63S-67S.

B. Mahony, S. M., S. A. Beck, and M. J. Tisdale. 1988. Comparison of weight loss induced by recombinant tumour necrosis factor with that produced by a cachexia-inducing tumour. Br. J. Cancer 57:385-389.

9. Lacey JM and Wilmore DW. 1990. Is glutamine a conditionally essential amino acid? Nutr. Rev. 48:297309.

10. Van der Hulst RRWJ, Kreel BK, Meyenfeldt MF, Brummer RJM, Arends JW, N. E. P. Deutz, and P. B. Soeters. 1993. Glutamine and the preservation of gut integrity. Lancet 341:1363-1365.

11. Ziegler TR, Young LS, Benfell K. Scheltinga M, Hortos K. Bye R, Morrow FD, Jacobs DO. Smith RJ. Antin $\mathrm{JH}$, and Wimore DW. 1992. Clinical and metabolic efficacy of glutamine-supplemented parenteral nutrition after bone marrow transplantation. Ann. Intern. Med. 116:821-828

12. Welbourne TC, King AB, and Horton K. 1993. Enteral glutamine supports hepatic glutathione efflux dunng inflammation. J. Nutr. Biochem. 4:236-242.

13. van Zaanen, H. C., H. van der Lelie, J. G. Timmer, P. Furst. and H. P. Sauerwein. 1994. Parenteral glutarnine dipeptide supplementation does not ameliorate chemotherapy-induced toxicity. Cancer 74:28792884.

14. Tremel, H., B. Kienle, L. S. Weileman, P. Stehle, and P. Furst. 1994. Glutamine dipeptide-supplemented parenteral nutrition maintains intestinal function in critically ill. Gastroenterology 107:1595-1601.

15. Douglas, R. G and J. H. Shaw. 1990 . Metabolic effects of cancer. Br. J. Surg. 77:246-254.

16. Anonymous. 1991. Perioperative total parenteral nutrition in surgical patients. The Veterans Affairs Tota! Parenteral Nutrition Cooperative Study Group. N. Engl. J. Med. 325:525-532.

17. Dempsey. D. T., J. L. Mulien, and G. P. Buzby. 1988. The link between nutritional status and clinical outcome: can nutritional intervention modify it? Am. J. Clin. Nutr. 47:35:-356.

18. Chen MK, Espat NJ, Bland KI, Copeland EM, and Souba WW. 1993. Influence of progressive tumor growth on glutamine metabolism in skeletal muscle and kidney. Ann. Surg. 217:655-667.

19. Souba WW. 1993. Glutamine and Cancer. Ann. Surg 218:715-728.

20. Waldegrave, W. Chaiman Council of Europearn Community. 1986. Guide for the care and use of laboratory animals, publication 86/609. European Community Publication, Brussels, Belgium.

21. Popp MB, Morrison SD, and Brennan MF. 1981. Totai parenteral nutrition in a methylcholanthrene-induced rat sarcoma model. Cancer Treat. Rep. 65:137-143

22. Burt ME, Lowry SF, Gorschboth C, and Brennan MF. 1981. Metabolic alterations in a noncachectic animal tumor system. Cancer 7:2138-2146. 
23. Morrison SD. 1983. In vivo estimation of size of experimental tumors. J. Natl. Cancer. Inst. 71:407-408.

24. Heindorff H, Almdal T, and Vilstrup H. 1990. Contradictory effects of uncomplicated versus complicated abdominal surgery on the hepatic capacity for urea synthesis in rats. J. Surg. Res. 49:239-243.

25. Lee VM, Wolfe BM. Hansen RJ, and Clifford AJ. 1988. Postsurgical muscle protein turnover in perfused hindquarters of the rat. J. Parenter. Enteral. Nutr. 12:452-456.

26. Heindorff $H$, Almdal $T$, and Vilstrup H. 1990. Effects of hysterectomy and semi-starvation on amino acid gradients across liver, muscle and gut in rats. Clin. Nutrition. 9:253-259.

27. Dejong, C. H. C., M. T. Kampman, N. E. P. Deutz, and P. B. Soeters. 1992. Altered glutamine metabolism in rat portal drained viscera and hindquarter during hyperammonemia. Gastroenterology 102:936-948.

28. de Blaauww, L. N. E. P. Deutz, and M. F. von Meyenfeldt. 1996. In vivo protein and amino acid turnover in rats: effects of short-term and prolonged starvation. Clin. Sci. Colch. (in press).

29. de Blaauw, I., N. E. P. Deutz, and M. F. von Meyenfeldt. 1996. In vivo amino acid metabolism of gut and liver during short and prolonged starvation. Am. J. Physiol. 270:G298-306.

30. van Eijk, H. M. H., M. P. Huinck, D. R. Rooyakkers, and N. E. P. Deutz. 1994. Automated simultaneous isolation and quantitation of labeled amino acid fractions from plasma and tissue by ion-exchange chromatography. J. Chromatogr. B. Biomed. Appl. 660:251-257.

31. Stryer, L. 1988. Biochemistry. L. Stryer, editor. Freeman and Company, New York. 495-515 pp.

32. Biolo, G., Chinkes D. Zhang XJ, and Wolfe RR. 1992. A new model to determine in vivo the relationship between amino acid transmembrane transport and protein kinetics in muscle. J. Parenter. Enterai. Nutr. 16:305-315.

33. Biolo, G., R. Y. Fleming, S. P. Maggi, and R. R. Wolfe. 1995. Transmembrane transport and intracellular kinetics of amino acids in human skeletal muscle. Am. J. Physiol. 268:E75-84.

34. Tourian A, Goddard J, and Puck $\pi$. 1969. Phenylalanine hydroxylase activity in mammalian cells. J. Cell. Physiol. 73:159-170.

35. Kominz DR, Hough A, Symonds P, and Laki K. 1954. The amino acid composition of actin, myosin, tropomyosin and the meromyosins. Arch. Biochem. Biophys. 50:148-159.

36. Norusis, M. J. 1989. SPSS/PC+ V4.0 BASE. MANUAL for the IBM PC/XT/AT and PS/2. SPSS Inc, Chicago, IL.

37. Ruderman NB and Berger M. 1974. The formation of glutamine and alanine in skeletal muscle. J. Biol. Chem. 249:5500-5506.

38. Souba WW. 1987. Interorgan ammonia metabolism in health and disease: A surgeon's view. J. Parenter. Enteral. Nutr. 11:569-579.

39. Newshoime, E. A., B. Crabtree, and M. S. Ardaw. 1985. Glutamine metabolism in lymphocytes: its biochemical, physiological and clinical importance. Q. J. Exp. Physiol. 70:473-489.

40. Albina, J. E., W. Henry, P. A. King. J. Shearer, B. Mastrofrancesco, L. Goldstein, and M. D. Caldwell. 1987 Glutamine metabolism in rat skeletal muscle wounded with lambda-carrageenan. Am. J. Physiol. 252:E4956.

41. Souba WW. 1991. Glutamine: a key substrate for the splanchnic bed. Annu. Rev. Nutr. 11:285-308

42. Yoshida, S., A. Kaibara, K. Yamasaki, N. Ishibashi, T. Noake, and T. Kakegawa. 1996. Effect of glutamine supplementaion on protein metabolism and glutathione in tumor bearing rats. JPEN. J. Parenter. Enteral. Nutr. 19:492-497.

43. Ardawi, M. S and E. A. Newsholme. 1983. Glutamine metabolism in lymphocytes of the rat Biochem. J. 212:835-842.

44. Deutz, N. E. P., P. L. Reijuen, G. Athanasas, and P. B. Soeters. 1992. Post-operative changes in hepatic, intestinal, splenic and muscle fluxes of amino acids and ammonia in pigs. Clin. Sci. Colch. 83:607-614.

45. Cruickshank, A M. D. T. Hansell, H. J. Burns, and A. Shenkin. 1989. Effect of nutritional status on acute phase protein response to elective surgery. Br. J. Surg. 76:165-168.

46. Douglas RG and Shaw JHF. 1989. Metabolic response to sepsis and trauma. Br. J. Surg. 76:115-122.

47. Bartielt, D. L. S. L. Charland, and M. H. Torosian. 1995. Reversal of tumor-associated hyperglucagonemia as treatment for cancer cachexia. Surgery 118:87-97.

48. Lundhoim K, Holm G, and Schersten T. 1978. Insulin resistance in patients with cancer. Cancer Res. 38:4665-4670. 
49. Lowry SF. Foster DM, Norton JA, Berman M, and Brennan MF, 1981. Glucose disposal and gluconeogenesis from alanine in tumor-bearing Fischer 344 rats. J. Natl. Cancer Inst. 66:653-658.

50. Fraker DL, Sheppard BC, and Norton JA. 1990. Impact of tolerance on antitumor efficacy of tumor necrosis factor in mice. Cancer Res. 50:2261-2267.

51. O'Keefe, S. J., P. M. Sender, and W. P. James. 1974. "Catabolic" loss of body nitrogen in response to surgery: Lancet 2:1035-1038.

52. Carli, F., J. Webster, V. Ramachandra, M. Pearson, M. Read, G. C. Ford, S. McArthur, V. R. Preedy, and D. Halliday. 1990. Aspects of protein metabolism after elective surgery in patients receiving constant nutritional support. Clin. Sci. Colch. 78:621-628.

53. Waterlow, J. C., J. Golden, and D. Picou. 1977. The measurements of rates of protein turnover, synthesis. and breakdorm in man and the effects of nutritional status and surgical injury. Am. J. Clin. Nutr. 30:13331339.

54. Taggari, D. P., D. C. McMillan, T. Preston, A. Shenkin, D. J. Wheatley, and H. J. Burns. 1991. Effect of surgical injury andi intraoperative hypothermia on whole body protein metabolism. Am. J. Physiol. 260:E11825.

55. Carli, F., V. Ramachandra, J. Gandy. H. Merritt, G. C. Ford, M. Read, and D. Halliday. 1990. Effect of general anaesthesia on whole body protein turnover in patients undergoing elective surgery. Br. J. Anaesth. 65:373-379.

56. Clague, M. B., M. J. Keir, P. D. Wright, and I. D. Johnston. 1983. The effects of nutrition and trauma on Whole-bodyf protein metabolism in man. Clin. Sci. 65:165-175.

57. Ward, H. C., D. Halliday, and A. J. Sim. 1987. Protein and energy metabolism with biosynthetic human growvih hormone after gastrointestinal surgery. Ann. Surg. 206:56-61.

58. Wolfe, R. R. 1984. Deterrnination of specific radioactivity. In Tracers in Metabolic Research. R. R. Wolfe, editor. Alan R. Liss, Inc, New York. 239-224.

59: Gelfand RA, Glickman MG, Castellino P, Louard RJ, and DeFronzo RA. 1988. Measurement of L-[1$14 \mathrm{C}$. Leucine kinetics in splanchnic and leg tissues in humans. Diabetes 37:1365-1372.

60. Fiyburg DA and Barrett EJ. 1993. Growth hormone acutely stimulates skeletal muscle but not whole-body protein synthesis in humans. Metabolism 42:1223-1227.

61. Essen, P., M. A. McNurlan, T. Sonnenfeld, E. Milne, E. Vinnars, J. Wemerman, and P. J. Garlick. 1993. Muscle protein synthesis anter operation: effecls of intravenous nutrition. Eur. J. Surg. 159:195-200.

62. Louard RJ, Barrett EJ, and Gelfand RA. 1990. Effect of infused branched-chain amino acids on muscle and whole-body amino acid metabolism in man. Clin. Sci. 79:457-466. 


\title{
INTESTINAL RESPONSES TO SURGERY IN TUMOR BEARING RATS
}

\author{
1. de Blaauw, N.E.P. Deutz, M.F. von Meyenfeldt
}

Submitted

\begin{abstract}
The early metabolic response to surgical stress is characterized by increased protein breakdown of the gut to deliver amino acids for the acute phase response. Because cancer is related to major disturbances in protein metabolism, we hypothesized that the normal metabolic response to surgery is attenuated in tumor bearing rats.

Female Lewis rats $( \pm 200 \mathrm{~g}$ ) were studied bearing a subcutaneous tumor or after sham implantation. Hysterectomy was performed in half of the tumor bearing and control rats as a standardized operative procedure. Postoperative an oral dose of lactulose and L-rhamnose was given and urinary recovery of the two sugar probes was determined after 12 hours to assess gut permeability. Protein and glutamine kinetics of the gut were determined using a primed constant infusion of $\mathrm{L}-\left[2,6-{ }^{3} \mathrm{H}\right]-$ phenylalanine and $\mathrm{L}-\left[3,4{ }^{3} \mathrm{H}\right]$-glutamine.

In control rats, net protein breakdown increased from $6 \pm 3$ to $32 \pm 8 \mathrm{nmol}$ phenylalanine $\times 100 \mathrm{~g} \mathrm{bw}^{-1} \times \mathrm{min}^{-1}$ after hysterectomy. This was accompanied by increased amino acid membrane transport rates and metabolic shunting. In tumor bearing rats this increased net protein breakdown was attenuated ( $8 \pm 4$ versus $17 \pm 4$ $\left.\mathrm{nmol} \times 100 \mathrm{~g} \mathrm{bw}^{-1} \times \mathrm{min}^{-1}\right)$. Glutamine is the major energy substrate of the gut. Intracellular glutamine uptake by the gut increased after hysterectomy in contro! rats from $427 \pm 28$ to $937^{\prime} \pm 114 \mathrm{nmol} \times 100 \mathrm{~g} \mathrm{bw}^{-1} \times \mathrm{min}^{-1}$ which response was attenuated in tumor bearing rats $\left(352 \pm 40\right.$ to $\left.613 \pm 78 \mathrm{nmol} \times 100 \mathrm{~g} \mathrm{bw}^{-1} \times \mathrm{min}^{-1}\right)$. The presence of tumor and surgery both increased lactulose/L-rhamnose recovery ratio indicating loss of gut barrier function induced by both events.

In conclusion, the study shows that a mild surgical trauma increases protein breakdown of the gut in conjunction with increased intracellular glutamine
\end{abstract}


consumption. In the presence of a tumor, intestinal protein turnover and glutamine uptake by the gut are chronically depressed resulting in an attenuated metabolic response to a surgical trauma with increased loss of gut barrier function.

Introduction

Cells of the gastrointestinal tract have a life span of approximately 48 hours (1) with a protein turnover of more than $100 \%(2,3)$ enabling the intestinal tract to adapt rapidily to fasting, feeding and metabolic stress (3). During metabolic stress the small intestine looses weight by increasing protein breakdown rates while protein synthesis rates remain relatively unchanged $(2,4,5)$. The breakdown of gut proteins and subsequent release of amino acids has been postulated to be of crucial importance in the early phase, the so-called "ebb" phase $(6)$, after severe injury or trauma $(7,8)$ Thus, besides it's absorptive and barrier function, the gut is currently recognized to have a central and regulatory role in protein and amino acid metabolism during injury, sepsis and severe metabolic stress $(9,10)$.

Both human and animal studies have revealed that glutamine is an important nutrient for the gut $(11,12)$. Glutamine is essential for enterocytes as energy source, as nucleotide precursor $(13,14)$ and for polyamine production (15). We previously reported several marked changes in glutamine metabolism of the gut in the progress of cancer (16). Arterial and intracellular glutamine concentrations decreased with increasing tumor loads and this was paralleled, in the large tumor bearing state, with increased intracellular glutamine turnover rates. These disturbances in glutamine metabolism were associated with decreased polyamine concentrations and loss of the gut barrier function. Thus, similar to severe trauma and sepsis we observed that the progress of cancer disturbs glutamine metabolism in such a manner that intestinal function is diminished (17-19).

To obtain more insight as to how cancer affects the normal metabolic and functional response of the gut to a surgical insult the current study was performed. Aim of the present study was twofold: to test whether the intestine of tumor bearing rats is still capable of producing amino acids by increasing it's protein breakdown rates after a mild surgical trauma. Furthermore, we wanted to examine how the cancer bearing state influences intracellular glutamine turnover and gut barrier function after a surgical trauma. 


\section{Materials and Methods}

\section{Animals and tumor model}

Female Lewis rats (190-210 gr., Centralized Animal Facilities, University of Limburg. Maastricht, NL) were individually housed in metabolic cages during the experiment after an adaptation period of 3 days. Rats were given standard laboratory rat chow (SRMA 1210, Hopefarms, Woerden, NL) and subjected to standard 12 hour light-dark cycle periods (7:30 A.M. to 7:30 P.M.) with room temperature maintained at $25^{\circ} \mathrm{C}$. The experiments were performed in accordance with the recommendations of the Guide for the Care and Use of Laboratory Animals (20) and approved by the Ethical Committee of Animal Research of the University of Limburg.

The tumor was induced by injecting $10 \mathrm{mg}$ methylcholantrene (MCA, Sigma Chemie, W6501, Axel, NL) subcutaneously (21). Afterwards, the tumor was maintained in vivo by serially transplanting tissue suspensions through a $18 \mathrm{G}$ needle. MCA tumors are often used in metabolic studies and are known for its rapid growth, invasion of local tissue and absence of metastatic potential (22-24). The tumor was allowed to grow until it reached $5-15 \%$ of the host body weight. Non-tumor bearing rats were sham implanted with saline. Tumor growth was monitored by measuring two orthogonal dimensions and by calculating the volume assuming the tumor to be a prolate spheroid (25). Rats were housed in metabolic cages and tumor size, body weight and food intake were monitored daily. Carcass weight was determined by subtracting estimated tumor weight from total body weight.

\section{Groups and surgical procedure}

Rats $(n=40)$ were randomly assigned to one of the following four groups:

1) control, sham anesthetized,

2) control, hysterectomized,

3) tumor-bearing, sham anesthetized,

4) tumor bearing, hysterectomized.

The surgical groups were subjected to a laparotomy under diethyl ether anesthesia (Merck 923, Darmstadt, Germany). The bicornuate uterus was dissected free and ligated on both sides from the ovaries with vicryl 3-0 (Ethicon, Norderstedt, Germany). The uterus was ligated at the basis with vicryl 3-0 and removed from the abdomen. The abdominal wound was closed in two layers with vicryl 3-0. The whole procedure took approximately 10-15 minutes. This standard procedure has been described previously (26-28). It involves the removal of a non-essential organ for the individual and metabolic responses to this kind of surgical trauma correspond with findings after cholecystectomy in patients (28). All non-operated rats underwent 
sham anesthesia with diethyl ether for 15 minutes. Food intake and body weight were monitored daily.

\section{Study procedures}

PDV fluxes, protein and glutamine turnover were examined as described previously $(3,29,30)$ and performed simultaneously with hindquarter measurements as described in chapter 9 . In brief, postabsorptive, uncler ether anesthesia and at constant, pre-anesthesia body temperature, rats were subjected to a laparotomy. The right renal vein, portal vein, a tertiary branch of the mesenteric vein and aorta were cannulated using a 25 gauge needle fixed in a Silastic tube (Silastic Medical Grade tubing $0.051 \mathrm{~cm} \mathrm{ID,} 0.094$ OD, Dow Corning Corporation, Midland, MO, USA) and fixed with cyano-acrylate. For flow measurements, the indicator dilution method with para-aminohippuric acid (PAH) was used (pH 7.4, iso-osmolaric, Sigma A 1422 , St Louis, MI, USA). A primed $\left(0.15 \mathrm{ml} \times 100 \mathrm{~g} \mathrm{bw}^{-1}, 50 \mathrm{mmol} / \mathrm{l}\right)$ constant infusion $\left(0.75 \mathrm{ml} \times 100 \mathrm{~g} \mathrm{bw}^{-1} \times \mathrm{h}^{-1}, 5 \mathrm{mmol} / \mathrm{L}\right)$ of PAH was infused in the mesenteric vein, using a Minipuls 3 Peristaltic Pump (Gilson Medical Electronics Inc., Villiers-le-Bel, France). For turnover studies, a primed $\left(1 \mu \mathrm{Ci} \times 100 \mathrm{~g} \mathrm{bw}^{-1}\right)$ constant infusion $(1 \mu \mathrm{Ci}$ $\left.\times 100 \mathrm{~g} \mathrm{bw}^{-1} \times \mathrm{h}^{-1}\right)$ of L-[3,4- $\left.{ }^{3} \mathrm{H}\right]$ phenylalanine (NEN Dupont, NET-493, Mechelen, Belgium) and L- $\left[3,4-{ }^{3} \mathrm{H}\right]$ glutamine (NEN Dupont, NET-551) was given in the right renal vein. A minimum infusion time of 30 minutes was needed to reach steady state concentrations for $\mathrm{PAH},{ }^{3} \mathrm{H}$-phenylalanine and ${ }^{3} \mathrm{H}$-glutamine (3). The right carotid artery was canulated during the equilibrium period with PE 50 catheter (Intramedic, $0.051 \mathrm{~cm} \mathrm{ID,} 0.094 \mathrm{~cm} \mathrm{OD}$, Clay Adams, Parispany, NY, USA). The complete procedure took approximately 40 minutes.

Blood $(1.0 \mathrm{ml}$ per catheter) was simultaneously sampled from the portal vein and carotid artery. All blood was collected in heparinized cups (Lithium-Heparin, D51588, Sarstedt, Germany) on ice. Hereafter, the small intestine was dissected free from the pyloric sphincter to the coecal valve, flushed with ice-cold saline and weighted. A small part of the jejunum was directly freeze-clamped, put in liquid nitrogen and stored at $-80^{\circ} \mathrm{C}$ until further analysis.

For PAH determinations, $50 \mu \mathrm{l}$ heparinized blood was added to $500 \mu \mathrm{l} \mathrm{TCA} 10 \%$ $(w / v)$, vortexed and centrifuged at $8,900 \mathrm{~g}$ at $4^{\circ} \mathrm{C}$. The supernatant was frozen in liquid nitrogen and stored at $-80^{\circ} \mathrm{C}$ until further analysis. For hematocrit determinations a micro-hematocrit tube was filled with heparinized blood and centrifuged at $10,000 \mathrm{~g}$ at room temperature. Hematocrit was read with a Micro Hematocrit Reader (Hawksley Ltd, UK). Plasma was obtained by whole blood centrifugation at $8,900 \mathrm{~g}$ at $4^{\circ} \mathrm{C}$ for 5 minutes. For ammonia, urea, glucose and lactate determinations, $200 \mu \mathrm{l}$ plasma was vortexed with $20 \mu \mathrm{l} \mathrm{TCA} 50 \%$, put into 
liquid nitrogen and stored at $-80^{\circ} \mathrm{C}$. To determine plasma amino acid specific activities and concentrations, $300 \mu$ plasma was added to $8 \mathrm{mg} 5$-sulfosalicylic acid, vortexed, frozen in liquid nitrogen and stored at $-80^{\circ} \mathrm{C}$.

\section{Biochemical analysis}

Plasma arnmonia, urea, glucose, lactate and PAH were determined spectrophotometrically on a Cobas Mira S (Roche Diagnostica, Hoffnnan-La Roche, Basel, Switzerland) by standard enzymatic methods, using commercially available kits $(3,29,30)$. Plasma amino acid concentrations and specific activity were determined by fully automated HPLC as described previously (31). For the determination of intestinal ammonia, amino acid concentrations and specific activities, tissue was pulverized using a mortar and pestle precooled in liquid nitrogen. The tissue was further homogenized and deproteinized in a MiniBeadbeater (Biospec proclucts, Bartlesville, USA). Approximately $100 \mathrm{mg}$ tissue was added to $400 \mu \mathrm{l} \mathrm{SSA} 5 \%$, with $300 \mathrm{mg}$ glass beads (diameter $1 \mathrm{~mm}$, Biospeck Products) and beaten for 30 seconds. The homogenate was centrifuged at $4^{\circ} \mathrm{C}$ at $11,000 \mathrm{~g}$ and the supernatant frozen in liquid nitrogen and stored at $-80^{\circ} \mathrm{C}$ until further determinations.

To determine tissue dry weight and water content approximately $200 \mathrm{mg}$ pulverized tissue was freeze dried for 24 hours in a Speedvac (SC200, Savant Instruments Inc., Farmingdale NY, USA) connected with a refrigerated condensation trap.

\section{Calculations}

Plasma flow and substrate fluxes

Plasma flow across the portal drained viscera was calculated using PAH in the indicator dilution method $(3,29,30)$. Substrate fluxes are calculated by multiplying the venous-arterial concentration differences with the mean plasma flow of the group and are expressed in $\mathrm{nmol} \times 100 \mathrm{gr}$. body weight ${ }^{-1} \times \mathrm{min}^{-1}$. A positive flux indicates net release, a negative flux reflects a net uptake. Total release of $\alpha$-amino-nitrogen was calculated as the sum of the individual amino acids which are released by the PDV except taurine (31). Tissue concentrations of amino acids are expressed in $\mu \mathrm{mol} / \mathrm{l}$ and derived by dividing the tissue homogenate amino acid concentration ( $\mu \mathrm{mol} / \mathrm{kg}$ wet weight) with the tissue water content. 


\section{Protein and glutamine kinetics}

Protein and glutamine turnover were calculated by the A-V dilution of tritium labeled phenylalanine and glutamine across the PDV calculated in a three compartment model $(30,32,33)$. Intracellular disposal (D) and production (P) of phenylalanine and glutamine can thus be calculated and reflect in vivo intracellular turnover of these amino acids. Production of phenylalanine reflects protein breakdown and disposal reflects protein synthesis because intestinal metabolism of phenylalanine is restricted to synthesis into and breakdown from protein (34). Furthermore, amino acid membrane transport rates can simultaneously be measured: $F_{i, a}$ are plasma-tissue inward directed transport rates, $F_{p j}$ are plasmatissue outward directed membrane transport rates and $F_{p . a}$ reflects metabolic shunting of amino acids $(30,32,33)$.

\section{Statistical Analysis}

Results are presented as mean \pm SEM. Statistical analysis was performed using the statistical package SPSS (35). Two-Way ANOVA was used to test effects of tumor load, hysterectomy and an interaction between tumor load and hysterectomy. Significance from zero was tested by the Wilcoxon signed-ranks test. Significance was considered present at $p<0.05$.

Results

Initial and preoperative carcass weights were similar in all groups (Table 1). Hysterectomized rats lost more of their body weight than sham anesthetized rats. Food intake was similar in all groups and remained unchanged in the preoperative period. Postoperative food intake decreased in hysterectomized control and tumor bearing rats to approximately $18-20 \%$ of the preoperative daily food intake.

\section{Plasma flow and fluxes}

Plasma flow across the portal drained viscera was in the same range as described previously $(29,30)$ and increased after hysterectomy in control and tumor bearing rats (Table 2). Glucose uptake by the portal drained viscera was not influenced by the presence of a tumor or by hysterectomy. However, it decreased to levels not different from zero in the tumor bearing hysterectomized rats. Lactate release changed to an uptake after hysterectomy in control rats. In the tumor bearing state lactate release was increased whereas a hysterectomy in tumor bearing rats had no effect on lactate flux. 


\begin{tabular}{|c|c|c|c|c|c|c|c|}
\hline & \multicolumn{2}{|c|}{ Control } & \multicolumn{2}{|c|}{ Tumor bearing } & \multicolumn{3}{|c|}{$p$ value } \\
\hline & sham & hysterectomy & sham & hysterectomy & $T$ & $\mathrm{~S}$ & I \\
\hline Tumor woight & - & - & $38 \pm 2$ & $32 \pm 3$ & $<0.001$ & ns & ns \\
\hline \multicolumn{8}{|l|}{ Carcass weight } \\
\hline Initial & $195 \pm 3$ & $200 \pm 3$ & $200 \pm 3$ & $204 \pm 3$ & ns & ns & ns \\
\hline Preoperative & $200 \pm$ & $205 \pm 4$ & $198 \pm 4$ & $201 \pm 4$ & ns & ns & ns \\
\hline Postoperative (day 2) & $190 \pm$ & $184 \pm 4$ & $191 \pm 7$ & $180 \pm 4$ & ns & 0.02 & ns \\
\hline \multicolumn{8}{|l|}{ Food intake } \\
\hline Initial & $18 \pm 1$ & $17 \pm 1$ & $17 \pm 1$ & $15 \pm 2$ & ns & ns & ns \\
\hline Preoperative & $17 \pm 1$ & $15 \pm 1$ & $17 \pm 1$ & $16 \pm 2$ & ns & ns & ns. \\
\hline Postoperative & $16 \pm 1$ & $4 \pm 2$ & $15 \pm 3$ & $3 \pm 1$ & ns & $<0.001$ & ns \\
\hline
\end{tabular}

Table 1. Carcass weight, tumor weight and food intake during the experiment. Values are mean \pm SEM. Carcass weight is in grams. food intake in gram/day except postoperative which is in total intake after hysterectorny or sham anesthesial the metabolic study procedure. Statistical analysis by Two-Way ANOVA: T= effects of tumor load, $\mathrm{S}=$ effects of surgery, $\mathrm{I}=$ interaction of tumor load and surgery. 


\begin{tabular}{|c|c|c|c|c|c|c|c|}
\hline & \multicolumn{2}{|c|}{ Control } & \multicolumn{2}{|c|}{ Tumor bearing } & \multirow[b]{2}{*}{$\mathbf{T}$} & $\mathrm{p}$ value & \multirow[b]{2}{*}{1} \\
\hline & sham & hysterectomy & sham & hysterectomy & & $\mathbf{S}$ & \\
\hline Plasma flow & $1.5 \pm 0.9$ & $4.9 \pm 2.5$ & $2.4 \pm 0.9$ & $4.2 \pm 1.5$ & ns & 0.05 & ns \\
\hline Glucose & $-641 \pm 274$ & $-1961 \pm 856$ & $-983 \pm 378$ & $-296 \pm 559$ & ns & ns & ns \\
\hline Lactate & $126 \pm 78$ & $-1378 \pm 624$ & $745 \pm 456$ & $688 \pm 365$ & 0.02 & ns & 0.02 \\
\hline Ammonia & $256 \pm 36$ & $620 \pm 91$ & $263 \pm 28$ & $474 \pm 49$ & ns & $<0.001$ & 0.04 \\
\hline Glutamine & $-427 \pm 28$ & $.937 \pm 114$ & $-352 \pm 48$ & $-613 \pm 78$ & 0.04 & $<0.001$ & 0.007 \\
\hline Glutamate & $32 \pm 3$ & $24 \pm 27$ & $24 \pm 7$ & $22 \pm 8$ & ns & ns & ns \\
\hline Alanine & $303 \pm 28$ & $807 \pm 91$ & $300 \pm 56$ & $598 \pm 55$ & ns & $<0.001$ & 0.04 \\
\hline Citrulline & $54 \pm 9$ & $131 \pm 14$ & $30 \pm 13$ & $69 \pm 11$ & 0.001 & $<0.001$ & 0.03 \\
\hline Total release $\alpha-A N$ & $491 \pm 83$ & $1318 \pm 230$ & $289 \pm 160$ & $877 \pm 147$ & 0.01 & 0.001 & 0.02 \\
\hline
\end{tabular}

Tabie 2. PDV plasma flow, ammonia and amino acid fluxes. Values are presented in nmol $x 100 \mathrm{gr}^{\text {. body weight }}{ }^{-1} \times$ min $^{-1}$ (mean \pm SEM). Total release $\alpha$-AN is the sum of all amino acids released by the portal drained viscera Statistical analysis; by Two-Way ANOVA: T $=$ effect of tumor, $S$ $=$ effect of surgery, 1 = effect of interaction between presence of a tumor and surgery. Significance from zero tested by Wilcoxon: \# not significant from zero $(p<0.05)$. Fluxes: $(-)$ reflects net uptake, $(+)$ reflects net release of a substrate. 
The hysterectomy increased net glutamine uptake by the gut. In tumor bearing rats glutamine uptake was decreased and, the postoperative increase was less than in control rats. Ammonia, glutamate, alanine and citrulline are the major end products of glutamine consumption by the gut (13). Ammonia release increased after surgery. This release was higher in control rats than in tumor bearing rats. Glutamate production by the gut remained unchanged after surgery in both control and tumor bearing rats. Alanine release increased after surgery but this release increased not as much in the tumor bearing rats than in the control rats. Citrulline release decreasecl in tumor bearing rats. It increased after surgery, but this response was also attenuated in the tumor bearing rats. Finally, the sum of $\alpha$-amino nitrogen released in the portal vein increased after hysterectomy. It was decreased in tumor bearing rats and the response to surgery was, again, attenuated.
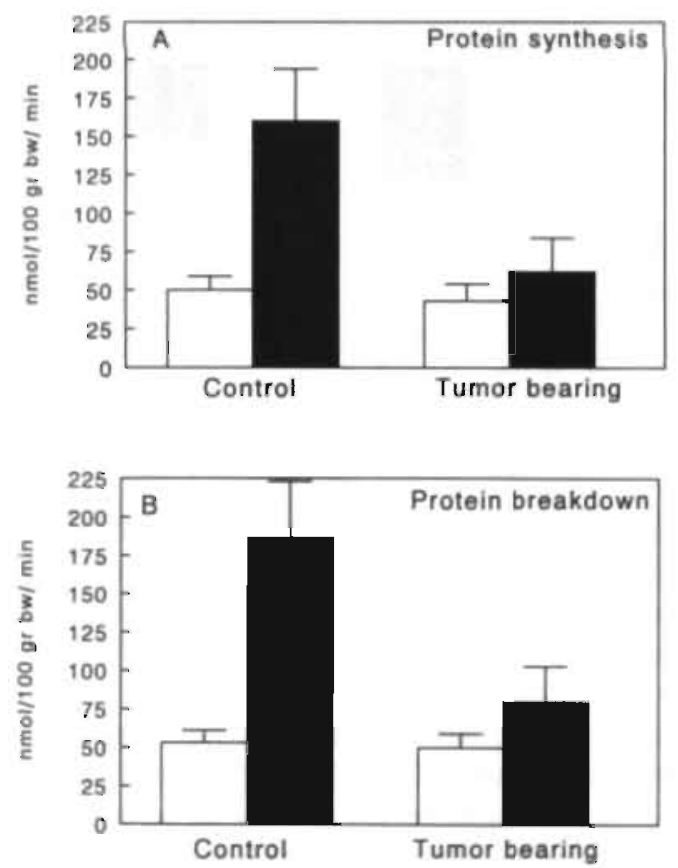

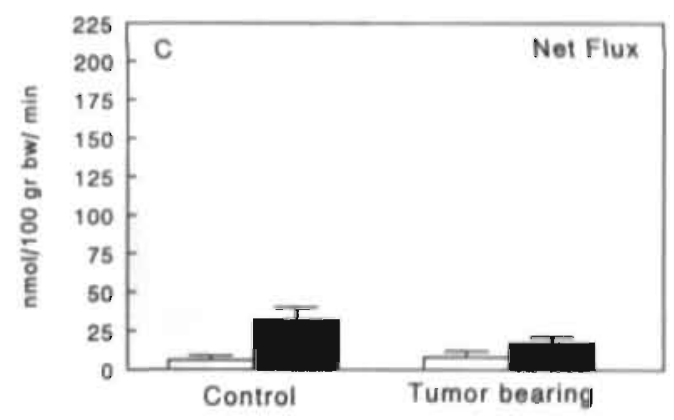

Figure 1. Intracellular protein turnover of the PDV. Values are mean \pm SEM. Intracellular protein synthesis is calculated as intracellular disposal of phenylalanine, protein breakdown as intracellular production of phenylalanine $(30,32)$. The flux of phenylalanine is the difference between protein synthesis and breakdown: (+) net release, (-) net uptake of phenylalanine. Statistical analysis by Two-Way ANOVA for effects of tumor load, hysterectomy and interaction of the two.

Sham anesthetized rats, - Hysterectomized rats. A Intracellular protein synthesis. Effect tumor: $p=0.003$; effect hysterectomy: 0.006 ; interaction: $p=0.02$. B: Intracellular protein breakdown. Effect tumor: $p=0.001$; effect hysterectomy: $p<0.001$; interaction $p=0.005$. C: Net phenylalanine flux. Effect tumor: ns; effect hysterectomy. $p<0.001$; interaction: $p=0.05$. 


\section{Protein and glutamine kinetics}

Intracellular disposal of phenylalanine (protein synthesis) and production of phenylalanine (protein breakdown) were lower in tumor bearing rats (Fig. 1). Both protein synthesis and breakdown increased after surgery but to a lesser extent in the tumor bearing rats. Protein breakdown rates increased more than synthesis rates resulting in an increased efflux of phenylalanine (net protein breakdown, Fig. 1, bottom panel) of the gut after surgery. Again, this net efflux was attenuated in the tumor bearing rats.

Phenylalanine membrane transport rates resembled intracellular protein turnover (Table 3). After the hysterectomized inward $\left(F_{l, a}\right)$ and outward $\left(F_{p_{j},}\right)$ membrane transport rates increased. In tumor bearing rats the postoperative increase of inward and outward membrane transport rates was attenuated. Metabolic shunting of phenylalanine was increased in tumor bearing rats. Surgery also increased metabolic shunting across the PDV.
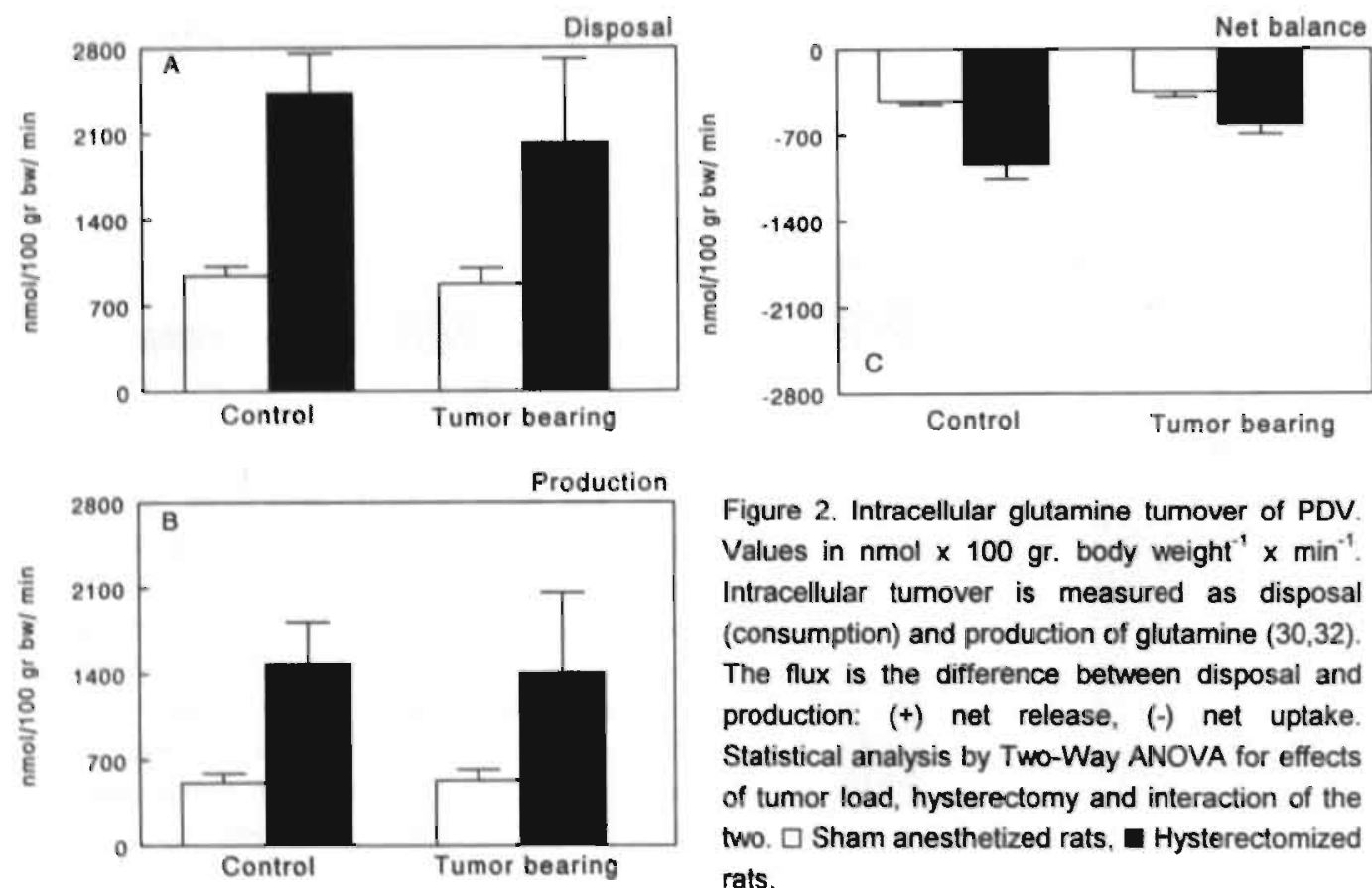

Figure 2. Intracellular glutamine tumover of PDV. Values in $\mathrm{nmol} \times 100 \mathrm{gr}$. bodty weight' $\times \mathrm{min}^{-1}$. Intracellular tumover is measured as disposal (consumption) and production of glutamine $(30,32)$. The flux is the difference between disposal and production: (+) net release, (-) net uptake. Statistical analysis by Two-Way ANOVA for effects of tumor load, hysterectomy and interaction of the two. $\square$ Sham anesthetized rats, $n$ Hysterectomized rats.
A: Intracellular disposal. Effect tumor: $n s$; effect hysterectomy: $p=0.001$; interaction: ns.
B: Intracellular production. Effect tumor; ns; effect hysterectomy: $p=0.002$; interaction: ns.
C: Net glutamine flux. Effect tumor: $p=0.002$; effect hysterectomy: $p<0.001$; interaction: $p=0.04$. 


\begin{tabular}{|c|c|c|c|c|c|c|c|c|c|c|c|c|c|}
\hline & \multicolumn{5}{|c|}{ Control } & \multicolumn{5}{|c|}{ Tumor bearing } & \multicolumn{3}{|c|}{$p$ value } \\
\hline & \multicolumn{3}{|c|}{ sham } & \multicolumn{2}{|c|}{ hysterectomy } & \multicolumn{3}{|c|}{ sham } & \multicolumn{2}{|c|}{ hysterectomy } & $T$ & \multirow[t]{2}{*}{$\mathrm{S}$} & \multirow[t]{2}{*}{1} \\
\hline & & & & & & & & & & & & & \\
\hline$F_{i a}$ & 24 & \pm & 4 & 102 & \pm 22 & 13 & \pm 1 & 13 & 34 & \pm & 0.002 & 0.002 & 0.02 \\
\hline$F_{p j}$ & 27 & \pm & 4 & 134 & $\pm \quad 22$ & 21 & \pm 1 & 11 & 51 & \pm 11 & 0.001 & $<0,001$ & 0.002 \\
\hline$F_{p . a}$ & 45 & \pm & 2 & 147 & $\pm \quad 43$ & 135 & \pm 2 & 23 & 204 & \pm 11 & 0.007 & 0.003 & ns \\
\hline \multicolumn{14}{|c|}{ Glutamine } \\
\hline$F_{\text {la }}$ & 588 & \pm 7 & 77 & 1194 & \pm 142 & 373 & \pm 4 & 47 & 776 & \pm 164 & 0.002 & $<0.001$ & ns \\
\hline$F_{D A}$ & 160 & \pm 6 & 63 & 256 & \pm 149 & 20 & \pm 3 & 33 & 163 & \pm 109 & ns & ns & ns \\
\hline$F_{p s}$ & 458 & \pm 7 & 73 & 1531 & 土 190 & 865 & \pm 6 & 62 & 1236 & \pm 139 & ns & $<0.001$ & 0.01 \\
\hline
\end{tabular}

Table 3. Phenylalanine and glutamine membrane transport rates across the PDV. Values are presented in nmol $\times 100 \mathrm{gr}^{\text {. body weight }}{ }^{-1} \times$ min $^{-1}$

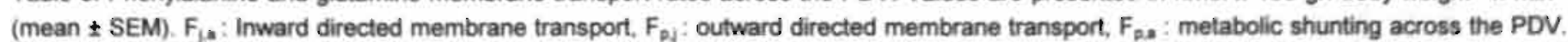
Statistical analysis by Two-Way ANOVA. $\mathrm{T}=$ effect of tumor, $\mathrm{S}=$ effect of surgery, I = effect of interaction between presence of a tumor and surgery. 
Intracellular glutamine disposal (consumption) increased after a hysterectomy (Fig. 2). Intracellular glutamine production was lower than disposal. Glutamine production increased after hysterectomy. The difference between consumption and production is reflected by the flux of glutamine (Fig. 2, Table 2). This flux (net uptake) was decreased in tumor bearing rats, increased after hysterectomy. The postoperative response was attenuated in tumor bearing rats. Glutamine inward $\left(F_{j, a}\right)$ membrane transport rates were decreased in the tumor bearing rats (Table 3). Surgery increased these rates, in both control and tumor bearing rats. Outward $\left(F_{p_{j}}\right)$ mernbrane transport rates was not significantly different between the groups, possibly due to the relatively high variation. Metabolic shunting of glutamine across the PDV $\left(F_{p, a}\right)$ increased after surgery in control rats. In tumor bearing rats, hysterectomy had a smaller effect because metabolic shunting was already elevated in the non-operated rats.

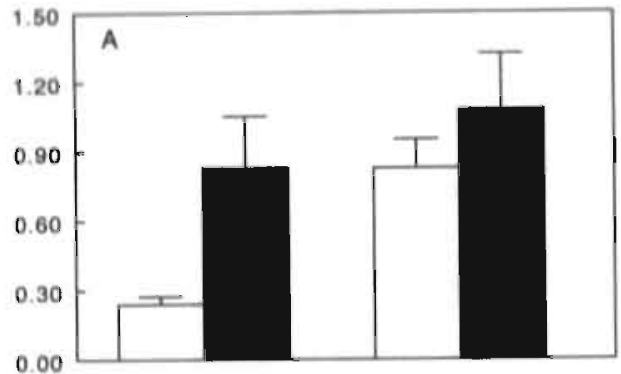

Control

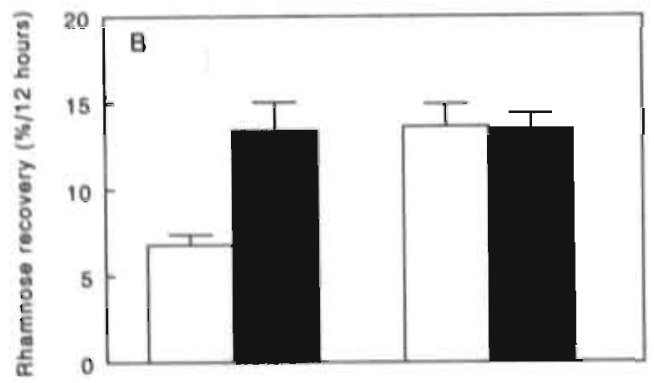

Control

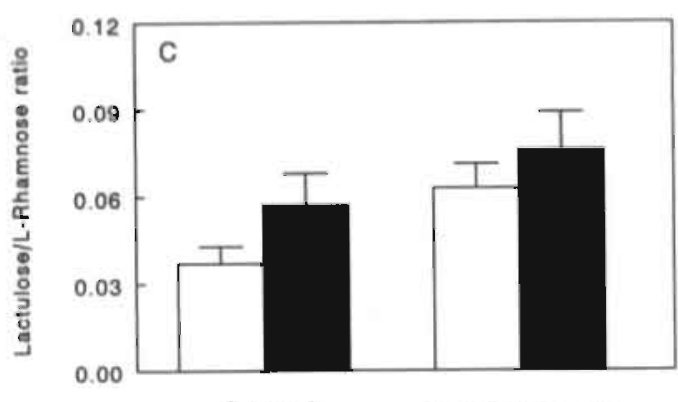

Control
Tumor bearing

Figure 3. Uninary recovery of lactulose, Lmamnose and its ratio to test gut permeability. An iso-osmolar oral dose of both sugar probes was given and the recovery was determined in urine after 12 hours. Gut permeability was assessed by the lactulose/L-rhamnose ratio of the urinary recovery. Values are means \pm SEM and in $\%$ per 12 hours. Statistical analysis by Two-Way ANOVA for effect tumor, effect surgery and the interaction between tumor and surgery. $\square$ Sham anesthetized rats, $\mathbf{n}$ Hsterectomized rats.
A: Lactulose recovery: effect tumor, $p=0.03$; effect surgery, $p=0.001$; interaction, ns
B: L-Rhamnose recovery; effect tumor, $p=0.02$; effect surgery, $p<0.001$; interaction, $p=0.02$.
C: Lactulose/rhamnose ratia: effect tumor, $p=0.05$; effect surgery, $p=0.01$; interaction, ns. 


\begin{tabular}{|c|c|c|c|c|c|c|c|c|}
\hline & \multicolumn{3}{|c|}{ control } & \multicolumn{2}{|c|}{ tumor bearing } & \multicolumn{3}{|c|}{$p$ value } \\
\hline & shar & & hysterectomy & sham & hysterectomy & $T$ & $\mathrm{~s}$ & 1 \\
\hline $\mathrm{H}_{2} \mathrm{O} \%$ & 74.1 & \pm 0.6 & $73.1 \pm 0.8$ & $73.5 \pm 0.9$ & $73.6 \pm 0.6$ & ns & ns & ns \\
\hline Ammonia & 2284 & \pm 84 & $2073 \pm 293$ & $2027 \pm 256$ & $1528 \pm 133$ & 0.01 & ns & $\mathrm{ns}$ \\
\hline Glutamine & 769 & \pm 54 & $845 \pm 66$ & $759 \pm 48$ & $748 \pm 47$ & ns & ns & ns \\
\hline Glutamate. & 2983 & \pm 184 & $3338 \pm 201$ & $2712 \pm 208$ & $2927 \pm 131$ & ns & ns & $\mathrm{ns}$ \\
\hline Alanine & 2082 & \pm 152 & $2643 \pm 316$ & $2597 \pm 253$ & $2707 \pm 270$ & ns & 0.05 & ns \\
\hline Citrulline & 218 & \pm 51 & $270 \pm 54$ & $216 \pm 31$ & $246 \pm 32$ & ns & ns & ns \\
\hline Phenylalanine & 151 & \pm 19 & $191 \pm 36$ & $215 \pm 21$ & $185 \pm 13$ & ns & ns & ns \\
\hline a-Amino-nitrogen & 11359 & \pm 156 & $13011 \pm 1180$ & $13946 \pm 783$ & $13118 \pm 1044$ & ns & ns & ns \\
\hline
\end{tabular}

Table 4. Jejunal hydration and intracellular ammonia and amino acid concentrations. Concentrations in $\mu$ moll (mean $\pm \mathrm{SEM}$ ). $\alpha$-Amino-nitrogen is the sum of individual amino acids measured except taurine (31). Statistical analysis by Two-Way ANOVA: $\mathrm{T}=$ effect of tumor, $\mathrm{S}=\mathrm{effect}$ of surgery, $I=$ effect of interaction between presence of a tumor and surgery. 


\section{Intracel/ular concentrations}

Intracellular water remained unchanged (Table 4). Intracellular ammonia was decreased in tumor bearing rats while hysterectomy had no effect on this. Intracellular alanine increased after hysterectomy in both control and tumor bearing rats. Intracellular glutamine, glutamate, phenylalanine, citrulline and total $\alpha$-aminonitrogen remained unchanged between the different groups.

\section{Lactulose and L-rhamnose recovery}

Urinary recovery of lactulose and L-rhamnose was increased in tumor bearing rats (Fig. 3). It also increased after surgery. The lactulose/L-rhamnose ratio, indicative for gut permeability, was increased in tumor bearing rats. Surgery also increased the recovery ratio.

\section{Discussion}

The main observation in the present study is that surgical stress increases gut protein turnover and amino acid membrane transport resulting in increased net breakdown of intestinal proteins with subsequent release of amino acids. The gut is a metabolically very active organ with protein turnover rates of more than $100 \%$ per day, one of the highest in the body (2). The high turnover rates are primarily needed to make up for the intraluminal cell loss. This accounts for approximately half of the protein synthesis rates in enterocytes (2). Both increasing amounts of exfoliated cells and increased secretion of proteins have been observed during severe stress $(36,37)$. This may partly be responsible for the increased protein turnover observed in the present study. However, high turnover rates are also of extreme importance for the gut to adapt rapidly to changing environmental conditions $(3,38)$. It has been outlined by Abumrad that in the early "ebb" phase of a trauma, breakdown of proteins with high turnover rates is initiated to transfer amino acids to visceral organs for gluconeogenesis and the production of acute phase proteins (7). The high protein turnover rates of the intestinal tract make this organ suitable to adapt to this first phase after a trauma. In a recently published study on exercise induced metabolic stress, 60-90 minutes of exercise almost doubled gut proteolysis apparently aimed at sparing muscle protein (8). The muscle proteolytic response with subsequent amino acid release is generally thought to occur in a later phase ("flow phase") after trauma (6). The close anatomic relationship of the gut with the liver has the other advantage that the release of amino acids in the portal vein makes them almost instantly available for gluconeogenesis and the production of acute phase proteins. As in 
humans direct measurements are difficult, Lund et al. calculated the intestinal release of amino acids indirectly in the portal vein from the total splanchnic amino acid uptake and the net urea production (39). They also found an increased release of amino acids into the portal vein during and in the early recovery phase after a cholecystectomy, a comparable trauma to the hysterectomy in rats (28).

The current study shows that the presence of cancer clepresses intestinal protein turnover resulting in a reduced net protein breakdown and $\alpha$-amino acid release. This could both have consequences for gluconeogenesis and for the early hepatic acute phase response. Arterial glucose, however, remained unchanged after surgery in the tumor bearing rats (see chapter 9 , table II) suggesting no major impairment of the gluconeogenesis. Furthermore, decreased acute phase protein production by the liver has previously been observed in both cancer patients and in malnourished children $(40,41)$. This impaired response may be related to the attenuated early mobilization of amino acids from the gut as observed in the current study.

Functioning of the gut itself was assessed by the metabolic kinetics of it's major energy substrate glutamine and by gut barrier function. The mild surgical trauma we applied increased intracellular glutamine consumption, production and net uptake by the gut. This is in agreement with increased glutamine consumption by the gut following a mild surgical trauma observed in dogs (10). In a piglet study, however, we observed a decreased glutamine uptake by the gut following major abdominal surgery (42). It has been postulated that mild metabolic stress increases glutamine consumption by the gut whereas in severe metabolic stress, e.g. sepsis or endotoxemia, glutamine consumption by the gut decreases (18). Our results therefore confirm that we studied protein and glutamine kinetics after a mild surgical trauma as stated previously.

The increased net uptake of glutamine by the gut was attenuated in tumor bearing rats although this became not significant for intracellular consumption. The postoperative increased uptake of glutamine by the PDV occurred in conjunction with increased ammonia, alanine and citrulline release which are end products of glutamine consumption by the gut (13). Measurement of end products is necessary because the portal drained viscera contain several organs capable of consuming glutamine. Glutamate is an end product of lymphocyte glutamine consumption whereas alanine and citrulline are end products of enterocyte glutamine consumption. Because we observed no change in glutamate release into the portal vein it seems reasonable to assume that the increased glutamine consumption in the portal drained viscera after a mild surgical trauma was mostly located in the gut. The postoperative release of glutamine end-products was also attenuated by the 
presence of a tumor, thus confirming that glutamine metabolism in the gut of tumor bearing rats was attenuated on the second postoperative day.

Increased consumption of glutamine by the gut has been related to decreased glucose consumption thus sparing glucose for tissues with an obligate glucose requirement $(11,43)$. In our study glucose consumption decreased to a value not significantly different from zero in hysterectomized tumor bearing rats indicating that a similar phenomenon is present. Particularly, the postoperative increased glucocorticoid release has been held responsible for this mechanism enabling the host to spare glucose for reparative tissues (11). Our data could thus also indicate that the postoperative metabolic response in tumor bearing rats is of benefit for reparative tissue but this needs further research.

Intestinal function was also tested by gut barrier function. Gut barrier function was measured by the recovery ratio of lactulose/L-rhamnose. This ratio increased in tumor bearing rats as was shown previously (16). It also increased after surgery confirming previous studies which showed that metabolic stress induced by multiple trauma (44), endotoxemia (45) or shock (46) decreases gut barrier function. Increased permeability has previously been postulated to be the cause of a constant state of systemic inflammation possible the basis and driving force of systemic endotoxemia and sepsis (43). Whether this is true in tumor bearing rats remains to be elucidated. The extra increase in the postoperative days after the surgical trauma in tumor bearing rats was small and the clinical relevance remains to be determined. Combined with the protein turnover data, however, the current study shows that in the presence of cancer one of the first immune stations of splanchnic organs, the liver, has to cope with a decreased nutrient supply and an increased immune challenge in the first postoperative days.

In conclusion, the study shows that a mild surgical trauma increases protein breakdown of the gut in conjunction with increased glutamine consumption. In the presence of a tumor, intestinal protein turnover, glutamine uptake and inward directed membrane transport are chronically depressed resulting in an attenuated response to a surgical trauma with a depressed mobilization of amino acids. Gut barrier function is decreased in the presence of a tumor. Surgery also decreases gut barrier function and the effects were strongest in tumor bearing rats. The diminished delivery of nutrients to other organs, particularly the liver, after surgical stress could be the cause of the decreased acute phase response previously reported in cancer patients.

\section{Acknowledgments}

The authors wish to thank Mr. HMH van Eijk and Mr. DR Rooyakkers for analytical help. 
1. Gleeson MH, Dowling RH, Peters TJ. Intestinal structure and function after small bowel by-pass in the rat. Clin Sci 1972;43:731-42.

2. McNulan MA. Tomkins AM, Garlick PJ. The effect of starvation on the rate of protein synthesis in rat liver and small intestine. Biochem J 1979:178:373-379.

3. de Blaaumi I, Deutz NEP, von Meyenfeldt MF. In vivo amino acid metabolism of gut and liver during short and prolonged starvation. Am J Physiol 1996;270(33):G298-306.

4. Preedy VR, Paska L, Sudgen PH, Schofiled PS, Sugden MC. The effects of surgical stress and short-term fasting on protein synthesis in vivo in diverse tissues of the mature rat. Biochem $J$ 1988;250:179-188.

5. Carter EA, Hatz RA, Yarmush ML, Tompkins RG. Injury-induced inhibition of small intestinal protein and nucleic acid synthesis. Gastroenterology 1990;98:1445-51.

6. Frayn KIN. Hormonal control of metabolism in trauma and sepsis. Clin Endocrinol Oxf 1986;24:577-99.

7. Molina PE, Abumrad NN. Gut-derived proteolysis during insulin-induced hypoglycemia: the pain that breaks down the gut. J Parenter Enteral Nutr 1994;18:549-56.

8. Williams BD, Wolfe RR, Bracy DP. Wasserman DH. Gut proteolysis contributes essential amino acids during exercise. Am J Physiol 1996;270(33):E85-90.

9. Evans DA, Jacobs DO, Wilmore DW. Tumor necrosis factor enhances glucose uptake by peripheral tissues. Am J Physiol 1989;257:R1182-9.

10. Souba $\mathbf{W}$. Wilmore DW. Postoperative alteration of arteriovenous exchange of amino acids across the gastrointestinal tract. Surgery 1983;94:342-50.

11. Souba WW, Smith RJ, Wilmore DW. Glutamine metabolism by the intestinal tract J Parenter Enteral Nutr 1985;9:608-617.

12. Van der Hulst RRWJ, Kreel BK, Meyenfeldt MF, Brummer RJM, Arends JW, Deutz NEP, Soeters PB. Glutamine and the preservation of gut integrity. Lancet 1993;3:41:1363-1365.

13. Windmueller HG, Spaeth $A E$. Intestinal metabolism of glutamine and glutamate from the lumen as compared to glutamine from blood. Arch Biochern Biophys 1975;171:662-672.

14. Windmueller HG, Spaeth AE. Respiratory fuels and nitrogen metabolism in vivo in small intestine of fed rats. J Biol Chem 1980;255:107-112.

15. Kandil HM, Argenzio RA, Chen W, Berschneider HM, Stiles AD, Westwick JK, Rippe RA, Brenner DA, Rhoads JM. L-Glutamine and Lasparagine stumulate ODC activity and prolifewration in a porcine jejunal enterocyte line. Am J Physiol 1995;32(4):G 591-9.

16. de Blaauw I. Deutz NEP, von Meyenfeldt MF. Glutamine depletion and increased gut permeability' in non-anorectic, non weight losing tumor bearing rats. Gastroenterology 1995;108(4):A721.

17. Dudrick PS, Souba WW. The role of glutamine in nutrition. Curr Opin Gastroenteroli 1991;7:299305.

18. Souba WW. Glutamine: a key substrate for the splanchnic bed. Annu Rev Nutr 1991;11:285-308.

19. Souba WW. Glutamine and Cancer. Ann Surg 1993;218:715-728.

20. Waldegrave W. Chairman Council of European Community. Guide for the care and use of laboratory animals. European Community 1986, Publication 86/609, Brussels, Belgium.

21. Boyland $\mathrm{E}$, Warren $\mathrm{FL}$. The induction of tumours by methylcholanthrene in two strains of mice. $\mathrm{J}$ Path Bact 1937;45:171-177.

22. Popp MB, Morrison SD. Brennan MF. Total parenteral nutrition in a methylcholanthrene-induced rat sarcoma model. Cancer Treat Rep 1981;65(Suppl 5): $137-43$. 
23. Burt ME, Lowry SF, Gorschboth C. Brennan MF. Metabolic alterations in a noncachectic animal tumor system. Cancer 1981;47:2138-2146.

24. Chen MK, Espat NJ, Bland KI, Copeland EM, Souba WW. Influence of progressive tumor growth on glutamine metabolism in skeletal muscle and kidney. Ann Surg 1993;217:655-667.

25. Morrison SD. In vivo estimation of size of experimental tumors. J Natl Cancer Inst 1983;1:407408.

26. Heindorff $\mathrm{H}$, Almdal $\mathrm{T}$, Vilstrup $\mathrm{H}$. Contradictory effects of uncomplicated versus complicated abdominal surgery on the hepatic capacity for urea synthesis in rats. J Surg Res 1990;49:239243.

27. Lee VM, Wolfe BM, Hansen RJ, Clifford AJ. Postsurgical muscle protein turnover in perfused hindquarters of the rat. J Parenter Enteral Nutr 1988;12:452-456.

28. Heindorff $H$, Almdal $T$, Vilstrup $H$. Effects of hysterectomy and semi-starvation on amino acid gradients across liver, muscle and gut in rats. Clin Nutrition 1990:9:253-259.

29. Dejong CHC, Kampman MT, Deutz NEP, Sceters PB. Altered glutamine metabolism in rat portal drained viscera and hindquarter during hyperammonemia. Gastroenterology 1992;102:936-948.

30. de Blaauw I, Deutz NEP. von Meyenfeldt MF. In vivo protein and amino acid turnover in rats: effects of short-term and prolonged starvation. Clin Sci Colch 1996 90:457-466.

31. van Eijk HMH, Huinck MP, Rooyakkers DR, Deutz NEP. Automated simultanerous isolation and quantitation of labeled amino acid fractions from plasma and tissue by ion-exchange chromatography. J Chromatogr 1994;660:251-7.

32. Biolo G, Chinkes D. Zhang XJ, Wolfe RR. A new model to determine in vivo the relationship between amino acid transmembrane transport and protein kinetics in muscle. J Parenter Enteral Nutr 1992;16:305-315.

33. Biolo G. Fleming RY, Maggi SP, Wolfe RR. Transmembrane transport and intracellular kinetics of amino acids in human skeletal muscle. Am J Physiol 1995;268:E75-84.

34. Tourian A, Goddard J, Puck TT. Phenylalanine hydroxylase activity in mammalian cells. J Cell Physiol 1969;73:159-170.

35. Norusis MJ. SPSS/PC+ V4.0 BASE MANUAL for the IBM PC/XT/AT and PS/2. SPSS Inc, 1989, Chicago, IL., USA.

36. Rafferty JF, Noguchi Y, Fischer JE, Hasselgren PO. Sepsis in rats stimulates cellular proliferation in the mucosa of the small intestine. Gastroenterology 1994;107:121-127.

37. Higashiguchi T, Noguchi Y, Noffsinger A, Fischer JE, Hasselgren PO. Sepsis increases production of total secreted proteins, vasoactive intestinal peptide, and peptide $\mathrm{YY}$ in isolated rat enterocytes. Am J Surg 1994:168:251-256.

38. Wolíe RR. Wolfe RR, editors. Tracers in Metabolic Research. New York: Alan R. Liss, Inc; 1984. chapter 19. Determination of specific radioactivity, p. 239-24.

39. Lund J, Stjernstrom $H$, Vinnars $E$, Jorfeldt $L$, Berghoim $U$, Wiklund $L$. The influence of abdominal surgery on the splanchnic exchange of amino acids. Acta Chir Scand 1986;152:191-7.

40. Cruickshank AM. Hansell DT. Bums HJ, Shenkin A. Effect of nutritional status on acute phase protein response to elective surgery. Br J Surg 1989;76:165-8.

41. Doherty JF, Golden MH, Raynes JG, Griffin GE, McAdam KP. Acute-phase protein response is impaired in severely malnourished children. Clin Sci 1993;84:169-75.

42. Deutz NEP, Reijven PL. Athanasas G, Soeters PB. Post-operative changes in hepatic, intestinal, splenic and muscle fluxes of amino acids and ammonia in pigs. Clin Sci 1992:83:607-14.

43. Wilmore DW, Smith RJ, O'Dwyer ST, Jacobs DO, Ziegler TR, Wang XD. The gut: a central organ after surgical stress. Surgery 1988;104:917-23. 
44. Yao YM, Bahrami S, Leichtfried G, Redl H, Schlag G. Pathogenesis of hemorthage-induced bacteria/endotoxin translocation in rats. Effects of recombinant bactericidal/permeabilityincreasing protein. Ann Surg 1995:221:398-405.

45. Pape HC, Dwenger A, Regel G, Auf'n'Kolck M, Gollub F, Wisner D, Sturm JA, Tscherne H. Increased gut permeability after multiple trauma. Br J Surg 1994;81:850-852.

46. Fink MP, Antonsson JB, Wang $\mathrm{H}$, Rothschild $\mathrm{HR}$. Increased intestinal permeability in endotoxic pigs. Arch Surg 1991;126:211-218. 


\section{SUMMARY AND PERSPECTIVES FOR THE FUTURE}

\section{Summary}

The presence of cancer is accompanied by metabolic disturbances resulting in wasting of body mass. These events have an adverse effect on clinical outcome and, if left untreated, inevitably contributes to an earlier death (1). The changes observed in cancer cover a broad spectrum of intermediary metabolism. In this thesis tumor induced changes in protein and amino acid metabolism are studied in a rat tumor model. In addition, the consequences of these metabolic changes for the response to a surgical trauma are studied.

The thesis consists of three parts. First, a model is described to study in vivo protein and amino acid turnover in organs. Second, the effect of an increasing tumor load on protein and amino acid metabolism in muscle, gut and liver is studied. Finally, the effects of a surgical trauma on protein and amino acid metabolism in these organs in the cancer bearing host are studied.

Chapter 3 and 4 describe several models to measure in vivo amino acid and protein turnover across muscle and splanchnic organs. In these studies we showed that the A-V dilution method is applicable to measure protein turnover in small laboratory animals. The major advantage of the method is the possibility to measure in vivo protein synthesis, protein breakdown and amino acid plasma tissue membrane transport rates simultaneously. Compartment modeling made: it possible to measure protein and amino acid kinetics across the portal drained viscera, the liver and hindquarter muscle. The results of chapter 3 and 4 further show that during short starvation protein synthesis measurements using the $A-V$ dilution method gives similar results as the measurements using by the incorporation technique. After a prolonged starvation of 112 hours, however, both methods showed an opposite change in protein synthesis rates. It appears that the disappearance of amino acids measured by the A$V$ dilution method is not into the proteins which are measured by the incorporation technique (TCA-insoluble proteins) but into soluble proteins which are not measured 
with the incorporation technique. These effects may have been induced by the experimental procedure which includes ether anesthesia and a laparotomy. If we want to extrapolate the results to the clinical setting, our data indicate that amino acid and protein turnover of the gut, liver and muscle increase in patients suffering from prolonged starvation and undergoing surgery. Whether this rapid tumover is a functional adaptation or is a futile cycle remains to be elucidated. We chose to measure protein and amino acid kinetics using the A-V dilution method because it allows the measurements of different parameters in the same animal at the same time.

in chapter 5, 6, 7 and 8 the effects of a MCA tumor on whole body, hindquarter muscle, gut and liver protein and amino acid metabolism was studied. MCA tumor have been used extensively to study tumor induced changes in feeding behavior and changes in carbohydrate, lipid and protein metabolism (2-5). In these studies Fisher 344 rats were used and the tumor repeatedly induced anorexia with severe cachexia resulting in death. In our laboratory, however, the presence of this type of tumor had no influence on food intake of rats during $3 \frac{3}{2}$ years of experiments. Moreover, we imported tissue from a MCA tumor line from the US (gift from W.T. Chance, PhD, University of Cincinnati Medical Center, Cincinnati, Ohio), which was known to induce anorexia, and implanted these in Fisher 344 rats. Surprisingly, again no anorexia occurred (unpublished results). It is beyond the scope of this thesis to explain the differences in feeding behavior but this may be related to the different microbiological status of animals, differences in components of rat chow or differences in susceptibility to cytokines as was shown in a colitis model $(6,7)$.

The tumor model used in the experiments described in this thesis induced no anorexia and only moderate or no carcass weight loss. With a tumor burden of 5$15 \%$ or $15-30 \%$ of body weight, nutrient delivery and intermediate metabolism of the host must have adapted. If extrapolation of the tumor model had to be made, it is therefore best comparable to early detected, non-anorectic, moderately weight losing cancer patients (e.g. colon cancer).

Results of experiments described in chapter 5 show that whole body protein turnover increased with increasing tumor loads. Muscle protein turnover and net breakdown increased in the small tumor bearing rats (tumor $5-15 \%$ of body weight). In large tumor bearing rats muscle protein turnover and net breakdown decreased to control values as if muscle tissue was exhausted. In conjunction with this. glutamine turnover and glutamine release by hindquarter muscle decreased to control values. This contrasted with whole body glutamine turnover which almost doubled in large tumor bearing rats. This may be related to an increased turnover of glutamine in the immune system. It may, however, also be related to changes in glucose metabolism which is related to glutamine metabolism by transamidation to glutamate and further processing to TCA cycle intermediates. 
In chapter 6 results of experiments are described which show that glutamine uptake by the gut increased in the presence of a large tumor load. This was, however, accompanied with decreased intracellular glutamine concentrations and an increased gut permeability. The latter was not related with signs of villus atrophy but may be related to a decreased differentiation of the mucosal cells as assessed by decreased intracellular polyamine concentrations.

The results of experiments described in chapter 7 show how the liver adapts to the increased demand for amino acids and proteins by e.g. tumor and immune cells. The liver increases the uptake of essential and gluconeogenic amino acids. These amino acids were not used for glucose production and urea synthesis but were mostly used for protein synthesis of export and structural proteins. Serum $\alpha_{2}$-macroglobulin, one of the most reactive acute phase proteins in the rat, increased to a level comparable to maximum levels after a laparotomy.

In chapter 8 liver glutamine handling in response to a tumor is described. The liver has a central role in glutamine homeostasis because it has high glutaminase activity and glutamine synthetase activity with consumption at the periportal hepatocytes and production at the perivenous hepatocytes. This results in a so called "intercellular" glutamine cycling. The three cornpartment model made it possible to give an in vivo estimate of the activity of both zones. The study indicated that changes in glutaminase activity in majority determined whether the liver consumed or released glutamine in the presence of cancer. Furthermore, it was shown that in the presence of a small tumor the liver changes from an organ of net glutamine release to an organ of net uptake. In large tumor bearing rats the liver changed again in an organ of net glutamine release. This occurred in conjunction with decreasing arterial glutamine concentrations indicating for an adaptative mechanism of the liver to maintain glutamine homeostasis.

Changes in protein turnover rates of different organs in tumer bearing rats are summarized in figure $1 \mathrm{~A}$ (disposal or protein synthesis). and B (production or protein breakdown). In control rats protein synthesis rates were highest in the gut followed by the total muscle compartment and was smallest in the liver. In tumor bearing rats muscle protein synthesis rates remaineci unchanged and intracellular gut protein synthesis rates decreased to a level only slightly higher than muscle. Liver protein synthesis increased and to a level similar to the muscle compartment in tumor bearing animals. In control rats intracellular protein breakdown was also highest in the gut. In small tumor bearing rats gut protein breakdown decreased to a level similar to the muscle compartment and the liver. In large tumor bearing rats protein breakdown decreased to zero whereas protein breakdown in the other two tissue compartments decreased only slightly. 
Intraceliular protein synthesis

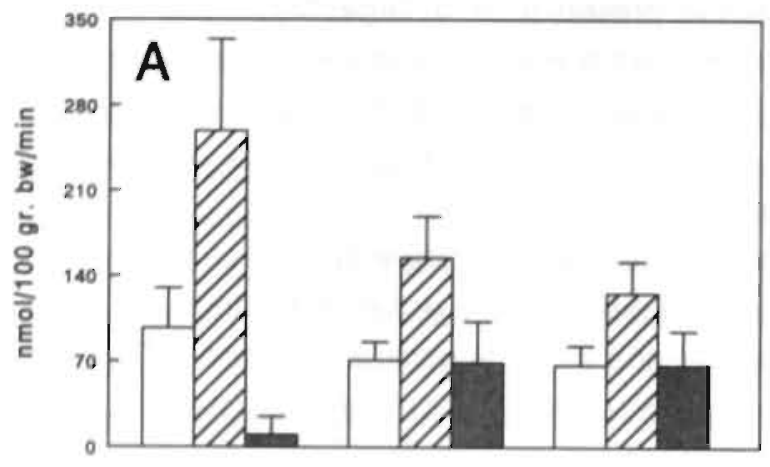

Intracellular protein breakdown

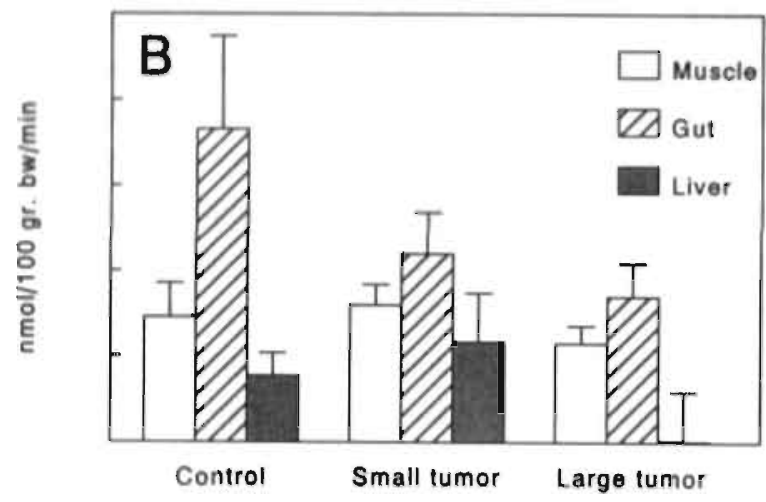

Figure! 1.

A: Intracellular protein synthesis in muscle, gut and liver tissue.

B: Intracellular protein breakdown in muscle, gut and liver tissue.

Data are derived from chapter 5, 6, and 7 and standardized to $100 \mathrm{gr}$. body weight. Hindquarter muscle compartment is assumed to account for approximately $50 \%$ of the whole body muscle compartment.

Changes in glutamine turnover are summarized in figure $2 \mathrm{~A}$ (disposal) and $2 \mathrm{~B}$ (production). Alterations in intracellular glutamine disposal predominantly occurred in the muscle compartment. Muscle glutamine turnover (both disposal and production) increased in the small tumor bearing rats. In large tumor bearing rats it decreased again. The latter was accompanied by increased glutamine disposal and production in the gut. In the liver glutamine disposal increased in small tumor bearing rats whereas it decreased again in large tumor bearing rats. Intracellular glutamine production did not significantly change in the liver of tumor bearing rats. Large tumor bearing animals therefore appear to have a decreased capacity of glutamine producing organs which results in depletion of both the intracellular and plasma glutamine pools. 
Intracellular disposal

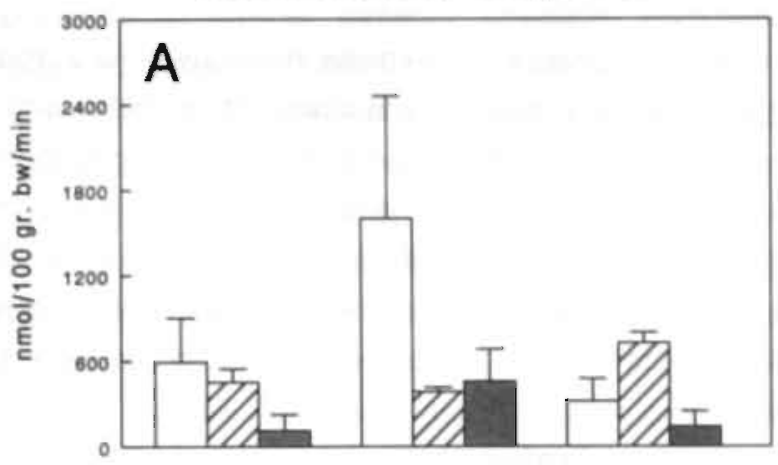

Intracellular production

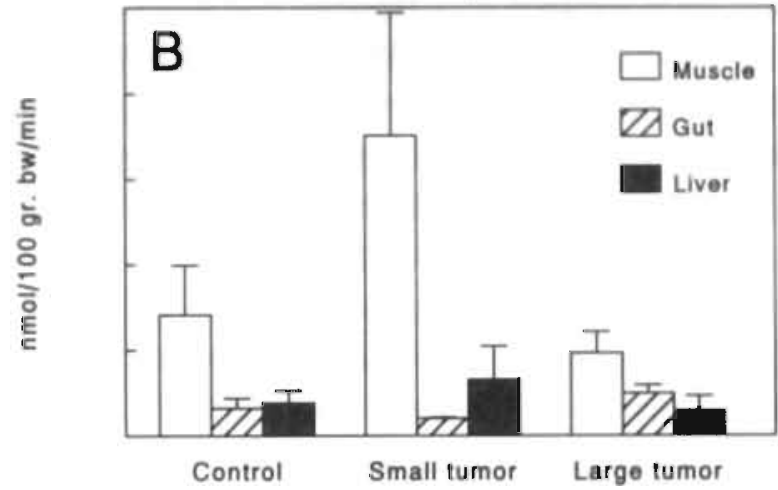

Figure 2.

Intracellular disposal (A) and production (B) of glutamine in muscle, gut and liver tissue.

Data are derived from chapter 5, 6, and 8 and standardized to $100 \mathrm{gr}$. body weight.

In chapter 9 and 10 the effects of cancer on postoperative muscie and gut protein and glutamine metabolism were studied. In both studies it was shown that amino acids are mobilized from muscle and gut tissue in response to a surgical trauma. It has been postulated that in the early phase after a trauma ("ebb phase") the mobilization of amino acids occurs from protein pools with a rapid turnover, e.g. from the gut (8). In a later phase amino acids are degraded from proteins with a slower tumover, e.g. muscle. In our experiments mobilization of amino acids was observed from proteins of both the gut and muscle. This indicates that measurements were performed at a time when the mobile pool of the gut was still prone to degradation whereas degradation of structural proteins of muscle already began. The experimental conditions, however, may also have caused the simultaneous degradation of the mobile proteins and less mobile proteins. The experimental conditions require anesthesia and a laparotomy and these conditions may also be seen as a second hit (first hit: hysterectomy). This second hit (anesthesia and laparotomy) may have again induced breakdown of mobile proteins of the gut whereas breakdown of muscle proteins was induced as a late response to the first 
hit, thus explaining the simultaneous presence of breakdown of gut and muscle proteins.

In the tumor bearing state, rats were unable to respond normally to a surgical trauma. This resulted in an attenuated protein breakdown of muscle with a decreased amino acid release. Glutamine is in this respect of particular importance as normally $30 \%$ of the amino acids release by muscle consists of glutamine and this release may overall be the limiting step in further metabolic pathways. This includes the obligatory increased uptake by immune cells in response to a trauma. A relatively decreased postoperative release of glutamine in cancer would thus compromise the host.

Protein breakdown and amino acid mobilization of the gut was also attenuated in the tumor bearing state. The uptake of glutamine by the gut of tumor bearing rats was relatively diminished in response to surgery. This resulted in a further decrease of gut barrier function. The cancer bearing state attenuates the normal postoperative amino acid release of both mobile and structural proteins and decreases gut barrier function. The studies suggest that the presence of cancer compromises the endogenous nutrient supply to facilitate the acute phase and immune response while, at the same moment, the antigenic load for the immune system, particularly that of the liver, increases.

\section{Perspectives for the future}

In this thesis several aspects of tumor induced changes in host protein and amino acid metabolism have been described. However, several of these descriptions resulted in more questions to be answered. Some of these questions need further fundamental research, others ask for intervention studies in humans or laboratory animals.

Prolonged starvation resulted in a discrepancy in two methods of measuring in vivo protein synthesis under our experimental conditions. Both methods appear to measure synthesis of two different protein pools in muscle, gut and liver tissue. One pool increases it's synthesis and turnover rates whereas the synthesis of another protein pool decreases it's turnover. To elucidate whether the high turnover of one of the pools is of benefit a better identification of the pool is needed. Furthermore, the discrepancy may also occur in disease and other experimental conditions. This warrants a careful in the interpretation of data when only one model is used. It also emphasizes the need for an adequate explanation of the phenomenon.

In chapter $\mathbf{4}$ it was shown that whole body glutamine turnover increased far more than expected to be needed for glutamine consumption only. The glucose-glutamine 
cycle was discussed but needs further research. This may also be of particular importance in cancer patients because increased glucose turnover rates and decreased arterial glutamine concentrations have both been observed in the progress of cancer. Recent studies showed that glutamine is a greater carbon donor to glucose than alanine which has always been assumed to be the primary gluconeogenic amino acid (9). The existence and extent of glutamine-glucose cycling may also be of importance in several studies giving glutamine supplementation in parenteral or enteral nutrition. More fundamental research needs to be initiated on the subject.

Recent studies on muscle protein breakdown revealed that this occurs in several wasting conditions, including cancer cachexia, by the ATP-ubiquitin degradation system (10-12). This pathway was first thought to be only active in the degradation of small, soluble, often incorrectly made proteins, but is now recognized to be involved in the degradation of structural proteins as well. Future research should answer the question whether the ATP-ubiquitin pathway targets specific proteins in cancer cachexia and to what extent this occurs in different organs.

Changes in protein and glutamine metabolism of the tumor bearing rat may be prevented or treated with nutritional interventions. Several animals and clinical studies have reported benefits of enteral and parenteral glutamine suppletion. Similarly, pharmacological interventions with e.g. growth hormone or IGF-1 are promising. Interestingly, combination therapy (nutritional and hormonal) have recently shown to have synergistic effects in vitro and in vivo (13-15). Particularly, the combination of glutamine and an anabolic agent seems to have the best prospects in the near future.

Although not studied in this thesis, interventions in the immune activation should be considered in the prevention and or treatment of cancer cachexia. The immune response is however a complex response having both beneficial and deleterious aspects. Simple blockades of TNF $\alpha$, IL1 or IL6 have proven to stop and even turn back several metabolic changes of cancer cachexia $(16,17)$. However, blockades of one central pathway have mostly shown to be of benefit in disease states involving disturbances in single biochemical or immunological pathways. The cachectic syndrome is of such a complex kind that a relatively "crude", single intervention can not really be expected to cover the complete changes in intermediary metabolism. Moreover, intervention studies directed against e.g. TNF $\alpha$, although recognized as key mediator of sepsis, worsened the clinical outcome of septic patients. Modulation of the metabolic changes, probably at several fronts, should be considered in future. This implicates that therapeutic interventions do not only have different aspects (pharmaceutical, hormonal, nutritional) but may also have to differentiate between 
different patient populations depending on the pending metabolic disturbances in carbohydrate, lipid or protein metabolism.

Of particular interest in this respect is the acute phase response. Acute phase proteins are recognized as proteins to modulate the immune response to trauma, infections and possibly cancer. Whether this is true for metabolic responses, particularly in cancer, is unknown but would be an interesting field of research. Acute phase proteins can thus help modulating the metabolic response or, when produced in excess, may further deteriorate this response.

Extrapolation of experimental data of this thesis to the clinical setting are a primary goal but should be done with great care and remain difficult. Fortunately, the department of surgery in Maastricht has the possibilities to do both clinical and experimental nutritional research. In the last few years clinical research has focused on the effects of glutamine suppletion to parenteral nutrition and several beneficial aspects have been observed. Although clinical research is expected to be able to assess fundamental aspects in the human situation using stable isotopes, specific effects at organ level still remain difficult to obtain and interpret as sampling of tissue specimens can only be done in selected cases. Clinical and experimental research should therefore be well attuned to each other with two-way directed exchange of information. These conditions appear to be present in the Maastricht clinical and research setting and progress in nutritional therapy for cancer cachexia is part of promising perspectives for the future.

References

1. Bozzelti F. Nutritional support in the adult cancer patient. Clin Nutrition 1992:11:167-9.

2. Chance WT. Thomas I, Fischer JE. Insulin reverses ammonia-induced anorexia and experimental cancer anorexia. Nutr Cancer 1994,21:213-22.

3. Burt ME, L.owry SF. Gorschboth C. Brennan MF Metabolic alterations in a noncachectic animal lumor system. Cancer 1981;47 2138-2146

4. Lowry SF, Foster DM, Norton JA, Berman M. Brennan MF. Glucose disposal and gluconeogenesis from alanine in tumor-bearing fischer 344 rats. J Natl Cancer Inst 1981;66:653658

5. Younes RN, Vydelingum NA. Noguchi Y. Brennan MF. Lipid kinetic alterations in tumor-bearing rats: reversal by tumor excision. J Surg Res 1990;48:324-8.

6. McCall RD, Haskill S, Zimmermann EM, Lund PK, Thompson RC, Sartor RB. Tissue interleukin 1 and interleukin-1 receptor antagonist expression in enterocolitis in resistant and susceptible rats. Gastroenterology 1994;106:960-72.

7. McCall RD, Haskill S, Zimmermann EM, Lund PK, Thompson RiC, Sartor RB. Tissue interieukin 1 and interleukin-1 receptor antagonist expression in enterocolitis in resistant and susceptible rats. Gastroenterology 1994:106:960-72. 
8. Molina PE, Abumrad NN. Gut-derived proteolysis during insulin-induced hypoglycemia: the pain that breaks down the gut. J Parenter Enteral Nutr 1994;18:549-56.

9. Nurjhan N, Bucci A, Perriello G, Stumvoll M, Dailey G, Bier DM, Toft I, Jenssen TG, Gerich JE. Glutamine: a major gluconeogenic precursor and vehicle for interorgan carbon transport in man. J Clin Invest 1995;95:272-7.

10. Hershko A, Ciechanover A. The ubiquitin system for protein degradation. Annu Rev Biochem 1992;61:761-807.

11. Costelli P, Garcia Martinez C, Llovera M, Carbo N, Lopez Soriano FJ, Agell N, Tessitore L, Baccino FM, Avgiles JM. Muscle protein waste in tumor-bearing rats is effectively antagonized by a beta 2-adrenergic agonist (clenbuterol). Role of the ATP-ubiquitin-dependent proteolytic pathway. J Clin Invest 1995;95:2367-72.

12. Wing SS, Goldberg AL. Glucocorticoids activate the ATP-ubiquitin-dependent proteclytic system in skeletal muscle during fasting. Am J Physiol 1993;264:E668-76.

13. Hoover Plow JL, Clifford AJ. The effect of surgical trauma on muscle protein turnover in rats. Biochem J 1978:176:137-42.

14. Byrne TA, Persinger RL, Young LS, Ziegler TR, Wilmore DW. A new treatment for patients with short-bowel syndrome. Growth hormone, glutamine, and a modified diet. Ann Surg 1995;222:24354.

15. Zhang W, Bain A, Rombeau $\mathrm{JL}$. Insulin-like growth factor-I (IGF-I) and glutamine improve structure and function in the small bowel allograft. J Surg Res 1995;59:6-12.

16. Sherry BA, Gelin J, Fong Y, Marano $M$, Wei $H$, Cerami A, Lowry SF, Lundholm KG, Moldawer $L L$. Anticachectinfumor necrosis faclor-a antibodies attenuate development of cachexia in tumor models. FASEB J 1989;3:1956-1962

17. Strassmann G, Kambayashi $T$. Inhibition of experimental cancer cachexia by anti-cytokine and anti-cytokine-receptor therapy. Cylokines \& Molecular Therapy 1995;1(2):107-13. 



\section{Samenvatting}

In de aanwezigheid van kanker ontstaan stoornissen in de stofwisseling die leiden tot gewichtsverlies en ondervoeding. Dit heeft een negatief effect op de uitkomst van de behandeling van kanker en draagt bij, indien onbehandeld, tot een vervroegde dood. De stoornissen in de stofwisseling betreffen zowel de suiker-, vet-, aminozuuren eiwit-stofwisseling. Doel van dit proefschrift was de door kanker geïnduceerde veranderingen in de aminozuur- en eiwit-stofwisseling te bestuderen in ratten waarbij tumoren onderhuids geimplanteerd zijn.

Het proefschrift bestaat uit drie delen. Allereerst wordt een model geïntroduceerd om in een verdoofde, levende rat (in vivo) de eiwit- en aminozuur-stofwisseling te meten in verschillende organen (spier, darm en lever). Als tweede worden de effecten van een steeds groter wordende tumor op de eiwit- en aminozuurstofwisseling van spier-, darm- en lever-weefsel bestudeerd. Tot slot wordt bestudeerd hoe de stofwisseling bij kanker-dragende ratten reageert op een standaard-operatie (chirurgisch trauma)

Deel I

Hoofdstuk 1 van het proefschrift vormt een introductie tot de algemene problematiek van de stofwisselingsstoornissen die gezien worden bij kanker en, meer specifiek, tot de eiwit- en aminozuur-stofwisselingsstoonissen bij kanker. Hoewel veel onderzoek op dit gebied reeds verricht is, heeft het nog niet geresulteerd in een goed begrip van de veranderingen en in een adequate behandeling van de verstoringen.

Hoofdstuk 2 geeft een samenvatting van de tot nu toe bekende mogelijkheden orn de eiwit- en aminozuur-stofwisseling te meten. Uit de bestaande literatuur bleek dat het nog niet mogelijk was om dit in vivo te kunnen meten in de rat. In hoofdstuk 3 en 4 worden daarom verschillende methoden en modellen getest en gevalideerd om aanınaak en verbruik (omzetting of turnover) van eiwitten en aminozuren te meten. In deze studies tonen we aan dat de zogenaamde arteriele-veneuze verdunningsmethode bruikbaar is om dit te meten en, in gezonde omstandigheden, vergelijkbaar is als de zogenaamde incorporatie-techniek. Indien daarbij een drie compartimenten rekenmodel gebruikt wordt kan tevens de snelheid van het membraan transport waarmee aminozuren vanuit het bloed nalar de weefsels gaan, 
gemeten worden. In hoofdstuk 3 laten we ook zien dat na langdurig hongeren de arteriele-veneuze verdunningsmethode een verhoging van de eiwitsynthese laat zien terwijl de zogenaamde incorporatie-techniek een daling in de eiwitsynthese laat zien. Het lijkt erop dat de incorporatie-techniek alleen de synthese meet van grote, niet in zuur oplosbare eiwitten, terwijl de arteriele-veneuze verdunningsmethode de synthese meet van grote en kleine eiwitten die zowel zuur-oplosbaar als niet-zuuroplosbaar zijn. De arteriele-veneuze verdunningsmethode laat dus zien dat na langdurig hongeren de eiwitafbraak en eiwitsynthese omhoog gaat hetgeen deels leidt tot een netto eiwit afbraak (afbraak gaat meer omhoog dan de synthese) en deels tot een verhoogde omzetting van eiwitten (zogenaamde verhoogde eiwit turnover). Of een verhoogde turnover van eiwitten van nut is of dat het een nutteloos en energie-kostend proces is, verdient nader onderzoek.

Deel II

In hoofdstuk 5,6,7 en 8 worden de effecten van een methylcholanthrene (MCA) geïnduceerde tumor op de turnover van eiwitten en aminozuren in spier, darm en lever gemeten. MCA tumoren zijn in veel onderzoeken gebruikt om stofwisselingsstoornissen bij kanker te bestuderen. In deze studies worden echter ratten van de Fisher stam gebruikt. Bij dit type rat leidt de aanwezigheid van een dergelijke tumor tot een drastische afname van de voedselinname dat gepaard gaat met een drastisch gewichtsverlies. In ons laboratorium hebben wij Lewis ratten gebruikt en, gedurende de $3 \frac{1}{2}$ jaar onderzoek, hebben wij nooit een afname in de voedselinname gezien en werd slechts een zeer mild verlies aan lichaamsgewicht waargenomen. Uiteindelijk hebben wij een MCA tumor uit Cincinatti (gekregen van WT Chance, Universiteit van Cincinatti) bij Fisher ratten geïmplanteerd op ons laboratorium. Hoewel deze tumor op het laboratorium te Cincinatti duidelijk veranderingen in de voedselinname induceerde, bleek dit niet het geval op ons laboratorium. Dit kan samenhangen met het verschil in het type voedsel dat in beide laboratoria gebruikt wordt, de verschillende bacteriën die in de darm aanwezig zijn bij ratten uit verschillende laboratoria, en mogelijk ook met het verschil in gevoeligheid van verschillende ratten stammen voor zogenaamde ontstekingsmediatoren (zoals ook beschreven is bij onderzoek naar de oorzaak van darmontstekingen). Het valt echter buiten de "scoop" van dit proefschrift om het gedragsverschil in voedselinname te verklaren.

Bij een tumor gewicht van $5-15 \%$ en $15-30 \%$ van het lichaamsgewicht vindt geen verandering in voedselinname plaats. Dit impliceert dat de stofwisseling wordt aangepast om met dezelfde hoeveelheid voedsel uit te komen. Indien deze 
aanpassingen en veranderingen in de stofwisseling vergeleken zouden moeten worden met de kliniek zou deze het best vergelijkbaar zijn met de vroeg ontdekte, nog niet anorectische kanker patiënt met matig gewichtsverlies (b.v. patiënt met kanker van de dikke darm).

In hoofdstuk 5 wordt beschreven hoe met toenemende tumor-grootte de omzetting van eiwitten en aminozuren omhoog gaat indien deze gemeten wordt over het gehele lichaam. Normaal bepaalt de eiwitstofwisseling van spierweefsel het merendeel van de eiwit turnover van het gehele lichaam. Bij eiwitafbraak komen aminozuren vrij en bij afbraak van spiereiwit worden deze voor een groot deel omgezet tot het aminozuur glutamine. Glutamine wordt vervolgens afgegeven aan de bloedbaan en getransporteerd naar andere organen (nier, lever en darm). De eiwit turnover en eiwitafbraak van spierweefsel neemt toe bij kleine tumor-dragende ratten (5-10\% van het lichaamsgewicht). Deze eiwitafbraak leidt tot een vergrootte uitscheiding van het aminozuur glutamine. Bij grote tumoren $(15-30 \%$ van het lichaamsgewicht) neemt de eiwit turnover en eiwitafbraak weer af alsof de spier (metabool) uitgeput raakt. Ook de glutamine turnover daalt naar het niveau van controle ratten. Dit contrasteert met de turnover van glutamine wanneer deze over het gehele lichaam gemeten wordt. De turnover van het gehele lichaam blijt juist onveranderd bij kleine tumoren en verdubbelt bij grote tumoren. De verdubbeling bij grote tumoren kan samenhangen met een vergrootte opname van glutamine als energie substraat en als substraat om nucleotiden te maken door het immuunsysteem. De verhoogde glutamine turnover kan echter ook samen hangen met veranderingen in de glucose stofwisseling aangezien glutamine tevens omgezet kan worden tot een intermediair van de citroenzuur cyclus.

In hoofdstuk 6 wordt beschreven hoe met het groter worden van de tumor de consumptie glutamine door de darm toeneemt. Dit gebeurt in de aanwezigheid van verlaagde glutamine concentraties in de darm zelf. Tevens wordt een toegenomen doorlaatbaarheid van de darm gezien zonder tekenen van atrofie (celverlies). De toegenomen doorlaatbaarheid was wel geassocieerd met een afgenomen differentiatie (ontwikkelingsgraad) van cellen van de darm.

De resultaten van hoofdstuk 7 laten zien hoe de lever aanpast aan de toegenomen behoefte aan eiwitten en aminozuren dat ontstaat door de ontwikkeling van een tumor en de hiermee gepaard gaande activatie van afweercellen. De lever zorgt in het algemeen voor een evenwichtige verdeling van aminozuren, maakt er suiker van en gebruikt een deel voor eigen eiwitsynthese. We laten zien dat, in de aanwezigheid van kanker, aminozuren worden opgenomen door de lever voor met name de aanmaak van structurele eiwitten van de lever zelf. Daarnaast worden aminozuren opgenomen voor zogenaamde export-eiwitten. Deze export-eiwitten zijn voor een groot deel de acute fase eiwitten. We laten tevens zien dat het 
zogenaamde $\alpha_{2}$-macroglobuline, een van de meest reactieve acute fase eiwitten in de rat, stijgt bij kanker-dragende ratten naar een niveau dat wij ook zien na bijvoorbeeld een grote operatie in de buik.

In hoofdstuk 8 wordt de stofwisseling van het aminozuur glutamine in de lever omschreven. De lever speelt een belangrijke rol in de stofwisseling van glutamine omdat het zowel glutamine kan aanmaken als afbreken. Dit resulteert normaliter in een zogenaamde "intercellulaire" glutamine cyclus tussen verschillende cel populaties in de lever. Het drie compartimenten model maakt het mogelijk om de snelheid van aanmaak en afbraak in de verschillende cel populaties in vivo te meten. De studie laat zien dat de afbraak van glutamine, die plaatsvindt in de zogenaamde periportale cellen, de belangrijkste determinant is die regelt of de lever glutamine netto uitstoot of opneemt. De studie laat verder zien dat de lever bij kleine tumoren de uitstoot van glutamine verandert in een opname van glutamine. Als de tumor groter wordt geeft de lever wederom netto glutamine af. Dit gebeurt in samenhang met verlaagcle arteriële glutamine concentraties. Het lijkt erop dat de lever glutamine afgeeft aan de bloedbaan bij groter wordende tumoren om de concentraties in het bloed op peil te houden.

Deel III

Hoofdstuk 9 en 10 werden de effecten van een standaard operatie op de eiwit- en aminozuur-stofwisseling bij kanker bestudeerd. In beide hoofdstukken wordt aangetoond dat na een operatie (chirurgisch trauma) aminozuren gemobiliseerd worden door eiwitafbraak in de darm en in spierweefsel. In de vroege, zogenaamde "ebb fase", na een chirurgisch trauma worden de aminozuren gemobiliseerd uit de eiwitten met een hoge omzettingssnelheid. Dit zijn voornamelijk de eiwitten van de darm. In de latere fase, de zogenaamde "flow fase", komen de aminozuren van de eiwitten met een langzamere omzettingssnelheid vij. Dit zijn voornamelijk de spiereiwitten. Kanker-dragende ratten kunnen niet normaal responderen op een chirurgisch trauma. De eiwitafbraak in spier weefsel blijt achter en er vindt met name onvoldoende mobilisatie van glutamine plaats vanuit de spier. Aangezien glutamine na een operatie nodig is voor de afweercellen, zal een verminderde beschikbaarheid van glutamine de afweer compromitteren.

De eiwitafbraak van de darm blijt ook achter bij de kanker-dragende rat. Dit gaat gepaard met een toegenomen doorlaatbaarheid van de darm voor lichaamsvreemde stoffen. Beide studies suggereren dat bij kanker de voorziening van belangrijke aminozuren achterblijft vergeleken bij de voorziening van nutrienten indien er sprake is van een gezonde conditie. Het niet kunnen aanpassen van de stofwisseling tijdens 
kanker compromitteert met name de acute fase respons en de immuunrespons, terwijl op hetzelfde moment het aanbod van vreemde stoffen waartegen het immuunsysteem moet strijden toegenomen is. Dit kan verklaren waarom kanker patiènten een verhoogd risico hebben op bijkomende ziekte na operaties en is richtinggevend voor keuzes van toekomstige interventies. 
Onderzoek naar ondervoeding in Nederland verzin je niet als je in Ethiopië werkzaam bent. Ondervoeding verwacht je ook niet in een overvoedde maatschappij met dierenambulances en bakkers die zich zorgen maken om hun brood als de bischop oproept het 7e gebod te negeren. Vreemder lijkt het nog dat chirurgen zich ermee bezig houden. Toch is onderzoek naar de oorzaken van ondervoeding ook chirurgisch onderzoek. In 1955 schreven Rhoads en Alexander dat "cases of starvation in the United States at the middle of the 20th century are largely surgical" (Nutritional problems of surgical patients. Ann NY Acad Sci, 1955;63:268-275). Hiermee vertolkten ze een algemene gedachtengang die aan de basis heeft gestaan van de ontwikkeling van parenterale voeding. Tevens is het de basis van het feit dat de chirurgie er historisch gezien mee belast is. Goede chirurgen behandelen en beheersen hun complicaties. Dit doe je niet altijd alleen. Zo ook dit onderzoek. Zoals al in zoveel proefschriften is geschreven, was dit proefschrift niet tot stand gekomen zonder de medewerking van en de samenwerking met anderen. Deze wil ik allemaal bedanken, ook degenen die in het nu volgende niet direct bij naam genoemd worden.

Professor von Meyenfeldt, beste Maarten, ook al had je het altijd druk, je was altijd bereid om een half uurtje over de resultaten te pruten, over nieuwe artikelen en het perspectief van ons onderzoek te filosoferen. De samenverking met jou beperkte zich niet alleen tot de wetenschap "pur sang" maar kreeg een extra dimensie door de niet wetenschappelijke gesprekken die we gevoerd hebben. Daarbij is een wederzijds respect gegroeid. Ik hoop en ben er eigenlijk van overtuigd dat we elkaar nog veel zullen zien, spreken en dat we met elkaar zullen samen werken.

Beste Mick, de afgelopen 3 jaren waren hectisch, tumultueus en onze relatie stond soms op gespannen voet. We hebben echter ook menig crisis doorstaan. Ondanks of dankzij de haat-liefde verhouding is dit proefschrift tot stand gekomen. Onze visie op wetenschap is verschillend en zal ook niet gauw dichter bij elkaar komen. Dit blijkt echter niet nodig te zijn om gezamenlijk onderzoek te doen, getuige dit proefschrift. Mick, bedankt voor alle steun, hulp en begeleiding die je gegeven hebt.

Beste Carlo (en Brigitte) en Stephen (en Marja); rond dezelfde tijd zijn we begonnen op het "aminozuur-lab" van de heelkunde. Het was goed bondgenoten te hebben om de dagelijkse sores van een onderzoeker in opleiding weg te kunnen praten of om een pilsje mee te drinken om dat ellendige "supergezwalk" te vergeten. Dit verliep in het algemeen ook heel goed in het buitenland rondom de beslommeringen van een congres. Meestal was Cees daar ook bij. Wetenschap gedijt bij enig alcohol. Cees, ook jij bedankt voor met name de morele steun de afgelopen jaren. Ik denk dat jij als geen ander mijn positie kon inschatten. Carlo. Brigitte en Stephen succes verder nog met de laatste loodjes van jullie boekje en de eerste loodjes van jullie opleiding.

Bas, ook jij begon rond dezelfde tijd (in Maastricht en nu in Eindhoven) en ik geloof dat we zelfs nog ooit hebben gefilosofeerd over metabool onderzoek na een gracilis plastiek. Dat zal er wel niet meer van komen maar we zullen nog genoeg samenwerken de komende 
jaren. Bas, succes met de allerlaatste loodjes. Dat. geldt ook voor jou, Maarten, ook jij succes met je boekje en tot gauw in Eindhoven.

De meeste bepalingen zijn gedaan op hett "aminozuur" lab (dat allangl geen "aminozuur-lab" meer is) verricht. Beste Dennis, Hans en Gabrie, precies en secuur zoals een echte analyticus behoort te zijn hebben jullie mij leren pipetteren. Jullie namen staan zo' $n$ beetje bij alle artikelen ais dank voor het analytisch werk. Dennis, het is fijn om dit project samen af te ronden.

Gaby en Moniek, beste kamergenootjes, het was geen kamer van rust waar je rustig een artikeltje ging lezen of schrijven. Dankzij jullie was het. wel een gezellige kamer met een stukje groen en radio Brussel. Bedankt ook voor de morele en fysieke ondersteuning van alle kweken van kankercelletjes en de bioassays. Het blijft jammer dat de samenwerking van beide laboratoria niet uitgewerkt kon worden. Het immunologische lab stond onder leiding van Wim Buurman. Bedankt Wim voor alle ondersteuning. In de vele uren die we gepraat hebben (meestal om vijf uur) zijn alle aspecten van onderzoek en maatschappij de revue gepasseerd. Verbazingwekkend blijft de hoeveelheid en diversiteit aan kennis die bij jou aanwezig is. Het blijt een onuitputtelijke kritische bron van ideeên en richtingen die het onderzoek op kon gaan.

Bedankt ook iedereen van de Centrale Proefdiervoorzieningen, mn Ton, Brigitte, Eep, Frans, Peter en alle andere verzorgers van de dieren. Ik geloof dat ik niet altijd even goed bereikbaar was. Hiervoor mijn excuses en bedankt voor de goede zorgen voor de ratjes. Thank you Bill Chance for allowing me to work in your laboratory in Cincinnnatti. Thank you for giving the new tumor celline. I hope we will be able to work together again in the near future.

Bijna tot slot, een lijstje met namen van allen die ik wil bedanken voor de samenwerking, de steun, de vlaaien, het helpen met foto's, stickers, copieren en zo kunnen er nog wel een paar regels met verrichtingen, karweitjes en mentale activiteit gevuld worden. Het lijsțe zal niet volledig zijn maar had het natuurlijk wel moeten zijn: bedankt Jessica, Sylvia, Britta, Mieke. Trudie. René. Bernadette, Karel, Marjan, Wilma, Anja, Anniek, Margriet.

Lieve familieleden en vrienden, dit is niet de eigenlijke plaats om jullie te bedanken maar eerder de plaats om enige spijt te betuigen voor het chronisch tijdsgebrek dat een promotie onderzoek nu eenmaal vraagt. ledereen bedankt voor steun en vriendschap zonder wie dit zeker niet tot stand was gekomen.

Dr. Prakken, dr. van Erp, dr. Repelaar-van Driel, dr. Den Butter, dr. Reemst, Berry, Jean Paul, Annet, Carel en Ronald bedankt voor het geduld en de ruimte die er was om het promotie onderzoek af te ronden. Ik verheug me op de samenwerking van de komende 3 jaren. Dit geld ook voor vele anderen in het Diaconessenhuis die ik uiteraard allemaal bij naam had willen noemen.

Tot slot, Nicole, uiteraard ben ik weer even sprakeloos als in ik ooit was aan het Zeelandse strand. Het mooiste hebben we gehad en het mooiste moet nog komen. 
Ivo de Blaauw werd op 28 november 1959 geboren te Amsterdam. In 1979 behaalde hij het diploma Gymnasium $\beta$ aan het stedelijk Gymnasium te Nijmegen. In 1979-1980 studeerde hij Spaanse Taal en Letterkunde aan de Katholieke Universiteit te Nijmegen. In 1980-1981 studeerde hij Geneeskunde aan de Rijksuniversiteit te Gent. In 1981 werd begonnen aan de studie Geneeskunde aan de Katholieke Universiteit te Nijmegen. In 1989 behaalde hij het doctoraal examen en in 1989 het artsexamen. In deze periode was hij gedurende 5 maanden als coassistent werkzaam in de $1^{\mathbf{e}}$-lijnsgezondheidszorg te Niquinohomo (Nicaragua). Van 1989-1991 was hij werkzaam als assistent chirurgie/gynaecologieverloskunde/interne geneeskunde in ziekenhuis de Gelderse Vallei te Ede in het kader van een tropenopleiding. In 1991 was hij werkzaam als arts in Mekele General Hospital te Tigray (Ethiopië) in het kader van een noodhulp-project van Artsen zonder Grenzen. Na terugkomst werkte hij als arts in het Asielzoekerscentrum te Udenhout, als AGNIO Chirurgie in het Rode Kruis ziekenhuis te Beverwijk en kortdurend in Lokichokio (Kenya) voor Artsen zonder Grenzen en de Verenigde Naties. De laatste werkzaamheden waren i.v.m. het opstarten en verzorgen van gezondheidszorg in een juist ontstaan Sudanees vluchtelingenkamp. Van oktober 1992 tot en met mei 1996 was hij werkzaam als onderzoeker in opleiding binnen het project "Karakterisering van het veranderd aminozuur metabolisme bij kanker en de relatie met cytokines" (N.W.O. project: 904-62-125) bij de vakgroep Algemene Heelkunde aan de Universiteit van Limburg te Maastricht hetgeen leidde tot dit proefschrift. Het onderzoek werd begeleid door Prof. dr. M.F. von Meyenfeldt en dr. N.E.P. Deutz. Sinds juni 1996 is hij werkzaam als arts-assistent in opleiding tot chirurg in het Diaconessenhuis te Eindhoven (opleider Dr. W.J. Prakken). Tot slot, de auteur is getrouwd met Nicole van de Kar. 

